Universidade de São Paulo

Escola de Engenharia de São Carlos

Departamento de Engenharia de Estruturas

\title{
COMPORTAMENTO DE JUNTAS DE ARGAMASSA SOLICITADAS À COMPRESSÃO NA LIGAÇÃO ENTRE ELEMENTOS PRÉ-MOLDADOS
}

\author{
Aline da Silva Ramos Barboza
}

Texto apresentado à Escola de Engenharia de São Carlos, da Universidade de São Paulo, como parte dos requisitos para obtenção do título de Doutor em Engenharia de Estruturas.

Orientador: Prof. Dr. Mounir Khalil El Debs

São Carlos - SP

2001 


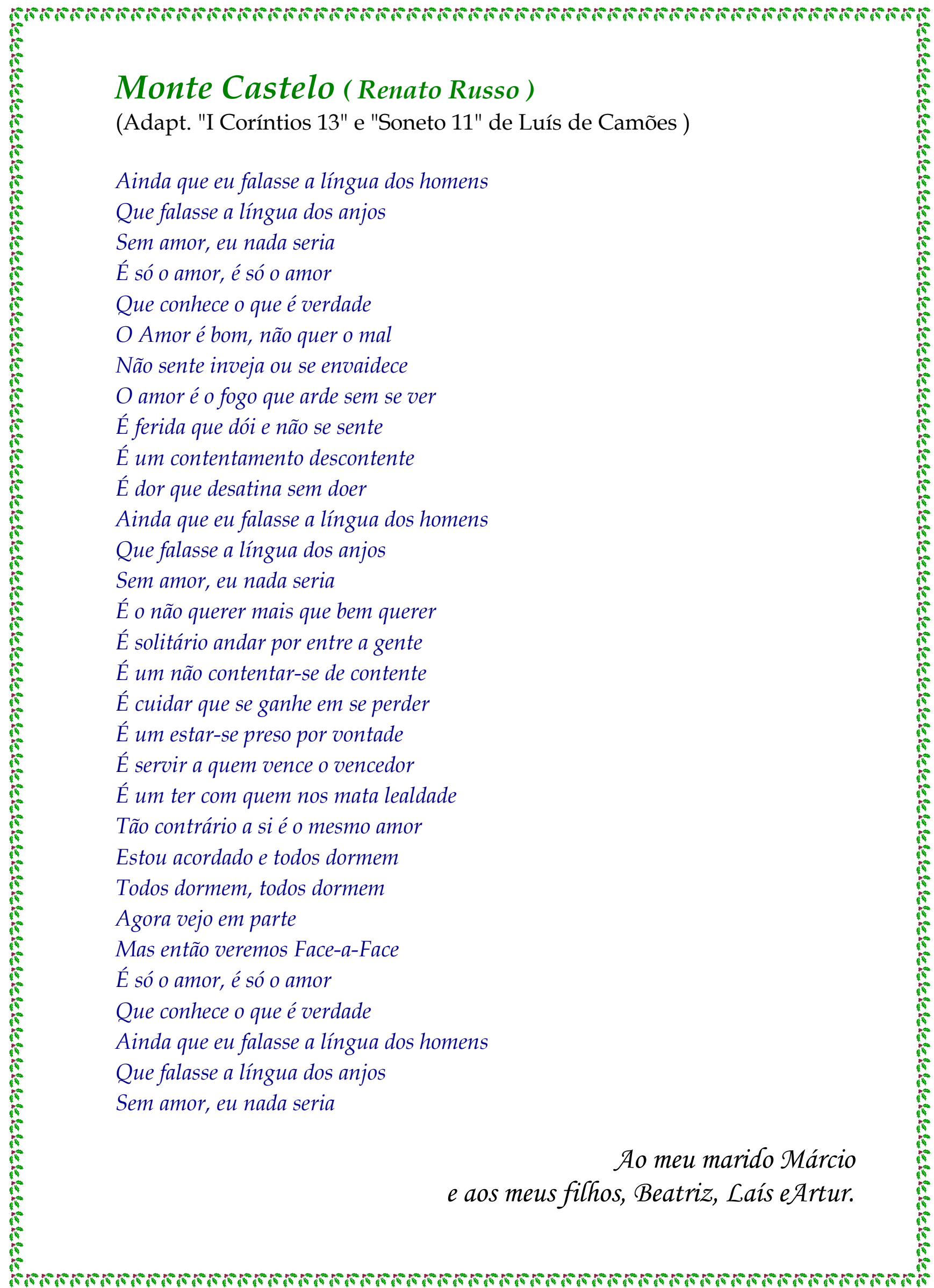




\section{Agradecimentos}

Antes de todos gostaria de agradecer a Deus por estar presente em todos os momentos da minha existência.

Aos meus pais, que mesmo diante das dificuldades que o destino tinha lhes reservado, foram capazes de me fazer absorver força e determinação para buscar meus objetivos e aos meus irmãos pela confiança sempre depositada.

Ao professor Mounir Khalil El Debs, não só pelos ensinamentos e orientação, mas também pela amizade já há algum tempo construída.

Aos colegas e amigos do Departamento de Engenharia de Estruturas da Universidade Federal de Alagoas, com os quais estarei repassando os conhecimentos adquiridos e aos professores amigos José Samuel Giongo e Toshiaki Takeya que dispensam qualquer comentário.

Aos amigos técnicos deixados no Laboratório de Estruturas da Escola de Engenharia de São Carlos, que compartilharam as horas mais difíceis do trabalho.

A todos os amigos alagoanos e paraibanos, com os quais eu pude dividir a saudade nesse tempo longe de casa.

A amiga Mary Cris, com quem eu compartilhei desespero, cansaço, mas principalmente alegrias durante todo o tempo de doutorado e se tornou presença constante em todos os momentos.

Aos amigos conquistados na pós-graduação, Crés, Ana Rita, Rita de Cássia, Suzana, Anamaria, Joel, Felício, Rejane, Vanessa, Kris, Osvaldo, Mônica, Tatiana, Ana Elizabeth e tantos outros que com certeza eu não vou conseguir listar por falta de espaço, mas vão estar sempre presentes nas minhas lembranças.

Às amigas Nadir e Rosi e a todos os funcionários do Departamento de Estruturas da Escola de Engenharia de São Carlos que mais uma vez acompanharam a realização de mais um objetivo.

A CAPES pela bolsa de estudo concedida.

A FOSROC Brasil, a REAX Indústria e Comércio Ltda. e a Rhodia Brasil Ltda. pela doação de materiais usados na pesquisa. 


\section{Sumário}

Capítulo 1- Introdução

1.1. Preliminares 1

1.2. Objetivos 6

1.3. Apresentação 6

Capítulo 2 - Revisão Bibliográfica

2.1. Preliminares 8

2.2. Literatura Encontrada 11

2.3. Comentários Adicionais 32

Capítulo 3 - Avaliação Numérica dos Parâmetros de Influência da Ligação

3.1. Preliminares 34

3.2. Comportamento Não-Linear do Concreto e da Argamassa 35

3.3. Discretização dos Modelos 40

3.4. Análise dos Parâmetros de Influência 42

3.4.1. Espessura da camada de argamassa $\quad 42$

3.4.2. Relação entre as resistências do concreto e da argamassa 49

3.4.3. Resistência do concreto pré-moldado 54

3.4.4. Rugosidade da superfície dos elementos pré-moldados 56

3.4.5. Forma do elemento pré-moldado 62

3.5. Comentários Adicionais 67

Capítulo 4 - Avaliação Experimental do Comportamento da Ligação

4.1. Preliminares 69

4.2. Planejamento do Programa Experimental 70

4.3. Descrição dos Modelos 71

4.4. Materiais $\quad 73$

4.4.1. Cimento 73

4.4.2. Areia 73

4.4.3. Brita 74

4.4.4. Armadura $\quad 74$

4.4.5. Aditivo $\quad 74$

$\begin{array}{ll}\text { 4.4.6. Argamassa } & 75\end{array}$ 
$\begin{array}{ll}\text { 4.5. Programa Experimental } & 75\end{array}$

4.5.1. Execução dos Modelos 77

4.5.2. Instrumentação dos modelos $\quad 81$

4.5.3. Procedimentos de Ensaio $\quad 83$

4.6. Ensaios Preliminares 84

4.6.1. Características dos Modelos $\quad 84$

4.6.2. Resultados dos Ensaios $\quad 87$

4.6.3. Análise dos Resultados 90

4.7. Ensaios dos Modelos 93

4.7.1. Dosagem das Misturas 93

4.7.2. Resultados dos Ensaios 93

4.8. Comentários Adicionais 107

Capítulo 5 - Análise dos Resultados

5.1. Preliminares 108

5.2. Influência da Espessura da Camada de Argamassa 108

5.3. Influência da Relação entre as Resistências 116

5.4. Influência da Resistência do Concreto Pré-Moldado 119

5.5. Influência da Armadura de Reforço 121

5.6. Influência do Tipo de Argamassa 123

5.7. Influência de um Contato Descontínuo entre os Segmentos Pré-moldados 126

5.8. Comportamento da Junta de Argamassa Comparada à Ligação com Almofada de Apoio de Argamassa Flexível 129

5.9. Comentários Adicionais 137

Capítulo 6 - Considerações Finais e Conclusões 139

$\begin{array}{lr}\text { Bibliografia } & 144\end{array}$

$\begin{array}{ll}\text { Apêndice } & 148\end{array}$ 


\section{Lista de Símbolos}

$\varepsilon_{\mathrm{J}}$ - deformação específica da junta;

$\Delta \ell_{\mathrm{T}}$ - deslocamento relativo do concreto pré-moldado, medido nos relógios comparadores;

$\Delta \ell_{\mathrm{J}} \quad$ - deslocamento relativo da junta, medido nos relógios comparadores;

$\varphi$ - ângulo de atrito do material

$\alpha$ - fator de eficiência da junta;

$\delta$ - relação entre a menor largura e a espessura da junta;

$\tau_{\mathrm{a}}$ - coeficiente que considera a influência de uma armadura transversal à junta.

$\eta_{e}$ - coeficiente que considera a influência da distribuição desigual de solicitação na junta e a influência da excentricidade de aplicação do esforço normal;

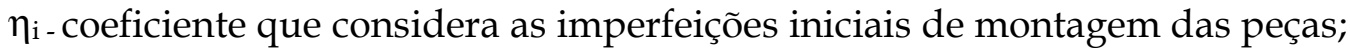

$\eta_{j}$ - coeficiente de redução global devido à presença da junta horizontal considerando todos os fatores de influência;

$\eta_{\mathrm{m}}$ - coeficiente que considera a qualidade da argamassa colocada na junta;

$\tau_{m}$ - coeficiente que leva em conta a influência da camada de argamassa presente na ligação entre elementos pré-moldados;

$\tau_{\mathrm{p}}$ - coeficiente que considera o aumento da resistência à compressão da argamassa devido à influência da compressão exercida pelos painéis;

$\tau_{R}$ - coeficiente que leva em conta a diminuição da resistência da parede sob compressão, devido à presença do momento de engastamento do painel inferior na junta, se opondo ao momento de tombamento do painel superior;

a - menor dimensão na seção transversal do elemento pré-moldado adjacente à junta; $A_{c}$ - área da seção transversal do elemento pré-moldado na junta;

$\mathrm{A}_{\mathrm{ef}}$ - área efetiva para transmissão de esforços através da junta de argamassa;

$\mathrm{A}_{\mathrm{s}}$ - área de aço colocada como reforço no elemento pré-moldado;

b - maior dimensão na seção transversal do elemento pré-moldado adjacente à junta; c - coesão do material; 
$\mathrm{D}_{\mathrm{j}}$ - deformabilidade da junta de argamassa;

$\mathrm{D}_{\mathrm{m}}$ - deformabilidade da ligação;

$\mathrm{E}_{\mathrm{c}}$ - módulo de elasticidade do concreto pré-moldado;

$E_{e}$ - módulo de elasticidade equivalente para o sistema pré-moldado;

$\mathrm{E}_{\mathrm{m}}$ - módulo de elasticidade da argamassa;

$\mathrm{f}_{\mathrm{c}}$ - resistência à compressão do concreto pré-moldado;

$\mathrm{f}_{\mathrm{cd}}$ - valor de cálculo da resistência à compressão do concreto pré-moldado;

$\mathrm{f}_{\mathrm{ck}}$ - resistência característica do concreto do elemento pré-moldado;

$\mathrm{f}_{\mathrm{j}}$ - capacidade resistente da ligação;

$\mathrm{f}_{\mathrm{m}}$ - resistência à compressão da argamassa;

$\mathrm{f}_{\mathrm{mu}}$ - resistência última à compressão da argamassa;

$\mathrm{f}_{\mathrm{u}}$ - tensão última atingida no ensaio do modelo;

$\mathrm{f}_{\mathrm{y}}$ - tensão de escoamento do aço;

$\mathrm{H}$ - altura;

$\mathrm{h}_{\mathrm{j}}$ - espessura da junta;

k - fator que representa uma relação entre a resistência à compressão da argamassa e a resistência à compressão do concreto; 
BARBOZA, A. S. R. (2002) Comportamento de juntas de argamassa solicitadas à compressão na ligação entre elementos pré-moldados. São Carlos. 154p. Tese (Doutorado) - Escola de Engenharia de São Carlos, Universidade de São Paulo, Brasil.

Este trabalho apresenta uma análise teórico-experimental do comportamento de juntas de argamassa solicitadas à compressão, usando para preenchimento da junta materiais comercialmente disponíveis e almofada de apoio de argamassa flexível, com o objetivo de propor recomendações de projeto que caracterizem a deformabilidade e a resistência da junta, visando um melhor aproveitamento da capacidade resistente do sistema pré-moldado. Inicialmente foi feito um levantamento bibliográfico sobre os principais parâmetros que influenciam o comportamento da junta e, posteriormente, foram realizadas algumas simulações numéricas utilizando-se o programa ANSYS 5.5.1. Em seguida, desenvolveu-se um programa experimental cujas variáveis foram: a espessura da camada de argamassa, a resistência do elemento pré-moldado e da argamassa, o material de preenchimento da junta, a presença de armadura de reforço na região adjacente à ligação e a rugosidade na superfície do elemento. Os resultados obtidos mostraram que a espessura de $20 \mathrm{~mm}$ seria a mais indicada, pois, além de minimizar o efeito de descontinuidade provocado pela presença da junta, melhora o controle da uniformidade da espessura e o aparecimento de vazios. Observou-se também que o uso de concreto de alta resistência no elemento pré-moldado faz com que as tensões de fendilhamento tenham maior importância. Para um maior aproveitamento da capacidade resistente do sistema, o material de preenchimento também deve ser de alta resistência. Dos diversos materiais usados para o preenchimento da junta, a argamassa do tipo "Dry Pack" foi a que ofereceu melhores condições de execução. Além de proporcionar total aproveitamento da capacidade resistente do sistema, diminuiu a deformabilidade da junta e, conseqüentemente, a fissuração.

Palavras-chave: ligação, concreto pré-moldado, juntas de argamassa. 


\section{Abstract}

BARBOZA, A. S. R. (2002) Compression mortar joints behavior at the precast elements connection. São Calos, 154p. Ph.D. Dissertation - Escola de Engenharia de São Carlos, Universidade de São Paulo, Brazil.

In this thesis a theoretical-experimental analysis of the compression mortar joints behavior is presented. The joints were produced with commercially available materials and flexible support cushion. The purpose of this research was to obtain design recommendations that characterize the deformability and the strength of the joints, in order to have a better use of the precast system bearing capacity. Previous studies of this problem showed the main parameters related to the joint behavior and numerical simulations were carried out using ANSYS 5.5.1. An experimental program was developed considering as variables the thickness of the mortar layer, the strength of the precast concrete element and of the mortar, the joint material, the additional reinforcement in the connection area and the roughness of the element surface. The results showed that a $20 \mathrm{~mm}$ thickness is most suitable, because besides minimizing the discontinuity effects, it improves the control of the uniformity of the thickness as well as the air retained in the joint. It was also observed that using high strength concrete precast elements the splitting stresses becomes more important. For a larger use of the bearing capacity of the system, the joint material should also be of high strength. The use of a "Dry Pack" mortar offered better execution conditions, improving the bearing capacity of the system, with less deformability as well as cracking.

Keywords: connection, precast-concrete, mortar joints. 


\section{Introdução}

\subsection{Preliminares}

A utilização de estruturas de concreto pré-moldadas surgiu com a busca de uma técnica alternativa de execução de estruturas dentro do canteiro de obras, que representasse um modelo mais racional para a construção convencional. Os primeiros elementos estruturais pré-moldados foram vigas do Cassino de Biarritz, na França, executadas em 1891. A partir dessa experiência, outras peças foram executadas nos Estados Unidos e na Europa e a técnica foi sendo difundida por todo o mundo.

À medida que as exigências de desempenho foram aumentando, a produção em canteiros de obras foi sofrendo limitações econômicas e de qualidade que impediam avanços no processo produtivo. A saída para tais limitações foi a criação de fábricas que permitiam o desenvolvimento de sistemas construtivos de alta qualidade e representavam o primeiro passo para o processo de industrialização da construção.

Após a Segunda Guerra Mundial, a escassez de recursos e a necessidade de reconstrução das cidades o mais rápido possível, impulsionaram a indústria de pré-moldados, pois trouxe uma forte conscientização para o uso 
racional dos componentes e dos materiais.

$\mathrm{Na}$ construção industrializada, o trabalho dos profissionais envolvidos se integra no produto, seja este um elemento ou um sistema estrutural completo. Nesse aspecto, o primeiro requisito para que qualquer sistema estrutural executado com elementos pré-moldados apresente um desempenho satisfatório é que as fases que vão desde a concepção do projeto até a execução da estrutura sejam cumpridas pensando-se numa construção pré-moldada, garantindo assim o aproveitamento de todos os recursos que a pré-moldagem oferece.

Desenvolver um projeto estrutural com elementos pré-moldados não significa cortar em partes um projeto estrutural já existente, mas sim empregar uma nova definição para o projeto, considerando todas as interações existentes entre os elementos.

As vantagens que a pré-moldagem oferece tais como: rapidez de execução, economia de materiais, redução de mão-de-obra, garantia de qualidade do produto, são consensos para todos os pesquisadores e usuários.

As desvantagens da pré-moldagem, ou os fatores que inviabilizam sua utilização estão relacionados às dificuldades de transporte e montagem dos elementos e principalmente à existência das ligações entre os elementos.

A existência das ligações representa a principal diferença entre um sistema estrutural monolítico e um sistema estrutural pré-moldado.

Devido ao seu comportamento próprio as ligações podem promover a redistribuição dos esforços nos elementos e ainda a modificação dos deslocamentos finais. As falhas de certas ligações quando submetidas a determinadas ações, bem como defeitos em sua execução, podem ocasionar deslocamentos excessivos e provocar o colapso da estrutura.

Para ORDÓÑEZ (1974), a influência das ligações na construção prémoldada é tão preponderante que elas têm impedido a superação dos métodos construtivos convencionais pelos pré-moldados. Dessa forma, o bom 
funcionamento de um sistema estrutural pré-moldado e consequentemente seu êxito comercial está diretamente relacionado com o desempenho das suas ligações.

BALLARIN (1993) comenta que embora alguns países venham realizando estudos experimentais sistemáticos sobre determinados tipos de ligações, nas últimas décadas, tal investigação não tem acompanhado a expansão na utilização das estruturas pré-fabricadas. Alerta ainda, da importância de um estudo aprofundado das ligações.

O comportamento estrutural das ligações é sempre complexo e na maioria das vezes necessita de estudo teórico-experimental para sua análise.

Segundo o Código Modelo - CEB/90 (1991) o projeto das ligações em estruturas pré-moldadas deve garantir os preceitos listados a seguir:

a) as ligações devem ser executadas de modo a garantir para a estrutura rigidez e estabilidade global;

b) devem ser consideradas tolerâncias de fabricação e montagem;

c) a ligação deve resistir às solicitações obtidas na análise da estrutura incluindo a verificação dos esforços de transferência nas partes dos elementos pré-moldados junto às ligações;

d) devem ser previstas prováveis acomodações da ligação até ela atingir sua capacidade.

Além desses fatores, dois aspectos ainda merecem destaque no projeto das ligações: a durabilidade e a ductilidade. A durabilidade é um fator importante pois sendo a ligação um ponto de descontinuidade da estrutura pré-moldada, a presença de elementos externos ao concreto pré-moldado, tais como conectores metálicos, podem determinar um ponto de falha para a estrutura.

Quanto à ductilidade, o que se busca é garantir um estado de ruptura caracterizado por grandes deformações, permitindo redistribuição dos 
esforços para evitar o colapso da estrutura.

Todos os critérios devem ainda estar aliados à simplicidade de execução. Dessa forma pode-se dizer que a configuração das ligações afeta a construtibilidade, estabilidade, resistência, flexibilidade e absorção de forças residuais na estrutura.

O estudo de ligações entre elementos estruturais pré-moldados iniciouse no Departamento de Estruturas da Escola de Engenharia de São Carlos/USP com o trabalho apresentado por BALLARIN (1993) onde foi feito um diagnóstico do estado-da-arte das ligações encontradas na bibliografia disponível. Logo após, o trabalho apresentado por FERREIRA (1993) estudava a deformabilidade de ligações típicas de estruturas pré-moldadas e apresentava uma metodologia analítica para o cálculo dessas deformabilidades.

Continuando o estudo do comportamento das ligações, o trabalho apresentado por SOARES (1998) analisava a deformabilidade da ligação vigapilar executada através de consolo e chumbador, encontrada comumente em galpões pré-moldados.

Num outro trabalho, FERREIRA (1999) avaliou a metodologia analítica proposta anteriormente para o cálculo das deformabilidades das ligações através de comparações com resultados experimentais de duas ligações típicas viga-pilar.

Dando continuidade à linha de pesquisa implantada no Departamento, este trabalho procurou analisar o comportamento da ligação entre elementos pré-moldados através de uma camada de argamassa ou concreto de granulometria fina, comumente chamada junta de argamassa.

A maior parte dos trabalhos encontrados na literatura trata de juntas de argamassa entre painéis de parede portante e entre pilares. Porém, esse tipo de ligação também aparece entre aduelas pré-moldadas de pontes e de torres e ainda como componente em partes comprimidas de ligações sujeitas à flexão. 
A justificativa para a continuidade do estudo de ligações, aparece no trabalho apresentado por CHEOK \& LEW (1991), que ressalta o assunto como um ponto de partida para o avanço das estruturas pré-moldadas. A necessidade de conhecimento sobre o comportamento das ligações é apresentada no trabalho de EL DEBS (1996) que mostra um levantamento de pesquisas, desenvolvidas ou em desenvolvimento, sobre concreto prémoldado.

A partir dessa realidade, observou-se que dentre os diversos tipos de ligações, a ligação entre elementos pré-moldados intercalando uma camada de argamassa ou concreto de granulometria fina é bastante utilizada devido a sua facilidade de execução. Porém, apesar de sua popularidade, ainda existe a necessidade de determinar parâmetros que caracterizem sua capacidade resistente considerando-se que atualmente pode-se fabricar elementos prémoldados com resistência do concreto bem maior que anteriormente, além de usar argamassa ou concreto de granulometria fina de alta resistência na região da ligação já comercialmente disponíveis.

Por sua utilização em sistemas de colunas pré-moldadas, o CEB -Bulletin d'Informattion № 228 (1995) chama a atenção para a necessidade de avaliar até que ponto o limite de resistência da argamassa ou microconcreto na ligação governa a capacidade de suporte de colunas de concreto de alto desempenho. Considerando-se as técnicas modernas de execução das juntas, que fator de redução global deveria ser considerado para o sistema.

Aqui no Brasil não existem estudos que tratem do assunto, dificultando assim a consideração de parâmetros necessários ao dimensionamento adequado da ligação e muitas vezes inibindo sua utilização em estruturas menos usuais pela falta de conhecimento. Tal realidade justifica ainda mais a necessidade de avaliar de forma mais detalhada o comportamento da ligação.

Para o desenvolvimento do trabalho foi considerado o objetivo mostrado a seguir. 


\subsection{Objetivos}

O objetivo principal do trabalho é analisar o comportamento de juntas de argamassa solicitadas à compressão na ligação entre elementos prémoldados, de forma a obter recomendações que caracterizem sua deformabilidade e resistência, e auxiliem o seu projeto. De forma mais específica tem-se os seguintes objetivos:

a) sistematizar os conhecimentos teóricos existentes sobre o assunto;

b) analisar numericamente o comportamento da ligação procurando obter os parâmetros de influência mais relevantes;

c) avaliar experimentalmente a deformabilidade e resistência da ligação, utilizando para preenchimento da junta materiais comercialmente disponíveis;

d) avaliar a necessidade de prever uma armadura de reforço na região do elemento prémoldado adjacente à junta, para evitar a ruptura localizada do elemento;

e) buscar recomendações práticas para utilização em projeto desse tipo de ligação.

\subsection{Apresentação}

O estudo da ligação na tese foi subdividido em capítulos considerandose os objetivos específicos apresentados.

\section{Capítulo 1 - Introdução}

Nesse capítulo é feita uma breve introdução sobre o comportamento das ligações nas estruturas pré-moldadas, caracterizando em seguida o tipo de ligação estudado. Além disso, são apresentadas as justificativas para o desenvolvimento da tese, bem como definidos os objetivos buscados com a pesquisa. 
Capítulo 2 - Revisão Bibliográfica

Este capítulo traz o levantamento bibliográfico realizado sobre o assunto, procurando caracterizar os principais parâmetros de influência do comportamento da ligação.

Capítulo 3 - Avaliação Numérica dos Parâmetros de Influência do Comportamento da Ligação

Neste capítulo, os parâmetros de influência do comportamento da ligação detectados através do levantamento bibliográfico, são explorados através de simulações numéricas realizadas com o software ANSYS 5.5.1. Com essas simulações foram estabelecidos os parâmetros de maior relevância a serem explorados no programa experimental.

Capítulo 4 - Avaliação Experimental do Comportamento da Ligação

Considerando-se os parâmetros mais relevantes para análise do comportamento da ligação, foi desenvolvido um programa experimental para caracterizar sua deformabilidade e resistência. Tal programa é descrito nesse capítulo.

\section{Capítulo 5 - Análise dos Resultados}

Nesse capítulo é feita a análise e discussão dos resultados obtidos com o programa experimental, buscando subsídios para as conclusões que serão apresentadas no trabalho.

Capítulo 6 - Considerações Finais e Conclusões

Nesse capítulo são apresentados os comentários finais do trabalho e as conclusões obtidas com o estudo desenvolvido. Além disso, apresentam-se algumas sugestões para continuidade da pesquisa. 


\section{Revisão Bibliográfica}

\subsection{Preliminares}

A finalidade estrutural da ligação num sistema estrutural pré-moldado é transferir forças de um elemento para outro. De forma geral, esta transferência de forças pode ser subdividida da seguinte forma:

- transferência de tensões de compressão;

- transferência de tensões de tração;

- transferência de tensões de cisalhamento.

Tratando especificamente da transferência de tensões de compressão, ela pode ser feita através de:

- almofadas de elastômero - utilizadas nas ligações viga-pilar por proporcionar uma distribuição mais uniforme das tensões de contato e permitir movimentos de rotação e translação;

- elementos metálicos - transfere bem as forças, porém apresenta menos facilidade de execução; 
- camada de argamassa ou concreto de granulometria fina moldado no local - tem a grande vantagem de não precisar de manutenção e quando comparada à almofada de elastômero tem maior capacidade resistente, porém menor deformabilidade.

Em alguns casos também é usado o apoio direto de um elemento sobre o outro, porém é um tipo de ligação bastante limitada. Segundo a NBR-9062 Projeto e execução de Estruturas de Concreto Pré-Moldado (1985) a junta a seco só é permitida no caso de elementos de pequenas dimensões cuja pressão de contato sobre os apoios não ultrapasse 3\% da menor resistência característica do concreto dos elementos pré-moldados. Além disso, as tensões de contato não devem ultrapassar 1,0MPa.

A ligação considerada aqui neste trabalho consiste numa camada de argamassa ou concreto de granulometria fina moldada entre dois elementos pré-moldados. Essa camada pode ser executada com:

- argamassa de assentamento - permite corrigir imperfeições existentes na superfície dos elementos e uniformiza a distribuição de tensões, porém apresenta dificuldade para manter a mesma espessura ao longo da ligação;

- argamassa de enchimento seca ou fluida - é inserida entre os elementos após a montagem dos mesmos;

- argamassa de enchimento a base de epóxi - é uma mistura de resina epóxi e areia usada quando se deseja alta resistência na camada.

É um tipo de ligação que possui aplicações diversas. Pode ser encontrada entre segmentos de pilares, entre painéis em estruturas de parede portante, entre pilar e laje, entre painéis e viga, como na Figura 2.1, e ainda em partes comprimidas de ligações submetidas à flexão. 
Em geral, como a resistência da argamassa é menor que a resistência do concreto utilizado nos elementos pré-moldados, a capacidade resistente da ligação é considerada com valor menor que a dos elementos pré-moldados. Isto faz com que a capacidade resistente desses elementos não seja completamente utilizada devido à limitação imposta pela camada de argamassa.

Vê-se então que a capacidade resistente das juntas representa um ponto importante para o projeto da ligação, já que a transferência de esforços através da ligação deve ser feita sem que haja dano nas superfícies de contato.

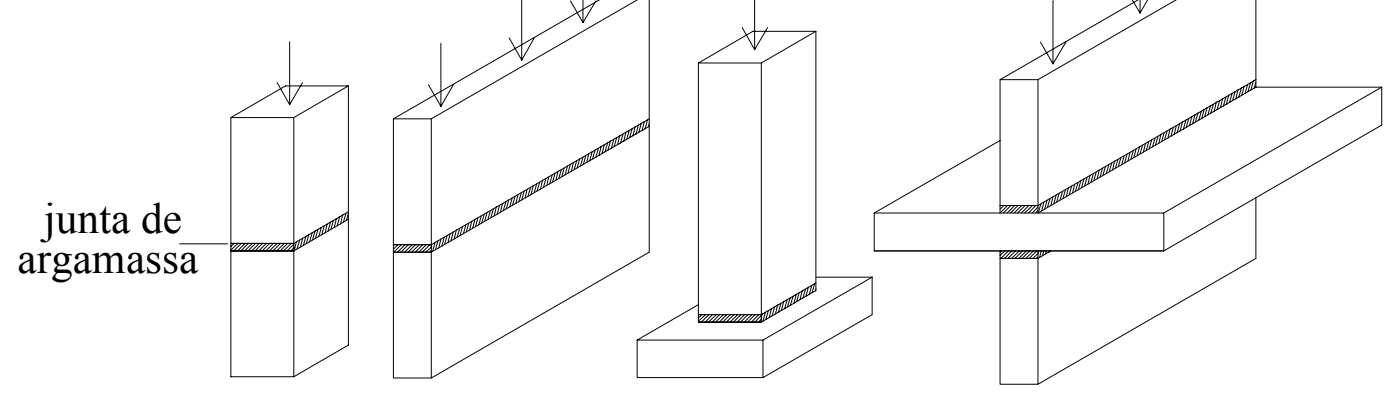

Figura 2. 1: Junta de argamassa entre elementos pré-moldados.

Fonte: DRAGOSAVIC (1978).

Segundo o CEB - Bulletin d'Informattion № 169 (1985) as ligações com juntas de argamassa podem ser agrupadas em dois tipos: juntas verticais, submetidas basicamente a esforços de cisalhamento e juntas horizontais solicitadas predominantemente à compressão. Neste trabalho, serão abordadas somente as juntas horizontais ou, mais especificamente, as juntas nas quais a solicitação predominante é compressão. 


\subsection{Literatura Encontrada}

De acordo com estudos realizados por alguns pesquisadores, para estabelecer a capacidade resistente da ligação com juntas horizontais de argamassa devem ser considerados como fatores de influência: a relação entre as resistências à compressão do concreto dos elementos pré-moldados e da argamassa, e as dimensões da junta. A literatura encontrada sobre o assunto está descrita a seguir seguindo uma ordem de encadeamento por assunto, independente da ordem cronológica.

DRAGOSAVIC (1978)

Considerando que as ligações são pontos cruciais para a segurança e economia de um sistema estrutural pré-moldado, foi estabelecido na Holanda um comitê denominado SBR-Committee B7, com a finalidade de investigar de forma mais detalhada o comportamento estrutural das ligações usadas nas construções. Os resultados dos estudos experimentais de quatro tipos de ligações, que teriam sido incorporados nas recomendações da Norma Holandesa, foram apresentados no trabalho de DRAGOSAVIC (1978). Com relação à ligação através de junta de argamassa, os experimentos mostraram que é razoável considerar que o valor da capacidade resistente da ligação está relacionado com a resistência à compressão da argamassa usada na junta, a resistência à compressão do concreto usado no elemento pré-moldado e as dimensões da camada de argamassa. A partir destas considerações estabeleceu-se que:

- quando a resistência à compressão da argamassa $\left(\mathbf{f}_{\mathbf{m}}\right)$ é maior que a resistência à compressão do concreto usado no elemento pré-moldado $\left(\mathbf{f}_{\mathfrak{c}}\right)$, a presença da camada de argamassa não reduz a capacidade resistente da junta. Conseqüentemente, a resistência à compressão da junta $\left(\mathbf{f}_{\mathbf{j}}\right)$ é 
considerada igual a $\mathbf{f}_{\mathbf{c}}$.

- quando $\mathrm{f}_{\mathrm{m}}<\mathrm{f}_{\mathrm{c}}$ e a relação $\mathbf{h}_{\mathrm{j}} / \mathbf{a}$ (espessura/menor dimensão da junta no plano da seção transversal) é muito grande, ou seja, $\mathbf{h}_{\mathbf{j}}>>\mathbf{a}$, a capacidade resistente da junta $\left(\mathbf{f}_{\mathbf{j}}\right)$ é igual a $\mathbf{f}_{\mathrm{m}}$.

- se $\mathbf{f}_{\mathbf{m}}<\mathbf{f}_{\mathbf{c}}$ e a relação $\mathbf{h}_{\mathbf{j}} / \mathbf{a}$ é pequena, a resistência $\mathbf{f}_{\mathbf{j}}$ é dada por:

$$
\mathrm{f}_{\mathrm{j}}=\alpha \cdot \mathrm{f}_{\mathrm{c}}
$$

O parâmetro $\alpha$, considerado como fator que mede a eficiência da junta, é definido no intervalo: $\mathbf{f}_{\mathrm{m}} / \mathbf{f}_{\mathrm{c}} \leq \alpha \leq 1,0$ como mostra o gráfico da Figura 2.2. Esse gráfico pode ser construído a partir da Equação 2.2 apresentada por VAMBERSKY (1990), arbitrando-se valores para $\boldsymbol{\delta}$.

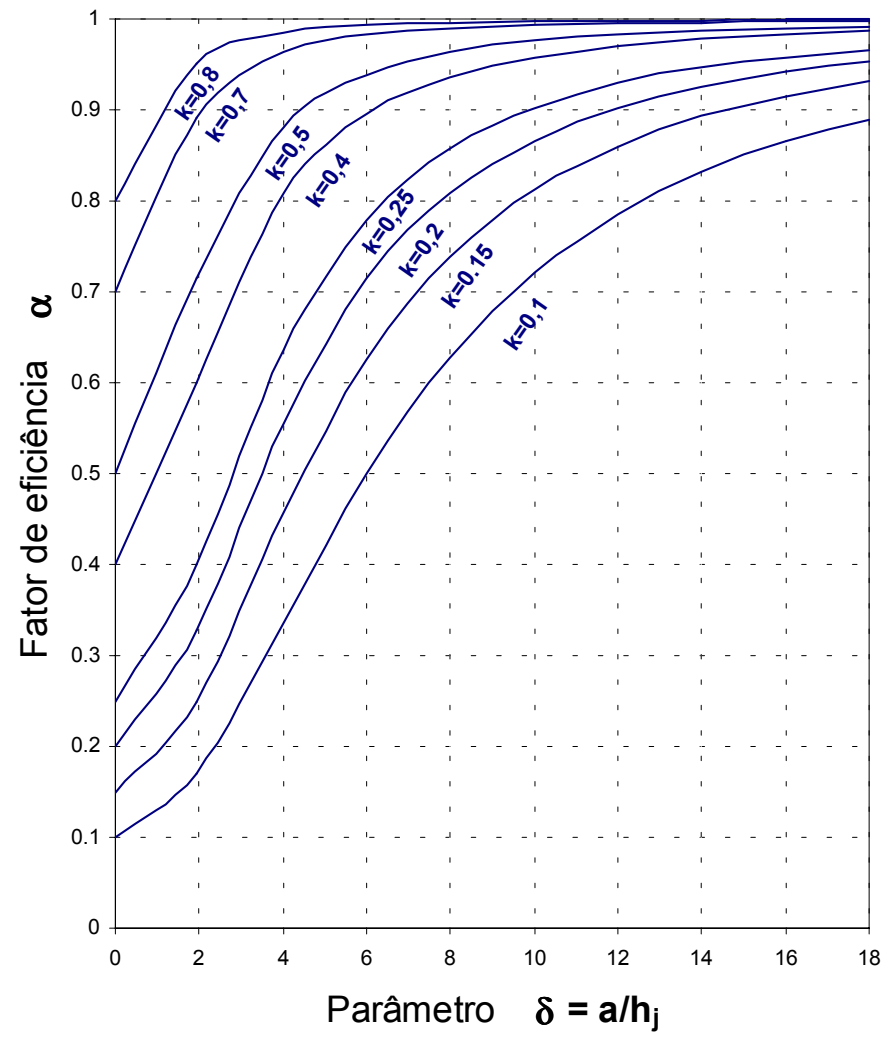

Figura 2. 2: Diagrama para determinação do fator de eficiência $\alpha$. 


$$
\alpha=\mathrm{k} \frac{5(1-\mathrm{k})+\delta^{2}}{5(1-\mathrm{k})+\mathrm{k} \delta^{2}}
$$

onde: $\mathrm{k}$ - relação entre a resistência à compressão da argamassa e a menor resistência à compressão do concreto dos elementos pré-moldados adjacentes à junta, afetada por um coeficiente redutor $\eta_{\mathrm{m}}$ que varia em função da qualidade da argamassa;

$\delta$ - relação entre a menor largura e a espessura da junta.

\section{LEWICKI (1982) e VAMBERSKY (1990)}

Em outros estudos, alguns pesquisadores verificaram que em muitos casos de juntas horizontais a capacidade resistente da ligação não era governada pela resistência ao esmagamento da argamassa, mas sim pelo fendilhamento do concreto nos elementos pré-moldados adjacentes a junta. Segundo LEWICKI (1982) e VAMBERSKY (1990), as tensões que causam esse fendilhamento aparecem como resultado de dois mecanismos:

- devido à deformabilidade diferenciada dos dois materiais, quando a argamassa é comprimida e não existe confinamento lateral ela é expulsa pelas extremidades, gerando assim forças de atrito na área de contato entre a argamassa e o elemento pré-moldado (ver Figura 2.3 a). Estas forças de atrito provocam o aparecimento de tensões de tração no elemento;

- com a expulsão da argamassa nas extremidades, ocorre uma concentração de tensões no meio da junta (ver Figura 2.3 b). Esta distribuição de tensões não uniforme gera tensões que provocam o fendilhamento do concreto no elemento pré-moldado. A trajetória das tensões é mostrada na Figura 2.3 c. 


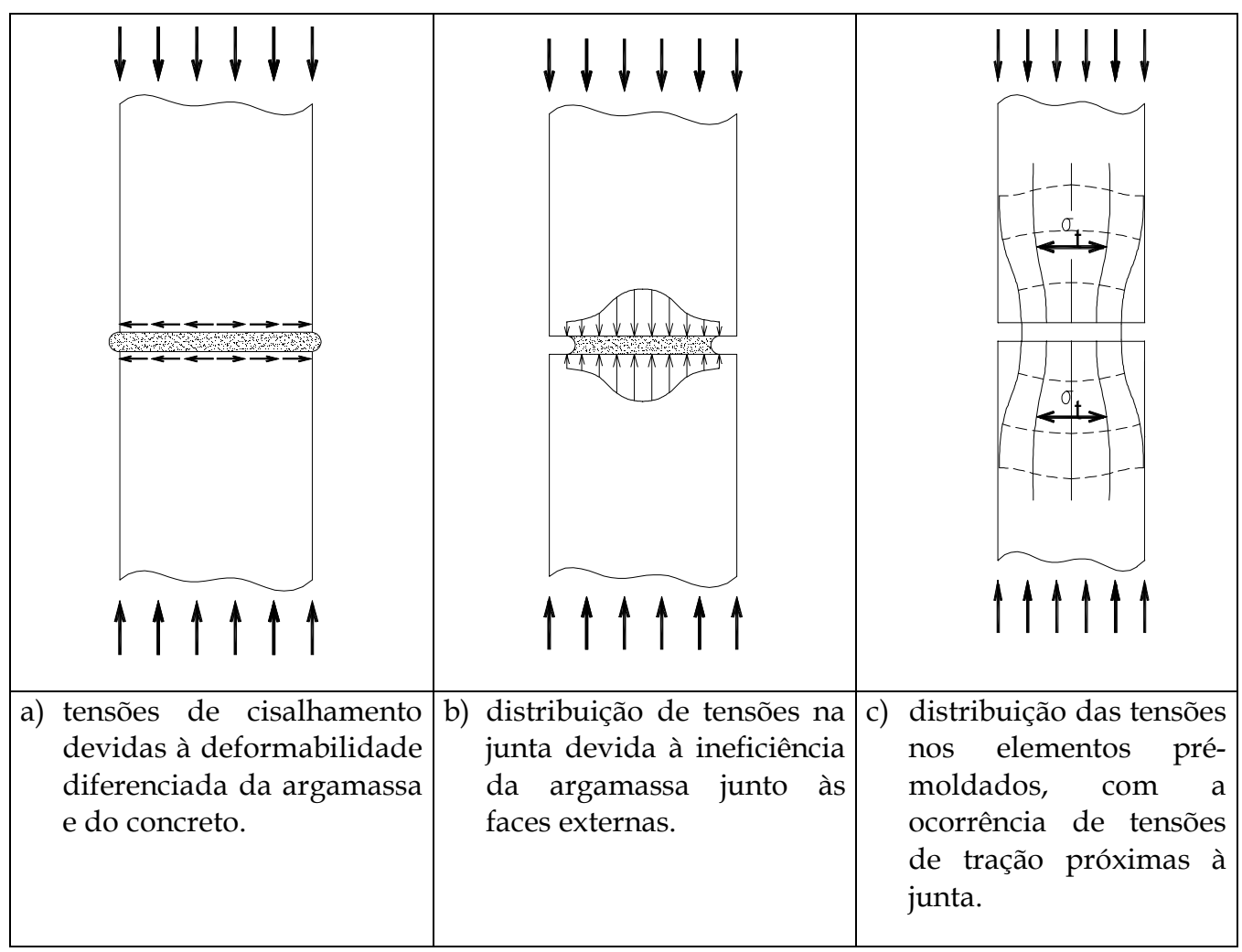

Figura 2. 3: Forças de atrito advindas da expulsão da argamassa e distribuição não uniforme de tensões na área da junta. Fonte: EL DEBS (2001).

\section{LEWICKI (1982)}

Com as observações anteriores, LEWICKI (1982) estabeleceu que a capacidade resistente da ligação horizontal entre painéis de parede portante poderia ser determinada através da seguinte expressão:

$$
F_{j}=\eta_{j} \cdot A_{c} \cdot f_{c}
$$

onde: $\eta_{j}$ - coeficiente de redução global que representa a redução da capacidade de suporte da seção plena do painel, devido à presença da junta horizontal;

$\mathrm{A}_{\mathrm{c}}$ - seção transversal do painel;

$\mathrm{f}_{\mathrm{c}}$ - resistência à compressão do concreto do painel. 
No início o coeficiente $\eta_{\mathbf{j}}$ era determinado experimentalmente usando-se amostras de painéis com junta intermediária na escala 1:1. Com o resultado experimental tinha-se caracterizada a resistência somente para aquela ligação e com isso o projeto de uma nova ligação recaía na necessidade de novos ensaios.

Durante os ensaios o autor observou que a junta deveria ser analisada considerando-se uma subdivisão em faixas verticais, devido a deformabilidade diferenciada de cada trecho. Esta observação tornou-se a base para a formulação analítica do problema.

O acúmulo de resultados experimentais possibilitou a formulação de um método analítico de cálculo para a resistência da ligação, estabelecendo-se uma expressão geral para $\eta_{j}$.

$$
\eta_{j}=\eta_{e} \cdot \tau_{p} \cdot \tau_{R} \cdot \tau_{m} \cdot \tau_{a}
$$

onde: $\eta_{\mathrm{e}}$ - coeficiente que leva em conta a influência da distribuição desigual de solicitação na junta e a influência da excentricidade de aplicação do esforço normal;

$\tau_{\mathrm{p}}$ - coeficiente que considera o aumento da resistência à compressão da argamassa devido à influência da compressão exercida pelos painéis; $\tau_{R}$ - coeficiente que leva em conta a diminuição da resistência da parede sob compressão, devido à presença do momento de engastamento do painel inferior na junta, se opondo ao momento de tombamento do painel superior;

$\tau_{\mathrm{m}}$ - coeficiente que leva em conta a influência da argamassa presente na ligação;

$\tau_{\mathrm{a}}$ - coeficiente que considera o aumento de resistência à compressão do painel, devido a presença de armadura transversal. 
O parâmetro $\eta_{\mathbf{e}}$, corrigido por meio do coeficiente $\tau_{\mathbf{p}}$, era o mais importante para a capacidade resistente da ligação.

O segundo em ordem de importância era o parâmetro $\tau_{\mathbf{a}}>\mathbf{1}$, que se constituía numa alternativa construtiva para aumentar a capacidade da ligação, projetando-se uma armadura transversal. $O$ parâmetro $\tau_{\mathbf{R}}$ era desprezível e o parâmetro $\tau_{\mathbf{m}}$ era importante exclusivamente, no caso de junta horizontal espessa ou de deformabilidade excessiva.

O parâmetro $\tau_{\mathrm{m}}$ que representa a influência da camada de argamassa na ligação era obtido utilizando-se a Equação 2.5:

$$
\tau_{\mathrm{m}}=\frac{1}{\sqrt{1+\mathrm{k}^{2} \frac{\mathrm{f}_{\mathrm{m}}}{0,15}}}
$$

onde: $\mathrm{k}$ - é função da relação entre as resistências da argamassa e do concreto pré-moldado, e da relação entre a menor largura do painel e a espessura da camada de argamassa; $\mathrm{f}_{\mathrm{m}}$ - resistência à compressão da argamassa.

O parâmetro $\mathbf{k}$ era obtido através da Equação 2.7 considerando que a relação entre os módulos de elasticidade dos dois materiais era definida pela Equação 2.6.

$$
\begin{aligned}
& \frac{E_{m}}{E_{c}}=0,5 \sqrt{\frac{f_{m}}{f_{c}}} \\
& k=\frac{0,2-0,1 \sqrt{\frac{f_{m}}{f_{c}}}}{0,5 \sqrt{\frac{f_{m}}{f_{c}}+\frac{h_{j}}{a}}}
\end{aligned}
$$


onde: $h_{j}$ - espessura da camada de argamassa;

a - menor largura do painel.

LEWICKI (1982) observou também que, de forma semelhante ao que acontecia com painéis, a deformação diferenciada da argamassa e do concreto pré-moldado também reduzia a capacidade resistente da ligação quando ela era usada entre pilares. Esse efeito era mais relevante nos pilares, devido ao estado tridimensional de deformação da junta.

Entretanto, como a resistência do material da junta não era muito diferente da resistência do concreto do elemento pré-moldado, a necessidade de considerar os efeitos da argamassa se apresentava exclusivamente no caso de camada espessa. Tais efeitos eram incorporados na resistência da ligação através de um novo coeficiente de redução apresentado por LUGEZ \& ZARZYCKI ${ }^{1}$ apud LEWICKI (1982), obtido com a Equação 2.8 e mostrado através da Figura 2.4.

$$
\tau_{\mathrm{m}}=1-3 \frac{\mathrm{h}_{\mathrm{j}}}{\mathrm{a}}\left(1-\frac{\mathrm{f}_{\mathrm{m}}}{\mathrm{f}_{\mathrm{c}}}\right)
$$

onde: $h_{j}$ - espessura da camada de argamassa;

a - menor largura da camada de argamassa;

$\mathrm{f}_{\mathrm{m}}$ - resistência da argamassa usada na junta;

$f_{c}$ - resistência do concreto usado no elemento pré-moldado.

\footnotetext{
${ }^{1}$ LUGEZ, J. \& ZARZYCKI, A. (1969) Influence des joints horizontaux sur la resistance des elements
} préfabriqués de murs porteurs. Cahier du CSTB, n.103, october, 1969. 


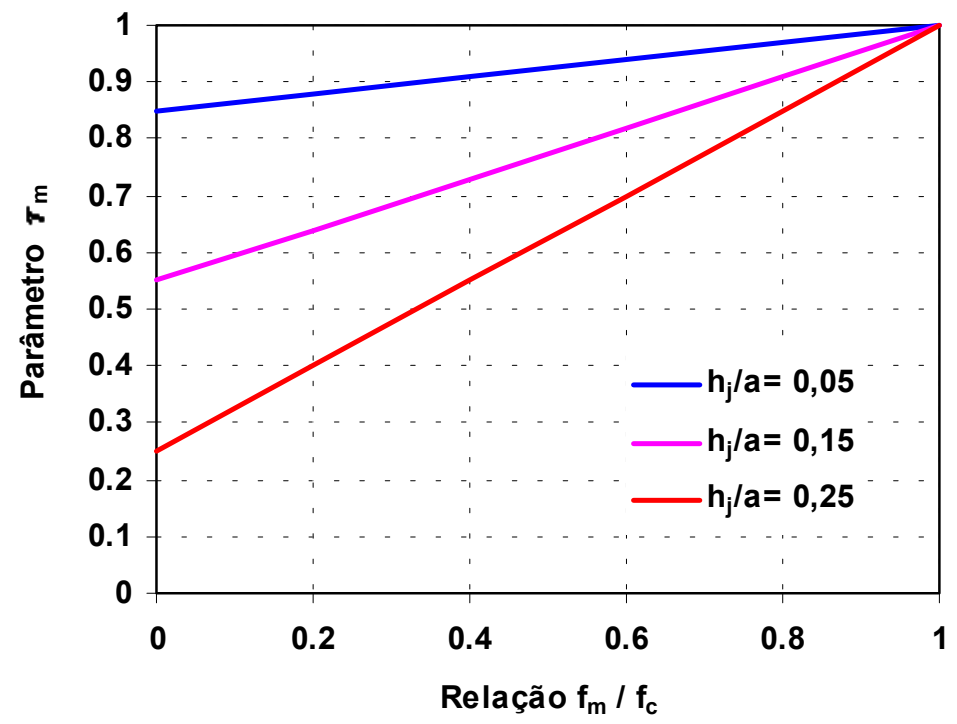

Figura 2. 4: Variação do parâmetro $\tau_{\mathrm{m}}$. Fonte:LEWICKI (1982).

\section{BJLUGER (1988)}

BJLUGER (1988) considerou que a deformabilidade da junta de argamassa entre painéis ou entre pilares dependia da resistência à compressão da argamassa usada na junta, mas era independente da espessura da camada. Entende-se por deformabilidade, o módulo da relação entre o deslocamento relativo entre os elementos e a tensão atuante na direção desse deslocamento. Baseado em resultados experimentais, o autor estabeleceu que para efeito de projeto o sistema pré-moldado seria considerado homogêneo com módulo de elasticidade equivalente definido pela Equação 2.9.

$$
E_{e}=\frac{1}{1 / E_{c}+D_{m} / H}
$$

onde: $\mathrm{E}_{\mathrm{c}}$ - módulo de elasticidade do elemento de concreto pré-moldado; $\mathrm{D}_{\mathrm{m}}$ - deformabilidade de todas as juntas no limite de um pavimento; $\mathrm{H}$ - altura do pavimento. 
A deformabilidade $\mathbf{D}_{\mathbf{m}}$ era obtida com a seguinte equação:

$$
\mathrm{D}_{\mathrm{m}}=\mathrm{nD}_{\mathrm{j}}+\frac{\mathrm{h}}{\sum_{\mathrm{l}} \frac{\mathrm{a}}{\mathrm{n}_{\mathrm{i}} \mathrm{D}_{\mathrm{j} 1}}}
$$

onde: $\mathrm{n}$ - número de juntas que atravessam toda a largura do elemento prémoldado, com deformabilidade $\mathbf{D}_{\mathbf{j}}$ definida de acordo com a Tabela 2.1; $\mathrm{i}$ - numero de juntas com largura a, espessura h e deformabilidade $\mathbf{D}_{\mathbf{j}}$ definida de acordo com a Tabela 2.1.

Tabela 2. 1 - Deformabilidade de diferentes tipos de juntas solicitadas à compressão. Fonte BLJUGER (1988)

\begin{tabular}{|c|c|c|c|c|}
\hline \multirow{2}{*}{$\begin{array}{c}\text { Tipo de } \\
\text { junta }\end{array}$} & $\begin{array}{c}\text { Material de } \\
\text { preenchimento } \\
\text { da junta }\end{array}$ & $\begin{array}{c}\text { Resistência `a compressão do concreto } \\
\text { ou argamassa em contato com os } \\
\text { elementos pré-moldados (m/MPa) }\end{array}$ \\
\cline { 3 - 5 } & Até $1 \mathrm{MPa}$ & $5 \mathrm{MPa}$ & $\geq 10 \mathrm{MPa}$ \\
\hline \multirow{2}{*}{$\begin{array}{c}\text { Entre } \\
\text { painéis }\end{array}$} & argamassa & $1 \times 10^{-4}$ & $0,6 \times 10^{-4}$ & $0,4 \times 10^{-4}$ \\
\cline { 2 - 5 } & concreto & - & - & $0,2 \times 10^{-4}$ \\
\hline \multirow{2}{*}{$\begin{array}{c}\text { Entre } \\
\text { pilares }\end{array}$} & argamassa & - & - & $0,5 \times 10^{-4}$ \\
\cline { 2 - 5 } & junta seca & - & - & $0,2 \times 10^{-4}$ \\
\hline
\end{tabular}

Entretanto, para definir a capacidade resistente da ligação entre painéis de parede portante, o autor estabeleceu que a influência dos deslocamentos dos eixos dos elementos, mostrados na Figura 2.5, bem como da espessura da camada de argamassa deveriam ser consideradas. Essa capacidade resistente era obtida com a seguinte equação:

$$
F_{j}=\eta_{j} \cdot A_{c} \cdot f_{c d}
$$

onde: $\eta_{j}$ - fator que considera todas as imperfeições iniciais mostradas na Figura 2.5; 
$\mathrm{A}_{c}$ - seção transversal do painel;

$\mathrm{f}_{\mathrm{cd}}$ - valor de cálculo da resistência à compressão do concreto prémoldado.

$\mathrm{O}$ valor de $\eta_{j}$ era calculado através de um produto de $\eta_{\mathrm{i}}$ imperfeições relevantes, devido à variação de parâmetros geométricos e de resistência ou de características estruturais da junta. De forma geral, o autor estabeleceu os seguintes parâmetros:

- $\eta_{1}=1-\mathrm{e} / \mathrm{h}$ (influência dos deslocamentos $\mathrm{e}_{1}$ ou $\mathrm{e}_{2}$ );

- $\eta_{2}=1\left(1+e_{t} / h\right)$ (influência da deformação gerada durante a fase de montagem);

- $\eta_{3}=\eta_{3}\left(f_{j}, h_{j}\right)$ (influência da espessura da camada, $h_{j}$, e da resistência da $\operatorname{argamassa}, \mathrm{f}_{\mathrm{m}}$ );

- $\eta_{4}$ - fator que representa a influência da forma estrutural da junta e possíveis defeitos locais.

$\mathrm{O}$ valor de $\eta_{3}$ para diferentes espessuras da camada de argamassa em função da relação entre as resistências à compressão dos dois materiais é mostrado na Tabela 2.2.

Tabela 2. 2: Valores de $\eta_{3}$ definidos de acordo com espessura da camada de argamassa e relação $\mathrm{f}_{\mathrm{m}} / \mathrm{f}_{\mathrm{cm}}$.

\begin{tabular}{|c|c|c|c|c|c|c|}
\cline { 2 - 7 } \multicolumn{1}{c|}{} & \multicolumn{6}{c|}{ Relação entre $\mathrm{f}_{\mathrm{j}} / \mathrm{f}_{\mathrm{cm}}{ }^{*}$} \\
\hline $\mathrm{h}_{\mathrm{j}}(\mathrm{mm})$ & 0,1 & 0,3 & 0,5 & 0,7 & 0,95 & $\geq 1$ \\
\hline 10 & 0,87 & 0,93 & 0,94 & 0,95 & 0,95 & 0,95 \\
\hline 30 & 0,60 & 0,78 & 0,85 & 0,90 & 0,93 & 0,95 \\
\hline 50 & 0,37 & 0,68 & 0,81 & 0,88 & 0,93 & 0,95 \\
\hline${ }^{*} \mathrm{f}_{\mathrm{cm}}=\mathrm{f}_{\mathrm{ck}}+8 \mathrm{MPa}$ & &
\end{tabular}




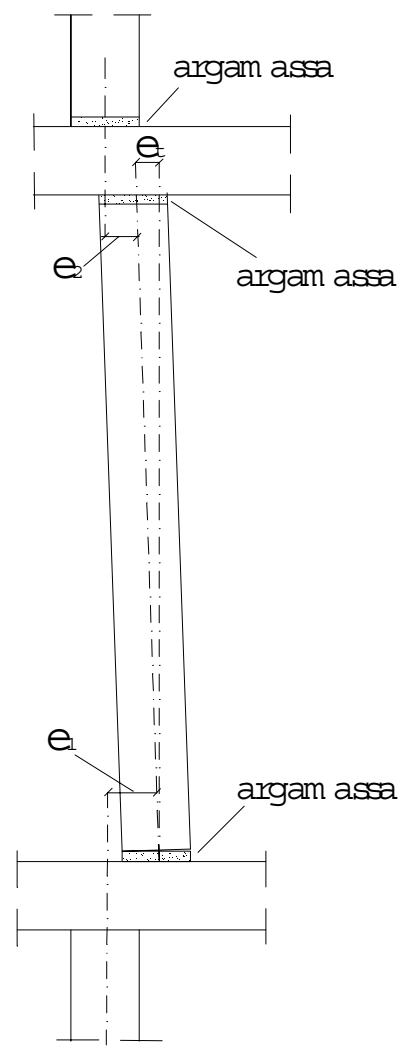

Figura 2. 5: Deslocamentos que influenciam na resistência da ligação.

Fonte BJLUGER(1988).

Já para avaliar a capacidade resistente da ligação entre pilares o autor afirma que a junta de argamassa não deve ser considerada, pois se deve sempre prever uma armadura contínua entre os elementos.

VAMBERSKY (1990)

VAMBERSKY (1990) analisou o comportamento de juntas de argamassa solicitadas à compressão com a finalidade de propor uma atualização das recomendações contidas na Norma Holandesa, apresentadas anteriormente por DRAGOSAVIC (1978), considerando a melhoria alcançada para os materiais usados na junta. Através de resultados experimentais o autor propôs a seguinte expressão para o cálculo da capacidade resistente da ligação: 


$$
\mathrm{f}_{\mathrm{j}}=\eta_{\mathrm{j}} \cdot \alpha \cdot \mathrm{f}_{\mathrm{c}}
$$

onde: $\eta_{\mathrm{j}}$ - fator de redução para a área da junta;

$\alpha$ - fator de eficiência da junta;

$\mathrm{f}_{\mathrm{c}}$ - menor resistência à compressão do concreto dos elementos prémoldados adjacentes à junta.

O fator $\boldsymbol{\alpha}$, presente na expressão de VAMBERSKY (1990) corresponde ao mesmo já apresentado por DRAGOSAVIC (1978) através do gráfico mostrado na Figura 2.2.

A atualização proposta pelo autor se refere aos parâmetros $\eta_{\mathbf{j}}$ e $\eta_{\mathbf{m}}$. $\mathrm{O}$ coeficiente $\eta_{\mathbf{j}}$ foi estabelecido considerando-se as novas técnicas de execução da junta:

- $\eta_{\mathrm{j}}=0,9$ para argamassa fluida colocada na junta após a montagem dos elementos pré-moldados;

- $\eta_{\mathrm{j}}=0,7$ para argamassa seca colocada na junta após a montagem dos elementos pré-moldados;

- $\quad \eta_{\mathrm{j}}=0,3$ se o elemento pré-moldado é colocado sobre argamassa já existente no local da junta.

O parâmetro $\eta_{\mathrm{m}}$ que avalia a qualidade da argamassa colocada na junta é considerado da seguinte forma:

- $\eta_{\mathrm{m}}=0,75$ se a qualidade da argamassa é verificada através de ensaios aos 28 dias, de corpos de prova moldados no local da obra, cuja estocagem foi feita em ambiente controlado. 
- $\eta_{\mathrm{m}}=1,0$ se a qualidade da argamassa é verificada através de ensaios usando-se amostras retiradas da junta executada.

Uma outra recomendação existente na Norma holandesa indicava a colocação de chapas metálicas, com espessura máxima de $50 \mathrm{~mm}$, na região de contato entre a argamassa e o concreto pré-moldado, com a finalidade de uniformizar as tensões naquela região. Para verificar essa recomendação o autor desenvolveu uma simulação numérica da ligação considerando várias espessuras para a chapa metálica.

Com os resultados obtidos na simulação, VAMBERSKY (1990) observou que as tensões que provocavam o fendilhamento do concreto no elemento prémoldado mantinham-se praticamente constantes com a variação da espessura da placa. Com isto, chegava-se a conclusão que o efeito suposto nas recomendações da Norma não aconteciam.

Concentrando-se mais detalhadamente no comportamento dos modelos numéricos o autor concluiu que:

- uma placa metálica delgada colocada na junta não melhorava a distribuição das tensões, e a distribuição não uniforme provocava o fendilhamento do concreto.

- a placa metálica espessa permitia uma distribuição de tensões mais uniforme, entretanto restringia a deformação lateral do concreto prémoldado. Com isto, as tensões de fendilhamento ocorriam e o efeito positivo da placa, mencionado anteriormente, era eliminado.

O autor analisou ainda a opção de substituir a placa metálica por uma armadura transversal reforçada na região do elemento pré-moldado adjacente à junta, com a finalidade de aumentar as tensões de confinamento na região da ligação. Entretanto, o autor verificou que esse procedimento não resulta em 
aumentos significativos para a capacidade resistente da ligação, pois o efeito da armadura só aparece quando a integridade do modelo já está parcialmente perdida.

A partir das observações citadas, o autor concluiu que o modo mais efetivo de aumentar a capacidade resistente da ligação com junta de argamassa é usar argamassa de alta resistência na junta e concreto pré-moldado de alta resistência nos elementos ligados, sendo a argamassa fluida mais recomendada.

\section{BRUGGELING \& HUYGHE (1991)}

BRUGGELING \& HUYGHE (1991), consideram como hipótese inicial que a espessura da camada de argamassa deve ser menor que $10 \%$ da menor dimensão da seção transversal do elemento pré-moldado.

A partir daí os autores estabelecem que a capacidade resistente da ligação entre elementos pré-moldados com junta de argamassa moldada no local, solicitada por compressão axial, é obtida combinando-se a resistência à compressão da argamassa e a resistência à compressão do concreto do elemento pré-moldado, de acordo com a seguinte expressão:

$$
f_{j}=f_{c}-\left(1-a / 10 h_{j}\right)^{2} \cdot\left(f_{c}-f_{m}\right)
$$

onde: $f_{c}$ - menor resistência à compressão do concreto do elemento prémoldado adjacente à junta;

$\mathrm{f}_{\mathrm{m}}$ - resistência à compressão da argamassa;

a - menor largura da junta;

$h_{j}$ - espessura da junta.

- $\operatorname{se} \mathbf{h}_{\mathbf{j}}<\mathbf{0 , 1} \mathbf{a}$, a resistência da ligação é igual a do concreto adjacente a ela; 
- $\quad$ se $\mathbf{h}_{\mathbf{j}}>\mathbf{0 , 5} \mathbf{a}$ a resistência da ligação é igual a da argamassa.

Ainda segundo os autores, devido a deformabilidade diferenciada dos materiais da junta, o detalhamento dos elementos pré-moldados adjacentes à junta deve considerar os seguintes efeitos:

- a transferência de forças através da ligação acontece numa situação de bloco parcialmente carregado, ou seja, parte da junta de argamassa definida a partir de uma distância de $\mathbf{2} \mathbf{h}_{\mathbf{j}}$ da borda não contribui para a transferência de cargas através da junta. A área efetiva (Aef) será determinada usando-se a Equação 2.14 e estará submetida a uma carga concentrada cujo valor último é dado pela Equação 2.15 .

$$
\begin{aligned}
& A_{e f}=\left(a-4 h_{j}\right) \cdot\left(b-4 h_{j}\right) \\
& F_{u}=A_{e f} \cdot 0,6 f_{c} \sqrt{A_{c} / A_{e f}}
\end{aligned}
$$

onde: $\mathrm{A}_{c}$ - é a área total da seção transversal;

a e b-dimensões da seção transversal da junta.

- uma vez que a rigidez da argamassa na direção transversal é geralmente menor que a do concreto adjacente, aparecerão tensões de tração no elemento pré-moldado numa zona ainda próxima da interface, como mostra a Figura 2.6. Apesar de ser bastante complexo calcular o valor dessas tensões, elas devem ser consideradas para evitar a fissuração na região. Esta fissuração deve ser combatida prevendo-se uma armadura na região, com valor dado através da Equação 2.16. 


$$
\mathrm{A}_{\mathrm{s}}=1,5 \cdot 10^{-3} \cdot \mathrm{a} \cdot \mathrm{b} \cdot \mathrm{f}_{\mathrm{y}}
$$

onde: $\mathrm{A}_{\mathrm{s}}$ - área de aço;

a e b - dimensões da seção transversal da junta; $\mathrm{f}_{\mathrm{y}}$ - tensão de escoamento do aço.
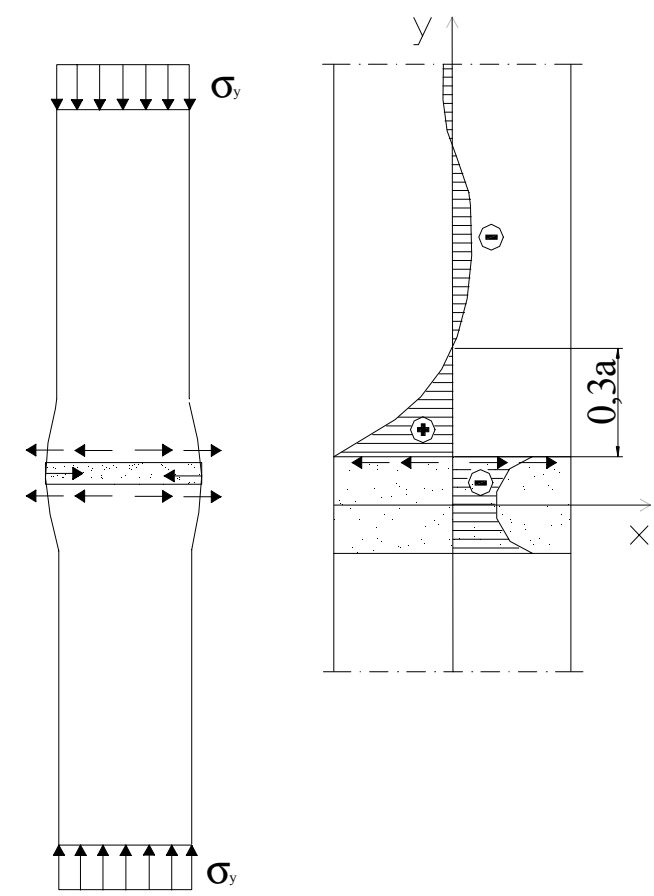

Figura 2. 6: Distribuição de tensões na argamassa e no elemento pré-moldado para a solicitação axial. Fonte: LEWICKI(1982).

\section{ELLIOT (1996)}

Segundo ELLIOT (1996), as juntas de argamassa usadas para transmissão dos esforços de compressão entre elementos pré-moldados devem obedecer aos seguintes critérios:

- a espessura da camada de argamassa deve ser de 10 a 15mm;

- os módulos de elasticidade dos materiais devem ser próximos, ou seja, a diferença existente deve ser menor que $20 \%$. Isto é importante 
principalmente em juntas espessas devido aos efeitos de cisalhamento e tensões de tração laterais que aparecem no elemento pré-moldado;

$\mathrm{O}$ autor considera ainda que o confinamento da argamassa entre os elementos pode fazer com que ela atinja uma resistência à compressão maior que a resistência última, $\mathbf{f}_{\mathbf{m u}}$. Porém, deve-se adotar uma resistência menor no projeto devido a uma distribuição não uniforme de tensões causada pela expulsão da argamassa nas extremidades.

Interpretando os resultados obtidos por VAMBERSKY (1990), o autor afirma que uma tensão de projeto igual a $\mathbf{4 0 \%}$ da resistência última $\left(\mathfrak{f}_{\mathbf{m u}}\right)$ da argamassa, pode ser adotada como capacidade resistente da ligação se:

- a relação entre a menor largura e a espessura da junta estiver entre 8 e 10;

- a diferença entre a resistência à compressão do elemento pré-moldado e a resistência à compressão da argamassa for menor que $25 \%$;

\section{GORGÜN (1997)}

Considerando que o comportamento de uma ligação entre elementos pré-moldados pode ser caracterizado analisando-se isoladamente a influência de cada um dos seus componentes, e que em qualquer tipo de ligação concentram-se grandes deformações nas interfaces concreto prémoldado/concreto moldado no local, GÖRGÜN (1997) ensaiou modelos formados por prismas de concreto simples, com resistência de $40 \mathrm{MPa}$, unidos por uma camada de concreto, para verificar a influência dessa camada no comportamento de uma ligação semi-rígida viga-pilar. Nos modelos foram usados dois valores para a resistência à compressão da camada de concreto: $20 \mathrm{MPa}$ e $40 \mathrm{MPa}$.

O objetivo dos ensaios era determinar a carga última atingida nos modelos e a deformabilidade na junta quando se tem concreto de resistências 
diferentes. Além de variar a resistência da camada de ligação, o autor considerou-a com espessuras diferentes.

Com os ensaios o autor verificou que, em alguns modelos, a presença da junta reduziu a resistência e o módulo de elasticidade da peça monolítica entre $6 \%$ e $21 \%$. A ruptura dos modelos se deu por esmagamento e aconteceu de forma brusca, com carga de ruptura menor em juntas mais espessas.

O autor verificou também que com baixos níveis de tensão a deformabilidade era muito alta devido à presença de vazios entre as interfaces.

\section{DILGER \& CHUI (1989)}

Para avaliar a capacidade de transferência de esforços de compressão através de uma junta de concreto moldada no local, considerando que a junta possuía um ângulo de inclinação em relação ao eixo do elemento prémoldado, DILGER \& CHUI (1989) analisaram a ligação entre elementos de cobertura em forma de arco. Através de uma revisão da literatura, os autores verificaram que os poucos estudos existentes sobre o assunto utilizavam na junta um concreto de baixa resistência, o que não refletia a situação do momento.

Com isso, os autores realizaram ensaios à compressão de modelos de concreto com seção transversal de $100 \mathrm{~mm}$ x $200 \mathrm{~mm}$ e altura de $450 \mathrm{~mm}$, concretados deixando-se uma camada vazia de $100 \mathrm{~mm}$ de espessura na região central, como mostra a Figura 2.7, que seria posteriormente preenchida com argamassa de alta resistência. A direção dessa camada era inclinada em relação ao eixo longitudinal do modelo, por um ângulo $\theta$ que variava desde $30^{\circ}$ até $90^{\circ}$, que corresponde à junta no plano da seção transversal. Nesses ensaios, além do ângulo de inclinação da junta em relação ao eixo da peça, os autores consideraram como variáveis a condição de rugosidade da superfície do concreto antes da execução da junta, e o tipo de concreto usado para o seu 
preenchimento. A partir dos resultados obtidos, os autores chegaram às seguintes conclusões:

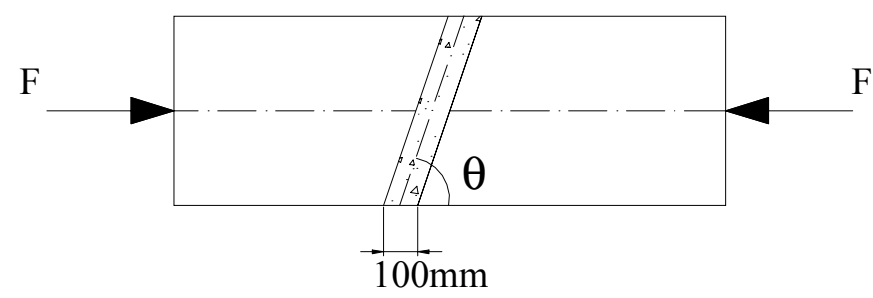

Figura 2. 7: Junta inclinada submetida à compressão axial.

- se a superfície dos elementos pré-moldados é muito rugosa, então toda a resistência à compressão do concreto de preenchimento pode ser considerada para juntas com ângulo de inclinação $\theta$ variando entre $40^{\circ}$ e $90^{\circ}$ graus. Para $\theta<40^{\circ}$ graus, ocorre ruptura por cisalhamento ao longo da junta;

- se a superfície dos elementos pré-moldados não é especialmente preparada, a transferência total de forças só é conseguida para juntas com ângulo $\theta$ variando entre $50^{\circ}$ e $90^{0}$ graus;

- produtos adesivos não devem ser usados em juntas inclinadas, pois os mesmos reduzem a condição de engrenamento existente entre um concreto novo e um velho, e produz ruptura prematura por cisalhamento ao longo da junta.

Vale ressaltar ainda que, nos modelos com junta plana, a ruptura se deu por compressão e a superfície rugosa nos elementos pré-moldados favoreceu a transferência de tensões através da junta.

STROBAND et al. (1996)

Considerando que as juntas de argamassa são freqüentemente 
usadas na ligação pilar-pilar e pilar-fundação, STROBAND et al. (1996) verificaram a possibilidade de utilizar a ligação entre pilares de concreto de alta resistência, sem que houvesse perda no aproveitamento da capacidade resistente do pilar devido a limitação imposta pela resistência da argamassa da junta. Para a investigação, foram ensaiados 20 modelos de pilares cujas variáveis foram: o detalhamento da junta, a qualidade da argamassa, a seção transversal do pilar e a armadura no pilar.

A espessura de junta adotada nos modelos foi de $15 \mathrm{~mm}$, por ser um valor normalmente adotado na prática profissional.

Com os resultados obtidos os autores concluíram que:

- a ruptura de pilares de alta resistência ligados através de junta de argamassa inicia-se com a formação de fissuras de fendilhamento no elemento pré-moldado, separando o cobrimento do núcleo da seção;

- a junta de argamassa não é adequada para pilares com alta taxa de armadura, mesmo sendo usada argamassa de alta resistência na junta. Para atingir uma boa eficiência na junta, deve-se buscar outras alternativas.

- as juntas de argamassa só apresentaram fissuras verticais;

- nos modelos com placas de aço adjacentes à junta, a ruptura iniciou-se no pilar, e essa alternativa mostrou-se eficiente para se obter um melhor aproveitamento da capacidade resistente da junta.

\section{SHU \& HAWKINS (1992)}

Sem tratar especificamente de juntas argamassa, SHU \& HAWKINS(1992) analisaram a influência de uma camada de concreto com resistência baixa sendo colocada entre pilares de concreto de alta resistência, para simular o comportamento das lajes entre pilares contínuos. O objetivo dessa investigação foi determinar que valor de projeto deveria ser considerado para a região da ligação, e a partir dos resultados obtidos desenvolver uma 
expressão que pudesse ser incorporada à Seção 10.13 da norma AMERICAN CONCRETE INSTITUTE-ACI 318(1983).

Nos modelos os autores consideravam que a única restrição à deformação da porção de laje provinha do concreto de alta resistência acima e abaixo dela.

Para a investigação os autores ensaiaram 54 modelos, solicitados axialmente, constituídos de dois segmentos de pilares de alta resistência unidos por uma camada de concreto. As variáveis consideradas nos ensaios foram: a espessura da camada de ligação dos pilares, a relação entre as resistências dos dois concretos e a influência da armadura na ligação.

Nos ensaios os autores observaram que, quando a relação entre a altura da camada de ligação $\left(\mathbf{h}_{\mathbf{j}}\right)$ e a menor dimensão da seção transversal do modelo (a) era pequena, e as resistências à compressão dos dois concretos $\left(\mathbf{f}_{\mathrm{c}}\right.$ e $\left.\mathbf{f}_{\mathrm{m}}\right)$ eram semelhantes, as fissuras apareciam primeiro na região do pilar. Com o aumento de $\mathbf{h}_{\mathfrak{j}} / \mathbf{a}$ ou $\mathbf{f}_{\mathbf{c}} / \mathbf{f}_{\mathbf{m}}$ a ruptura foi ficando restrita à região da ligação.

Após a análise dos resultados os autores concluíram que, quando a relação entre as resistências do concreto dos pilares e da laje era maior que 1,4, o valor da resistência de projeto, para a ligação, dado pelo ACI-318(1983) era muito conservador na análise de pilares de canto e pilares de extremidade. Para pilares internos, em algumas relações espessura da junta/largura do pilar, os valores previstos pelo ACI-318(1983) eram inseguros, necessitando assim de maiores estudos do comportamento da ligação. As recomendações dos autores foram incluídas no ACI-318(1999).

NBR 9062 - PROJETO E EXECUÇÃO DE ESTRUTURAS DE CONCRETO PRÉ-MOLDADO (1985)

A Norma Brasileira NBR 9062 (1985) não traz nenhuma recomendação para o uso de junta de argamassa como ligação entre elementos pré-moldados, apesar da sua utilização aqui no Brasil. De acordo com a Norma, o uso de 
argamassa de assentamento entre elementos só é permitido com a finalidade de corrigir pequenas imperfeições e para evitar a transmissão de cargas por poucos pontos de contato.

\subsection{Comentários adicionais}

Fazendo um resumo das principais abordagens encontradas na literatura, tratando especificamente das juntas de argamassa, tem-se o Quadro 2.1, mostrado a seguir. Pode-se perceber que a quantidade de pesquisas desenvolvidas considerando-se a melhoria da qualidade dos materiais disponíveis para preenchimento da junta ainda é muito pequena. Isto faz com que não se tenha uma recomendação consensual para o melhor aproveitamento da capacidade resistente da ligação.

No capítulo seguinte, serão feitas algumas simulações numéricas da ligação em estudo, para avaliar a influência dos parâmetros citados nas referências.

Quadro 2. 1: Resumo das principais considerações obtidas no levantamento bibliográfico.

\begin{tabular}{|c|l|c|l|}
\hline Pesquisadores & \multicolumn{1}{|c|}{$\begin{array}{c}\text { Parâmetros de influência } \\
\text { destacados }\end{array}$} & $\begin{array}{c}\text { Característica do } \\
\text { material de } \\
\text { preenchimento da junta }\end{array}$ & $\begin{array}{c}\text { Principais } \\
\text { recomendações } \\
\text { para a capacidade } \\
\text { resistente da junta }\end{array}$ \\
\hline $\begin{array}{c}\text { DRAGOSAVIC } \\
(1978)\end{array}$ & $\begin{array}{l}\text { Relação } \mathrm{f}_{\mathrm{m}} / \mathrm{f}_{\mathrm{c}} \\
\text { Relação } \mathrm{h}_{\mathrm{j}} / \mathrm{a}\end{array}$ & $\begin{array}{c}\text { Resistência à } \\
\text { compressão semelhante } \\
\text { ao concreto pré- } \\
\text { moldado }\end{array}$ & $\begin{array}{l}\text { Considerar um fator de } \\
\text { eficiência para a junta em } \\
\text { função do controle de } \\
\text { qualidade da argamassa }\end{array}$ \\
\hline LEWICKI & $\begin{array}{l}\text { Excentricidade do carregamento } \\
\text { Presença de armadura na ligação } \\
\text { Espessura da camada de } \\
\text { argamassa }\end{array}$ & $\begin{array}{l}\text { Resistência inferior ao } \\
\text { elemento pré-moldado }\end{array}$ & $\begin{array}{l}\text { Considerar um fator de } \\
\text { eficiência para a junta em } \\
\text { função dos parâmetros de } \\
\text { influência }\end{array}$
\end{tabular}


Quadro 2.1: Resumo das principais considerações obtidas no levantamento bibliográfico.

\begin{tabular}{|c|c|c|c|}
\hline Pesquisadores & $\begin{array}{c}\text { Parâmetros de influência } \\
\text { destacados }\end{array}$ & $\begin{array}{c}\text { Característica do } \\
\text { material de } \\
\text { preenchimento da junta }\end{array}$ & $\begin{array}{c}\text { Principais } \\
\text { recomendações } \\
\text { para a capacidade } \\
\text { resistente da junta }\end{array}$ \\
\hline $\begin{array}{c}\text { BJLUGER } \\
(1988)\end{array}$ & $\begin{array}{l}\text { Relação } \mathrm{f}_{\mathrm{m}} / \mathrm{f}_{\mathrm{c}} \\
\text { Deslocamentos dos eixos dos } \\
\text { elementos } \\
\text { Espessura da junta } \\
\text { Deformabilidade diferenciada dos } \\
\text { materiais }\end{array}$ & $\begin{array}{l}\text { Resistência inferior ao } \\
\text { elemento pré-moldado }\end{array}$ & $\begin{array}{l}\text { Considerar um fator de } \\
\text { eficiência para a junta em } \\
\text { função dos parâmetros de } \\
\text { influência para os painéis } \\
\text { e desconsiderar sua } \\
\text { contribuição entre pilares. }\end{array}$ \\
\hline $\begin{array}{c}\text { VAMBERSKY } \\
\text { (1990) }\end{array}$ & $\begin{array}{l}\text { Relação } \mathrm{f}_{\mathrm{m}} / \mathrm{f}_{\mathrm{c}} \\
\text { Relação } \mathrm{h}_{\mathrm{j}} / \mathrm{a} \\
\text { Tipo de argamassa } \\
\text { Presença de chapas metálicas na } \\
\text { interface } \\
\text { Armadura transversal adicional no } \\
\text { elemento pré-moldado }\end{array}$ & $\begin{array}{c}\text { Material com resistência } \\
\text { à compressão } \\
\text { semelhante ou maior } \\
\text { que o concreto pré- } \\
\text { moldado }\end{array}$ & $\begin{array}{l}\text { Atualização das } \\
\text { recomendações de } \\
\text { DRAGOSAVIC (1978) e } \\
\text { uso de material de alta } \\
\text { resistência no } \\
\text { preenchimento da junta }\end{array}$ \\
\hline $\begin{array}{c}\text { BRUGGELING } \\
\text { (1991) }\end{array}$ & $\begin{array}{l}\text { Relação } f_{m} / f_{c} \\
\text { Deformabilidade diferenciada }\end{array}$ & $\begin{array}{l}\text { Resistência inferior ao } \\
\text { elemento pré-moldado }\end{array}$ & $\begin{array}{l}\text { Espessura mínima } \\
\text { Armadura transversal } \\
\text { adicional no elemento pré- } \\
\text { moldado }\end{array}$ \\
\hline $\begin{array}{c}\text { ELLIOT } \\
(1996)\end{array}$ & $\begin{array}{l}\text { Considera os mesmos de } \\
\text { VAMBERSKY(1990) } \\
\text { Deformabilidade diferenciada }\end{array}$ & $\begin{array}{l}\text { Resistência inferior ao } \\
\text { elemento pré-moldado }\end{array}$ & $\begin{array}{l}\text { Espessura mínima } \\
\text { Limite para as relações } \\
\mathrm{f}_{\mathrm{m}} / \mathrm{f}_{\mathrm{c}} \text { e } \mathrm{h}_{\mathrm{j}} / \text { a de acordo com } \\
\text { os ensaios de } \\
\text { VAMBERSKY(1990) }\end{array}$ \\
\hline $\begin{array}{c}\text { STROBAND } \\
(1996)\end{array}$ & $\begin{array}{l}\text { Relação } \mathrm{f}_{\mathrm{m}} / \mathrm{f}_{\mathrm{c}} \\
\text { Tipo de argamassa } \\
\text { Presença de chapas metálicas na } \\
\text { interface } \\
\text { Armadura transversal adicional }\end{array}$ & $\begin{array}{c}\text { Material com resistência } \\
\text { à compressão } \\
\text { semelhante ou maior } \\
\text { que o concreto pré- } \\
\text { moldado }\end{array}$ & $\begin{array}{l}\text { Utilizar chapas metálicas } \\
\text { na região da ligação. }\end{array}$ \\
\hline
\end{tabular}




\section{Avaliação Numérica dos Parâmetros de Influência da Ligação}

\subsection{Preliminares}

Com base na revisão bibliográfica do assunto, podem ser considerados como parâmetros de influência para o comportamento da ligação entre elementos pré-moldados utilizando juntas de argamassa, os seguintes fatores:

a) Tipo de argamassa usada na junta: graute ou argamassa;

b) Espessura da camada de argamassa;

c) Relação entre as resistências da argamassa e do concreto pré-moldado;

d) Resistência do concreto pré-moldado;

e) Rugosidade da superfície dos elementos na ligação sem argamassa;

f) Armadura de reforço na região do elemento pré-moldado adjacente à ligação;

g) Excentricidade do carregamento;

h) Variação na forma da seção transversal dos elementos pré-moldados. 
A deformabilidade diferenciada dos materiais da junta, caracterizada pelos fatores descritos nas letras a, c e d, e a relação entre a espessura da camada de argamassa e a menor dimensão da seção transversal do elemento pré-moldado, são os parâmetros considerados de maior relevância pelos pesquisadores, portanto, mais explorados nas simulações. Entretanto, com o objetivo de auxiliar o planejamento do programa experimental, foram feitas algumas simulações considerando os outros parâmetros.

As simulações numéricas foram feitas utilizando-se o software ANSYS 5.5.1, que utiliza o método dos elementos finitos para obter os deslocamentos e os esforços na estrutura sob a ação do carregamento aplicado, e permite que considerar na simulação o comportamento não-linear dos materiais.

Segundo BLJUGER $(1977,1978)$, a capacidade resistente da ligação com junta de argamassa deve sempre ser estabelecida considerando-se os efeitos de não-linearidade dos materiais, devido à grande influência nos valores e na distribuição de tensões, podendo inclusive resultar num dimensionamento mais econômico.

\subsection{Comportamento Não-Linear do Concreto e da Argamassa}

Com a possibilidade de considerar a não-linearidade dos materiais na simulação, torna-se necessário definir no programa ANSYS 5.5.1 um critério de resistência para o concreto e conseqüentemente para a argamassa, que melhor represente as condições reais daquela não-linearidade.

Segundo PROENÇA (1988) o comportamento do concreto é muito complexo, e além disso, depende entre muitos fatores, das propriedades físicas e mecânicas do agregado e da pasta de cimento e da natureza do carregamento. Além disso, a não-linearidade decorrente da fissuração dificulta a execução de uma simulação numérica que reproduza o comportamento do 
concreto ao longo de todo o processo de carregamento. Com isso, o concreto tem sido modelado através da teoria da plasticidade adotando-se hipóteses simplificadoras para o comportamento do material.

O conjunto de hipóteses simplificadoras procura reproduzir os fenômenos isolados do concreto através de procedimentos simples, mas que levem a resultados numéricos satisfatórios.

Segundo CHEN(1982) um conjunto de hipóteses muito usado para modelagem do concreto é o seguinte:

a) ele se torna um material perfeitamente plástico após atingir a capacidade máxima de carga;

b) a superfície de ruptura é considerada como sendo a superfície de escoamento no espaço das tensões;

c) o vetor incremental de deformações plásticas é considerado normal à superfície de escoamento no estado de tensão corrente. Esta hipótese procura associar a evolução da superfície de escoamento com a história do carregamento.

Segundo PROENÇA (1988), em estados de tensão multiaxiais, o limite da região elástica é representado no espaço das tensões através de uma superfície que separa os estados de tensão elásticos daqueles que geram deformações permanentes. Esta superfície inicial de plastificação tem sua representação matemática genérica dada pela seguinte expressão:

$$
f(\sigma)=0
$$

onde: $\sigma$ - tensor das tensões.

Essa representação é feita de tal modo que a superfície descrita no 
espaço das tensões só é alterada quando ocorre um processo de carregamento.

O programa ANSYS 5.5.1 tem definido oito tipos de comportamento não-linear para materiais. Dentre eles foram escolhidos, para a modelagem da ligação, os seguintes:

a) Plasticidade independente do tempo: é caracterizada através das deformações instantâneas irreversíveis que ocorrem no material;

b) Concrete: introduz no material capacidade de fissuração e esmagamento.

Para considerar a plasticidade independente do tempo o programa permite escolha entre sete relações diferentes. Dentre estas relações, será adotado aqui no trabalho, o critério de plastificação estabelecido por DRUCKER-PRAGER.

Esse critério considera que o material é elástico-perfeitamente plástico, com diagrama definido de acordo com a Figura 3.1.

No critério de DRUCKER-PRAGER o escoamento do material é caracterizado através dos parâmetros $\beta$ e $\sigma_{\mathrm{y}}$ definidos por:

$$
\begin{gathered}
\beta=\frac{2 \operatorname{sen} \varphi}{\sqrt{3}(3-\operatorname{sen} \varphi)} \\
\sigma_{y}=\frac{6 c \cos \varphi}{\sqrt{3}(3-\operatorname{sen} \varphi)}
\end{gathered}
$$

onde: c - coesão;

$\varphi$ - ângulo de atrito interno do material. 


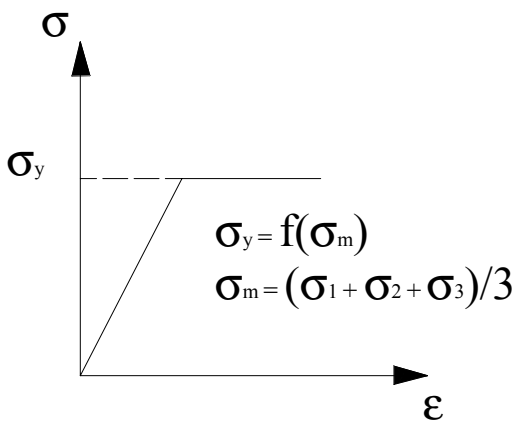

Figura 3. 1: Diagrama tensão-deformação para o critério de DRUCKER-PRAGER.

O critério de DRUCKER-PRAGER representa uma modificação do critério de plastificação de VON MISES, considerando-se a influência da componente de tensão hidrostática: quanto maior a tensão hidrostática maior a resistência ao escoamento.

A Figura 3.2 mostra a superfície de escoamento do critério de DRUCKER-PRAGER. No trabalho de PROENÇA (1988) tem-se a descrição detalhada desse critério e sua aplicação ao concreto. Ainda segundo PROENÇA (1988), a desvantagem desse critério está na pouca concordância com os resultados experimentais.

O outro critério considerado nas simulações, denominado CONCRETE, corresponde ao critério estabelecido por WILLAM-WARNKE1 apud CHEN (1982). Neste critério, os pesquisadores se preocuparam em encontrar uma expressão para seção transversal de ruptura que obedecesse a critérios de simetria, suavidade e convexidade. Isto foi conseguido considerando a seção transversal formada por trechos elípticos, como mostra a Figura 3.3, no espaço tridimensional das tensões principais. Os parâmetros que caracterizam a superfície de ruptura são os seguintes:

$\mathrm{f}_{\mathrm{t}}$ - resistência última à tração axial;

\footnotetext{
${ }^{1}$ Willam, K. J. \& E. P. Warnke (1975) Constitutive model for the triaxial behaviour of concrete. In: ASSOC. BRIDGE STRUCT. ENG. SEM. CONCR. SUBJECTED TRIAXIAL STRESSES, Bergamo, Italy, 1974. Proceedings. Italy, ASSOC. OF BRIDGE STRUCTURAL ENGENEERING, v.19, p.1-31.
} 
$\mathrm{f}_{\mathrm{c}}$ - resistência última à compressão axial;

$\mathrm{f}_{\mathrm{cb}}$ - resistência última à compressão bi-axial;

$\mathrm{f}_{1}$ - resistência última à tração para um estado de tensão bi-axial;

$\mathrm{f}_{2}$ - resistência última à compressão para um estado de tensão bi-axial.

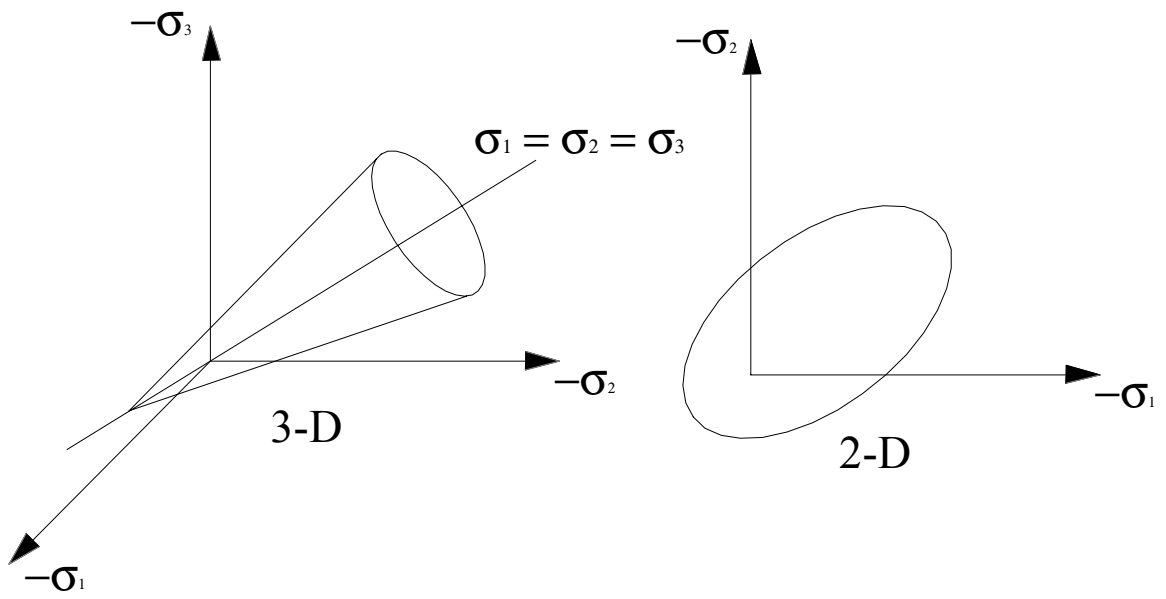

Figura 3. 2: Superfície de escoamento definida por DRUCKER-PRAGER.

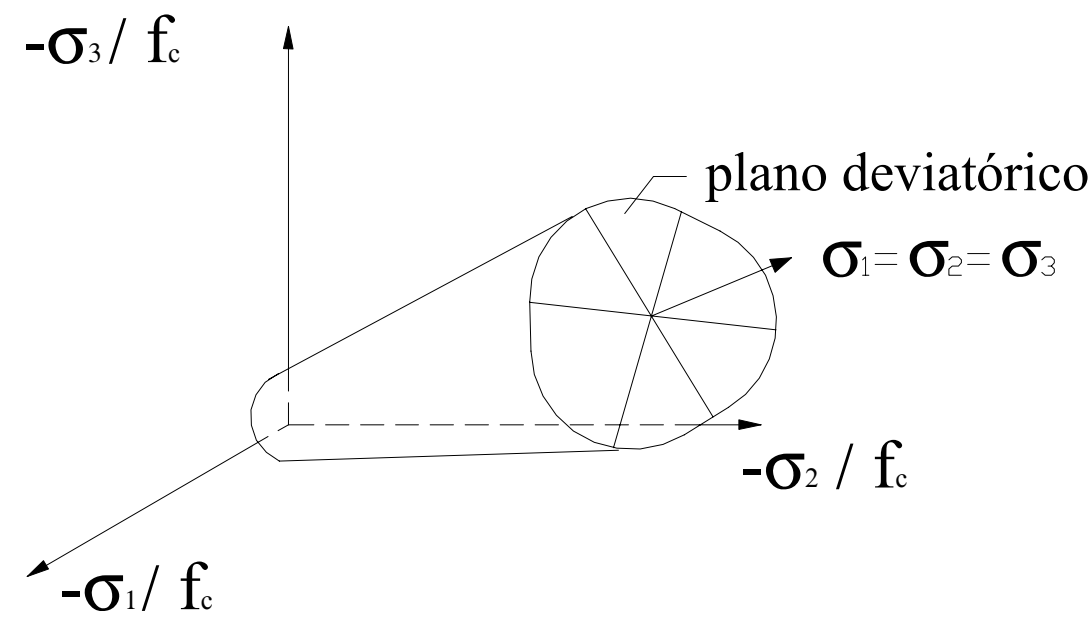

Figura 3. 3: Superfície de ruptura definida por Willam-Warnke.

O programa ANSYS 5.5.1 permite que sejam especificados apenas dois parâmetros, $\mathbf{f}_{\mathrm{c}}$ e $\mathbf{f}_{\mathrm{t}}$, e assume valores para os outros três através das seguintes relações:

$$
f_{c b}=1,2 f_{c}
$$




$$
\begin{aligned}
& \mathrm{f}_{1}=1,45 \mathrm{f}_{\mathrm{c}} \\
& \mathrm{f}_{2}=1,725 \mathrm{f}_{\mathrm{c}}
\end{aligned}
$$

Segundo CHEN (1982), o critério definido por WILLAM-WARNKE representa uma suavização das superfícies definidas por DRUCKER-PRAGER e VON MISES, de tal forma que esses dois critérios podem ser obtidos através de particularizações daquele primeiro. No trabalho de CHEN (1982) tem-se uma descrição detalhada do critério com aplicação ao concreto.

\subsection{Discretização dos Modelos}

Os modelos tridimensionais analisados nas simulações foram discretizados utilizando-se o elemento finito SOLID65 definido por oito nós, como mostrado na Figura 3.4. Cada nó possui três graus de liberdade que são as translações nas direções $x, y$ e $z$. Com esse elemento o sólido modelado é capaz de sofrer fissuração (em três direções ortogonais) e esmagamento, já que é o único capaz de incorporar o critério CONCRETE associado com o critério de DRUCKER-PRAGER, descritos anteriormente.

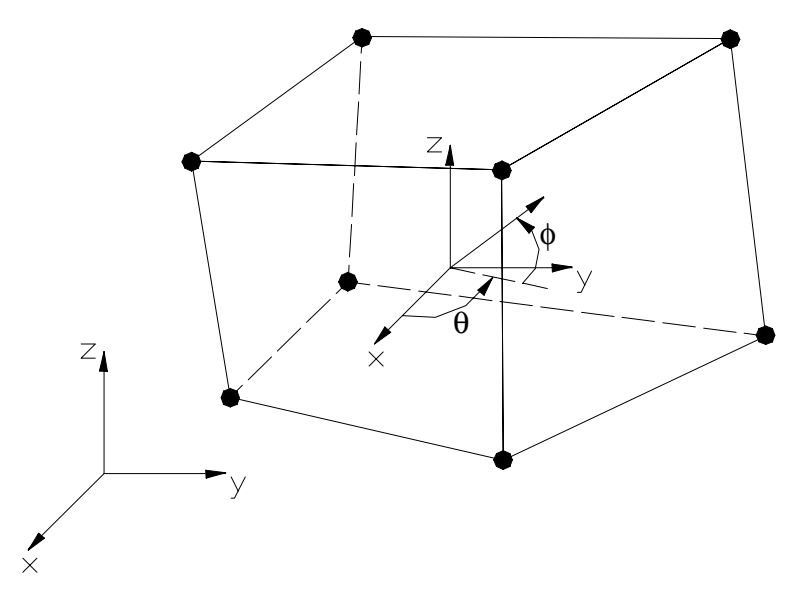

Figura 3. 4: Elemento SOLID65. 
Com a associação dos dois critérios, o ANSYS verifica se as deformações existentes no modelo correspondem a um nível de plastificação anterior à ruptura frágil por fissuração. As propriedades de não-linearidade embutidas no elemento incluem ainda a fluência, porém esse efeito não foi considerado nas simulações.

A direção das tensões no elemento é paralela ao sistema de coordenadas do elemento, mostrado na Figura 3.4, e as condições de não-linearidade aparecem somente se forem especificadas para a resolução do problema.

Para a modelagem de sólidos de concreto armado, a armadura pode ser incorporada no elemento através de taxas dispostas em três direções diferentes, através dos parâmetros $\theta$ e $\phi$ vistos na Figura 3.4.

Os modelos simulados são semelhantes aos modelos ensaiados por SHU \& HAWKINS (1992). Estes modelos consistem em blocos de concreto não armados, com altura de $400 \mathrm{~mm}$ e seção transversal quadrada de $175 \mathrm{~mm}$ de lado, ligados através de uma camada de argamassa, como mostra a Figura 3.5.

A vinculação adotada no modelo impede as translações em todas as direções na extremidade inferior. O carregamento aplicado corresponde a uma pressão uniformemente distribuída na extremidade superior do modelo. Esse carregamento foi aplicado subdividido em passos de carga, para considerar o efeito de não-linearidade dos materiais.

As variáveis usadas para análise dos parâmetros de influência estão detalhadas na Tabela 3.1, mostrada a seguir.

Para análise da influência da rugosidade partiu-se de um modelo com carregamento contínuo em toda a superfície superior, para simular uma superfície plana. Em seguida, aplicou-se o carregamento em faixas não adjacentes ao longo da superfície superior para simular a existência de dentes na superfície do elemento. 


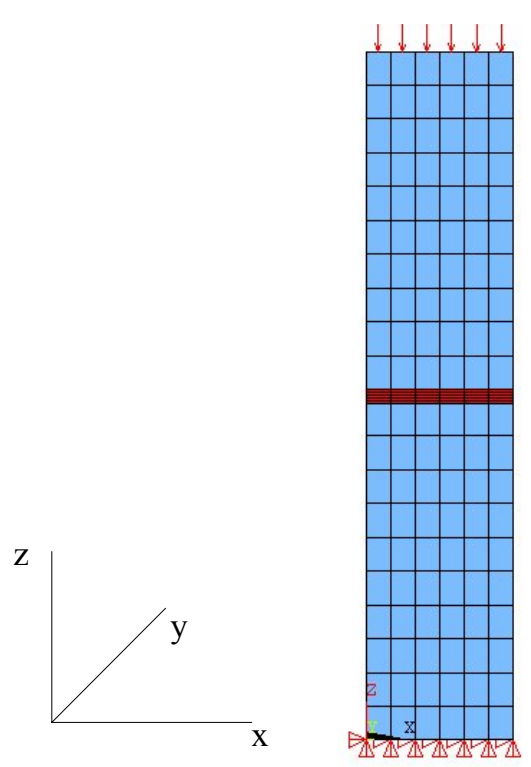

Figura 3. 5: Discretização dos modelos usando o elemento SOLID65.

Tabela 3. 1: Variáveis usadas na simulação numérica da ligação

\begin{tabular}{|c|c|c|c|c|}
\hline $\begin{array}{c}\text { Espessura } \\
(\mathrm{mm})\end{array}$ & $\begin{array}{c}\text { Relação } \\
\mathrm{f}_{\mathrm{m}} / \mathrm{f}_{\mathrm{c}}\end{array}$ & $\begin{array}{c}\text { Resistência do } \\
\text { concreto }(\mathrm{MPa})\end{array}$ & $\begin{array}{c}\text { Largura da } \\
\text { faixa }\end{array}$ & $\begin{array}{c}\text { Forma da } \\
\text { seção } \\
\text { transversal }\end{array}$ \\
\cline { 1 - 2 } 15 & \multirow{2}{*}{0,63} & 35 & plana & \multirow{2}{*}{ quadrada } \\
\cline { 1 - 1 } \cline { 4 - 5 } & \multirow{2}{*}{1,5} & \multirow{2}{*}{113} & $5 \mathrm{~mm}$ & retangular \\
\cline { 1 - 1 } \cline { 4 - 5 } & & & $20 \mathrm{~mm}$ & \\
\hline 45 & & &
\end{tabular}

\subsection{Análise dos parâmetros de influência}

\subsubsection{Espessura da camada de argamassa}

Para avaliação do comportamento da ligação considerando a influência da espessura da junta, foram simuladas quatro espessuras diferentes: $15 \mathrm{~mm}$, 25mm, 35mm e $45 \mathrm{~mm}$. Nos modelos, as propriedades mecânicas adotadas para o concreto e argamassa foram as mesmas usadas nos modelos de STROBAND et al. (1996), mostradas na Tabela 3.2.

O carregamento distribuído aplicado no topo do modelo foi de $75 \mathrm{MPa}$, 
subdividido inicialmente em 30 passos de carga. Posteriormente, com o aumento das deformações, o programa automaticamente ajusta o valor de convergência do carregamento aplicado até que ocorra a ruptura total do modelo.

Tabela 3. 2: Propriedades Mecânicas do Concreto e da Argamassa

\begin{tabular}{|l|c|c|}
\hline \multicolumn{1}{|c|}{ Propriedades } & Concreto & Argamassa 1 \\
\hline Resistência à compressão $(\mathrm{MPa})$ & 113,0 & 71,0 \\
\hline Resistência à tração $(\mathrm{MPa})$ & 5,9 & 5,0 \\
\hline Módulo de Elasticidade Longitudinal $(\mathrm{MPa})$ & 37400 & 16500 \\
\hline Coeficiente de Poisson & 0,2 & 0,3 \\
\hline
\end{tabular}

Com os resultados obtidos nas simulações numéricas, foram determinados os deslocamentos referentes aos nós destacados na Figura 3.6 e traçados os gráficos mostrados nas Figura 3.7 e 3.8.

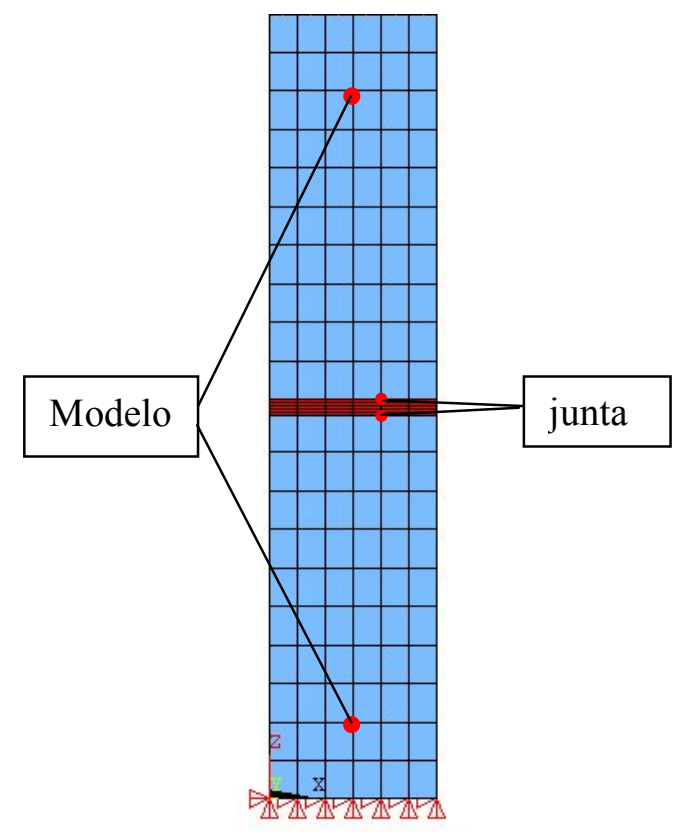

Figura 3. 6: Nós usados para avaliação da deformabilidade do modelo. 
O critério CONCRETE incorporado ao modelo faz com que ao se atingir um nível alto de fissuração, ocorra a ruptura. Observa-se que quanto mais espessa a junta mais cedo isso ocorre.

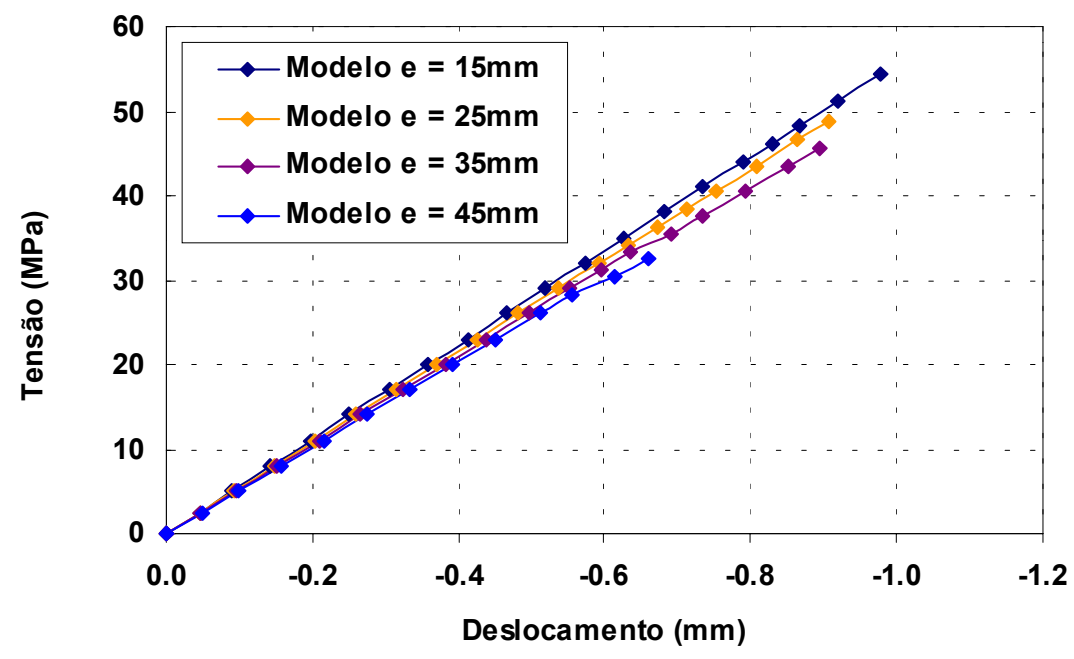

Figura 3. 7: Diagrama tensão $x$ deslocamento para avaliar a deformabilidade aparente do modelo em função da espessura da junta.

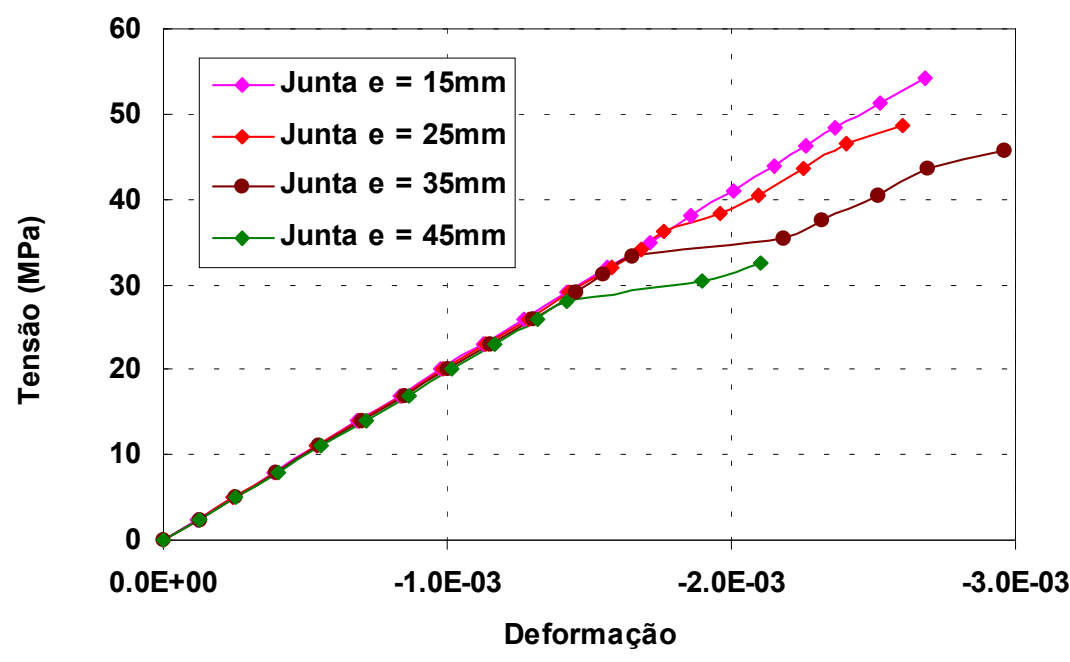

Figura 3. 8: Deformação da junta em função da espessura.

A deformabilidade da ligação é definida como sendo a relação entre o deslocamento relativo entre os elementos e a tensão atuante na direção desse deslocamento. Entretanto para caracterizar a variação da deformabilidade da 
junta em função da espessura, considerou-se a deformação relativa mostrada na Figura 3.8. Com o início da fissuração o aumento da espessura da junta aumenta a deformabilidade. Os valores obtidos para a deformabilidade nos modelos, no início da fissuração, são mostrados na Tabela 3.3.

Tabela 3. 3: Deformabilidade da junta de argamassa nos modelos

\begin{tabular}{|c|c|}
\hline Espessura (mm) & Deformabilidade (mm/MPa) \\
\hline 15 & $7,3 \times 10^{-4}$ \\
\hline 25 & $1,2 \times 10^{-3}$ \\
\hline 35 & $1,8 \times 10^{-3}$ \\
\hline 45 & $2,3 \times 10^{-3}$ \\
\hline
\end{tabular}

Com o quadro de fissuração apresentado por cada modelo, mostrado na Figura 3.9, pode-se perceber um aumento da quantidade de fissuras com o aumento da espessura. Com isso, tem-se a ruptura antecipada do modelo e o aumento da deformabilidade. No modelo com junta mais espessa, as fissuras se concentraram no elemento pré-moldado superior.

Um exemplo da configuração deformada dos modelos é mostrado na Figura 3.10. Observa-se a tendência de expulsão da argamassa nas extremidades e o destacamento do cobrimento nos elementos pré-moldados, efeitos descritos anteriormente por LEWICKI (1982) e VAMBERSKY (1990). No modelo com junta mais espessa, o destacamento do cobrimento foi mais acentuado no elemento pré-moldado superior.

Com a expulsão da camada externa da junta de argamassa, a distribuição das tensões verticais $\sigma_{z}$ nas proximidades da junta não é uniforme. Ocorre, portanto, uma concentração de tensões na região central como mostra a Figura 3.11.

A Figura 3.12 mostra a distribuição das tensões transversais $\sigma_{x}$, que, por ter o modelo seção quadrada, é igual à tensão $\sigma_{y}$. 


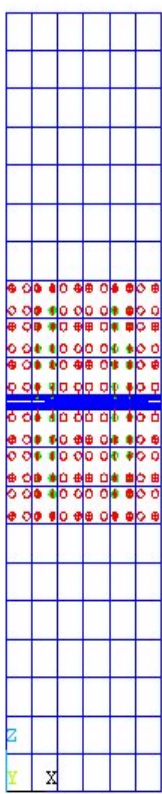

a) $h_{j}=15 \mathrm{~mm}$

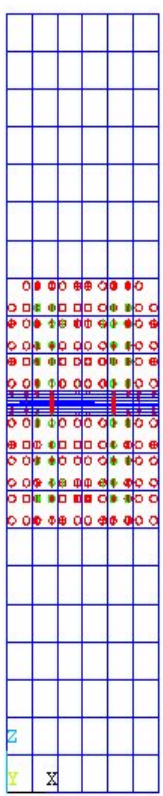

b) $h_{j}=25 \mathrm{~mm}$

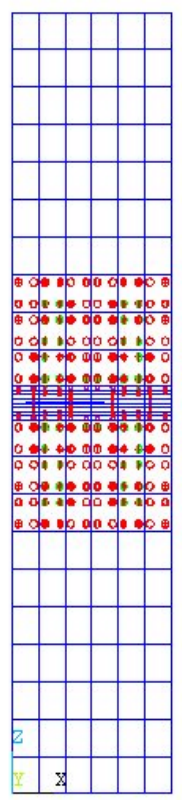

c) $h_{j}=35 \mathrm{~mm}$

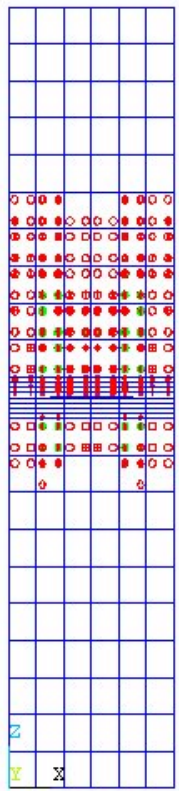

d) $h_{j}=45 \mathrm{~mm}$

Figura 3. 9: Fissuração existente nos modelos antes da ruptura.

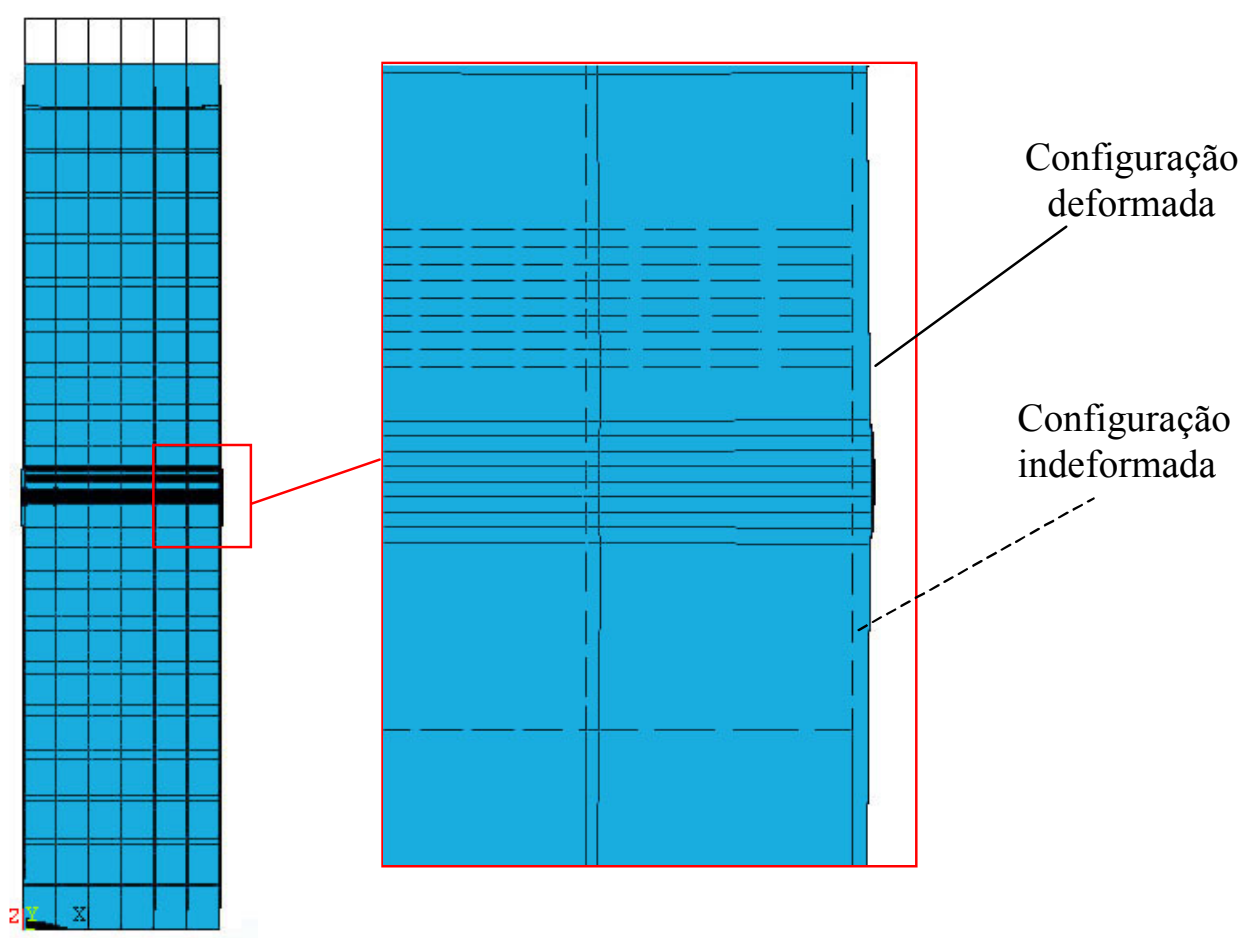

Figura 3. 10 Tendência de expulsão da argamassa nas extremidades. 


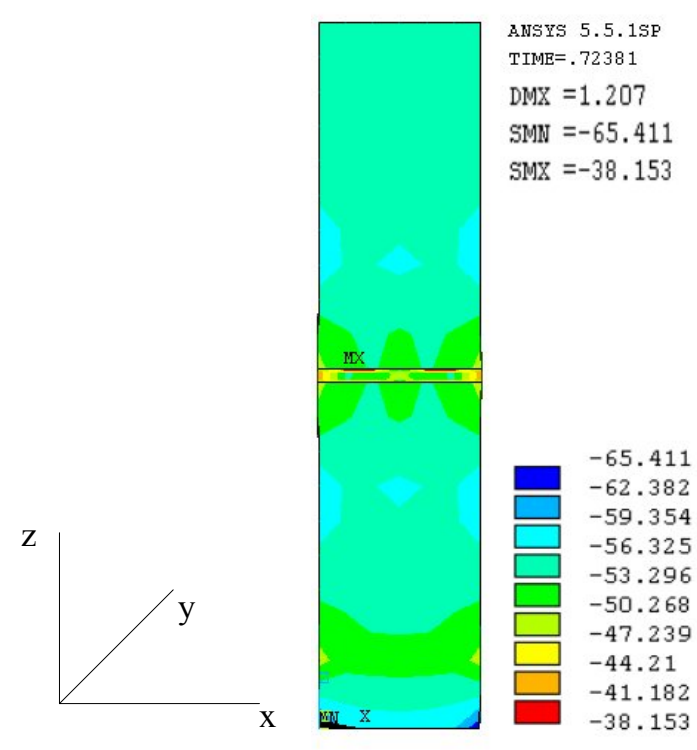

a) $h_{j}=15 \mathrm{~mm}$

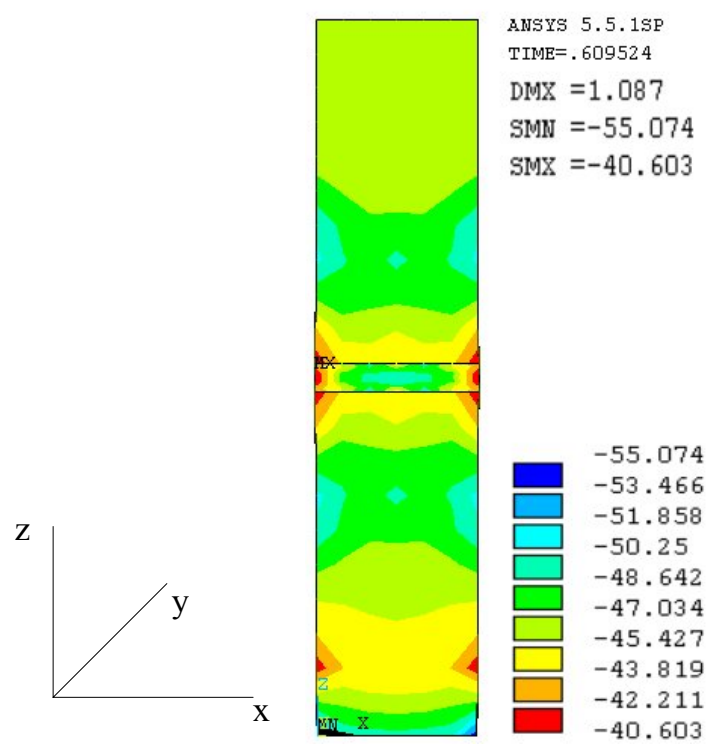

a) $h_{j}=35 \mathrm{~mm}$

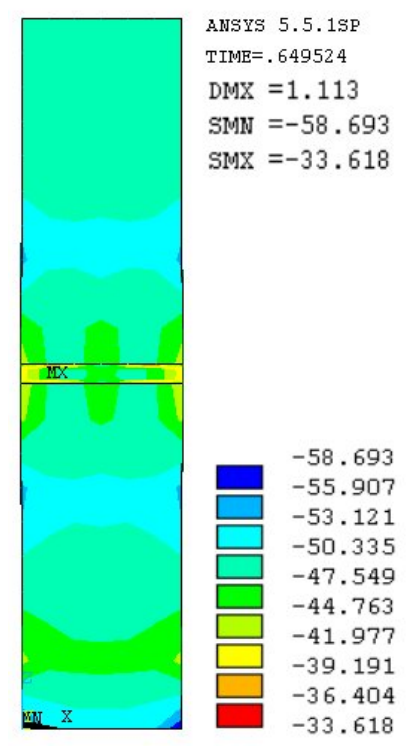

b) $h_{j}=25 \mathrm{~mm}$

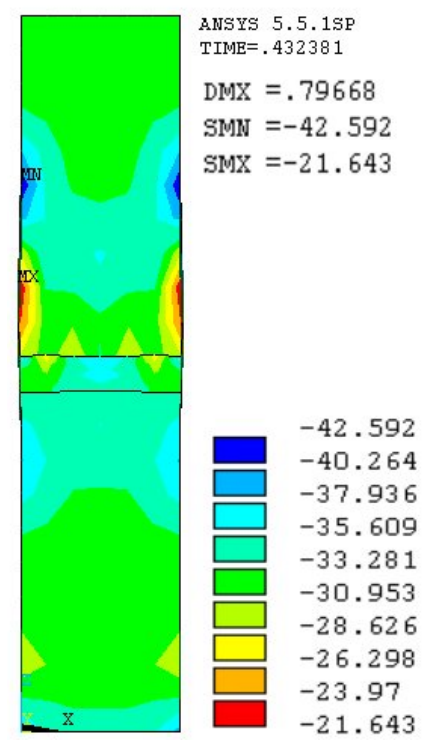

b) $h_{j}=45 \mathrm{~mm}$

Figura 3. 11: Distribuição das tensões verticais $\sigma_{z}(\mathrm{MPa})$. 

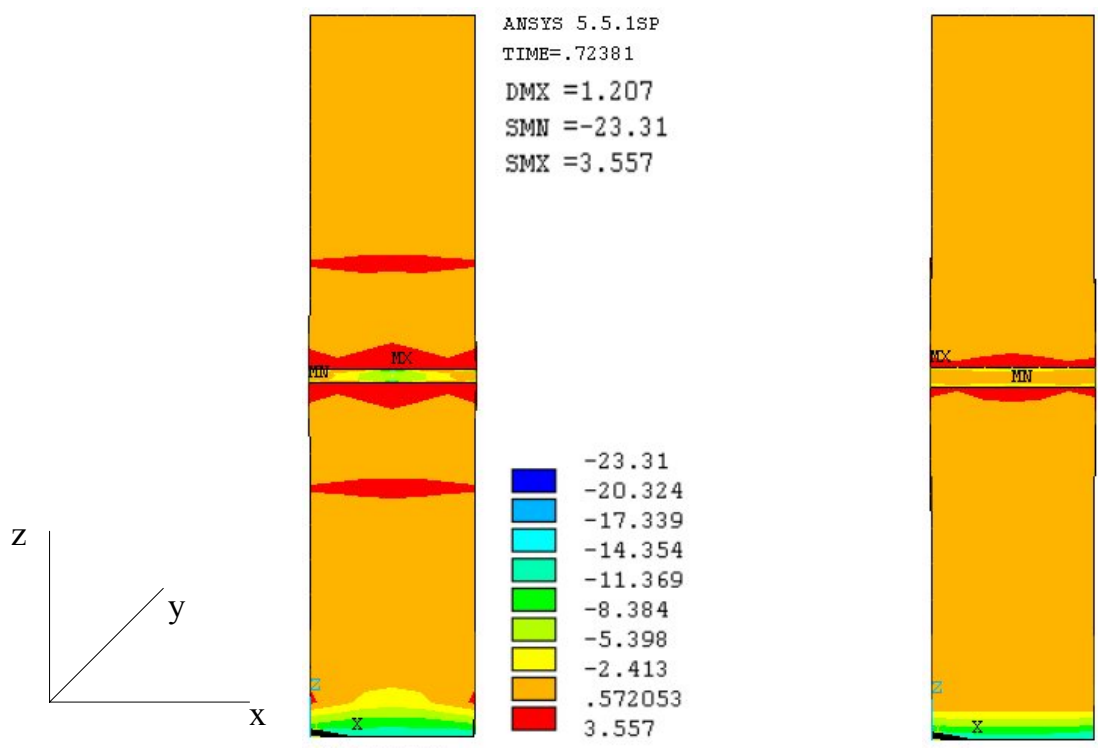

ANSYS 5.5.15P TIME $=.649524$

DMX $=1.113$

SMN $=-20.794$

SMX $=4.299$

a) $h_{j}=15 \mathrm{~mm}$

b) $h_{j}=25 \mathrm{~mm}$
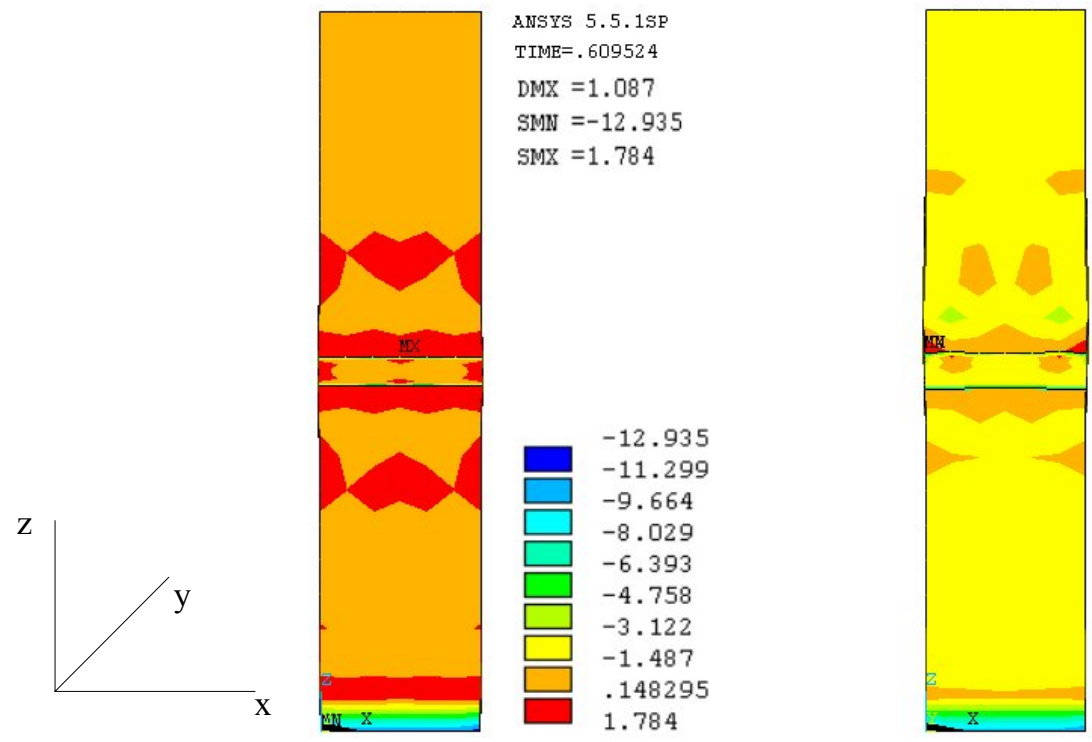

ANSYS 5.5.15P TIME $=.432381$ $\mathrm{DMX}=.79668$ SMN $=-10.447$ $\operatorname{SMX}=3.442$

a) $h_{j}=35 \mathrm{~mm}$

b) $h_{j}=45 \mathrm{~mm}$

Figura 3. 12: Distribuição das tensões $\sigma_{x}(\mathrm{MPa})$

Como a resistência dos elementos de concreto pré-moldado é maior que a da argamassa usada na junta, aqueles exercem uma pressão de confinamento sobre a argamassa comprimindo-a transversalmente, isto é, segundo xy. Essa região comprimida, mostrada na Figura 3.12, encontra-se um pouco afastada 
da borda e caracteriza assim, um núcleo central resistente para a seção de argamassa. Esse efeito começa a desaparecer com o aumento da espessura da junta. Pode-se observar também altas tensões de tração na interface dos dois materiais.

\subsubsection{Relação entre as resistências do concreto e da argamassa}

Para avaliar o segundo parâmetro de influência o material de preenchimento da junta passou a ser uma argamassa com resistência maior que a do concreto, com propriedades características mostradas na Tabela 3.4. Esta argamassa foi utilizada nos ensaios de STROBAND et al. (1996) e melhorou a capacidade resistente do modelo experimental. Por esse motivo, o carregamento aplicado no topo do modelo foi de $115 \mathrm{MPa}$, subdividido inicialmente em 30 passos de carga.

Tabela 3. 4: Propriedades Características da Argamassa de Alta Resistência

\begin{tabular}{|l|c|}
\hline \multicolumn{1}{|c|}{ Propriedades } & Argamassa 2 \\
\hline Resistência à compressão $(\mathrm{MPa})$ & 170,0 \\
\hline Resistência à tração $(\mathrm{MPa})$ & 27,72 \\
\hline Módulo de Elasticidade Longitudinal $(\mathrm{MPa})$ & 54600 \\
\hline Coeficiente de Poisson & 0,27 \\
\hline
\end{tabular}

Comparando-se os valores da carga última obtida para os dois tipos de argamassa, como mostra a Figura 3.13, pode-se observar o aumento na absorção de esforços com o uso da argamassa de alta resistência. Vê-se também, que todos os modelos tiveram, praticamente, o mesmo valor para carga última. Isso mostra que a variação da espessura da camada de argamassa não traz efeitos significativos quando se usa na ligação uma argamassa com resistência maior que o concreto do elemento pré-moldado. 


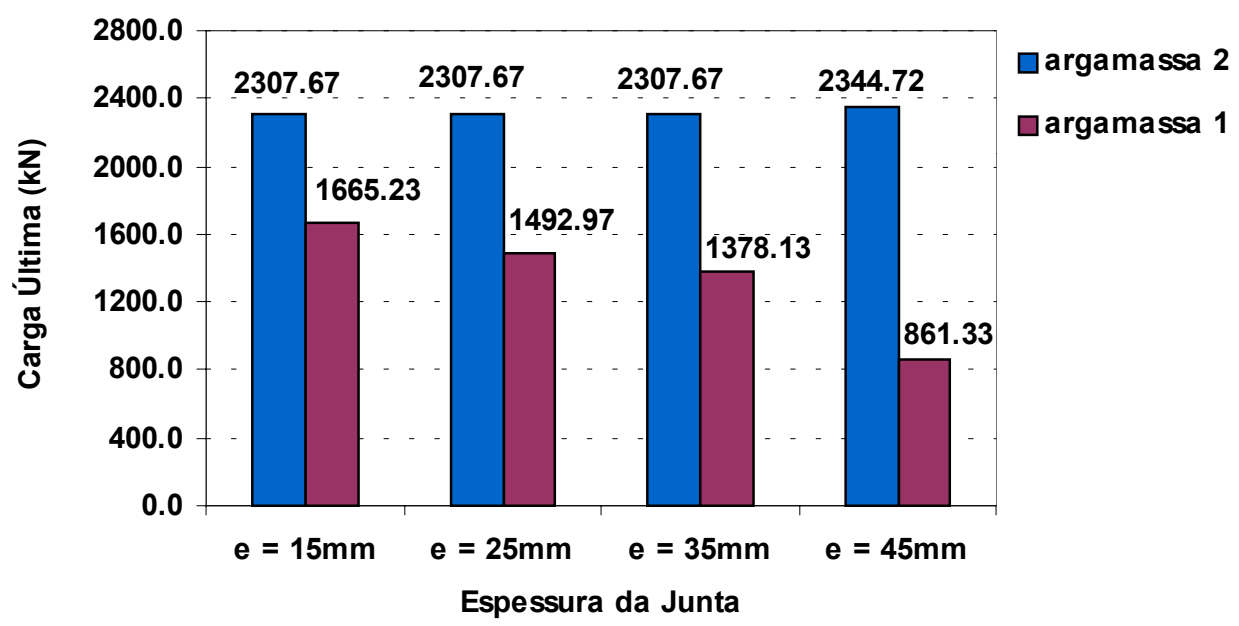

Figura 3. 13: Comparação para os valores de carga última.

Comparando-se a deformabilidade aparente do modelo e a deformação relativa da junta, com os dois tipos de argamassa, têm-se os gráficos mostrados nas Figuras 3.14 e 3.15. Observa-se que praticamente não há variação para o modelo como um todo, ocorrendo apenas um acréscimo de resistência. Já para a junta, observa-se que a argamassa de alta resistência é mais rígida, o que faz com que a ligação fique mais resistente. Além disso, não há variação com a mudança de espessura.
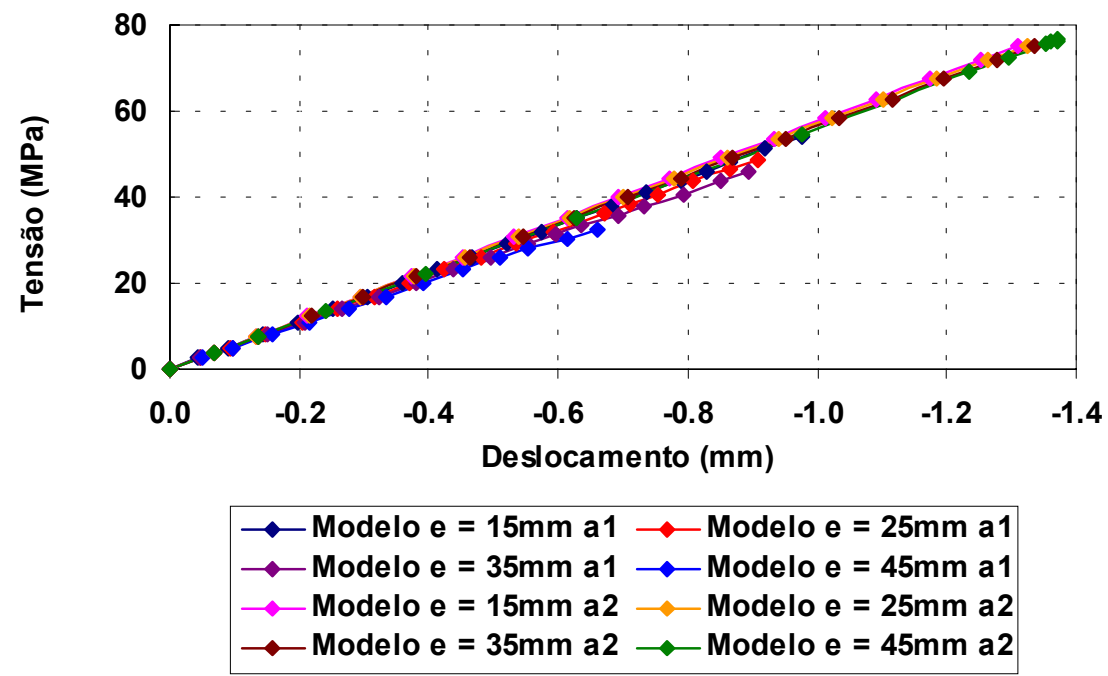

Figura 3. 14: Diagrama tensão $x$ deslocamento usado para comparação da deformabilidade aparente dos modelos. 

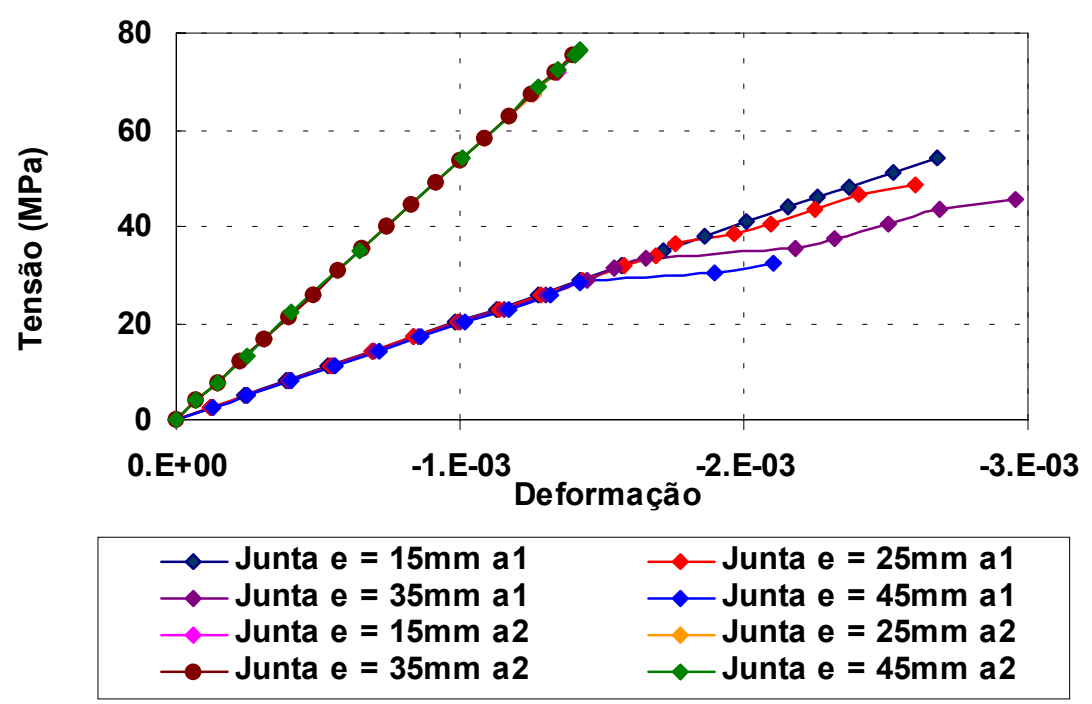

Figura 3. 15: Comparativo da deformação relativa da junta.

As Figuras 3.16 e 3.17 mostram a distribuição das tensões verticais $\sigma_{z}$ e transversais $\sigma_{x}$, respectivamente. Pode-se observar a uniformidade na distribuição de tensões caracterizando que até a ruptura os modelos se comportaram como se não houvesse descontinuidade.

A Figura 3.18, mostra a distribuição de fissuras antes da ruptura do elemento. Observa-se que a causa da ruína não foi mais a perturbação existente na região da ligação, mas sim o efeito de concentração de tensões nas extremidades do modelo. Alem disso, como a distribuição de tensões é praticamente uniforme na junta, a tendência de expulsão da argamassa pelas extremidades não é mais significativa. 


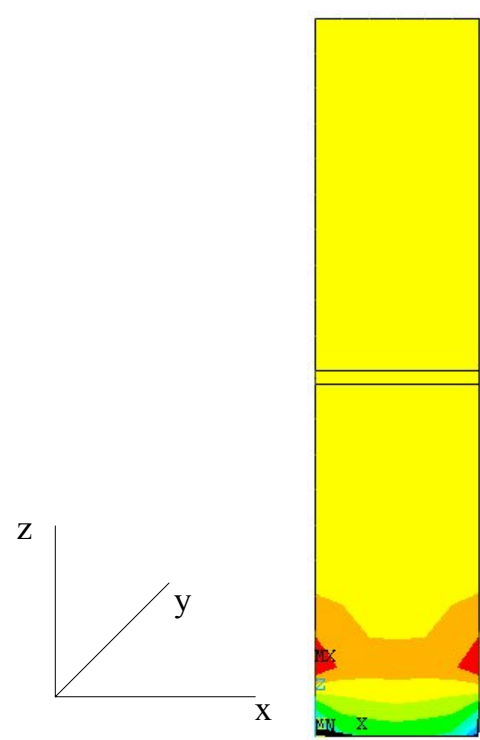

a) $h_{j}=15 \mathrm{~mm}$

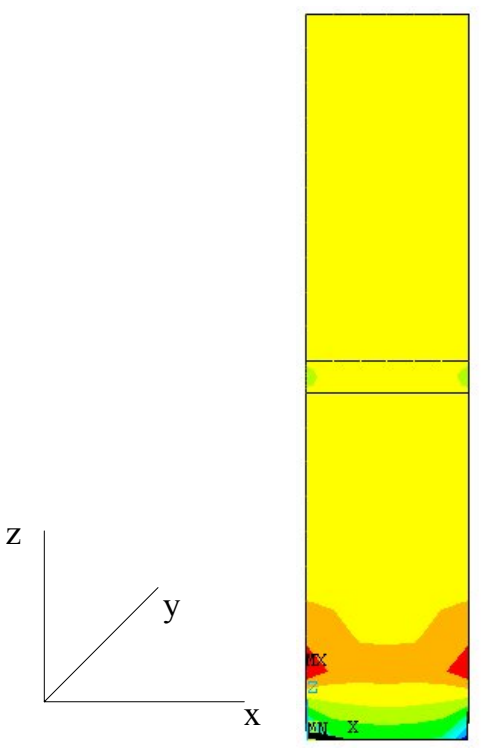

a) $h_{j}=35 \mathrm{~mm}$
ANSYS $5.5 .1 \mathrm{SP}$ TIME $=.655238$

$\mathrm{DMX}=1.656$

SMN $=-91.164$

SMX $=-69.436$

ANSYS $5.5 .1 \mathrm{SP}$

TIME $=.655238$

sMX $=-69.573$
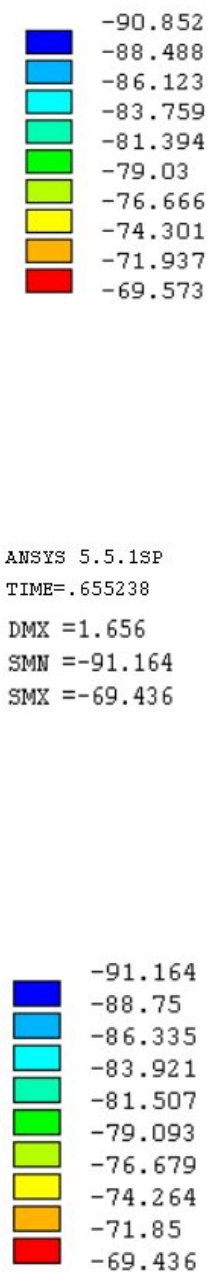

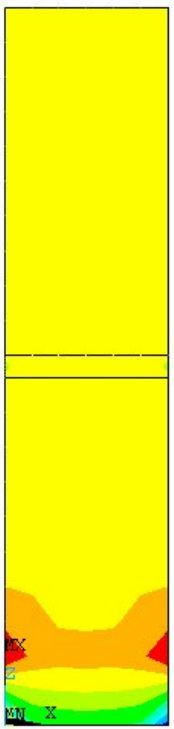

ANSYS $5.5 .1 \mathrm{SP}$ TIME $=.655238$

$\operatorname{DMX}=1.642$

SMN $=-91.164$

SMX $=-69.436$

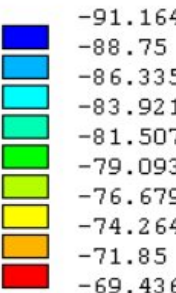

b) $h_{j}=25 \mathrm{~mm}$

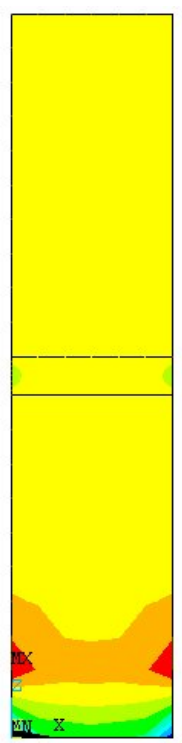

ANSYS $5.5 .1 \mathrm{SP}$ TIME $=.665673$

DMX $=1.696$

SMN $=-92.524$

SMX $=-70.785$

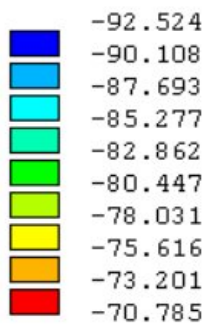

b) $h_{j}=45 \mathrm{~mm}$

Figura 3. 16: Distribuição das tensões $\sigma_{z}(\mathrm{MPa})$ usando a argamassa 2. 

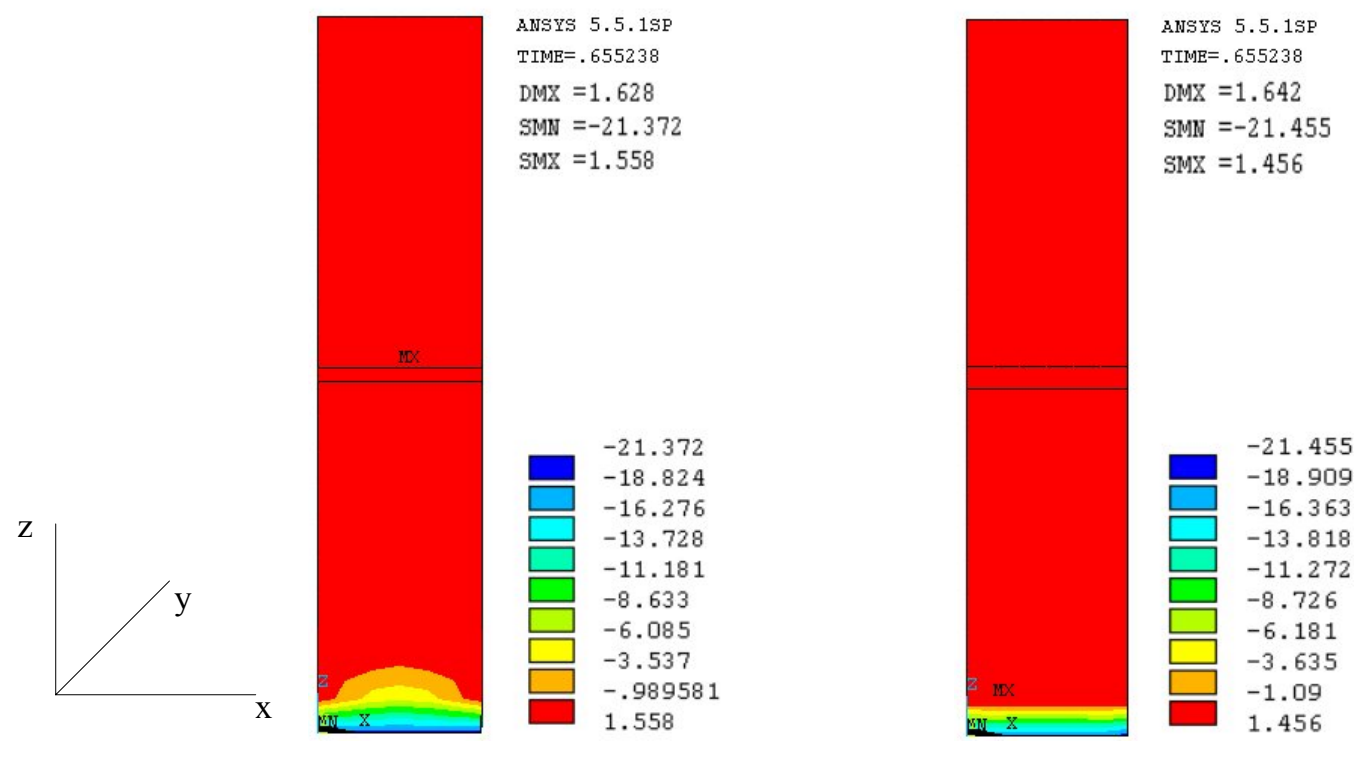

a) $h_{j}=15 \mathrm{~mm}$

b) $h_{j}=25 m m$

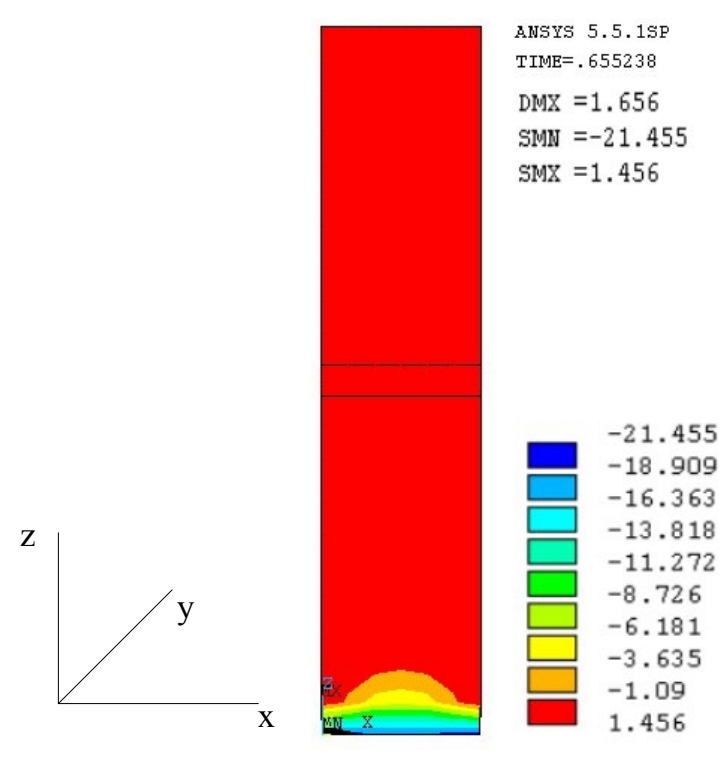

a) $h_{j}=35 \mathrm{~mm}$

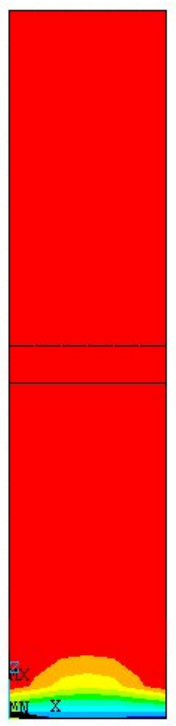

ANSYS $5.5 .1 \mathrm{SP}$

TIME $=.665673$

$\mathrm{DMX}=1.696$

SMN $=-21.763$

SMX $=1.506$

b) $\mathrm{h}_{\mathrm{j}}=45 \mathrm{~mm}$

Figura 3. 17: Distribuição das tensões $\sigma_{x}(\mathrm{MPa})$ usando a argamassa 2 . 


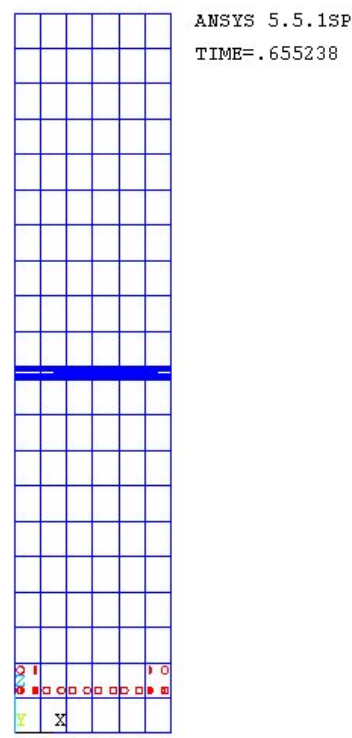

Figura 3. 18: Fissuração dos modelos usando argamassa 2 na junta.

\subsubsection{Resistência do concreto pré-moldado}

O terceiro parâmetro avaliado nas simulações procura identificar que vantagens ou desvantagens podem ser conseguidas para a ligação, fixando-se a relação entre as resistências da argamassa e do concreto pré-moldado, e variando-se o tipo de concreto usado para os elementos pré-moldados.

Seguindo a recomendação de BRUGGELING \& HUYGHE (1991) que estabelece que a espessura da camada de argamassa deve ser menor que $10 \%$ da menor largura da seção transversal da junta, foi usada nas simulações uma espessura de $15 \mathrm{~mm}$ para a junta de argamassa e adotadas duas resistências à compressão para o concreto pré-moldado, conforme mostra a Tabela 3.5.

O primeiro concreto corresponde a um concreto usual para os elementos pré-moldados e o segundo concreto corresponde a um concreto de alta resistência. Foram consideradas três relações $\mathbf{f}_{\mathbf{m}} / \mathbf{f}_{\mathbf{c}}$.

Nos modelos com resistência à compressão do concreto igual a 35MPa, foi aplicado um carregamento de $75 \mathrm{MPa}$ e nos modelos com resistência mais alta o carregamento foi de $115 \mathrm{MPa}$. 
Tabela 3. 5: Resistências adotadas nas simulações

\begin{tabular}{|c|c|}
\hline Concreto (MPa) & Relação $\mathbf{f}_{\mathbf{m}} / \mathbf{f}_{\mathrm{c}}$ \\
\hline 35 & 0,7 \\
\hline 113 & $\begin{array}{l}1,0 \\
1,5\end{array}$ \\
\hline
\end{tabular}

Com os resultados obtidos, observou-se que para uma mesma relação entre as resistências, o uso do concreto de alta resistência permite uma maior capacidade resistente para o modelo. Nas Figuras 3.19 e 3.120 tem-se um exemplo do comportamento da junta de argamassa e do modelo para os dois tipos de concreto. Observa-se que no modelo com concreto de alta resistência a junta ficou mais rígida.

Nos modelos com resistência à compressão mais baixa a ruptura foi instantânea. Nos modelos com concreto de alta resistência ainda foi possível visualizar fissuras no elemento pré-moldado antes da ruptura.

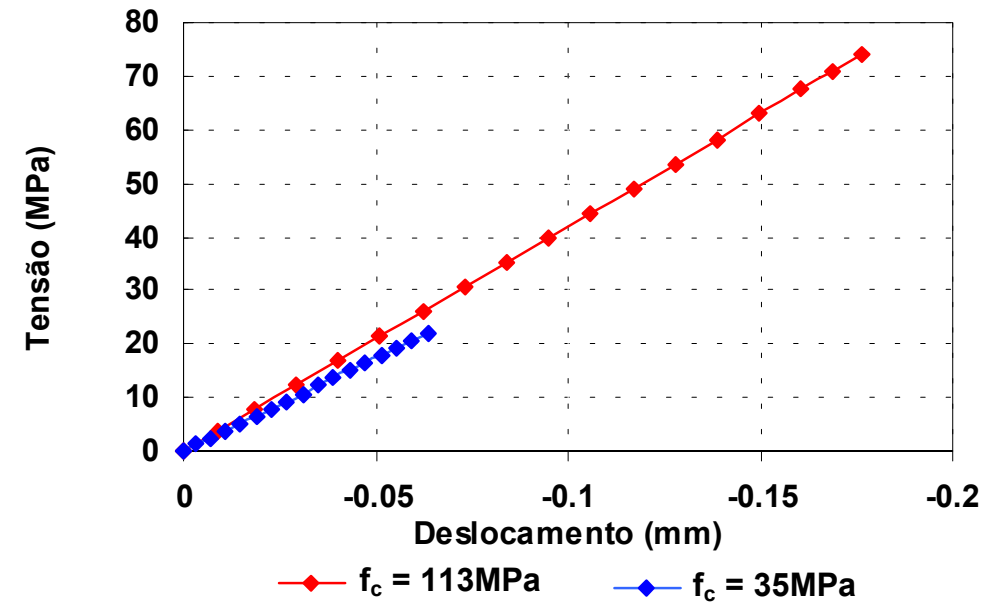

Figura 3. 19: Comportamento da junta de argamassa com $h_{j}=15 \mathrm{~mm}$. 


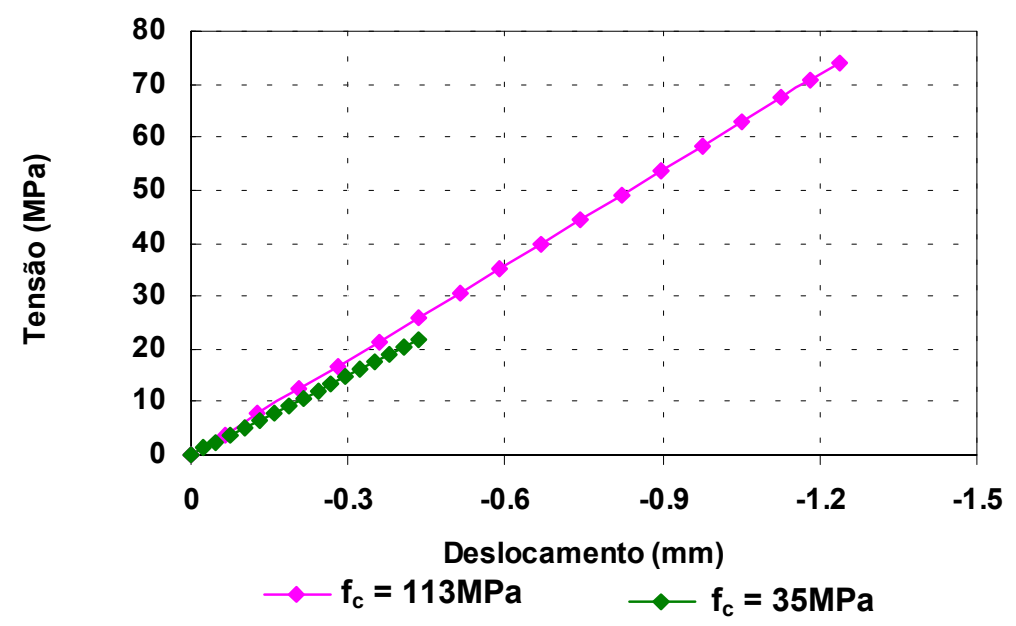

Figura 3. 20: Comportamento do modelo.

\subsubsection{Rugosidade da superfície dos elementos pré-moldados}

De acordo com o trabalho de DILGER \& CHUI (1989), a rugosidade da superfície dos elementos pré-moldados interfere no comportamento da ligação com junta de argamassa, devido às forças de atrito que agem na interface argamassa / concreto. O objetivo dos autores era avaliar essa interferência em juntas inclinadas, mas também foram realizados alguns ensaios em juntas horizontais.

A partir disso, resolveu-se fazer algumas simulações com um modelo bidimensional, mostrado na Figura 3.21, considerando a existência de saliências na superfície do mesmo. Estas saliências faziam com que o carregamento fosse contínuo ao longo de pequenos trechos, como mostra a Figura 3.21.

Os modelos foram discretizados usando-se o elemento plano PLANE42 que possui quatro nós, com dois graus de liberdade em cada um: translações nas direções x e y. Esse elemento permite incorporar plasticidade, fluência, dilatação e é capaz de sofrer grandes deformações. Além disso, tem-se a opção 
de especificar um valor para a espessura. O critério adotado para plastificação foi o critério de DRUCKER-PRAGER, já descrito anteriormente.

Nas simulações, adotou-se um concreto com resistência à compressão igual $35 \mathrm{MPa}$ e foi adotada uma espessura de $10 \mathrm{~mm}$ para o modelo. Foram considerados três tipos de rugosidade:

- uma rugosidade com maior área de contato aplicando-se o carregamento de forma descontínua a cada $5 \mathrm{~mm}$ da superfície;

- uma rugosidade com menor área e contato aplicando-se o carregamento de forma descontínua a cada $20 \mathrm{~mm}$ da superfície.

- uma rugosidade média aplicando-se o carregamento de forma descontínua a cada $10 \mathrm{~mm}$ da superfície;

Para efeito de comparação foi considerado também um elemento sem rugosidade.

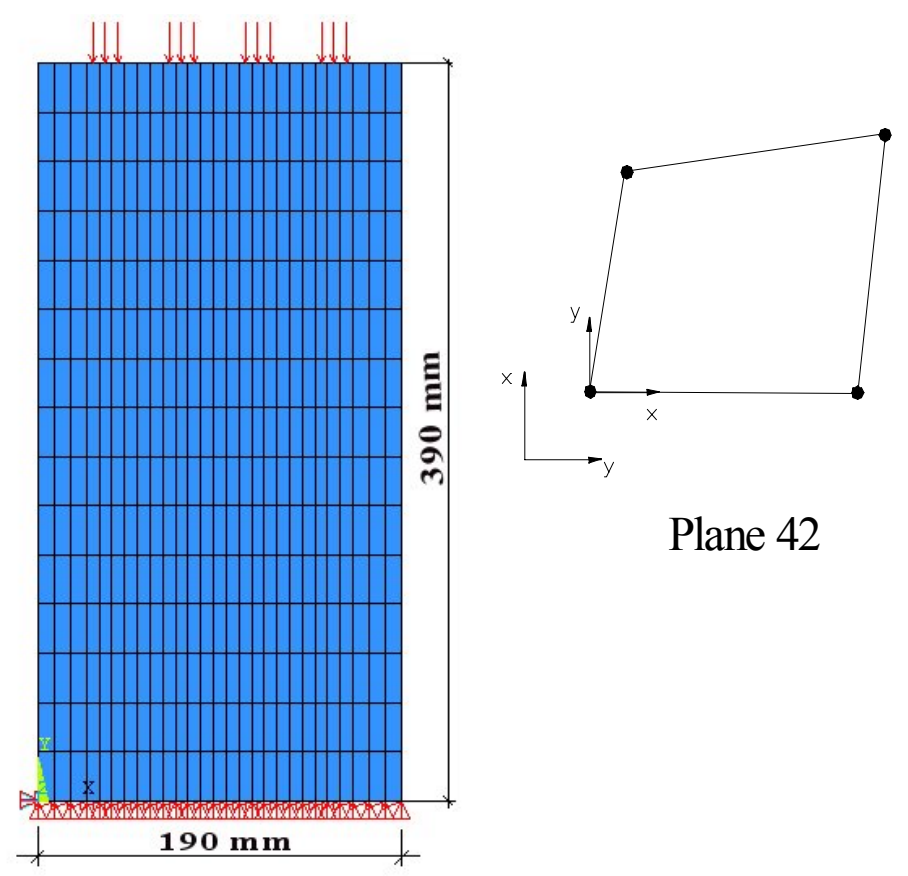

Figura 3. 21: Modelo para simular a influência da rugosidade. 
A distribuição das tensões verticais $\sigma_{y}$, obtida para cada modelo, é mostrada na Figura 3.22 . No elemento com superfície plana, a zona de perturbação restringe-se à região dos apoios e é possível visualizar o efeito arco no caminhamento das tensões.
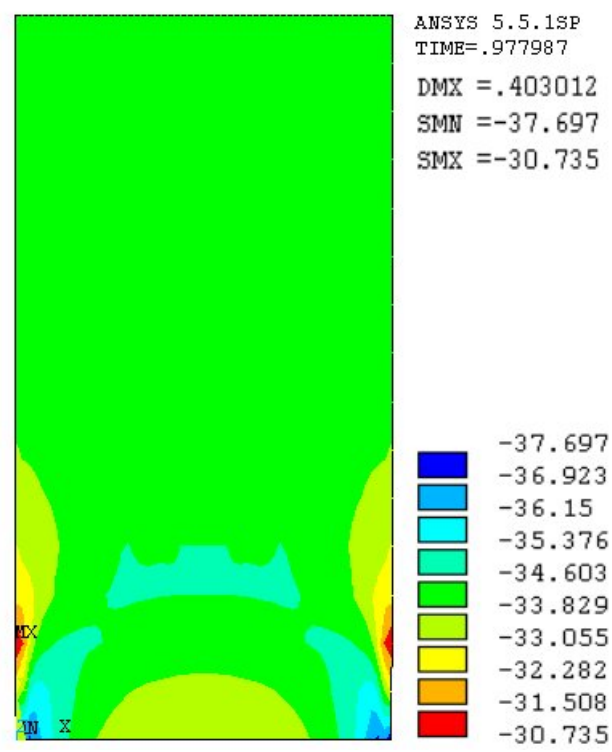
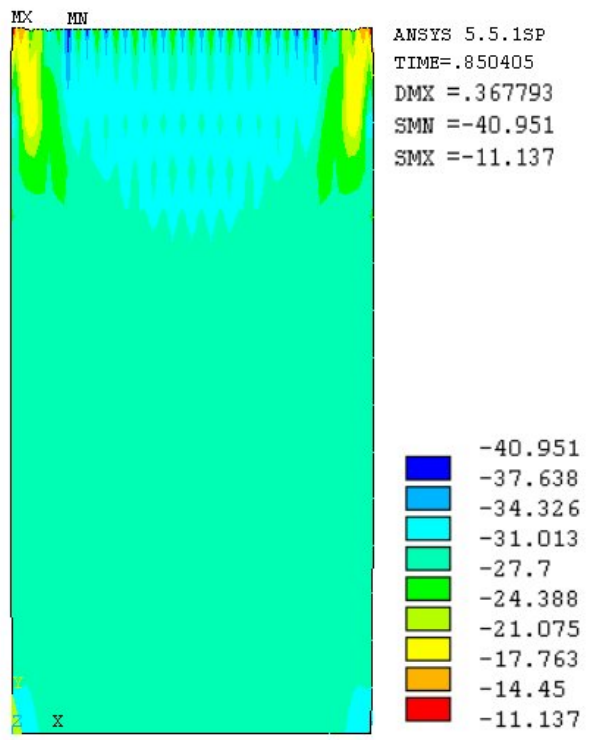

a) Sem rugosidade
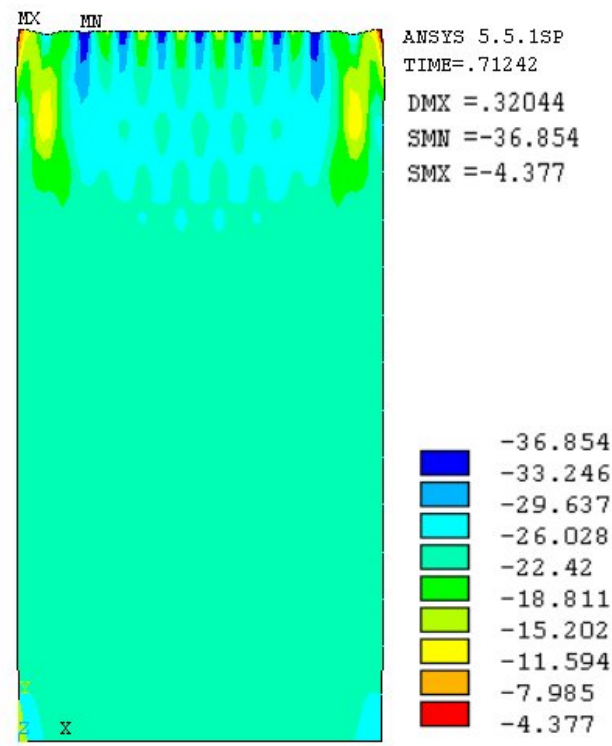

b) Rugosidade a cada $5 \mathrm{~mm}$

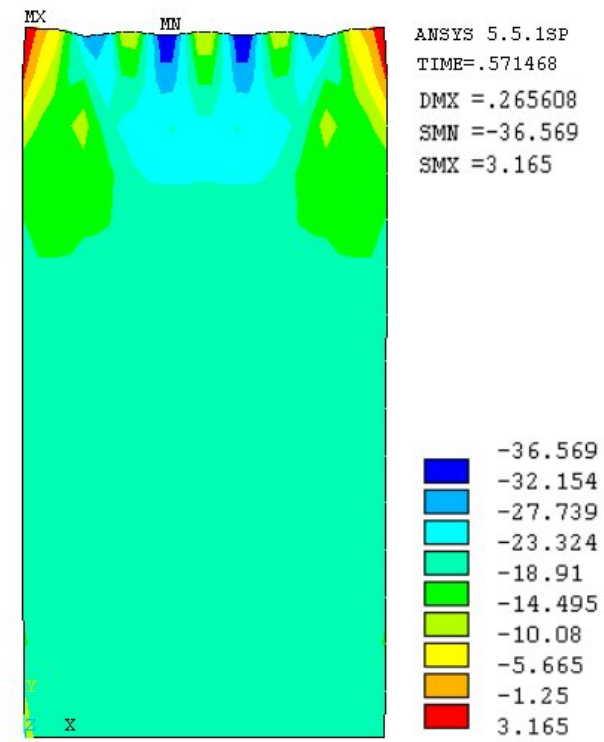

c) Rugosidade a cada $10 \mathrm{~mm}$

d) Rugosidade a cada $20 \mathrm{~mm}$

Figura 3. 22: Distribuição das tensões $\sigma_{\mathrm{y}}(\mathrm{MPa})$ para cada rugosidade. 
Com a existência da rugosidade, o carregamento aplicado de forma descontínua gera um fluxo de tensões que parte dos pontos de aplicação do carregamento e se dirige para o centro da peça, formando um bulbo.

Quando a rugosidade é mais intensa, caso $\mathbf{b}$, o fluxo de tensões se dispersa mais próximo do centro da peça, pois as tensões são mais distribuídas. Quando a rugosidade é mais discreta, como no caso d, o fluxo de tensões se concentra mais próximo da superfície, as tensões são mais altas nos pontos de aplicação do carregamento provocando fendilhamento no modelo e começam a aparecer tensões de tração nas extremidades laterais, ocasionando a ruptura da peça nesses pontos. Além disso, a carga última atingida no modelo diminui.

A distribuição das tensões transversais $\sigma_{x}$ é mostrada na Figura 3.23. Assim como visto para a tensão $\sigma_{y}$, a região adjacente à superfície rugosa é uma região de perturbação para a tensão transversal.

No elemento com superfície plana em que a distribuição é praticamente uniforme, com exceção dos apoios, não existem pontos de ruptura localizada. Já nos elementos em que se tem uma superfície rugosa, as tensões de tração máximas ocorrem em pontos localizados e com valores bem maiores.

Para visualizar a perturbação na distribuição de tensões causada por cada relação de rugosidade foram traçados os gráficos mostrados nas Figuras 3.24 e 3.25 , com valores medidos ao longo da largura do elemento numa faixa situada à 364mm a partir da superfície do apoio. 


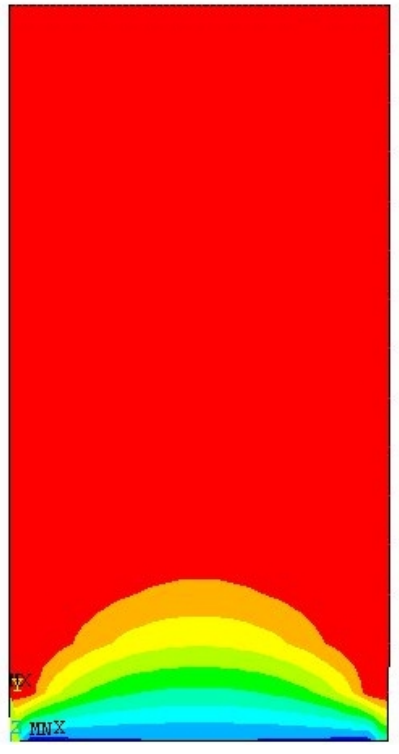

a) Sem rugosidade

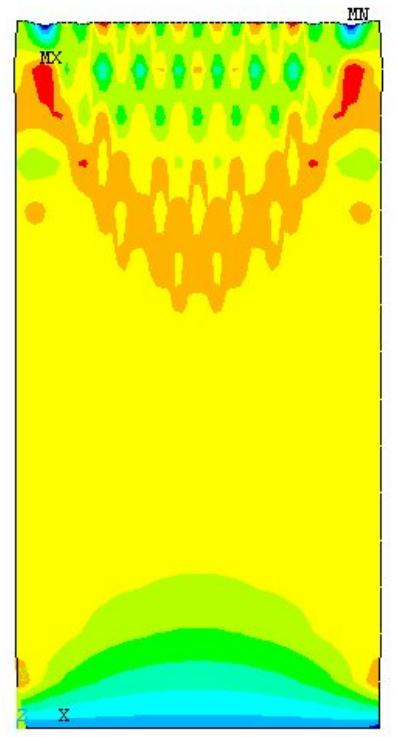

a) Rugosidade a cada $10 \mathrm{~mm}$
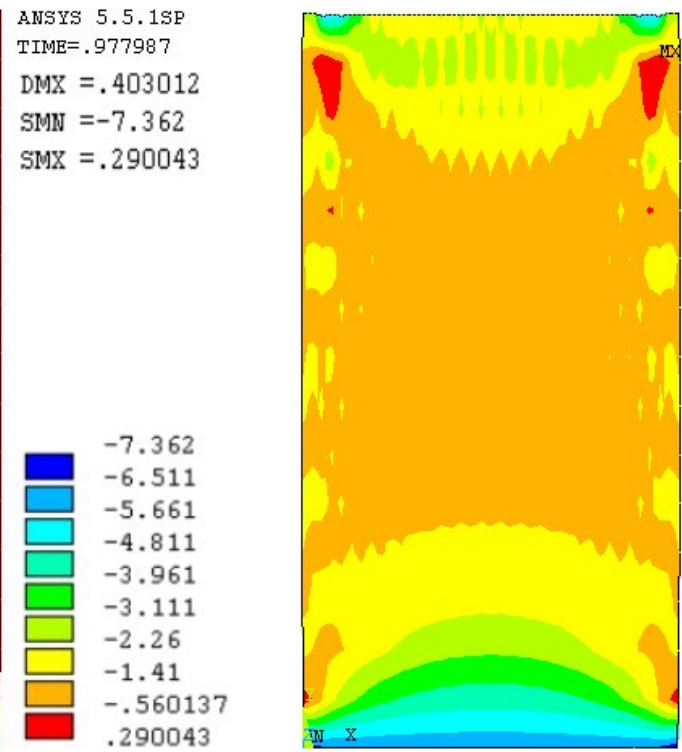

ANSYS 5.5.1SP TIME $=.850405$

$\mathrm{DMX}=.367793$

SMN $=-6.998$

SMX $=1.997$

b) Rugosidade a cada $5 \mathrm{~mm}$

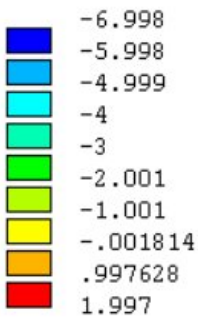

1.997

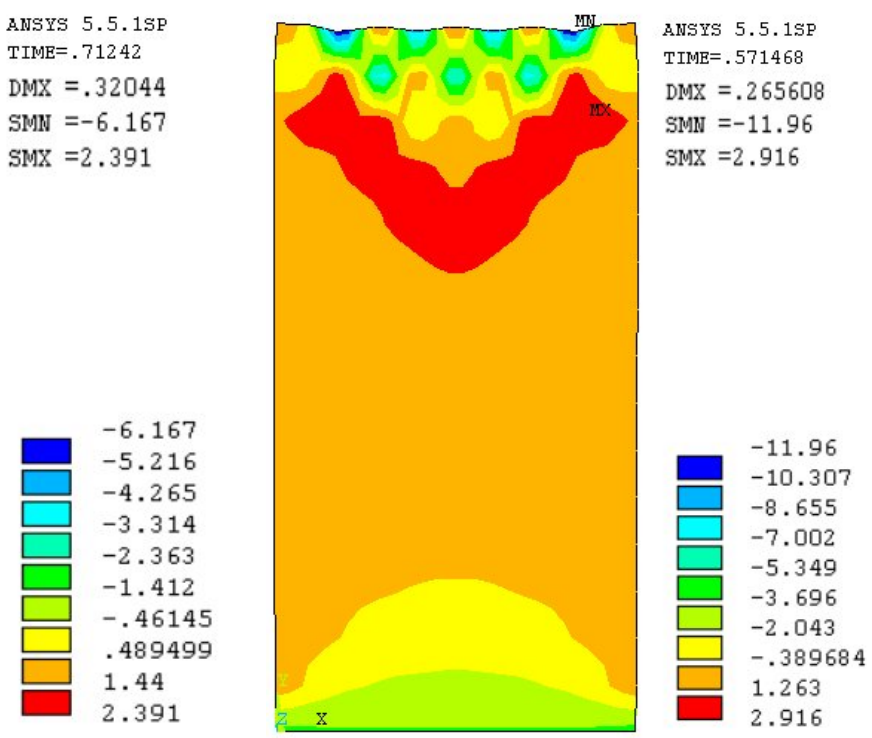

Figura 3. 23: Distribuição das tensões $\sigma_{x}(\mathrm{MPa})$ para cada tipo de rugosidade. 


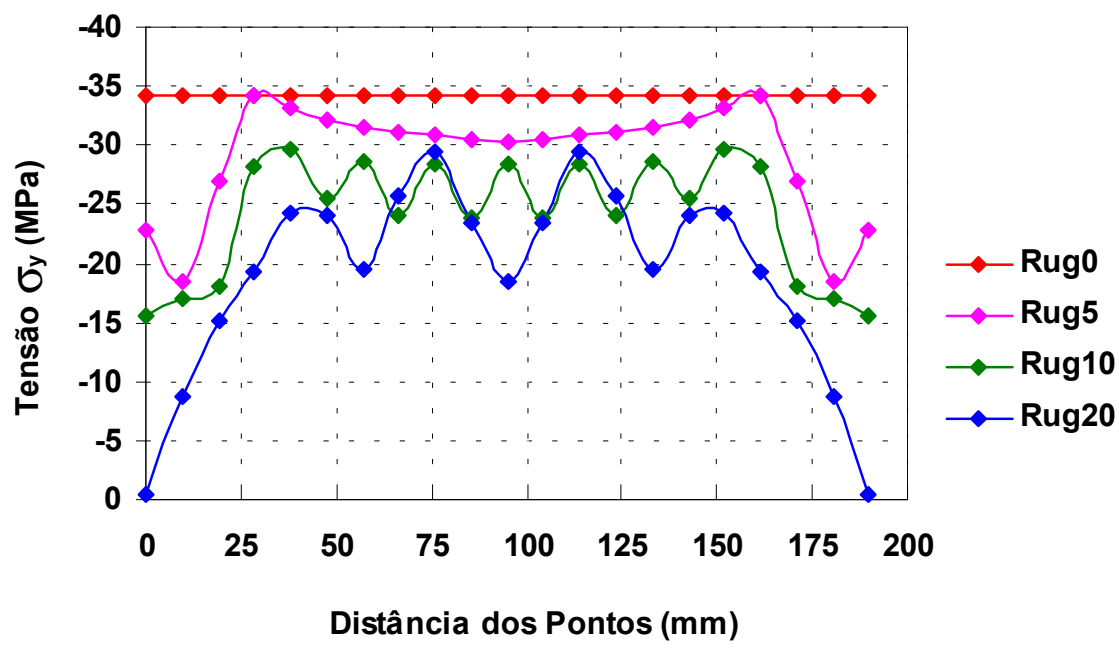

Figura 3. 24: Influência da rugosidade na distribuição das tensões $\sigma_{y}$.

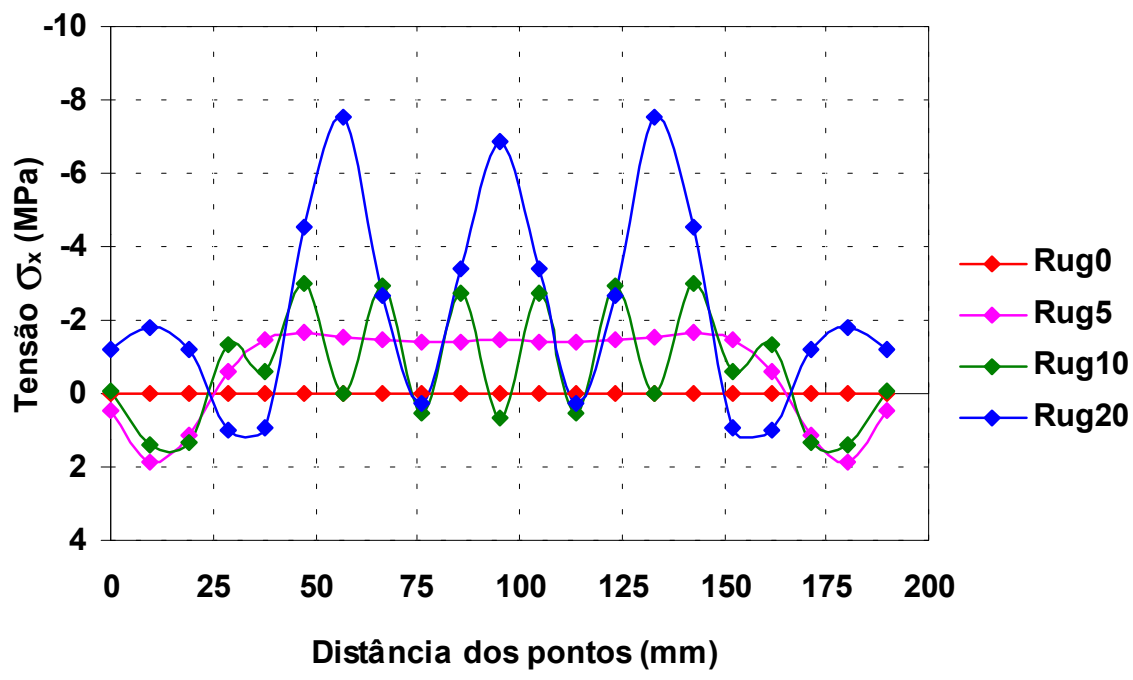

Figura 3. 25: Influência da rugosidade na distribuição das tensões $\sigma_{\mathrm{y}}$.

Na Figura 3.24, pode-se observar os picos de tensão nos pontos de aplicação do carregamento e a diminuição da tensão última. Além disso, com a ruptura localizada das extremidades do modelo, tem-se uma concentração de tensões na região central.

Situação semelhante acontece com as tensões transversais mostradas na 
Figura 3.25. Observa-se que com uma condição de rugosidade mais discreta, ou seja, com menos pontos de aplicação do carregamento, tem-se um alto pico de tensão na região central do elemento e uma inversão de solicitação nas extremidades. As tensões de tração transversais nas extremidades, antes da ruptura, são praticamente idênticas para todos os modelos, com valor médio em torno de 1,5MPa. Entretanto vale ressaltar que, quanto mais discreta a rugosidade, mais cedo aparece esse estado de tensão. Essa tração elevada define pontos de ruptura localizada.

Na Figura 3.26 tem-se um diagrama Força $x$ Deslocamento no topo do modelo, onde é possível observar que a ruptura acontece mais cedo para rugosidade com menos pontos de aplicação do carregamento.

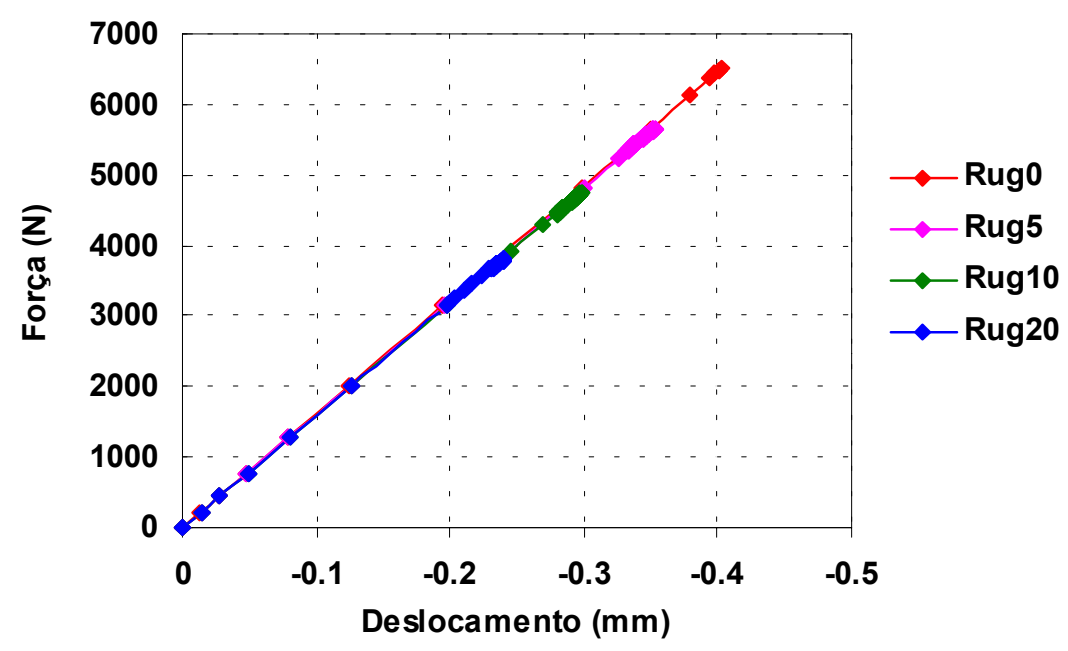

Figura 3. 26: Diagrama Força x Deslocamento para os modelos simulados.

\subsubsection{Forma do elemento pré-moldado}

Segundo LEWICKI (1982), a diminuição da capacidade resistente do elemento pré-moldado devida à presença da junta é mais significativa em pilares devido ao estado tridimensional de tensões na junta.

Partindo dessa afirmação e pensando em generalizar os resultados 
obtidos nas simulações para o comportamento de juntas de argamassa, qualquer que seja a forma da seção transversal dos elementos pré-moldados, procurou-se avaliar esse comportamento em um modelo com outra relação $\mathbf{a} / \mathbf{b}$, onde $\mathbf{a}$ e $\mathbf{b}$ são as dimensões da seção transversal.

Para analisar o efeito da mudança de seção, adotou-se um modelo semelhante ao usado por DILGER \& CHUI (1989) no estudo do comportamento de juntas inclinadas, com dimensões $100 \mathrm{~mm}$ x $200 \mathrm{~mm} \times$ 400mm, mostrado na Figura 3.27.

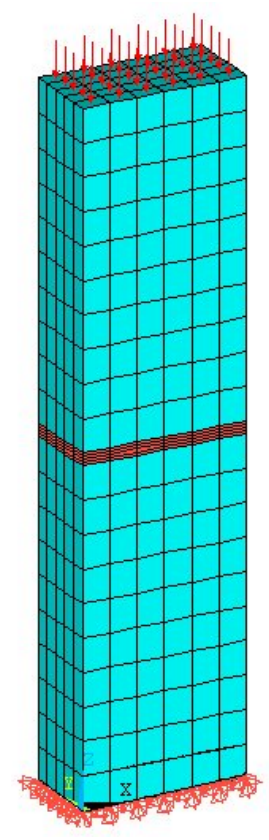

Figura 3. 27: Modelo com seção transversal retangular.

A vinculação e as características mecânicas usadas no modelo são as mesmas já adotadas nas simulações dos segmentos de seção quadrada, bem como o carregamento aplicado. A espessura da junta adotada foi de $15 \mathrm{~mm}$.

Assim como nos modelos de seção quadrada, foram considerados dois valores para a relação $\mathbf{f}_{\mathrm{m}} / \mathbf{f}_{\mathrm{c}}: \mathbf{0 , 7}$ e $\mathbf{1 , 5}$. Os resultados obtidos foram comparados com os resultados já apresentados no item 3.4.2. 
As Figuras 3.28 e 3.29 mostram o comportamento do modelo e da junta nos modelos de seção retangular e quadrada e a distribuição de fissuras, considerando a junta preenchida com argamassa de resistência inferior ao concreto dos elementos pré-moldados. Observa-se que os dois modelos se comportam de forma semelhante. $\mathrm{O}$ elemento retangular absorve menos esforços, pois tem uma área resistente menor que a seção quadrada.

A concentração de tensões na região da ligação aparece nos dois modelos. Com isso, tem-se um quadro de fissuração idêntico nas duas situações.

Nas Figuras 3.30 e 3.31, faz-se a mesma comparação usando na junta uma argamassa com resistência maior que a do elemento pré-moldado. Da mesma forma que nos modelos de seção quadrada, com uma argamassa mais resistente na junta, a ruptura do modelo se deu devido à perda de resistência do elemento pré-moldado. As fissuras se concentraram nas extremidades dos modelos onde ocorre a concentração de tensões.

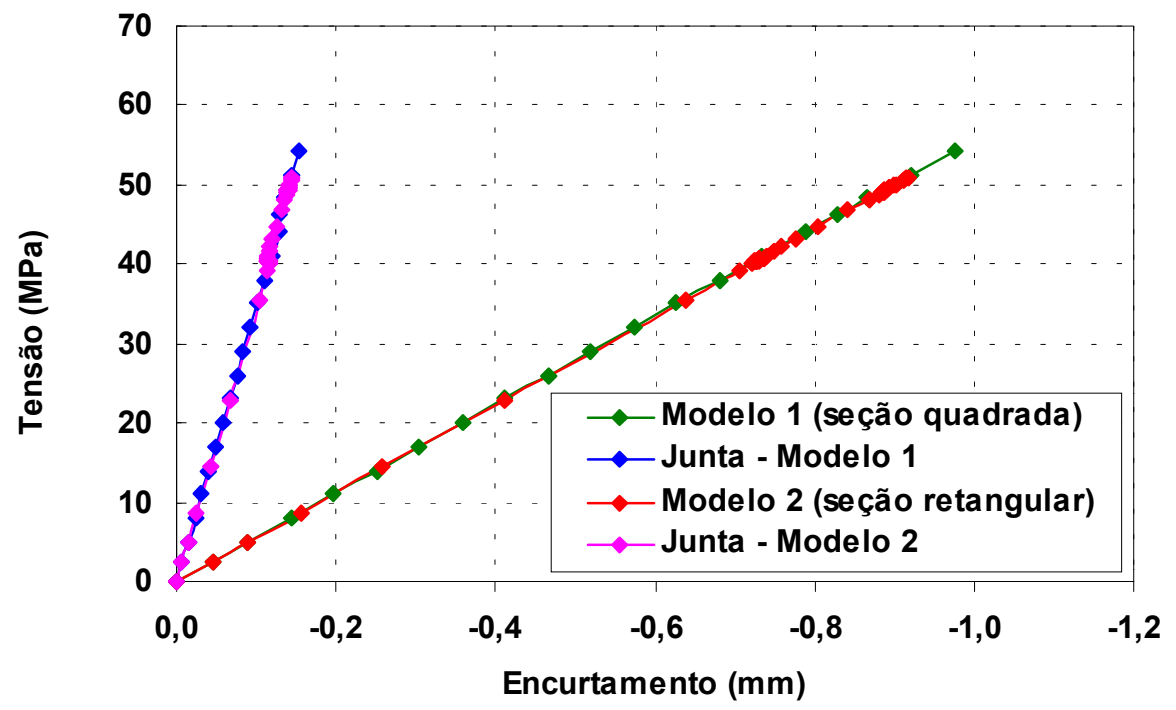

Figura 3. 28: Comparativo para o comportamento do modelo e da junta. 


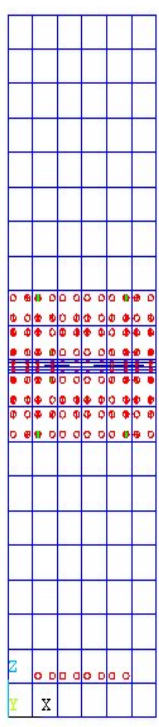

a) seção retangular

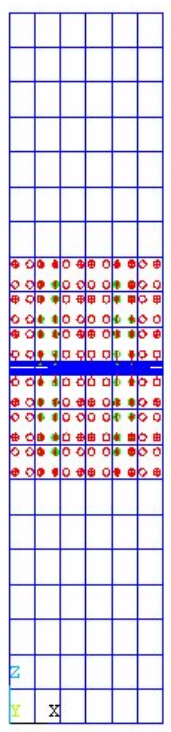

b) seção quadrada

Figura 3. 29: Quadro de fissuração nos modelos.

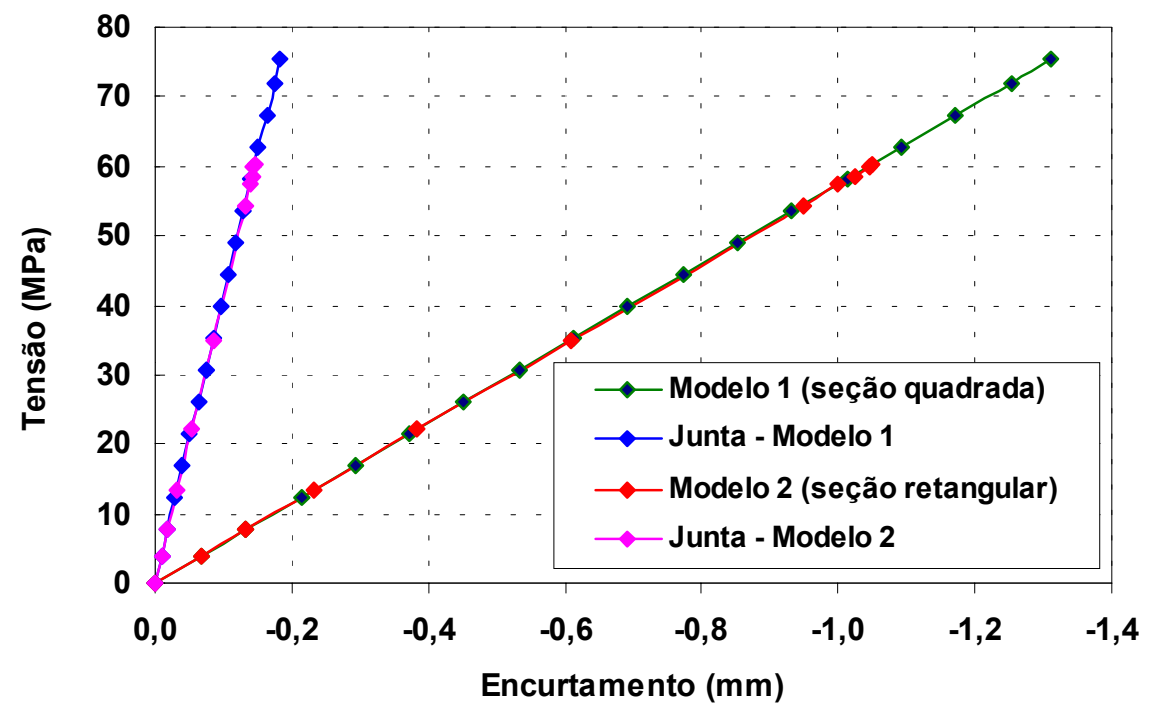

Figura 3. 30: Comparativo para o comportamento do modelo e da junta com argamassa de alta resistência.

Comparando-se os valores das cargas últimas obtidas em cada modelo, como mostra a Figura 3.32, vê-se que o ganho que se obtém na capacidade resistente do elemento pré-moldado ao usar na junta uma argamassa de alta resistência é maior para o modelo de seção quadrada, situando-se em torno de 
$40 \%$. Isso se deve ao confinamento exercido pelos elementos pré-moldados, num estado tridimensional de tensões.

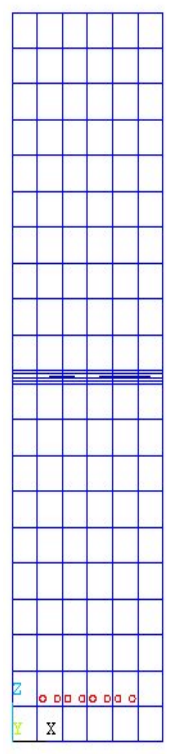

a) seção retangular

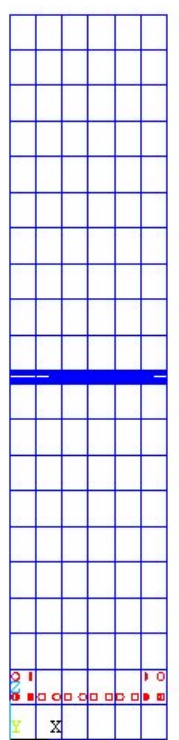

b) seção quadrada

Figura 3. 31: Distribuição de fissuras nos modelos usando argamassa de alta resistência.

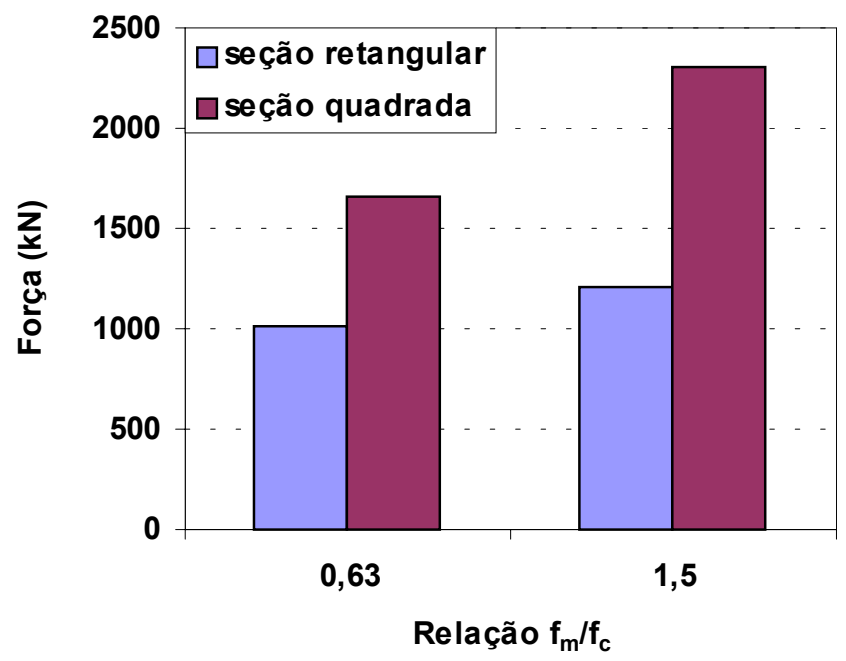

Figura 3. 32: Comparativo das cargas últimas atingidas em cada modelo. 


\subsection{Comentários Adicionais}

Os resultados obtidos com as simulações mostraram que os parâmetros que mais influenciam o comportamento da ligação são: espessura da camada de argamassa e a relação entre as resistências do concreto pré-moldado e da argamassa.

$\mathrm{O}$ uso da argamassa de alta resistência na junta permitiu um aumento de $40 \%$ na capacidade resistente do modelo com junta mais delgada e diminuiu a tendência de expulsão da argamassa nas extremidades. Pode-se dizer que isso se deve ao comportamento mais rígido da argamassa de alta resistência. Porém, as tensões transversais de tração, existentes no elemento pré-moldado, podem provocar o descolamento do cobrimento de concreto e causar a ruptura prematura do elemento.

A existência de rugosidades na superfície do elemento pré-moldado concentra tensões nos pontos de aplicação do carregamento e cria pontos de ruptura localizada. Além disso, a existência de altas tensões de tração nas extremidades provoca o fendilhamento dos elementos pré-moldados.

A variação na geometria da seção transversal do elemento não trouxe mudanças significativas para o comportamento da ligação. Entretanto, observou-se que a tendência de confinamento da argamassa exercida pelos elementos pré-moldados é mais preponderante nos modelos de seção quadrada.

Considerando-se o modelo com concreto pré-moldado de resistência $35 \mathrm{MPa}$, junta de argamassa de $15 \mathrm{~mm}$ de espessura e relação entre a resistência da argamassa e do concreto do elemento pré-moldado igual a 0,7 , fez-se um gráfico comparativo entre o valor da capacidade resistente da ligação obtido na simulação e os valores encontrados aplicando-se as expressões recomendadas na literatura disponível, como mostra a Figura 3.32. 


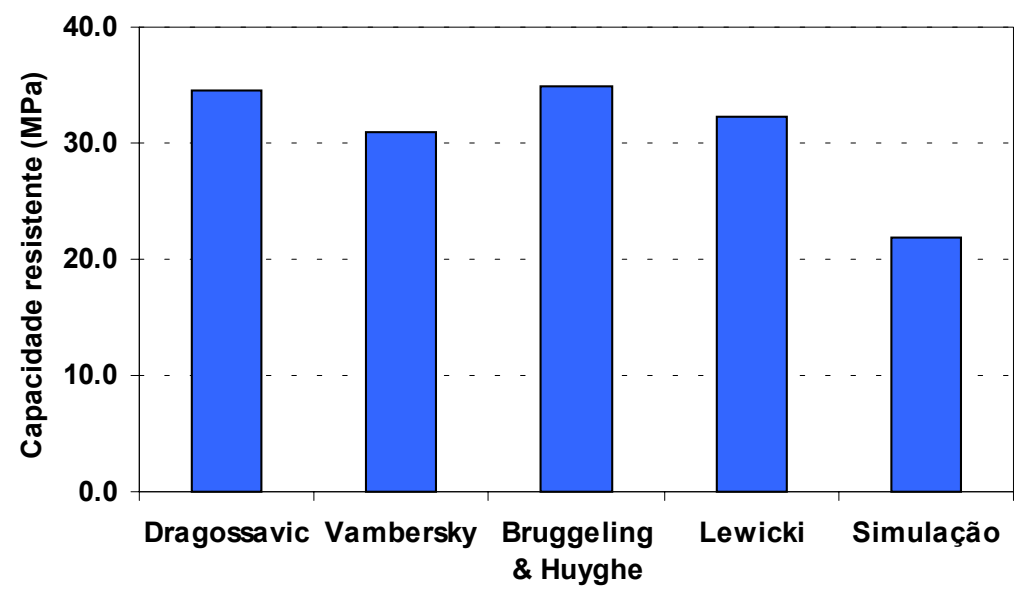

Figura 3. 33: Comparativo dos valores da capacidade resistente da ligação.

Observa-se que o valor obtido na simulação corresponde a 71\% do valor teórico obtido por VAMBERSKY (1990), cuja expressão corresponde à forma mais recente de avaliação da capacidade resistente de juntas de argamassa. Acredita-se que a diferença entre os dois valores se deve ao uso do critério CONCRETE, que impõe ao material um comportamento elasto-frágil na tração causando ruptura brusca do modelo com o aumento da fissuração, ou seja, não apresenta condições de ductilidade. Por outro lado, se o modelo já está fissurado pode-se dizer que a ligação não está mais resistindo aos esforços, o que reduziria sua capacidade resistente.

Comparando-se os valores das deformabilidades dos modelos simulados nos itens 3.4.1 e 3.4.2, com o valor recomendado por BJLUGER (1988), como mostra a Tabela 3.6, vê-se que nas simulações a junta de argamassa ficou bem mais flexível, o que reduz sua capacidade resistente.

Tabela 3. 6: Comparativo das deformabilidades simuladas.

\begin{tabular}{|c|c|c|c|}
\hline $\begin{array}{c}\text { Espessura } \\
(\mathrm{mm})\end{array}$ & $\begin{array}{c}\text { Deformabilidade } \\
(\mathrm{m} / \mathrm{MPa}) \\
\text { normal }\end{array}$ & $\begin{array}{c}\text { Deformabilidade } \\
(\mathrm{m} / \mathrm{MPa}) \\
\text { alta resistência }\end{array}$ & $\begin{array}{c}\text { Deformabilidade } \\
\text { BJLUGER (1988) } \\
(\mathrm{m} / \mathrm{MPa})\end{array}$ \\
\hline 15 & $7,3 \times 10^{-4}$ & $2,8 \times 10^{-4}$ & \multirow{2}{*}{$0,4 \times 10^{-4}$} \\
\hline 25 & $1,2 \times 10^{-3}$ & $4,6 \times 10^{-4}$ & \\
\hline 35 & $1,8 \times 10^{-3}$ & $6,5 \times 10^{-4}$ & \\
\hline 45 & $2,3 \times 10^{-3}$ & $8,4 \times 10^{-4}$ & \\
\hline
\end{tabular}




\section{Avaliação Experimental do Comportamento da Ligação}

\subsection{Preliminares}

A simulação numérica da ligação com junta de argamassa permitiu uma primeira visualização do comportamento da mesma frente aos parâmetros de influência descritos na literatura. Para dar continuidade à análise desse comportamento, foram realizados ensaios em modelos que simulavam a ligação em estudo, usando para preenchimento da junta materiais comercialmente disponíveis e utilizados normalmente nas construções atuais. Foi incluído ainda um estudo exploratório da ligação com almofada de apoio que consistia numa argamassa à base de cimento modificada pela adição de látex e fibras de polipropileno ou fibras de PVA.

Para reduzir a quantidade de ensaios a serem realizados o planejamento do programa experimental foi estabelecido considerando-se os parâmetros de maior relevância de acordo com a revisão bibliográfica e a simulação numérica desenvolvidas. Além disso, como se tratava de um modelo com várias etapas de concretagem, todos os procedimentos deveriam ser executados de forma cuidadosa, o que demandaria mais tempo de preparação. 


\subsection{Planejamento do Programa Experimental}

Procurou-se, inicialmente, estabelecer um conjunto de variáveis que permitisse explorar o efeito dos diversos parâmetros de influência do comportamento da ligação. A partir daí, seriam definidas as variáveis para o programa experimental. Com os resultados obtidos nas simulações numéricas e o levantamento bibliográfico do assunto, chegou-se ao conjunto de variáveis mostrado no Quadro 4.1.

Quadro 4. 1: Variáveis consideradas para estudo da ligação

\begin{tabular}{|l|l|}
\hline \multicolumn{1}{|c|}{ Parâmetros } & \multicolumn{1}{c|}{ Variáveis } \\
\hline Forma da seção de contato & $1: 1,1: 2,1: 3$ \\
\hline Tipo de argamassa & $\begin{array}{l}\text { Graute; Argamassa do tipo "Dry Pack"; } \\
\text { Sem argamassa }\end{array}$ \\
\hline Espessura $(\mathrm{mm})$ & $15 ; 22,5 ; 30$ \\
\hline Relação $\mathrm{f}_{\mathrm{m} / \mathrm{f}_{\mathrm{c}}}$ & $\mathrm{f}_{\mathrm{m}}<\mathrm{f}_{\mathrm{c}} ; \mathrm{f}_{\mathrm{m}}=\mathrm{f}_{\mathrm{c}} ; \mathrm{f}_{\mathrm{m}}>\mathrm{f}_{\mathrm{c}}$ \\
\hline Resistência do concreto & $35 ; 60$ \\
\hline Rugosidade & Lisa; Rugosa \\
\hline Carga & Centrada; Excêntrica \\
\hline Armadura & Normal; Reforçada \\
\hline
\end{tabular}

A primeira limitação para a quantidade de ensaios foi estabelecida considerando-se que, segundo LEWICKI (1982), a redução na capacidade resistente da ligação por causa da diferença de deformabilidade entre a argamassa e o elemento pré-moldado é mais relevante nos pilares, devido ao estado tridimensional de deformação da junta, como mostra a Figura 4.1.

Considerou-se também que na prática, as juntas de argamassa são mais comumente aplicadas entre painéis, onde a excentricidade do carregamento aplicado é praticamente inexistente. Com isso adotou-se somente carregamento centrado.

A partir do levantamento bibliográfico do assunto e das simulações numéricas desenvolvidas, observou-se que a espessura da camada de argamassa e a relação entre as resistências do concreto e da argamassa são as 
variáveis que mais influenciam o comportamento da ligação. Sendo assim, seriam as mais exploradas nos modelos.

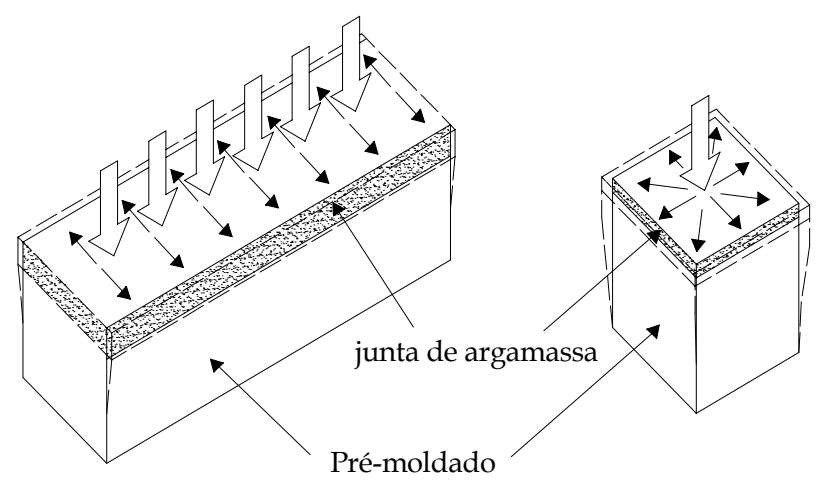

Figura 4. 1: Estado de tensão em juntas horizontais entre painéis e entre pilares. Fonte LEWICKI(1982).

Foram considerados ainda, os trabalhos experimentais desenvolvidos por STROBAND et al. (1996) e SHU \& HAWKINS (1992).

No primeiro trabalho, os autores ensaiaram modelos formados por blocos de concreto armado de alta resistência com seção quadrada de $175 \mathrm{~mm}$ de lado e altura de $400 \mathrm{~mm}$, mantendo fixa a espessura da junta em $15 \mathrm{~mm}$ e variando a disposição das armaduras e a resistência do material da junta.

No segundo trabalho, os pesquisadores ensaiaram blocos de concreto simples e concreto armado, com seção quadrada de 152,4mm de lado, altura de $304,8 \mathrm{~mm}$ e arranjo de armadura fixo, variando a espessura da junta que ligava os blocos.

\subsection{Descrição dos Modelos}

Com base nas observações descritas no item anterior e nos trabalhos citados, chegou-se à configuração dos modelos mostrada na Figura 4.2. 
Para evitar a ruptura prematura nas extremidades dos elementos prémoldados, onde seria aplicado o carregamento, foi feito um reforço que consistia em confinar as extremidades do modelo com anéis de aço preenchidos com micro-concreto. Esse reforço, mostrado na Figura 4.3, já havia sido adotado por STROBAND et al. (1996) e tinha sido bastante eficiente.
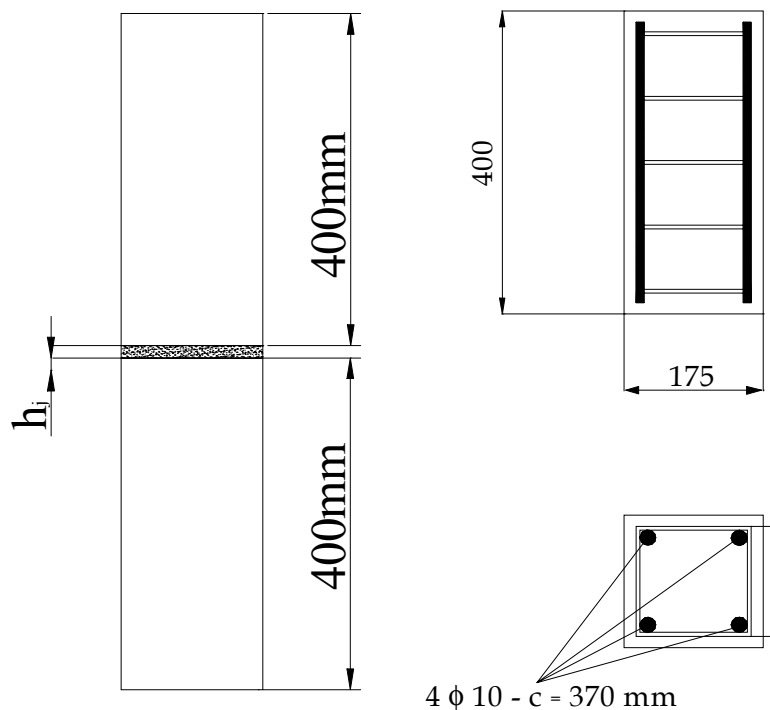

$$
\begin{array}{c|c} 
& \\
\Xi \\
\Xi \\
0 \\
0 \\
0 \\
0 \\
0 \\
0 \\
0 \\
\ddots \\
\circ \\
+1
\end{array}
$$

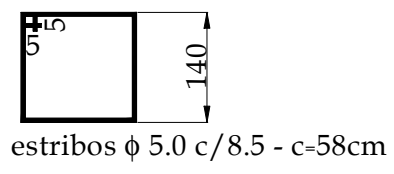

Figura 4. 2: Dimensões dos modelos.

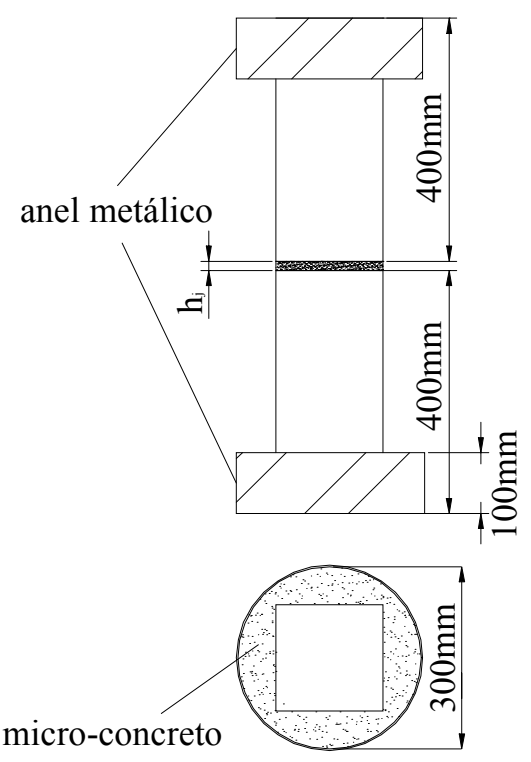

Figura 4. 3: Reforço nas extremidades do modelo 
Além dos tipos de argamassa descritos no Quadro 4.1, foi analisado ainda, o comportamento da ligação colocando-se uma almofada de apoio entre os elementos pré-moldados. Essa almofada foi executada com um material deformável, que vem sendo estudado numa outra pesquisa descrita no trabalho de EL DEBS et. al. (2001).

\subsection{Materiais}

Os materiais utilizados na execução dos modelos foram caracterizados no Laboratório de Construção Civil da EESC, com exceção daqueles que já possuíam especificação prévia dos fabricantes.

\subsubsection{Cimento}

Foi utilizado o cimento Portland de alta resistência inicial CP V ARI, da marca CIMINAS, pela possibilidade de realizar os ensaios em modelos com idades menores. A massa específica caracterizada pelo fabricante, de acordo com a NBR 6474/84, foi de $3,12 \mathrm{~g} / \mathrm{cm}^{3}$.

\subsubsection{Areia}

A areia usada nos ensaios foi do tipo quartzosa e sua análise granulométrica foi feita seguindo-se as recomendações da NBR 7217/87. O resultado dessa análise é mostrado na Figura 4.4.

Em função do módulo de finura, cujo valor foi 2,37, a areia foi classificada como média e a massa específica, de acordo com a NBR 9776/87, foi de $2,591 \mathrm{~g} / \mathrm{cm} 3$. 


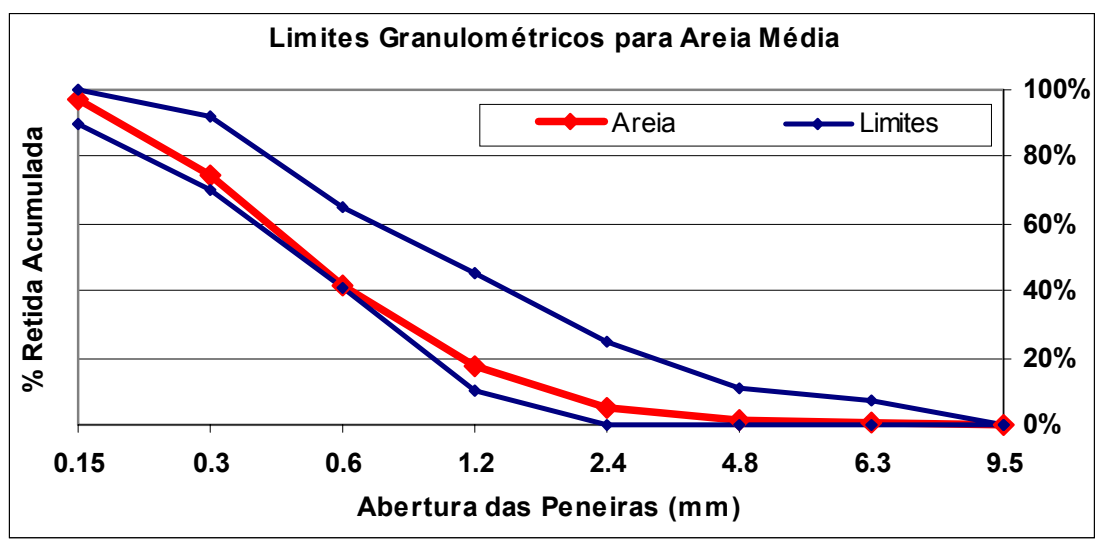

Figura 4. 4: Curva granulométrica da areia usada nos modelos.

\subsubsection{Brita}

Utilizou-se nos modelos uma pedra britada de origem basáltica, da região de Araraquara - SP. A análise granulométrica, feita de acordo com a NBR 7217/87, caracterizou um diâmetro máximo de 19mm e módulo de finura 3,56. A massa específica obtida, de acordo com a NBR 9776/87, foi 2,857g/ $\mathrm{cm}^{3}$.

\subsubsection{Armadura}

Foram utilizadas barras de aço CA-50 de diâmetros 10,0mm, como armadura longitudinal e 5,0 mm como armadura transversal.

\subsubsection{Aditivo}

Foi usado um aditivo superplastificante da Reax Indústria e Comércio Ltda, denominado RX 3000, isento de cloretos e obtido através de doação do fabricante. 


\subsubsection{Argamassa}

Foram usados quatro tipos de argamassa para preenchimento da junta. Essas argamassas são fabricadas pela FOSROC Brasil e foram obtidas como doação pelo fabricante.

O primeiro tipo foi um graute não retrátil para uso geral, à base de cimento, denominado Fosgrout Plus. Segundo o fabricante, esse graute é uma mistura de cimento Portland, agregados graduados e aditivos químicos que controlam a expansão no estado plástico e minimizam o consumo de água, garantindo assim um graute fluido e não retrátil de alta resistência inicial e final.

O segundo tipo foi um graute denominado Conbextra $\mathbf{P}$ constituído de cimento Portland, agregados graduados e aditivos especiais, bastando adicionar água para obter um graute bombeável de alta fluidez, com retração compensada, alta resistência mecânica inicial e final e isento de cloreto e ferro.

O terceiro tipo, denominado Shim Set, é uma argamassa seca a base de cimento, monocomponente, isenta de retração e apresenta excelente compatibilidade com o concreto. Sua aplicação é feita pelo sistema "Dry Pack", ou seja, compactando-se o material de forma confinada, no local de aplicação.

O quarto tipo foi um graute de alta fluidez, à base de resina epóxi, denominado Conbextra EPR. Esse graute é indicado para uso em situações onde aparecem altas cargas dinâmicas ou móveis.

\subsection{Programa Experimental}

O modelo de referência adotado para o programa experimental foi o modelo denominado M1G15ILN-35. A partir daí, os modelos foram agrupados em séries mantendo-se fixo o tipo de material da junta e 
considerando-se as outras variáveis. Em cada série, as variáveis foram analisadas como apresentadas na Tabela 4.1 .

Tabela 4. 1: Detalhamento do Programa Experimental

\begin{tabular}{|c|c|c|c|c|c|c|}
\hline $\begin{array}{c}\text { Denominação do } \\
\text { modelo }\end{array}$ & $\begin{array}{c}\text { Tipo de } \\
\text { argamassa }\end{array}$ & $\begin{array}{c}\text { Espessura } \\
(\mathrm{mm})\end{array}$ & $\begin{array}{c}\text { Relação } \\
\mathbf{f}_{\mathbf{m}} / \mathbf{f}_{\mathbf{c}}\end{array}$ & $\begin{array}{c}\text { Resistência } \\
\text { do } \\
\text { concreto } \\
(\mathrm{MPa})\end{array}$ & Rugosidade & Armadura \\
\hline M1G15ILN-35 & \multirow[t]{7}{*}{ Graute } & 15 & 0,7 & 35 & \multirow{7}{*}{ Lisa } & \multirow{6}{*}{ Normal } \\
\hline M2G22ILN-35 & & 22,5 & & & & \\
\hline M3G30ILN-35 & & 30 & & & & \\
\hline M4G15MLN-35 & & 15 & 1,0 & & & \\
\hline M5G15SLN-35 & & 15 & 1,5 & & & \\
\hline M6G15ILN-60 & & 15 & 0,7 & 60 & & \\
\hline M7G15ILR-35 & & 15 & 0,7 & 35 & & Especial \\
\hline M8AF15SLN-35 & \multirow{2}{*}{$\begin{array}{l}\text { Almofada } \\
\text { de apoio }\end{array}$} & \multirow[t]{2}{*}{15} & \multirow[t]{2}{*}{1,5} & \multirow[t]{2}{*}{35} & \multirow[t]{2}{*}{ Lisa } & \multirow{7}{*}{ Normal } \\
\hline M9AF15SRN-35 & & & & & & \\
\hline M10DP15SLN-35 & "Dry Pack" & 15 & 0,7 & 35 & Lisa & \\
\hline M11SLN-35 & \multirow{4}{*}{$\begin{array}{c}\text { Sem } \\
\text { argamassa }\end{array}$} & \multirow[t]{4}{*}{-} & \multirow[t]{4}{*}{-} & \multirow[t]{2}{*}{35} & Lisa & \\
\hline M12SRN-35 & & & & & Rugosa & \\
\hline M13SLN-60 & & & & \multirow[t]{2}{*}{60} & Lisa & \\
\hline M14SRN-60 & & & & & Rugosa & \\
\hline
\end{tabular}

A denominação dos modelos foi feita considerando-se a letra M seguida do número dos mesmos e da simbologia adotada para cada parâmetro, ressaltando-se no final a resistência à compressão do concreto pré-moldado usado no elemento. A simbologia adotada para cada parâmetro está detalhada no Quadro 4.2.

Como exemplo, o modelo denominado M1G15ILN-35, é o modelo número 1, cuja junta foi preenchida com graute, com $15 \mathrm{~mm}$ de espessura e resistência à compressão inferior à resistência do concreto pré-moldado, com superfície lisa dos segmentos pré-moldados na região da junta, sem armadura de reforço na região da ligação e cujo concreto usado para confecção do elemento pré-moldado possui resistência à compressão de $35 \mathrm{MPa}$.

Para cada modelo foram moldadas três amostras, com exceção dos modelos sem argamassa e com almofada de apoio de material flexível. 
Quadro 4. 2: Simbologia adotada para as variáveis analisadas.

\begin{tabular}{|l|l|}
\hline \multicolumn{1}{|c|}{ Variável } & \multicolumn{1}{c|}{ Simbologia } \\
\hline Tipo de argamassa & $\mathrm{G}$ - graute \\
& $\mathrm{DP}-$ argamassa seca tipo “Dry Pack” \\
& AF - almofada de material flexível \\
& $\mathrm{S}-$ sem argamassa \\
\hline Espessura & $15 ; 22 ; 30$ \\
\hline Relação $\mathbf{f}_{\mathrm{m} / \mathrm{f}_{\mathrm{c}}}$ & $\mathrm{I}-\mathrm{f}_{\mathrm{m}}<\mathrm{f}_{\mathrm{c}}$ \\
& $\mathrm{M}-\mathrm{f}_{\mathrm{m}}=\mathrm{f}_{\mathrm{c}}$ \\
& $\mathrm{S}-\mathrm{f}_{\mathrm{m}}>\mathrm{f}_{\mathrm{c}}$ \\
\hline Rugosidade & $\mathrm{L}-$ lisa \\
& $\mathrm{R}-$ rugosa \\
\hline Armadura & $\mathrm{N}-$ normal \\
& $\mathrm{R}-$ reforçada \\
\hline
\end{tabular}

\subsubsection{Execução dos Modelos}

Os segmentos pré-moldados eram confeccionados na posição vertical, usando-se formas de madeira compensada plastificada com $15 \mathrm{~mm}$ de espessura, como mostra a Figura 4.5. Foi confeccionado um par de formas para permitir a moldagem simultânea das amostras de cada modelo.

Nos modelos M9AF15SRN-35, M12SRN-35 e M14SRN-60, a superfície rugosa dos segmentos pré-moldados foi executada colando-se ripas de madeira de $5 \mathrm{~mm}$ de altura no fundo das formas, como mostra a Figura 4.6a.

$\mathrm{O}$ adensamento da mistura era feito usando-se vibrador de agulha e em cada moldagem eram retirados 6 corpos-de-prova $100 \mathrm{~mm}$ x 200mm para determinar as resistências à compressão e à tração do concreto usado no segmento pré-moldado. Esses corpos-de-prova eram deixados em câmara úmida até o dia anterior ao ensaio. No dia do ensaio, os corpos-de-prova usados para determinar a resistência à compressão eram capeados com enxofre. Em algumas moldagens foram retirados mais três corpos-de-prova para determinação do módulo de elasticidade, que seria usado nas simulações numéricas dos modelos. 


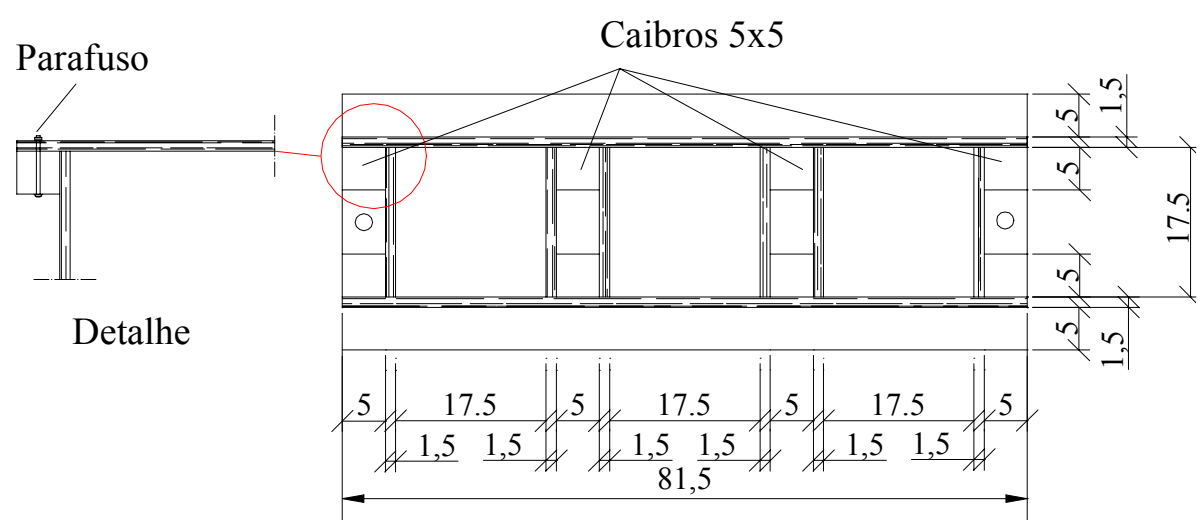

Vista em planta

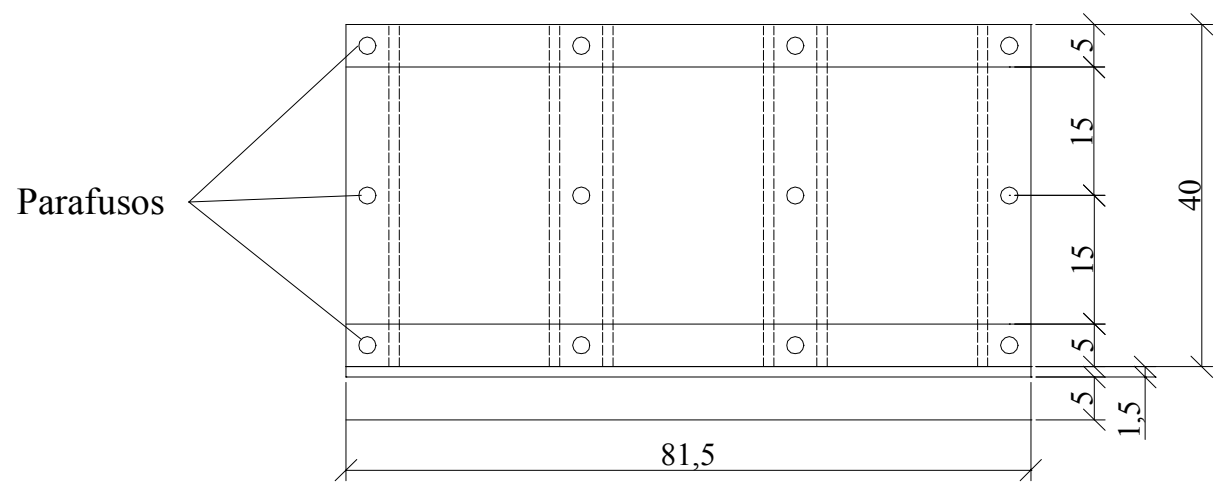

Vista frontal

Figura 4. 5: Fôrmas para execução dos modelos.

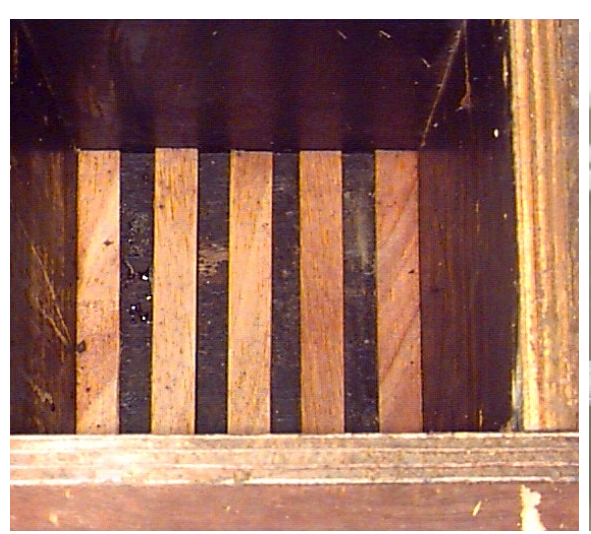

a) ripas coladas no fundo da forma

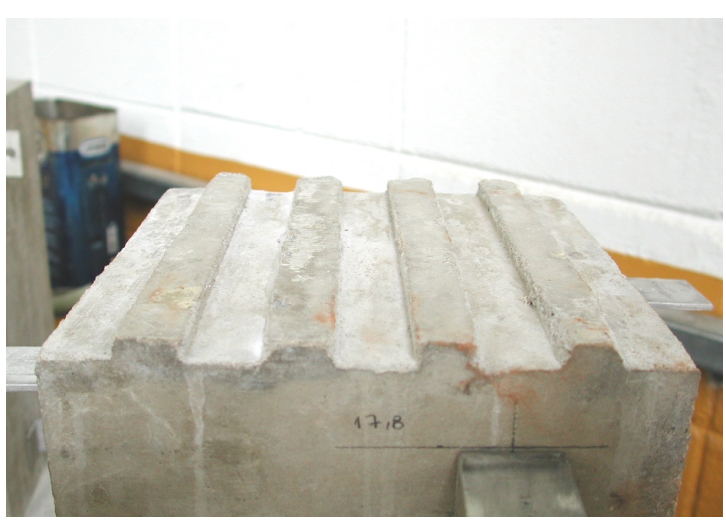

b) superfície dos modelos após a concretagem

Figura 4. 6: Forma para execução dos segmentos pré-moldados com superfície rugosa e amostra do segmento executado. 
O uso de corpos-de-prova de 100mm x $200 \mathrm{~mm}$ veio a partir de limitações existentes nas máquinas de ensaios quando era usado concreto de alta resistência. De acordo com a NBR 5738 (1994), que estabelece recomendações para moldagem e cura de corpos-de-prova, a dimensão básica escolhida deve ser maior que três vezes o diâmetro máximo do agregado usado para o concreto. No caso de corpos-de-prova cilíndricos, essa dimensão básica corresponde ao diâmetro, e a altura deve ser duas vezes esse valor.

Como na confecção dos modelos foi usado como agregado graúdo a Pedra 1, com diâmetro máximo de 19,4mm, o corpo-de-prova de dimensões $100 \mathrm{~mm} \times 200 \mathrm{~mm}$ foi adequado.

Após a moldagem os segmentos pré-moldados permaneciam na forma durante dois dias, sendo curados com uma manta de espuma molhada posicionada na parte superior. No terceiro dia, as formas eram retiradas e os segmentos eram posicionados, como na Figura 4.7, para concretagem dos anéis de reforço. O micro-concreto usado para preenchimento dos anéis era adensado, também, com vibrador de agulha. Em seguida, os segmentos eram deixados em temperatura ambiente no laboratório de ensaios, por mais dois dias.

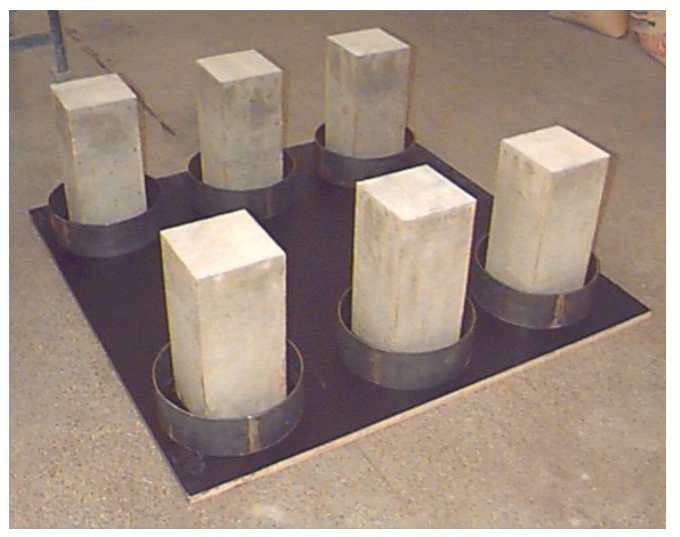

Figura 4. 7: Segmentos posicionados para concretagem dos anéis 
Para a execução da junta, foi montado um pórtico de altura regulável, como mostra a Figura 4.8, onde os segmentos eram posicionados na vertical, com um espaçamento entre eles.

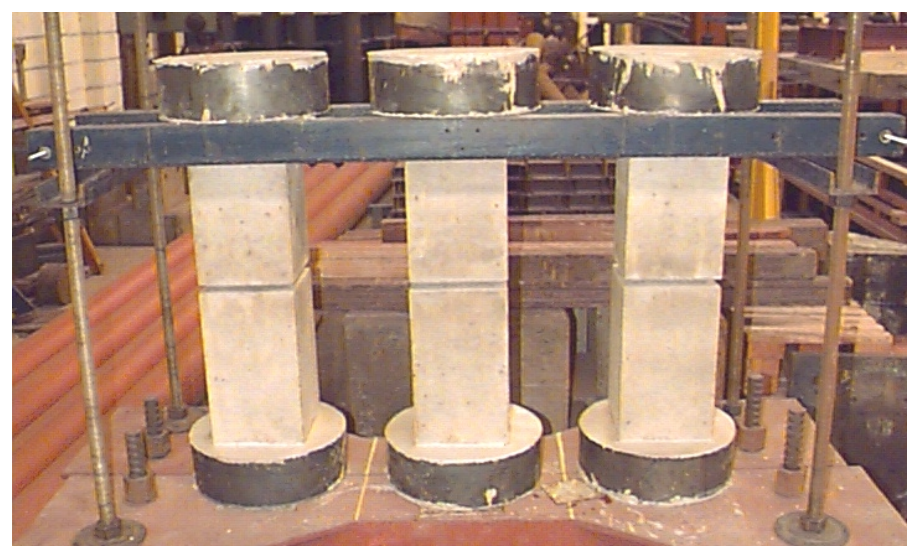

Figura 4. 8: Segmentos posicionados para execução da junta.

A execução da junta no primeiro modelo concretado foi feita usando-se uma forma de madeira na região da ligação com um furo em um dos lados para permitir a colocação do material de preenchimento. No lado oposto da forma, foi feito um outro furo para funcionar como saída de ar e evitar o aparecimento de bolhas na ligação. Essa montagem é mostrada na Figura 4.9.

Em algumas amostras percebeu-se que, se houvesse alguma inclinação na superfície dos segmentos pré-moldados, a junta não era preenchida completamente. Com isso, resolveu-se adotar uma forma acrílica que permitia visualizar o preenchimento. Um dia após a execução, a forma era retirada e o modelo permanecia em temperatura ambiente dentro do laboratório até o dia do ensaio. 


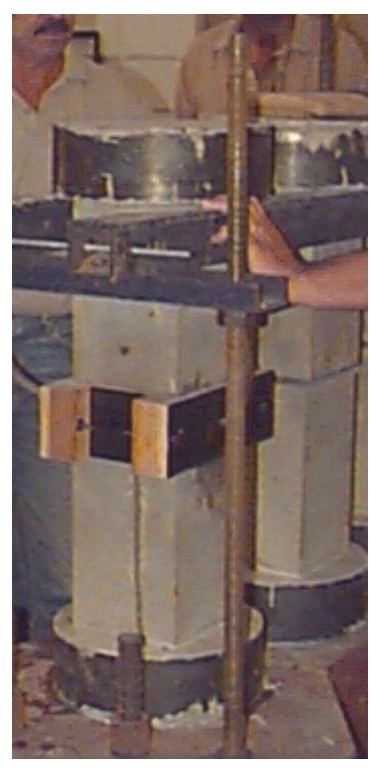

a) forma de madeira para execução da junta

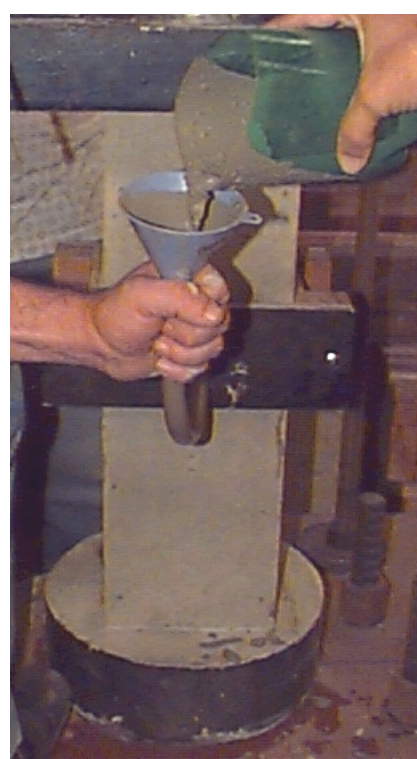

b) colocação do graute

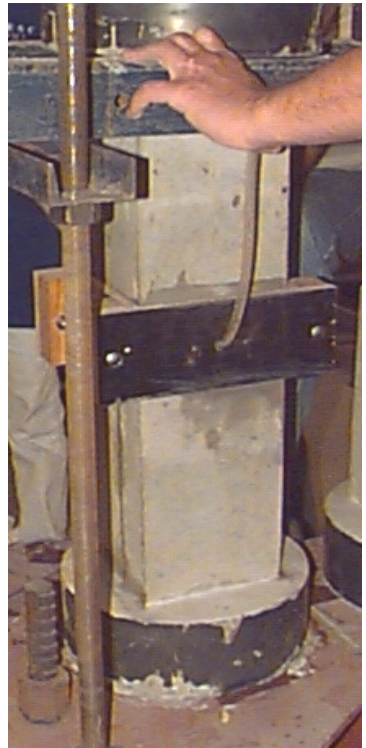

c) saída de ar para evitar o aprisionamento de bolhas

Figura 4. 9: Execução da junta de argamassa.

\subsubsection{Instrumentação dos modelos}

De forma geral, os modelos foram instrumentados com dois relógios comparadores em cada face, como mostra a Figura 4.10a, sendo um com base de medida 510mm centralizado ao longo da face e outro com base de medida 60mm posicionado próximo à junta. A numeração dos transdutores usada para o sistema de aquisição de dados é mostrada na Figura 4.10b.

Além de medir a variação global no modelo, o primeiro transdutor auxiliava a centralização do carregamento nos ensaios. Já o segundo transdutor era usado para medir a variação na espessura da camada de argamassa.

No modelo de referência, M1G15ILN-35, os transdutores de duas faces opostas, em uma das amostras, foram substituídos por extensômetros elétricos tipo strain gage KFG10, colados ao longo do comprimento, como mostrado na Figura 4.10c. Estes extensômetros tinham a finalidade de medir as deformações 
nas direções longitudinal e transversal e a partir daí caracterizar a distribuição de tensões no modelo.

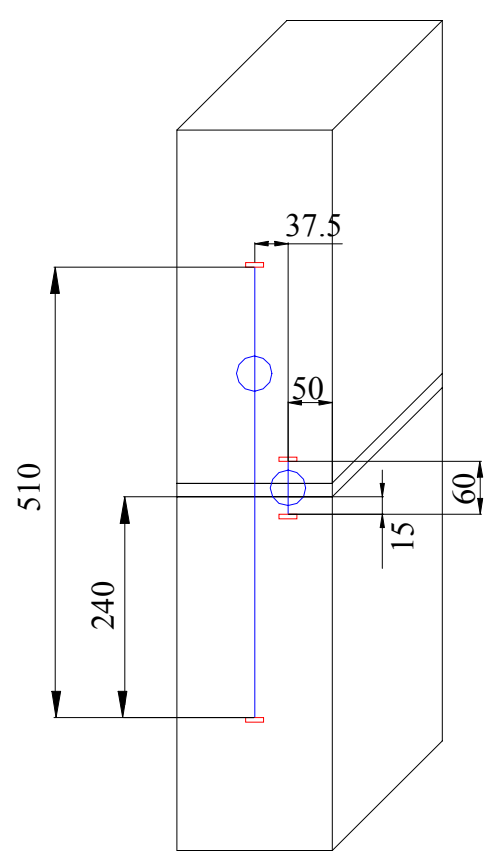

(medidas em mm)

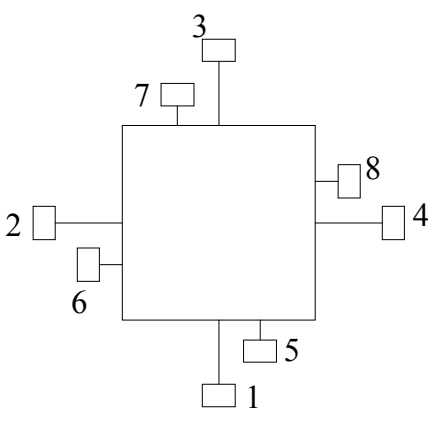

(medidas em mm)
a) Posicionamento dos
b) Numeração dos transdutores
c) Instrumentação com extensômetros

Figura 4. 10: Instrumentação dos modelos .

No modelo M7G15ILR-35 foi avaliada a influência de uma armadura de reforço, recomendada por BRUGGELING \& HUYGHE (1991), posicionada na região do elemento pré-moldado adjacente à ligação. Esta armadura de reforço, mostrada na Figura 4.11a, foi instrumentada com extensômetros elétricos tipo strain gage KFG5, como mostrado na Figura 4.11b. 


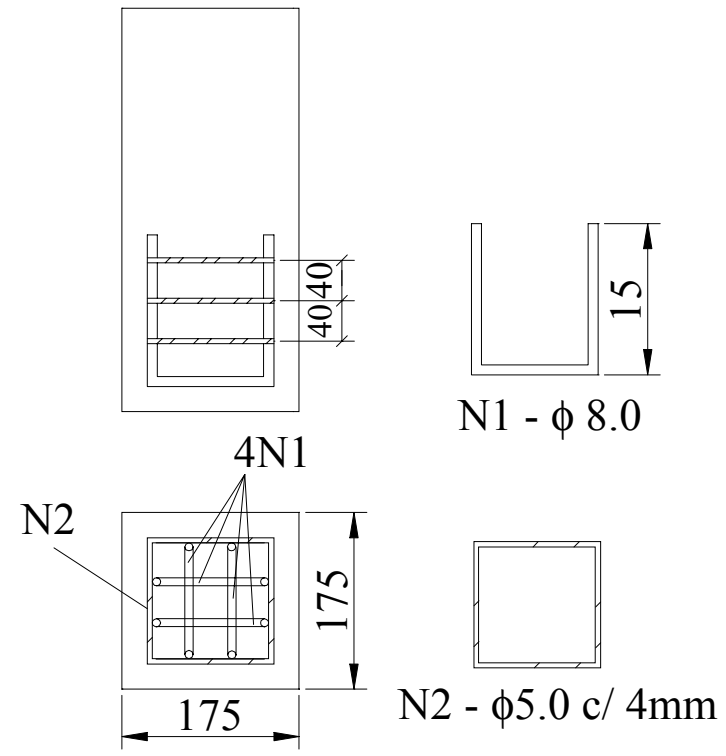

a) Armadura de reforço na região da ligação

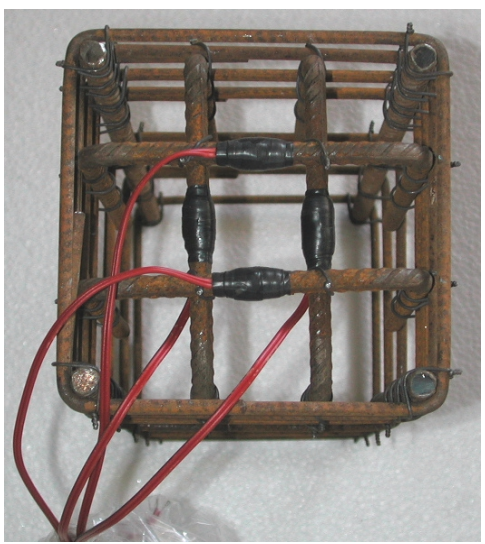

b) Instrumentação da armadura

Figura 4. 11: Detalhamento e instrumentação da armadura de reforço.

\subsubsection{Procedimentos de Ensaio}

Os modelos foram ensaiados aos 14 dias, na máquina servo-hidráulica INSTRON, com controle digital por computador, instalada no Departamento de Estruturas da EESC/USP.

Os modelos eram primeiro posicionados no eixo central da máquina, como mostra a Figura 4.12, e em seguida eram instalados os relógios comparadores. Para uniformizar a aplicação do carregamento, colocava-se uma chapa de aço na extremidade superior.

Os modelos eram ensaiados sob condições de deformação controlada a uma velocidade de $0,002 \mathrm{~mm} / \mathrm{s}$ e os resultados eram obtidos através de um sistema de aquisição de dados automático, modelo SYSTEM 5000. Antes do ensaio propriamente dito, era aplicada uma carga de $50 \mathrm{kN}$ para fazer o escorvamento do modelo e verificar a centralização do carregamento. 


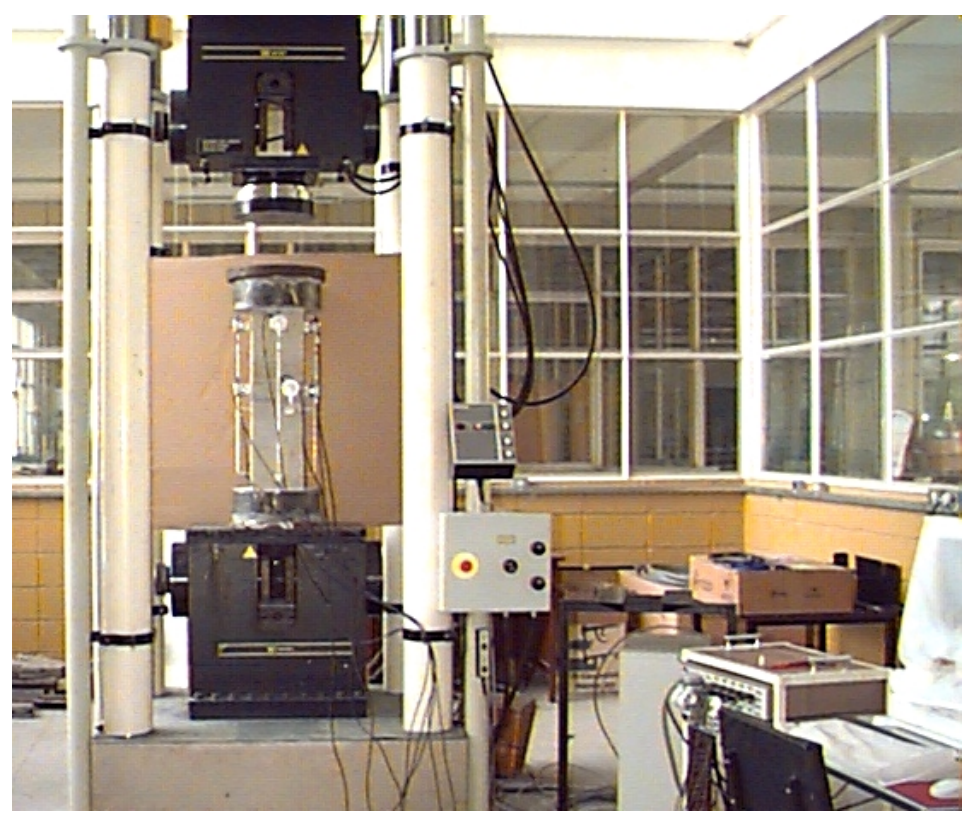

Figura 4. 12: Posicionamento dos modelos para ensaio.

\subsection{Ensaios Preliminares}

\subsubsection{Características dos Modelos}

Com a finalidade de avaliar as etapas de execução e detectar possíveis dificuldades, foram executados dois ensaios preliminares, considerando-se todos os procedimentos descritos no item anterior, executando a junta, com $15 \mathrm{~mm}$ de espessura, usando forma de madeira.

O traço adotado para o concreto usado nos elementos pré-moldados do primeiro ensaio preliminar, foi estabelecido baseado em traços usados em outras pesquisas. $\mathrm{O}$ mesmo procedimento foi feito para o concreto usado nos anéis de enrijecimento. Estes traços foram os seguintes:

- Segmentos pré-moldados

Resistência prevista: $40 \mathrm{MPa}$

Traço (em massa): $1: 1,6: 2,3: 0,42$ 
- Anéis de reforço

Resistência prevista: $60 \mathrm{MPa}$

Aditivo: REAX RX3000

Traço (em massa): $1: 2,0: 1,0: 0,4$

Para a execução da junta foi usado o graute denominado Fosgrout Plus. Inicialmente, considerou-se a dosagem recomendada pelo próprio fabricante, mostrada a seguir.

- Graute à base de cimento

Resistência prevista aos 3 dias: $30 \mathrm{MPa}$

Traço (em massa) para a mistura pronta: $1: 0,125$

O cronograma seguido para preparação do primeiro ensaio está mostrado no Quadro 4.3 e os resultados obtidos através dos corpos-de-prova para as resistências à tração e à compressão de cada material estão mostrados nas Tabelsa 4.2; 4.3 e 4.4 .

Quadro 4. 3: Cronograma de preparação para o primeiro ensaio preliminar

\begin{tabular}{|l|c|}
\hline \multicolumn{1}{|c|}{ Etapas } & Data \\
\hline Concretagem dos pilares & $06 / 04 / 00$ \\
\hline Concretagem dos anéis & $10 / 04 / 00$ \\
\hline Execução da junta & $12 / 04 / 00$ \\
\hline $\begin{array}{l}\text { Ensaio de 3 corpos-de-prova à compressão e 3 corpos-de-prova } \\
\text { à tração do concreto usado nos segmentos }\end{array}$ & $13 / 04 / 00$ \\
\hline $\begin{array}{l}\text { Ensaio dos modelos e dos 6 corpos-de-prova de concreto, } \\
\text { micro-concreto e graute }\end{array}$ & $20 / 04 / 00$ \\
\hline
\end{tabular}


Tabela 4. 2: Resistências mecânicas do concreto usado nos segmentos pré-moldados

\begin{tabular}{|c|c|c|c|c|c|}
\hline \multirow{2}{*}{ Data } & \multicolumn{2}{|c|}{ Resistência à tração $\left(\mathrm{f}_{\mathrm{t}}\right)$} & \multicolumn{2}{|c|}{ Resistência à compressão $\left(f_{c}\right)$} & \multirow{2}{*}{$\begin{array}{c}\text { Relaçãc } \\
\mathrm{f}_{\mathrm{t}} / \mathrm{f}_{\mathrm{c}} \\
\text { Média } \\
(\%)\end{array}$} \\
\hline & $\begin{array}{c}\text { Corpos-de-prova } \\
(\mathrm{MPa})\end{array}$ & $\begin{array}{l}\text { Média } \\
(\mathrm{MPa})\end{array}$ & $\begin{array}{c}\text { Corpos-de-prova } \\
(\mathrm{MPa})\end{array}$ & $\begin{array}{l}\text { Média } \\
(\mathrm{MPa})\end{array}$ & \\
\hline \multirow{3}{*}{$\begin{array}{c}7 \text { dias } \\
13 / 04 / 00\end{array}$} & 3,77 & \multirow{3}{*}{3,51} & 67,43 & \multirow{3}{*}{66,64} & \multirow{3}{*}{5,27} \\
\hline & 3,88 & & 65,14 & & \\
\hline & 2,89 & & 67,36 & & \\
\hline \multirow{3}{*}{$\begin{array}{l}14 \text { dias } \\
20 / 04 / 00\end{array}$} & 4,48 & \multirow{3}{*}{4,30} & 73,81 & \multirow{3}{*}{73,36} & \multirow{3}{*}{5,86} \\
\hline & 3,95 & & 74,02 & & \\
\hline & 4,47 & & 72,24 & & \\
\hline
\end{tabular}

Tabela 4. 3: Resistências mecânicas do concreto usado nos anéis.

\begin{tabular}{|c|c|c|c|c|c|}
\hline \multirow{2}{*}{ Data } & \multicolumn{2}{|c|}{ Resistência à tração $\left(\mathrm{f}_{\mathrm{t}}\right)$} & \multicolumn{2}{|c|}{ Resistência à compressão $\left(\mathrm{f}_{\mathrm{c}}\right)$} & $\begin{array}{c}\text { Relação } \\
\mathrm{f}_{\mathrm{t}} / \mathrm{f}_{\mathrm{c}}\end{array}$ \\
\cline { 2 - 4 } & $\begin{array}{c}\text { Corpos-de-prova } \\
(\mathrm{MPa})\end{array}$ & $\begin{array}{c}\text { Média } \\
(\mathrm{MPa})\end{array}$ & $\begin{array}{c}\text { Corpos-de-prova } \\
(\mathrm{MPa})\end{array}$ & $\begin{array}{c}\text { Média } \\
(\mathrm{MPa})\end{array}$ & $\begin{array}{c}\text { Média } \\
(\%)\end{array}$ \\
\hline \multirow{3}{*}{$20 / 04 / 00$} & 3,21 & \multirow{2}{*}{3,16} & 55,89 & \multirow{2}{*}{58,19} & \multirow{2}{*}{5,43} \\
\cline { 2 - 2 } & 2,95 & 59,70 & 58,99 & \\
\cline { 2 - 3 } & 3,31 & & &
\end{tabular}

Tabela 4. 4: Resistências mecânicas do graute.

\begin{tabular}{|c|c|c|c|c|c|}
\hline \multirow{2}{*}{ Data } & \multicolumn{2}{|c|}{ Resistência à tração $\left(\mathrm{f}_{\mathrm{tm}}\right)$} & \multicolumn{2}{|c|}{ Resistência à compressão $\left(\mathrm{f}_{\mathrm{m}}\right)$} & $\begin{array}{c}\text { Relação } \\
\mathrm{f}_{\mathrm{tm}} / \mathrm{f}_{\mathrm{m}}\end{array}$ \\
\cline { 2 - 2 } & $\begin{array}{c}\text { Corpos-de-prova } \\
(\mathrm{MPa})\end{array}$ & $\begin{array}{c}\text { Média } \\
(\mathrm{MPa})\end{array}$ & $\begin{array}{c}\text { Corpos-de-prova } \\
(\mathrm{MPa})\end{array}$ & $\begin{array}{c}\text { Média } \\
(\mathrm{MPa})\end{array}$ & $\begin{array}{c}\text { Média } \\
(\%)\end{array}$ \\
\hline \multirow{3}{*}{$20 / 04 / 00$} & 2,80 & \multirow{2}{*}{4,17} & 59,91 & & \multirow{2}{*}{56,29} \\
\cline { 2 - 2 } & 4,58 & 54,33 & 7,41 \\
\cline { 2 - 2 } & 5,12 & 54,63 & \\
\end{tabular}

Com os resultados obtidos com os corpos-de-prova, observou-se que a dosagem do concreto utilizada para os segmentos pré-moldados, bem como para o graute, resultaram valores muito altos para as resistências. Nos modelos definitivos, deveriam ser feitos alguns ajustes.

Para a segunda amostra, então, resolveu-se usar na junta uma mistura mais fluida, para diminuir a resistência à compressão do material. $\mathrm{O}$ traço adotado para a mistura foi o seguinte: 
- Graute à base de cimento

Traço (em massa) para a mistura pronta: $1: 0,137$

As resistências mecânicas encontradas aos 8 dias de idade para a segunda mistura estão mostradas na Tabela 4.5.

Tabela 4. 5: Características mecânicas do graute

\begin{tabular}{|c|c|c|c|c|c|}
\hline \multirow{2}{*}{ Data } & \multicolumn{2}{|c|}{ Resistência à tração $\left(\mathrm{f}_{\mathrm{tm}}\right)$} & \multicolumn{2}{|c|}{ Resistência à compressão $\left(\mathrm{f}_{\mathrm{m}}\right)$} & $\begin{array}{c}\text { Relação } \\
\mathrm{f}_{\mathrm{tm}} / \mathrm{f}_{\mathrm{m}}\end{array}$ \\
\cline { 2 - 4 } & $\begin{array}{c}\text { Corpos-de-prova } \\
(\mathrm{MPa})\end{array}$ & $\begin{array}{c}\text { Média } \\
(\mathrm{MPa})\end{array}$ & $\begin{array}{c}\text { Corpos-de-prova } \\
(\mathrm{MPa})\end{array}$ & $\begin{array}{c}\text { Média } \\
(\mathrm{MPa})\end{array}$ & $\begin{array}{c}\text { Média } \\
(\%)\end{array}$ \\
\hline \multirow{3}{*}{$12 / 05 / 00$} & 3,47 & \multirow{2}{*}{2,76} & 34,46 & \multirow{2}{*}{32,66} & \multirow{2}{*}{8,45} \\
\cline { 2 - 2 } & 1,59 & 30,57 & 32,96 & \\
\cline { 2 - 2 } & 3,21 & & &
\end{tabular}

Na primeira amostra a relação $f_{m} / f_{c}$ foi igual a 0,77 e na segunda amostra a relação foi 0,45 .

\subsubsection{Resultados dos Ensaios}

Como dito anteriormente, os transdutores posicionados no meio da face dos modelos, ao longo do comprimento, serviriam como referência para centralização do carregamento. Nos ensaios preliminares, observou-se desde o início, que havia um certo desnível na superfície superior e isso geraria então uma certa flexão nos modelos.

No ensaio da primeira amostra, mesmo tendo aplicado o carregamento com controle de deslocamento, o modelo teve uma ruptura brusca devido à alta resistência do concreto pré-moldado. O processo de ruptura teve início na aresta mais solicitada do segmento pré-moldado superior, com rápida expansão através da ligação para o segmento inferior. 
Devido à ação de tensões de fendilhamento, verificou-se um acentuado destacamento do cobrimento de concreto nos segmentos pré-moldados. Observou-se também, que não houve fissuração nas extremidades, mostrando então a eficiência do reforço.

No ensaio da segunda amostra, observou-se que não houve ruptura brusca e que ela iniciou-se com o descolamento da camada externa da junta de argamassa. Dessa forma, a região de ruptura ficou restrita às proximidades da junta e não houve destacamento acentuado do cobrimento nos segmentos prémoldados. A configuração de ruína das amostras é mostrada nas Figuras 4.13 e 4.14 .

Com os resultados obtidos no ensaio, através dos relógios comparadores, foram traçados os gráficos mostrados na Figura 4.15. Nesses gráficos tem-se a média dos encurtamentos na região da junta de argamassa, considerando os relógios de base $60 \mathrm{~mm}$, e a média dos encurtamentos da amostra considerando os relógios de base $510 \mathrm{~mm}$. As leituras individuais de cada relógio podem ser vistas no apêndice.

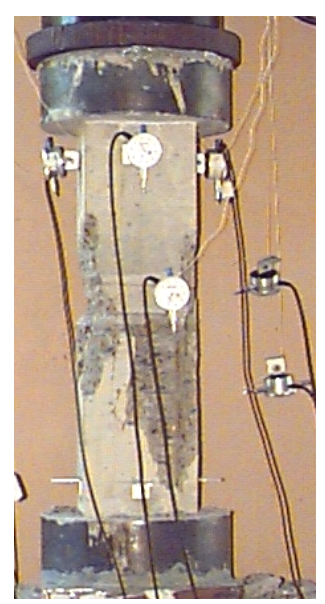

a) configuração de ruína.

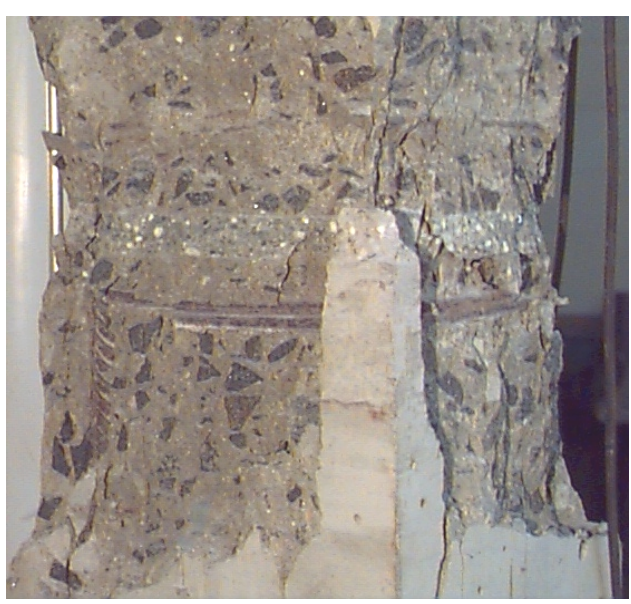

b) detalhe da região da ligação.

Figura 4. 13: Configuração de ruína do primeiro ensaio preliminar. 


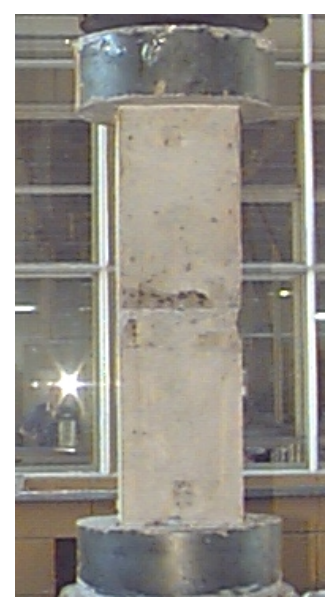

a) configuração de ruína.

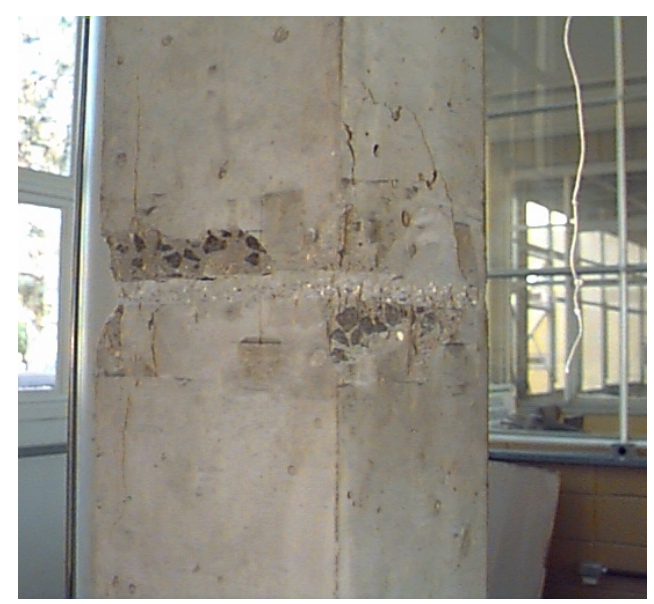

b) detalhe da região da ligação.

Figura 4. 14: Configuração de ruína do segundo ensaio preliminar.

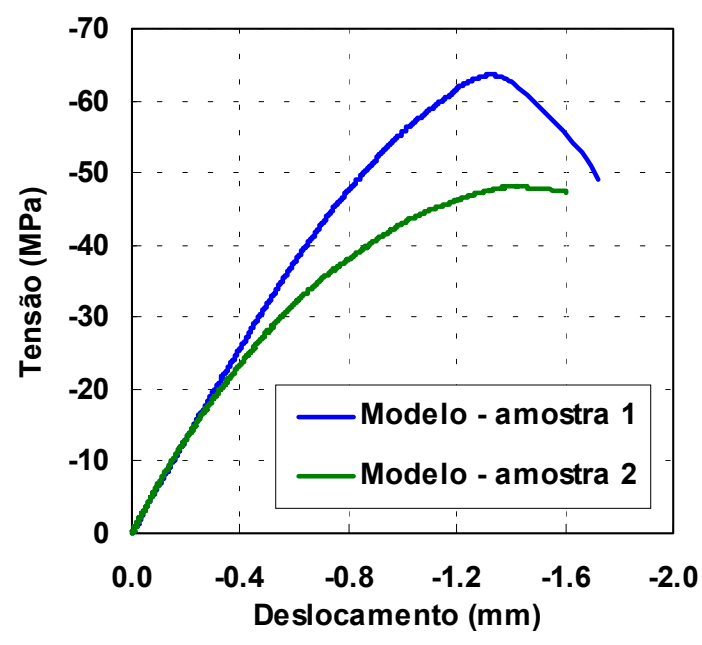

a) modelo

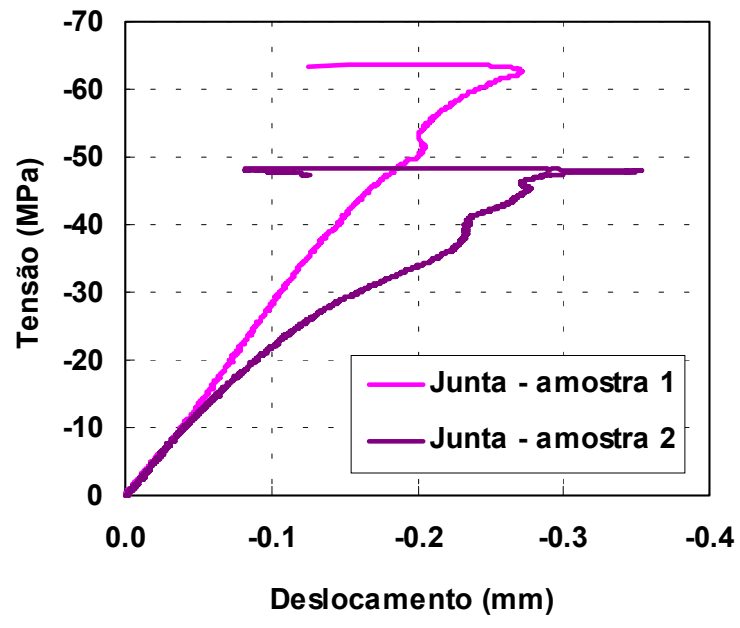

b) junta

Figura 4. 15: Diagrama Tensão x Média dos Encurtamentos

A tensão última para a amostra 1 , na qual a relação $f_{m} / f_{c}$ é igual a 0,79 , foi $63,6 \mathrm{MPa}$. Esta tensão é inferior à resistência à compressão do concreto usado nos segmentos pré-moldados, mas é maior que a resistência à compressão obtida para o graute. Já para a amostra 2 , na qual a relação $f_{m} / f_{c}$ é igual a 0,44 , a tensão última foi $48,2 \mathrm{MPa}$. Esta tensão é maior que resistência à compressão do graute usado na junta. 
O módulo de elasticidade aparente do modelo, para $40 \%$ da tensão última atingida, foi 32785MPa na amostra 1 e 31157MPa na amostra 2. Para a junta de argamassa, este valor foi 16841MPa na amostra 1 e $13544 \mathrm{MPa}$ na amostra 2.

Calculando-se a deformabilidade da ligação, no início da fissuração, como sendo a relação entre o deslocamento relativo entre os elementos e a tensão solicitante na direção desse deslocamento, este valor para a amostra 1

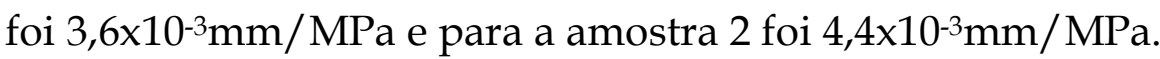

\subsubsection{Análise dos Resultados}

Com os gráficos mostrados na Figura 4.15, pode-se observar a deformabilidade diferenciada da junta de argamassa nas duas amostras. Podese perceber a influência da resistência da argamassa na capacidade resistente da ligação, bem como na configuração de ruína.

Para a amostra 1, a relação entre a resistência do graute e a tensão última atingida vale 0,88 . Este valor representa um acréscimo de resistência igual a $12 \%$, provavelmente advindo do efeito de confinamento exercido pelos elementos pré-moldados.

Para a amostra 2, a relação entre a resistência do graute e a tensão última atingida vale 0,68. Esta relação dá um acréscimo de resistência à ligação de $32 \%$, quase 3 vezes mais que no anterior.

Reduzindo-se a resistência do graute em $42 \%$ houve uma redução de $24 \%$ na tensão última, entretanto o efeito de confinamento exercido pelos elementos pré-moldados para aumentar a resistência da ligação, foi mais significativo. Além disso, a região de ruína ficou mais limitada à região da ligação.

Com os dados experimentais obtidos para as características mecânicas 
das duas amostras, determinou-se a carga última teórica resistida pelo elemento pré-moldado, através da Equação 4.1. Comparando-se o valor obtido através dessa equação, com a carga de ruptura dos ensaios obtém-se uma perda de $13,0 \%$ para a primeira amostra 1 e de $34,0 \%$ para a amostra 2 .

$$
P_{u}=A_{c} \cdot f_{c}
$$

onde: $\mathrm{P}_{\mathrm{u}}$ - carga de ruptura teórica;

$$
\begin{aligned}
& A_{c} \text { - área total de concreto; } \\
& f_{c} \text { - resistência à compressão do concreto; }
\end{aligned}
$$

Segundo EL DEBS (2001), para efeito de projeto, a deformabilidade da ligação pode ser incorporada no elemento pré-moldado substituindo-se o módulo de elasticidade $E_{c}$ do concreto por um módulo de elasticidade equivalente definido na Equação 4.2. Nesse procedimento, os elementos ligados pela junta de argamassa são substituídos por um elemento equivalente, como mostra a Figura 4.16.

$$
\mathrm{E}_{\mathrm{e}}=\frac{1}{\frac{1}{\mathrm{E}_{\mathrm{c}}}+\frac{\mathrm{D}_{\mathrm{m}}}{\mathrm{h}_{\mathrm{j}}}}
$$

onde: $h_{j}$ - espessura da junta;

$D_{m}$ - deformabilidade da junta de argamassa;

$\mathrm{E}_{\mathrm{c}}$ - módulo de elasticidade do concreto pré-moldado;

O valor do módulo de elasticidade indicado pela norma norueguesa NS 3473E (1992) para concreto de alta resistência é definido pela Equação 4.3. 
Aplicando-se essa equação ao concreto usado para os segmentos prémoldados, tem-se um módulo de elasticidade igual a 34469MPa.

$$
E_{c}=9500 .\left(f_{c}\right)^{0,3}
$$
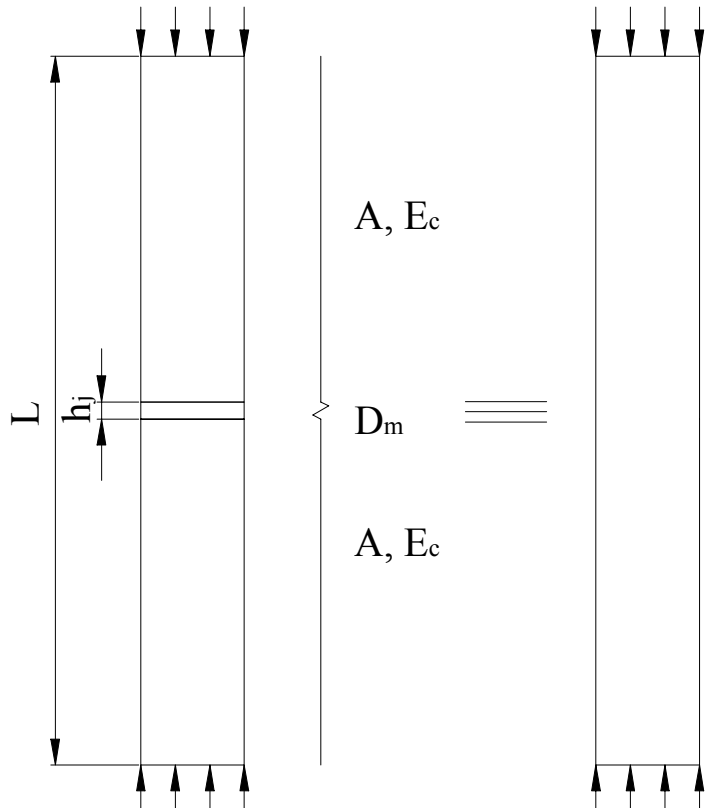

$\mathrm{A}, \mathrm{Ee}$

Figura 4. 16: Incorporação da deformabilidade da junta de argamassa no elemento pré-moldado. Fonte EL DEBS (2001).

Aplicando-se a Equação 4.2 nas amostras ensaiadas, com junta de $15 \mathrm{~mm}$ de espessura, comprimento total de $815 \mathrm{~mm}$ e deformabilidade total da junta obtida nos ensaios, tem-se:

$$
\begin{aligned}
& E_{e}=29915 \mathrm{MPa} \text { para a amostra } 1 \\
& E_{e}=29061 \mathrm{MPa} \text { para a amostra } 2
\end{aligned}
$$

Comparando-se esses valores com os valores dos módulos de elasticidade equivalente experimentais, tem-se uma redução de $15,2 \%$ para a amostra 1 e de $18,6 \%$ para a amostra 2 . 
O processo de execução dos modelos também foi analisado nos ensaios preliminares e detectadas suas falhas. A principal delas relacionava-se ao fato de que a superfície dos elementos pré-moldados não era perfeitamente plana e isso interferia no preenchimento da junta. Havendo falhas no preenchimento, a ligação ficava mais flexível e conseqüentemente menos resistente. Procurouse então diminuir esse efeito nos modelos definitivos descritos no programa experimental.

\subsection{Ensaios dos Modelos}

\subsubsection{Dosagem das Misturas}

A dosagem adotada para a execução dos segmentos pré-moldados de cada modelo, bem como para o preenchimento dos anéis metálicos e da junta estão especificadas na descrição de cada modelo, no apêndice. A dosagem do material de preenchimento da junta foi estabelecida seguindo-se recomendações do fabricante.

\subsubsection{Resultados dos Ensaios}

As resistências à compressão e à tração do concreto dos elementos prémoldados, bem como do concreto de preenchimento dos anéis e do material de preenchimento da junta, estão mostradas na Tabela 4.6. Para o material de preenchimento da junta estes valores foram determinados usando-se corposde-prova cilíndricos de 50mm x 100mm.

Verificou-se uma grande variação nos valores encontrados, apesar de usar sempre a mesma dosagem e os mesmos materiais. Entretanto, percebeuse que durante o inverno o concreto ficava mais fluido e que dependendo do lote de cimento usado tinha-se um acréscimo de resistência. 
Tabela 4. 6: Resistências dos concretos e argamassas usados nos modelos.

\begin{tabular}{|l|c|c|c|c|c|c|}
\hline \multicolumn{1}{|c|}{ Modelo } & $\mathrm{f}_{\mathrm{c}}(\mathrm{MPa})$ & $\mathrm{f}_{\mathrm{t}}(\mathrm{MPa})$ & $\mathrm{f}_{\mathrm{ca}}(\mathrm{MPa})$ & $\mathrm{f}_{\mathrm{ta}}(\mathrm{MPa})$ & $\mathrm{f}_{\mathrm{m}}(\mathrm{MPa})$ & $\mathrm{f}_{\mathrm{tm}}(\mathrm{MPa})$ \\
\hline M1G15ILN-35 & 32,5 & 2,4 & 63,7 & 4,3 & 29,0 & 2,9 \\
\hline M2G22ILN-35 & 44,4 & 3,7 & 58,9 & 3,8 & 33,8 & 2,6 \\
\hline M3G30ILN-35 & 35,1 & 4,1 & 63,8 & 3,8 & 25,7 & 3,6 \\
\hline M4G15MLN-35 & 36,6 & 3,4 & 58,0 & 4,0 & 31,9 & 2,9 \\
\hline M5G15SLN-35 & 33,9 & 4,2 & 60,5 & 3,9 & 80,0 & 4,5 \\
\hline M6G15ILN-60 & 67,9 & 4,2 & 61,2 & 3,8 & 25,3 & 1,8 \\
\hline M7G15ILR-35 & 29,5 & 1,2 & 52,3 & 2,7 & 29,0 & 2,9 \\
\hline M8AF15SLN-35 & 33,2 & 3,3 & 60,6 & 4,4 & - & - \\
\hline M8AF15SLN-60 & 73,4 & 5,9 & 58,2 & 5,4 & - & - \\
\hline M9AF15SRN-35 & 30,6 & 3,3 & 64,2 & 3,9 & - & - \\
\hline M10DP15SLN-35 & 40,0 & 4,3 & 59,9 & 4,4 & 50,4 & 4,3 \\
\hline M11SLN-35 & 30,5 & 3,3 & 54,5 & 4,5 & - & - \\
\hline M12SRN-35 & 30,6 & 3,3 & 64,2 & 3,9 & - & - \\
\hline M13SLN-60 & 56,5 & 3,7 & 65,1 & 3,8 & - & - \\
\hline M14SRN-60 & 56,5 & 3,7 & 65,1 & 3,8 & - & - \\
\hline
\end{tabular}

No modelo M8AF15SLN-35 foi usada uma almofada de apoio feita com argamassa de cimento Portland, modificada com látex de estirenobutadieno e adição de fibras de polipropileno, que apresentou boa resistência à compressão e baixo módulo de elasticidade. A dosagem de materiais usada na mistura foi a seguinte:

\begin{tabular}{|c|c|c|c|c|}
\hline Cimento & Areia & Látex & Água & Fibra \\
\hline 1 & 0,3 & 0,3 & 0,1 & $1 \%$ \\
\hline
\end{tabular}

Esta mistura apresentou resistência à compressão de 40,3MPa, resistência à tração de $3,6 \mathrm{MPa}$ e módulo de elasticidade de $7200 \mathrm{MPa}$. No modelo M9AF15SRN-35, adotou-se esta mesma mistura.

No modelo M8AF15SLN-60 foi usada uma almofada de apoio feita com uma argamassa de cimento Portland, modificada com látex de estirenobutadieno e adição de fibras de PVA. A dosagem dos materiais na mistura foi a seguinte: 


\begin{tabular}{|c|c|c|c|c|}
\hline Cimento & Areia & Látex & Água & Fibra \\
\hline 1 & 0,3 & 0,3 & 0,1 & $4 \%$ \\
\hline
\end{tabular}

Por ser menos flexível foi possível usar uma quantidade maior de fibra de PVA na mistura. Esta mistura apresentou resistência à compressão de $27,0 \mathrm{MPa}$, resistência à tração de $4,0 \mathrm{MPa}$ e módulo de elasticidade de $11812 \mathrm{MPa}$.

Com os dados obtidos no ensaio de cada amostra, determinou-se a carga última para cada modelo como uma média dos valores obtidos nas amostras. Estes valores determinados foram comparados com valores obtidos com a Equação 4.1, que representa a capacidade resistida pelo concreto e com a Equação 2.12 definida por VAMBERSKY (1990), como mostra a Tabela 4.7.

Tabela 4. 7: Comparativo entre a carga última experimental e valores teóricos.

\begin{tabular}{|l|c|c|c|c|c|}
\hline \multicolumn{1}{|c|}{ Modelo } & $\begin{array}{c}\text { Relaçã } \\
\text { o fm/ }_{\mathrm{c}}\end{array}$ & $\begin{array}{c}\text { Carga } \\
\text { última - } \\
\mathrm{P}_{\text {exp }}(\mathrm{kN})\end{array}$ & $\begin{array}{c}\text { Carga } \\
\text { teórica } \\
\mathrm{P}_{\text {teo }}(\mathrm{kN})\end{array}$ & $\mathrm{P}_{\text {exp }} / \mathrm{P}_{\text {teo }}$ & $\begin{array}{c}\text { VAMBERSKY } \\
(1990) \\
(\mathrm{kN})\end{array}$ \\
\hline M1G15ILN-35 & 0,75 & 956,6 & 995,3 & 0,96 & 1002,1 \\
\hline M2G22ILN-35 & 0,76 & 1292,5 & 1359,7 & 0,95 & 1193,1 \\
\hline M3G30ILN-35 & 0,73 & 855,5 & 1075,0 & 0,8 & 920,5 \\
\hline M4G15MLN-35 & 0,90 & 873,1 & 1120,9 & 0,78 & 1002,1 \\
\hline M5G15SLN-35 & 2,36 & 1089,4 & 1038,2 & 1,05 & 922,7 \\
\hline M6G15ILN-60 & 0,40 & 1210,3 & 2079,4 & 0,58 & 1754,8 \\
\hline M7G15ILR-35 & 1,00 & 713,7 & 903,4 & 0,79 & 810,3 \\
\hline M8AF15SLN-35 & 1,21 & 862,0 & 1016,7 & 0,85 & - \\
\hline Polipropileno) & & & & & - \\
\hline M8AF15SLN-60 (PVA) & 0,37 & 996,1 & 2247,8 & 0,44 & - \\
\hline M9AF15SRN-35 & 1,13 & 679,6 & 937,1 & 0,75 & 857,4 \\
\hline M10DP15SLN-35 & 1,26 & 1183,4 & 1261,1 & 0,94 & - \\
\hline M11SLN-35 & - & 831,8 & 970,9 & 0,86 & - \\
\hline M12SRN-35 & - & 744,3 & 974,0 & 0,76 & - \\
\hline M13SLN-60 & - & 947,2 & 1765,1 & 0,54 & - \\
\hline M14SRN-60 & - & 852,8 & 1765,1 & 0,48 & \\
\hline
\end{tabular}

Para cada modelo, determinou-se um diagrama tensão $\mathrm{x}$ deslocamento médio, com a finalidade de avaliar a deformabilidade da junta de argamassa e 
a deformabilidade aparente do modelo. Estes diagramas, bem como a configuração de ruína dos modelos, estão mostrados nas Figuras 4.17 a 4.42.

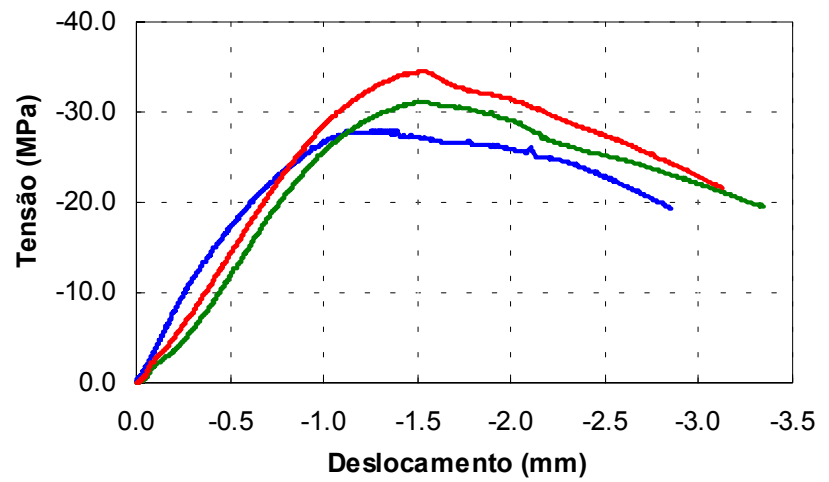

Média - Amostra 1 —Média -Amostra 2 —Média - Amostra 3

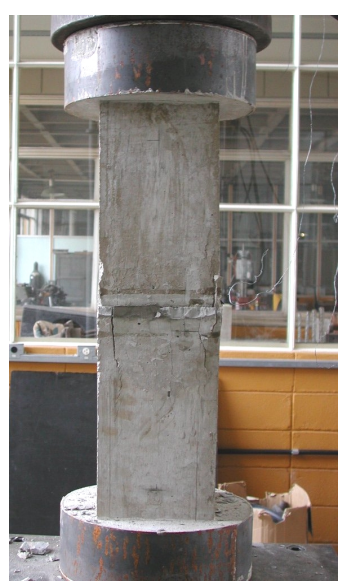

Figura 4. 17: Diagrama tensão x deslocamento do modelo M1G15ILN-35 e configuração de ruína.

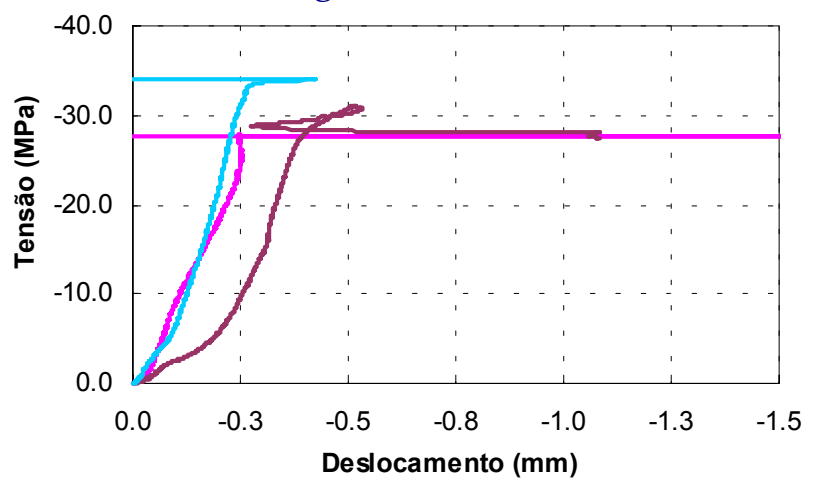

—Média - Junta 1 Média - Junta 2 Média - Junta 3

Figura 4. 18: Diagrama tensão $\mathrm{x}$ deslocamento da junta de argamassa no modelo M1G15ILN-35.
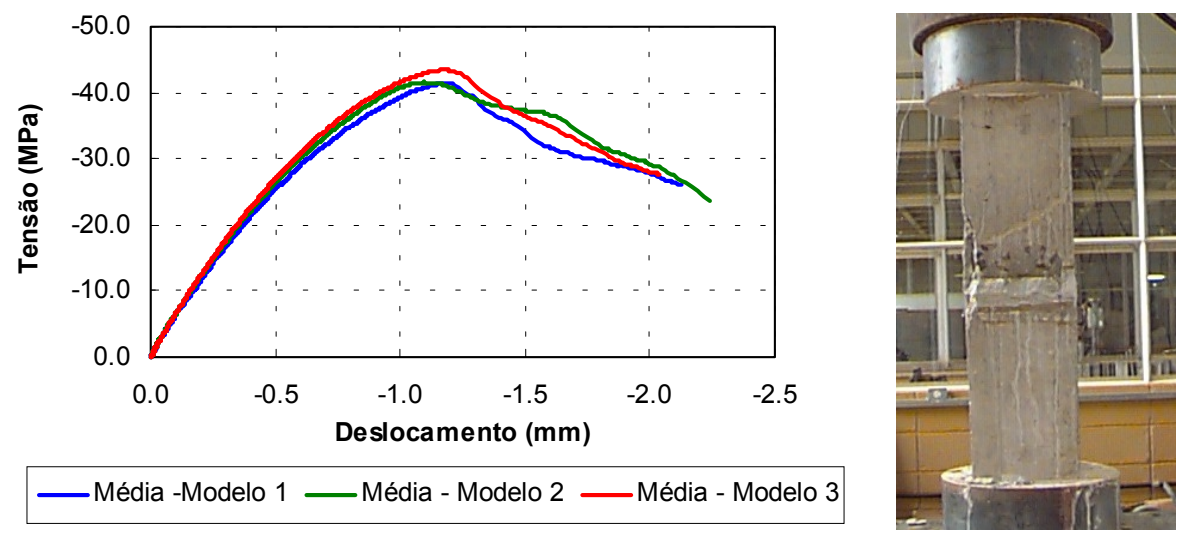

Figura 4. 19: Diagrama tensão $x$ deslocamento do modelo M2G22ILN-35 e configuração de ruína. 


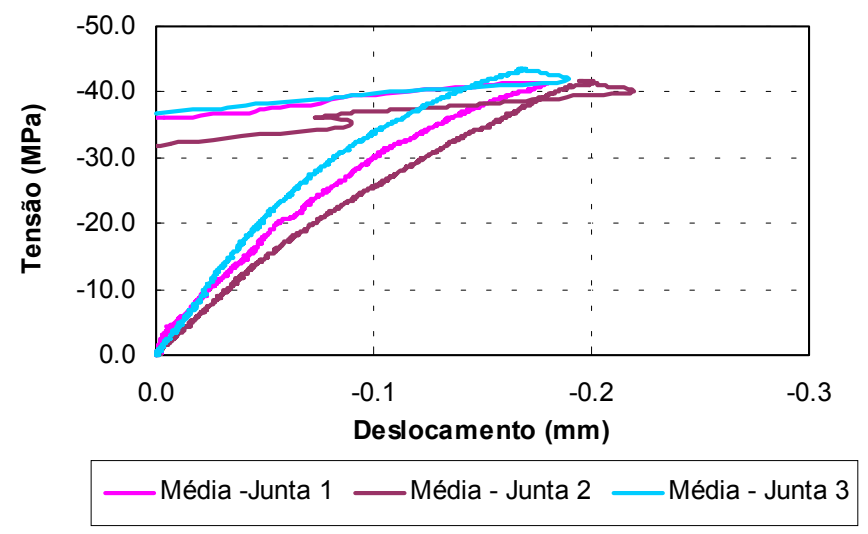

Figura 4. 20: Diagrama tensão $x$ deslocamento da junta de argamassa no modelo M2G22ILN-35.
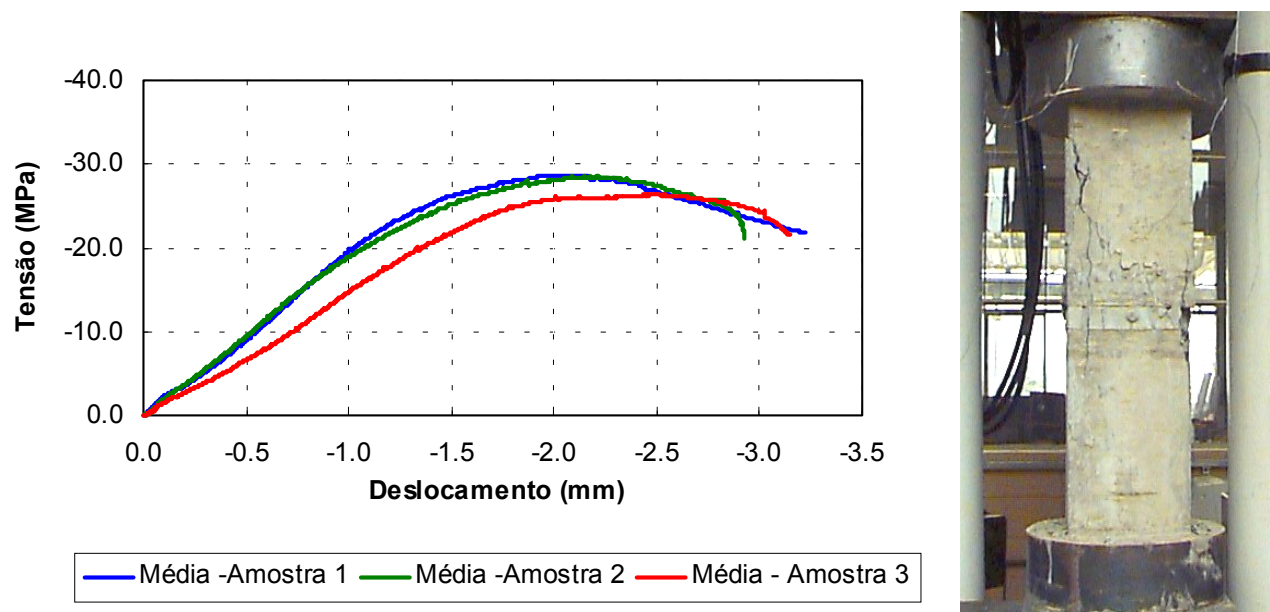

Figura 4. 21: Diagrama tensão x deslocamento do modelo M3G30ILN-35 e configuração de ruína.

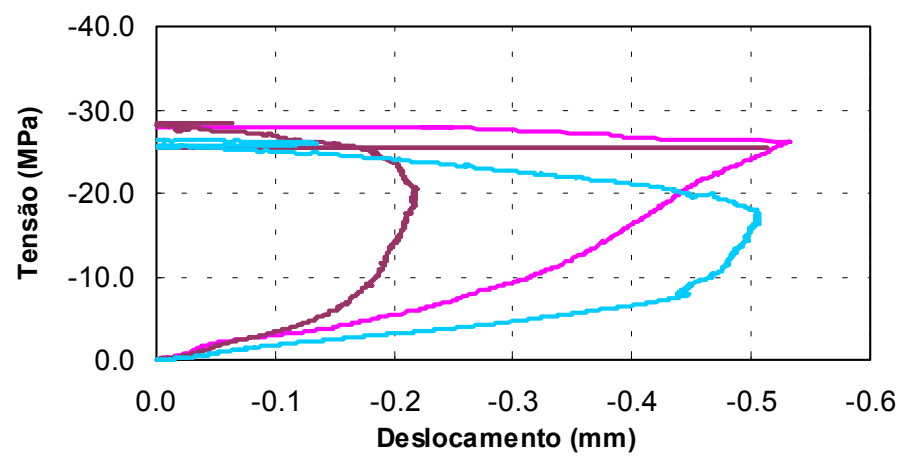

—Média - Junta 1 Média - Junta 2 Média - Junta 3

Figura 4. 22: Diagrama tensão x deslocamento da junta de argamassa no modelo M3G30ILN-35. 


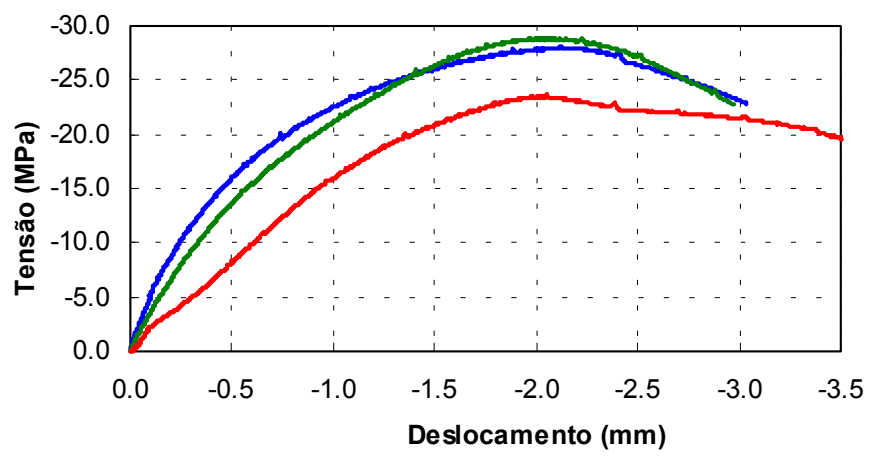

—Média - Amostra 1 - Média - Amostra 2 -Média - Amostra 3

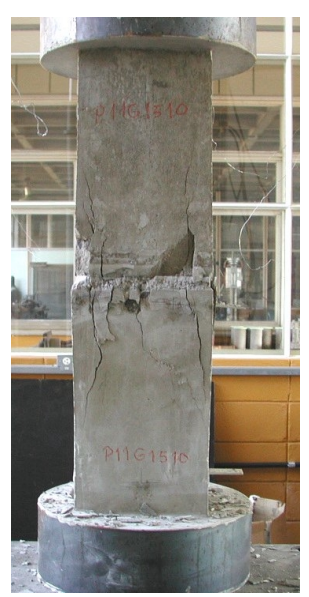

Figura 4. 23: Diagrama tensão x deslocamento do modelo M4G15MLN-35 e configuração de ruína.

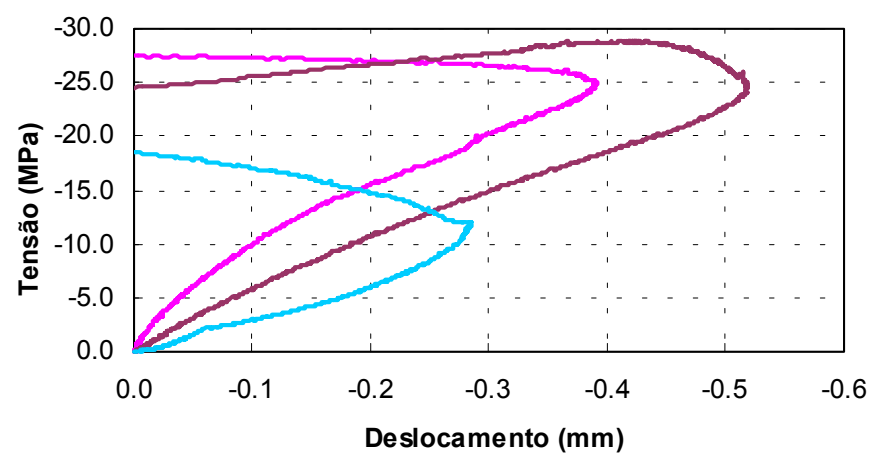

Média - Junta 1 Média - Junta 2 Média - Junta 3

Figura 4. 24: Diagrama tensão $x$ deslocamento da junta de argamassa no modelo M4G15MLN-35.
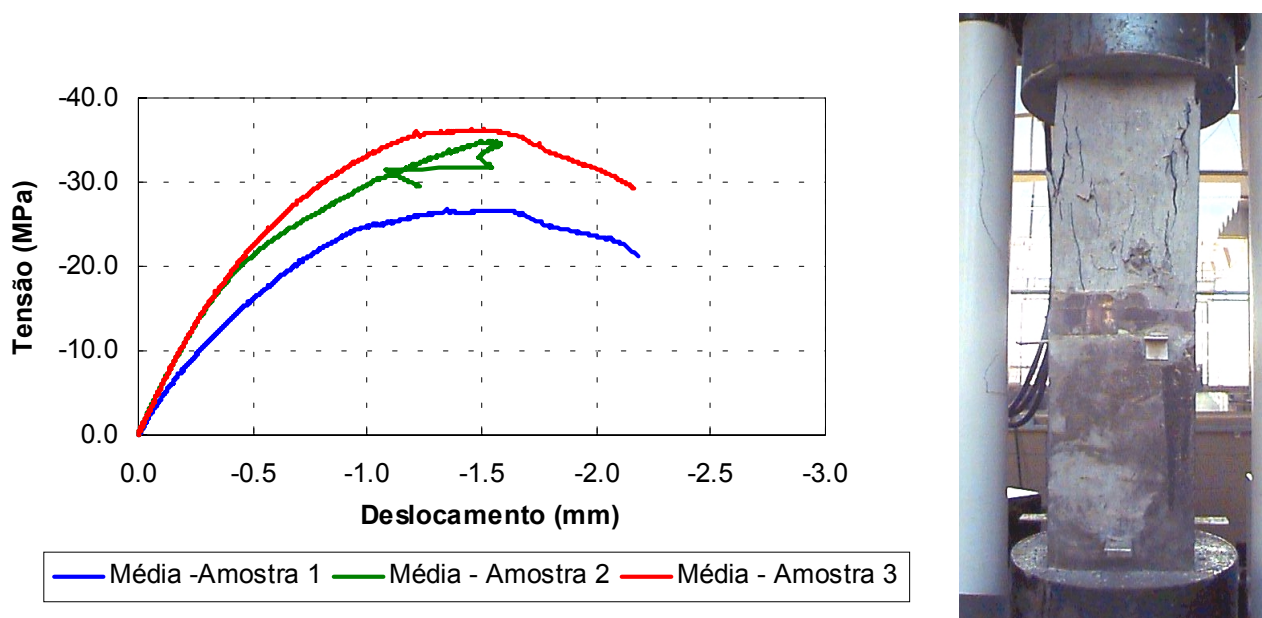

Figura 4. 25: Diagrama tensão x deslocamento do modelo M5G15SLN-35 e configuração de ruína. 


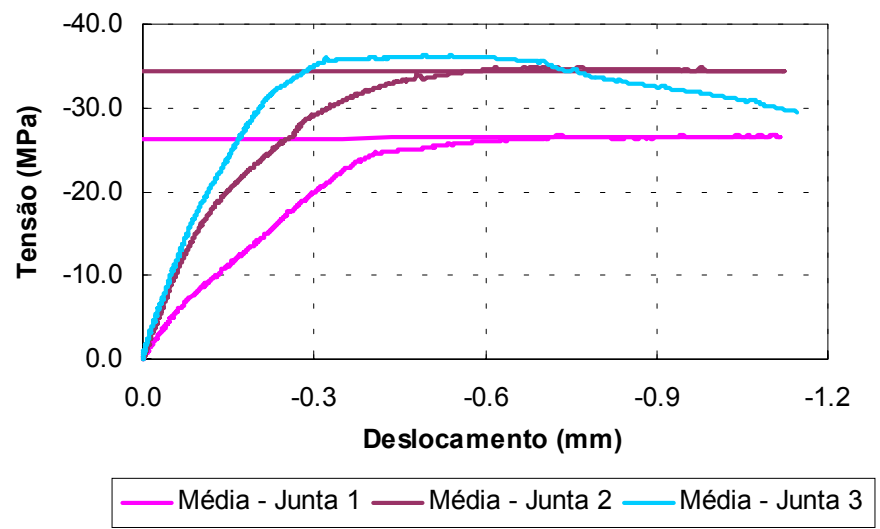

Figura 4. 26: Diagrama tensão $x$ deslocamento da junta de argamassa no modelo M5G15SLN-35.

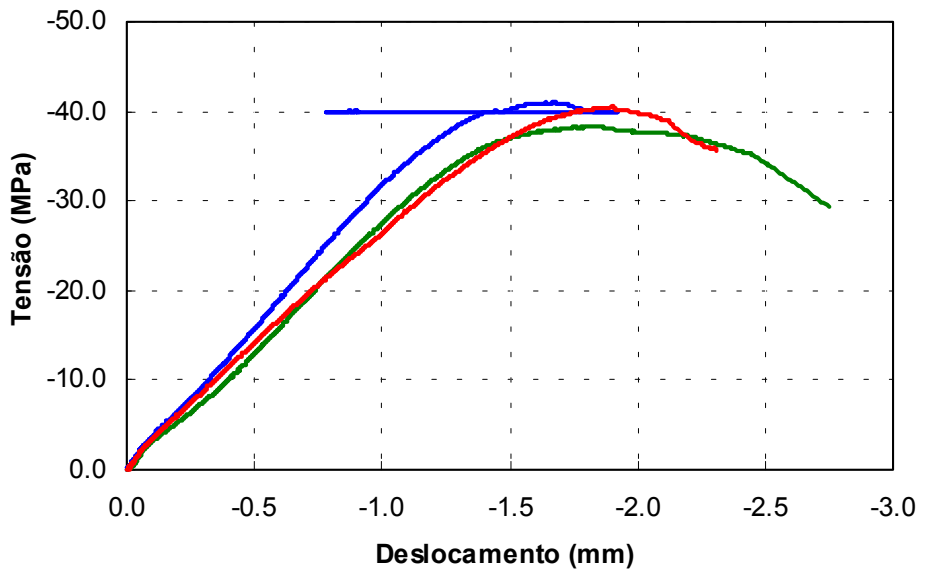

Média -Amostra 1 -Média - Amostra 2 Média - Amostra 3

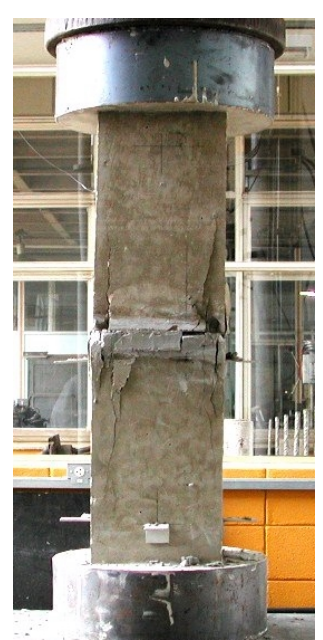

Figura 4. 27: Diagrama tensão x deslocamento do modelo M6G15ILN-60 e configuração de ruína.

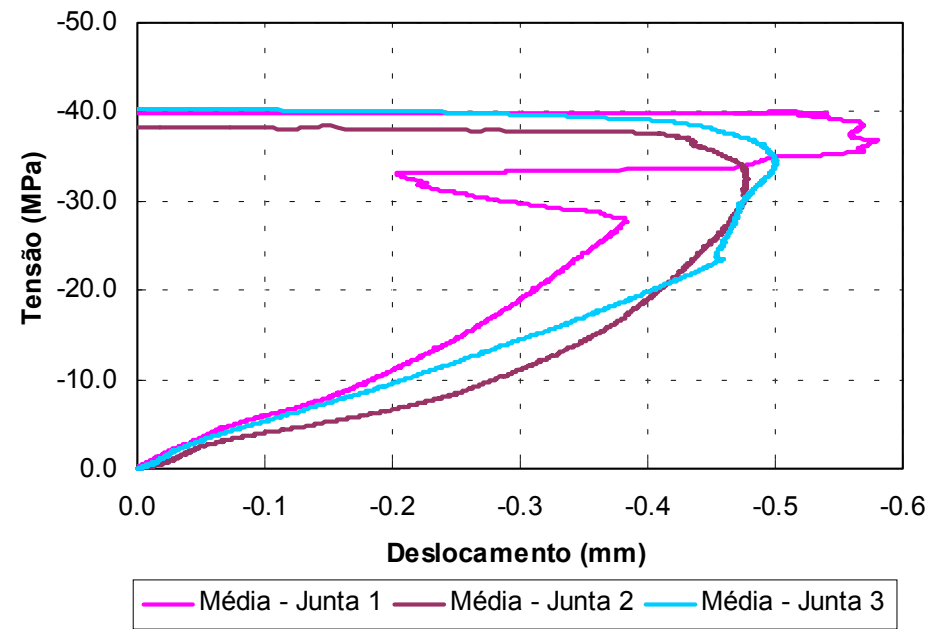

Figura 4. 28: Diagrama tensão x deslocamento da junta de argamassa no modelo M6G15ILN-60. 


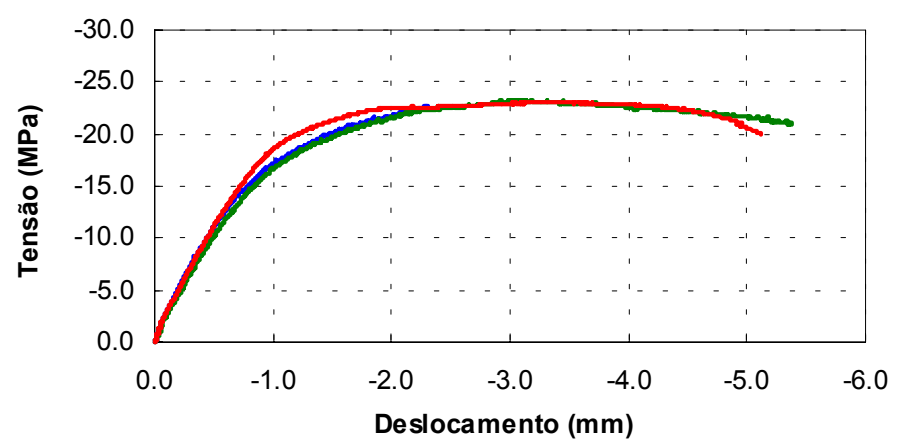

Média - Amostra 1 -Média - Amostra 2 Média -Amostra 3

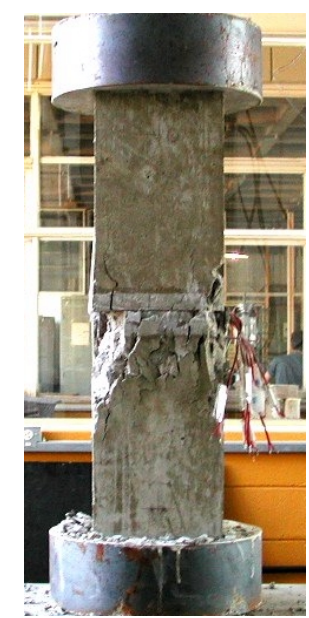

Figura 4. 29: Diagrama tensão x deslocamento do modelo M7G15ILR-35 e configuração de ruína.

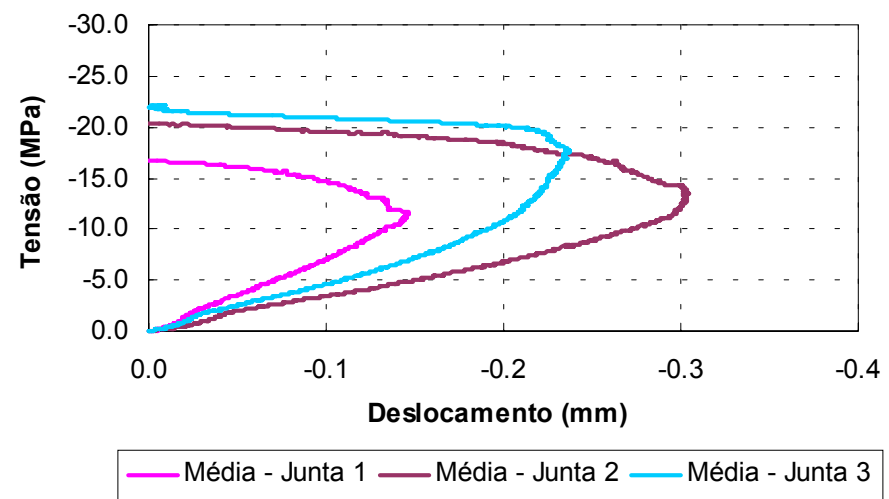

Figura 4. 30: Diagrama tensão x deslocamento da junta de argamassa no modelo M7G15ILR-35.

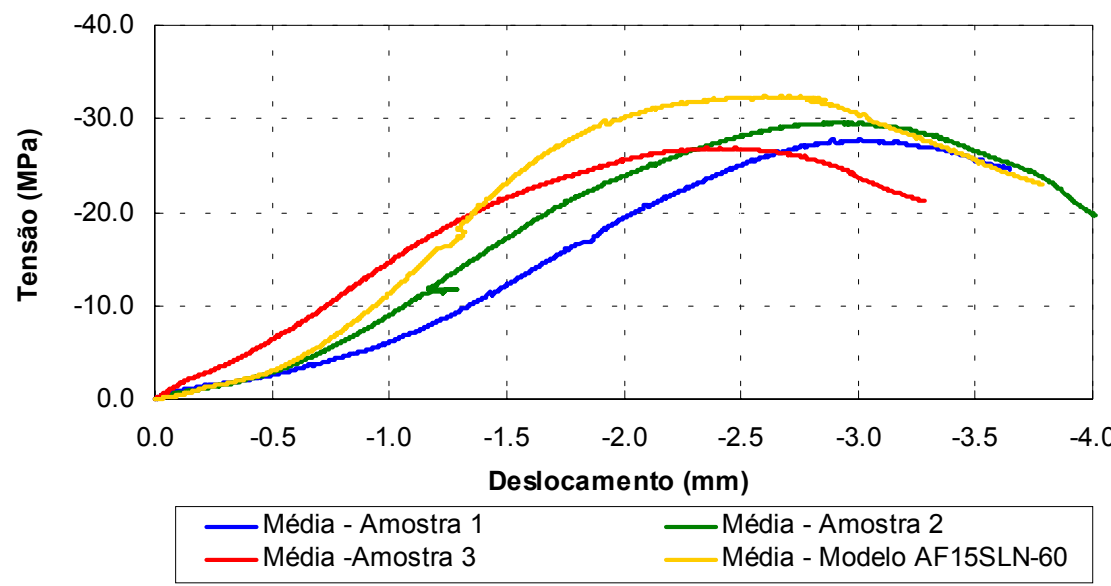

Figura 4. 31: Diagrama tensão $x$ deslocamento das amostras do modelo M8AF15SLN-35 e da amostra do modelo M8AF15SLN-60. 


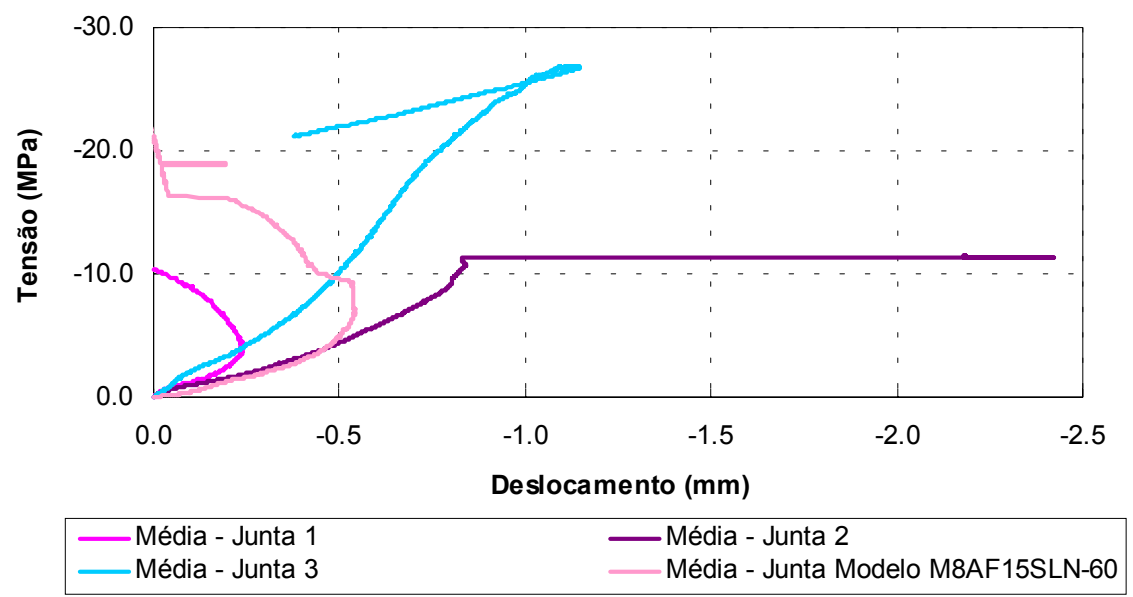

Figura 4. 32: Diagrama tensão $x$ deslocamento da junta de argamassa nas amostras do modelo M8AF15SLN-35 e da amostra do modelo M8AF15SLN-60.

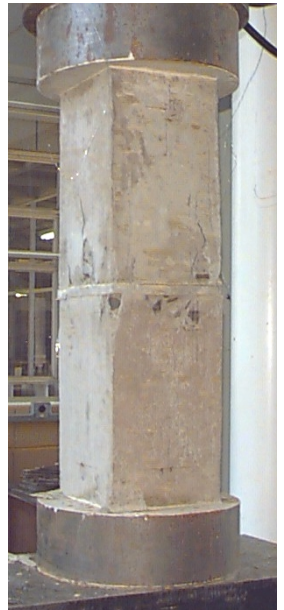

a) modelo com

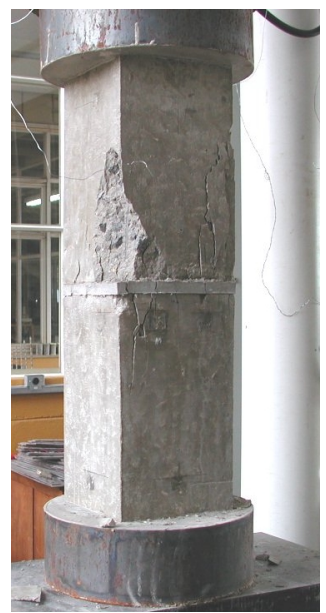

b ) modelo com almofada contendo fibra de PVA.

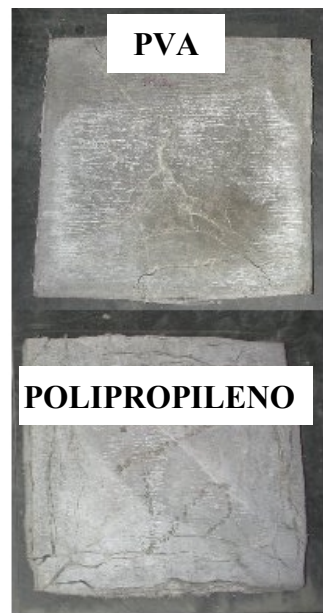

c) configuração de ruína das almofadas. almofada contendo fibra de Polipropileno.

Figura 4. 33: Configuração de ruína dos modelos M8AF15SLN-35.

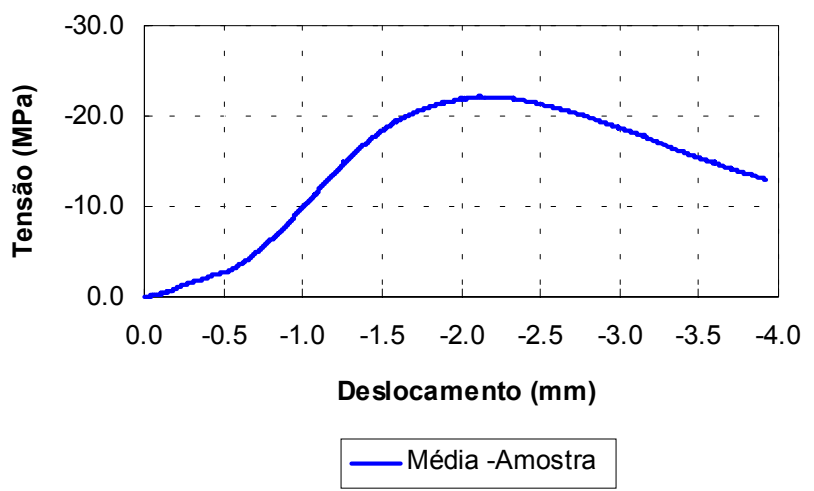

Figura 4. 34: Diagrama tensão x deslocamento do modelo M9AF15SRN-35. 


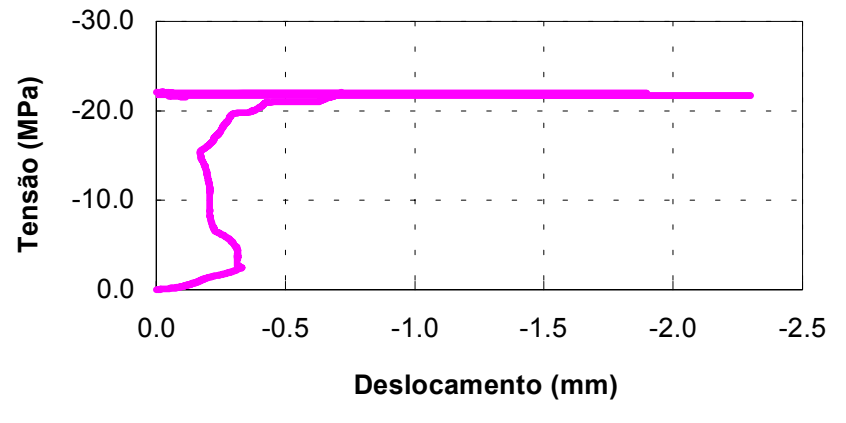

Média - Junta

Figura 4. 35: Diagrama tensão x deslocamento da junta de argamassa no modelo M9AF15SRN-35.
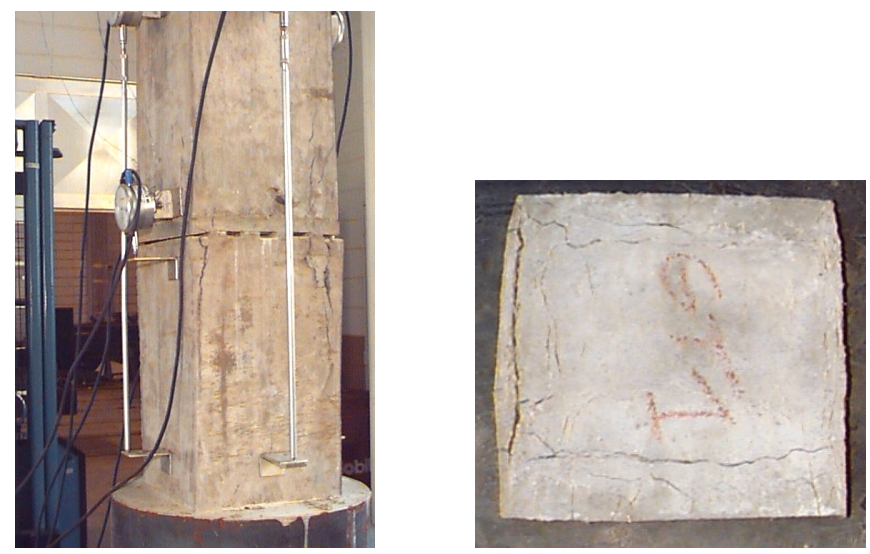

Figura 4. 36: Configuração de ruína do modelo M9AF15SRN-35.
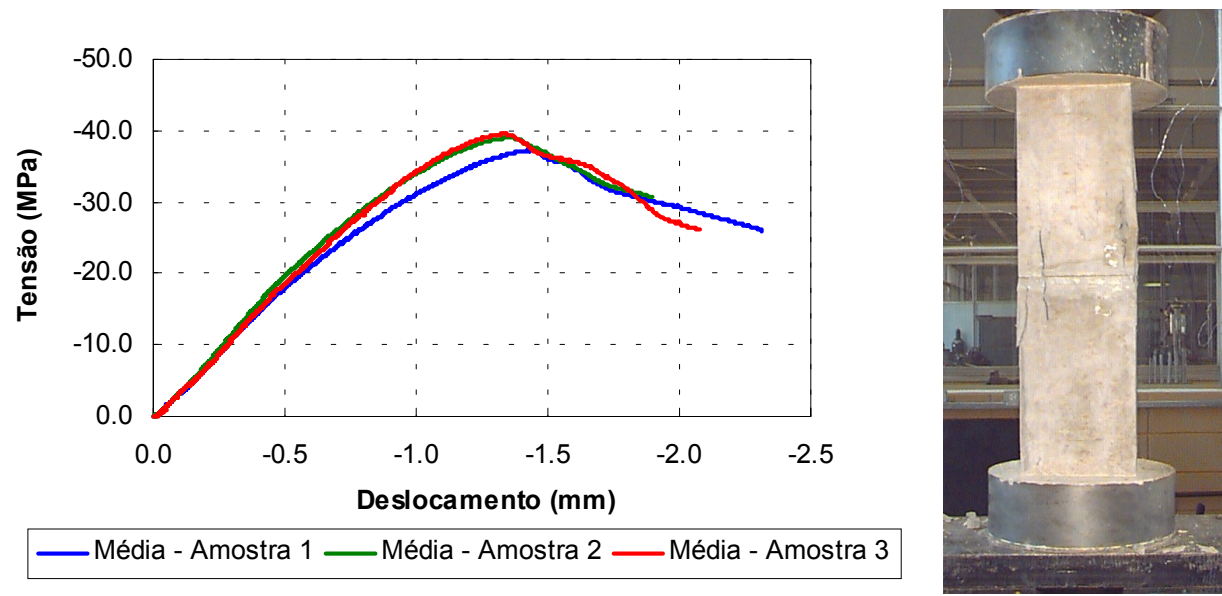

Figura 4. 37: Diagrama tensão x deslocamento do modelo M10DP15SLN-35 e configuração de ruína. 


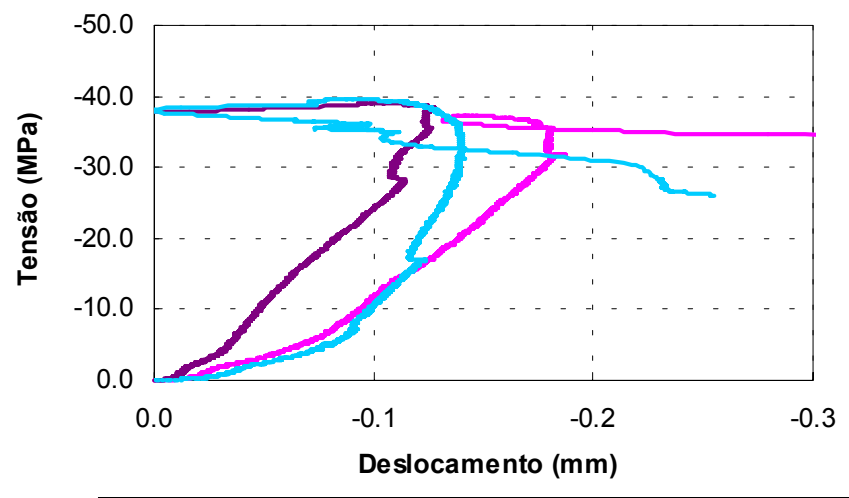

Figura 4. 38: Diagrama tensão x deslocamento da junta de argamassa no modelo M10DP15SLN-35.

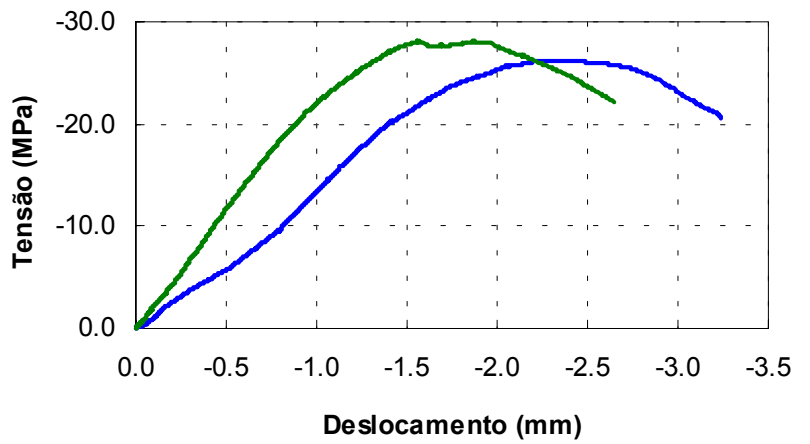

- Média - Amostra 1 Média - Amostra 2

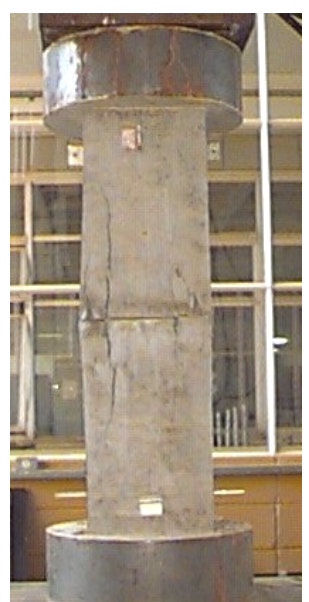

Figura 4. 39: Diagrama tensão x deslocamento do modelo M11SLN-35.

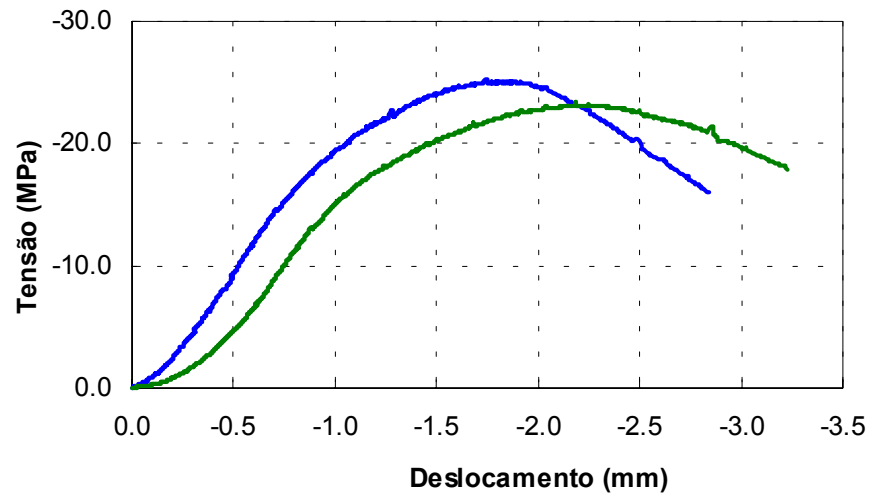

- Média - Amostra 1 Média - Amostra 2

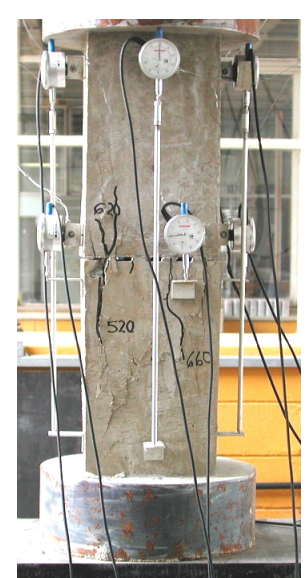

Figura 4. 40: Diagrama tensão x deslocamento do modelo M12SRN-35. 

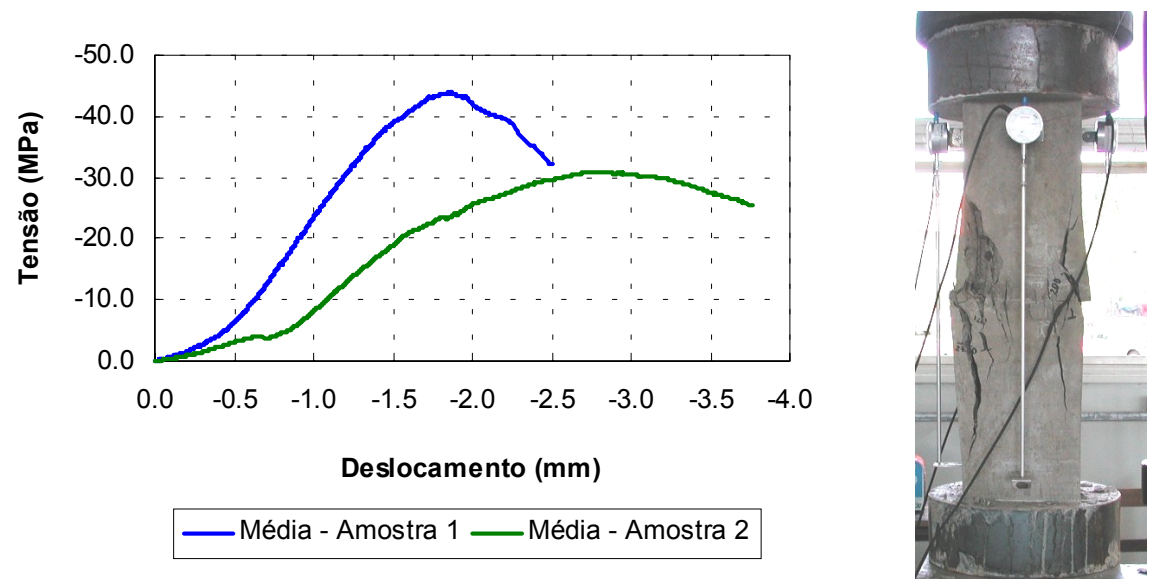

Figura 4. 41: Modelo M13SLN-60.
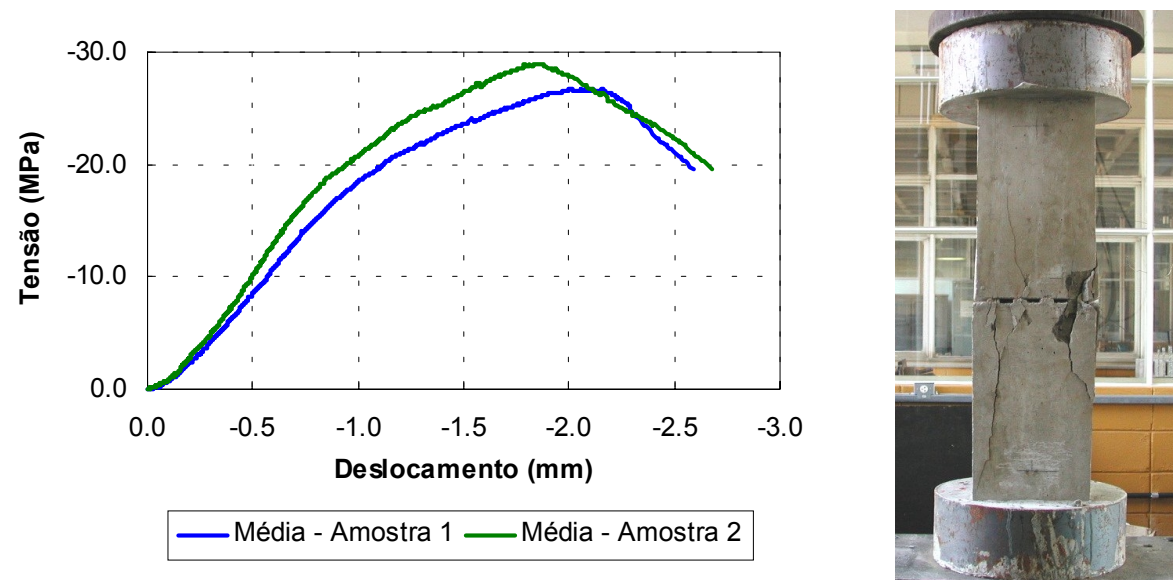

Figura 4. 42: Modelo M13SRN-60.

Além dos resultados obtidos com os relógios comparadores, duas faces de uma das amostras do modelo M1G15ILN-35 foram instrumentadas com extensômetros elétricos do tipo strain gage KFG10, ao longo do comprimento, nas direções horizontal e vertical, permitindo-se assim uma visualização das deformações no modelo. Os gráficos obtidos com a média das leituras dos extensômetros estão mostrados nas Figuras 4.43 e 4.44.

No diagrama das deformações horizontais médias, vê-se uma inversão de solicitação nas proximidades da junta, caracterizando o efeito de confinamento exercido pelos segmentos pré-moldados. Além disso, é possível 
observar a existência de altas tensões de tração no segmento pré-moldado, fazendo com que haja o descolamento do cobrimento de concreto.

Com as deformações verticais, pode-se verificar que a distribuição de tensões não é uniforme e a partir de uma distância igual a $3 h_{j}$ tem-se as maiores deformações.

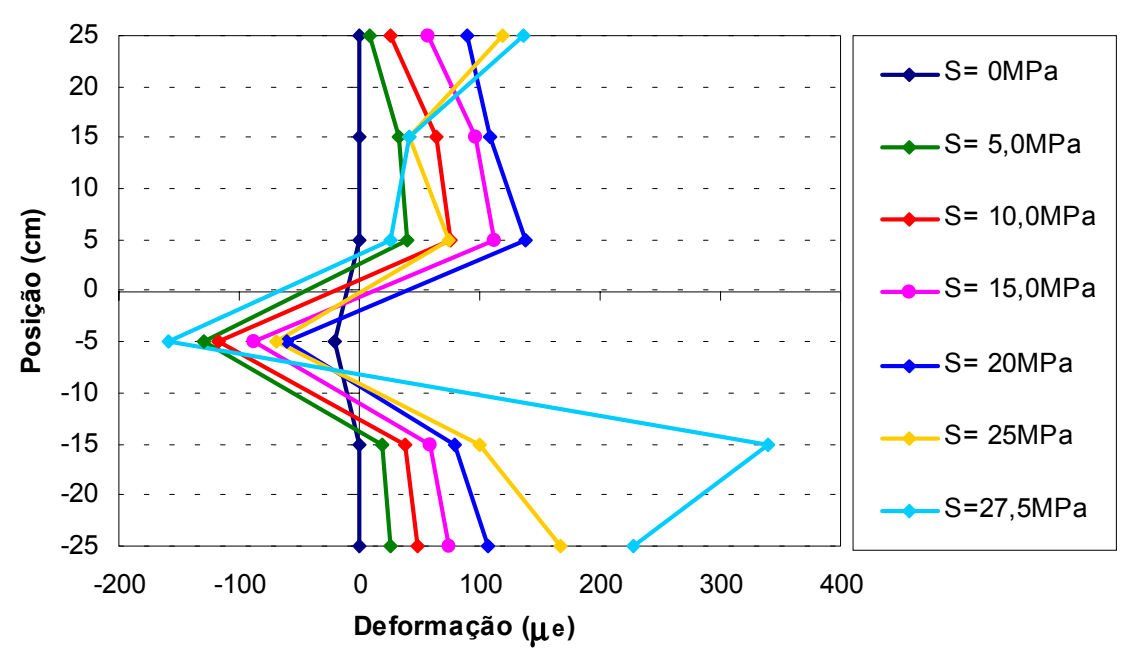

Posicionamento dos Extensômetros elétricos

Figura 4. 43: Deformações horizontais médias ao longo do modelo de acordo com cada estágio de carregamento.
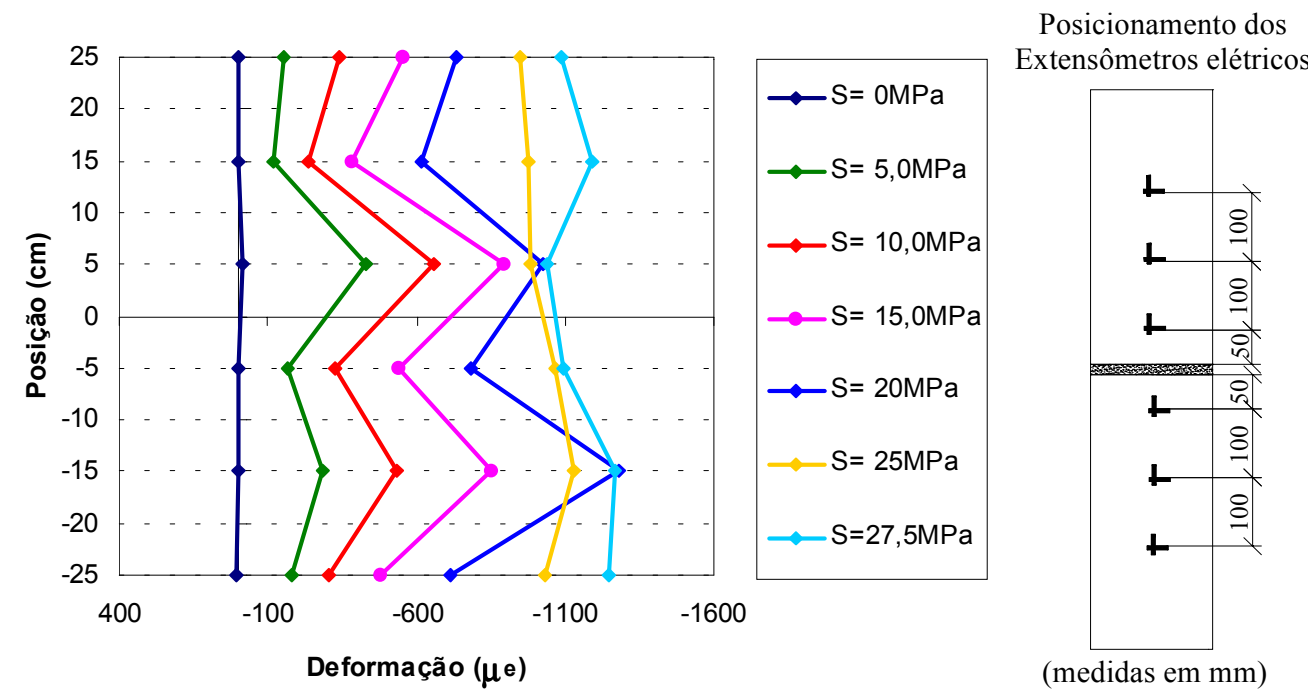

Figura 4. 44: Deformações verticais médias ao longo do modelo de acordo com cada estágio de carregamento. 
No modelo M7G15ILR-35 a armadura de reforço, posicionada nos segmentos pré-moldados, foi instrumentada com extensômetros elétricos do tipo strain gage KFG5. Com a leitura dos extensômetros foram traçados os gráficos mostrados nas Figuras 4.45 a 4.47.

No modelo as barras 1, 2, 3 e 4 estavam posicionadas no segmento prémoldado inferior e as barras 5, 6, 7 e 8 no segmento pré-moldado superior. Em todos os modelos, a armadura entrou em escoamento com cerca de $60 \%$ da carga última atingida.
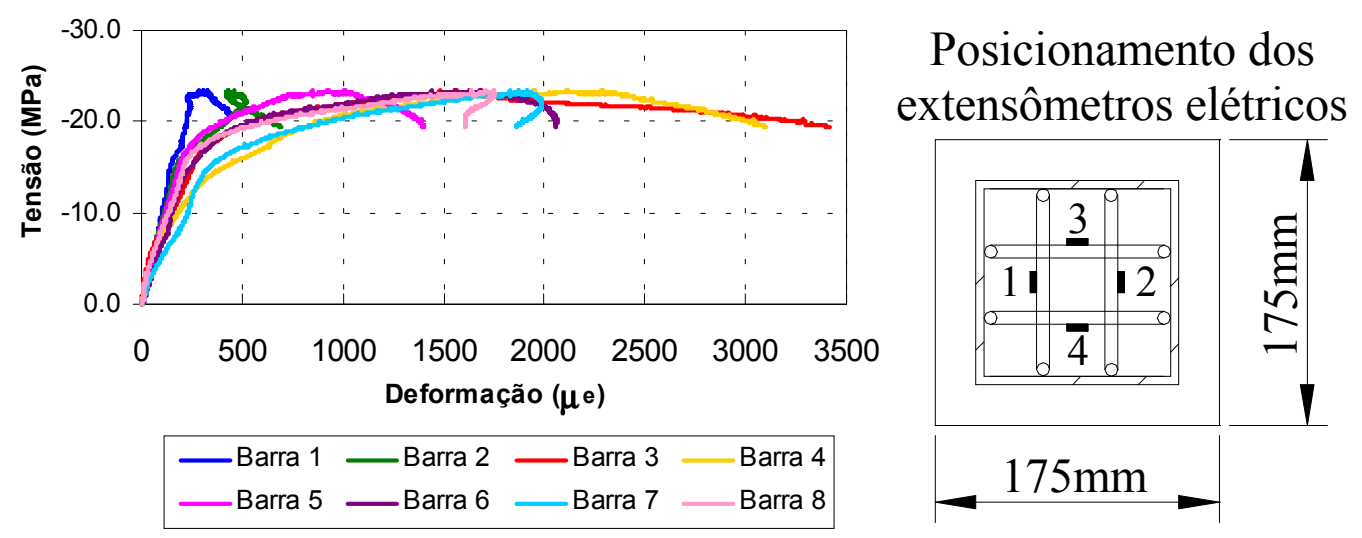

Figura 4. 45: Comportamento dos extensômetros na amostra 1.

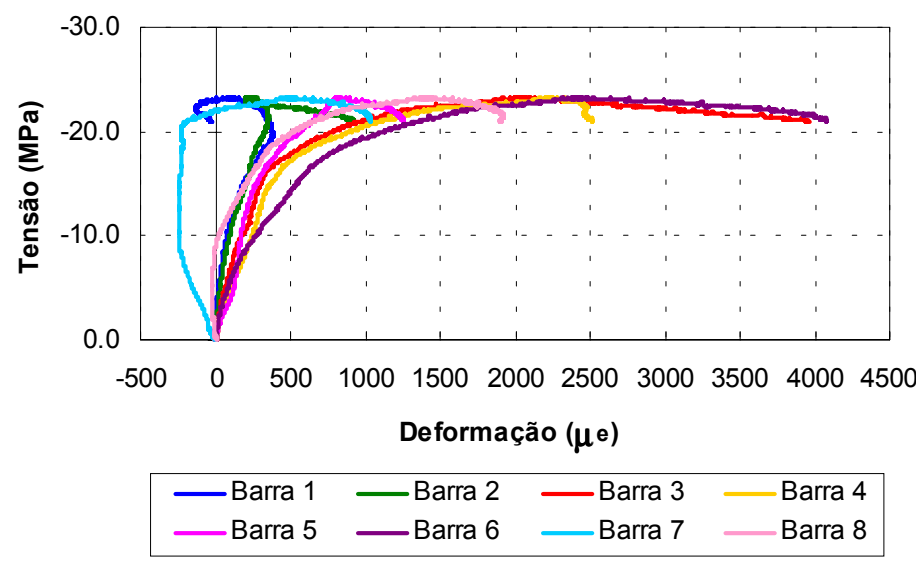

Figura 4. 46: Comportamento dos extensômetros na amostra 2. 


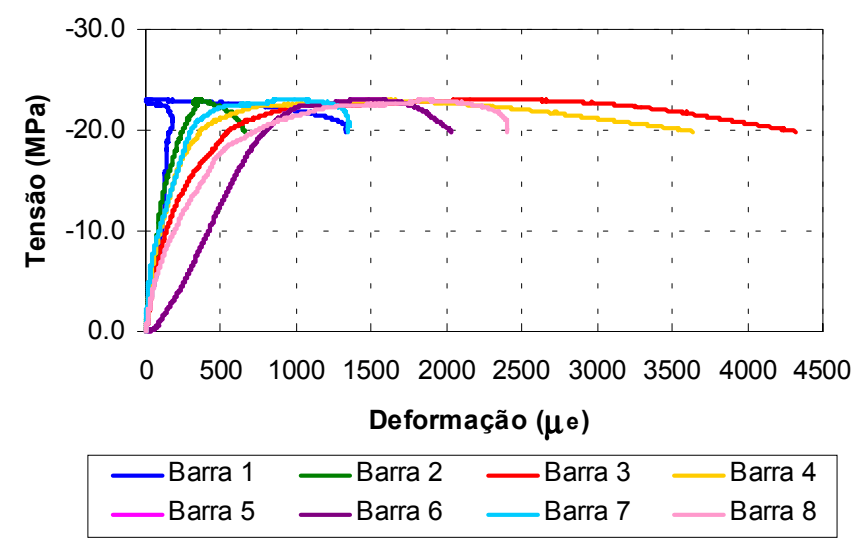

Figura 4. 47: Comportamento dos extensômetros na amostra 3.

\subsection{Comentários Adicionais}

Com os resultados dos ensaios pode-se perceber que a maior dispersão ocorreu nos modelos em que havia pequenos defeitos na junta de argamassa. Estes defeitos ocorriam porque a superfície dos segmentos pré-moldados não era perfeitamente plana e dependendo do tipo de graute utilizado se tornavam mais significativos.

Nos modelos com almofada de apoio, a falta de um contato perfeito entre as partes foi ainda mais significativa, pois foi possível perceber uma acomodação inicial devida às folgas existentes e, posteriormente, devida à flexibilidade do material, uma falta de uniformidade no comportamento da junta.

No capítulo seguinte será feita uma análise mais detalhada do comportamento experimental da ligação, de acordo com os resultados obtidos, em função dos parâmetros de influência do seu comportamento. 


\section{Análise dos Resultados}

\subsection{Preliminares}

Para fazer uma análise dos resultados experimentais obtidos, tomou-se como referência os parâmetros de influência mais significativos apontados pela revisão bibliográfica e pela simulação numérica, desenvolvidas anteriormente. Além disso, fez-se algumas simulações do modelo de referência usando-se o software ANSYS 5.5.1, para avaliar a dispersão de resultados devida aos problemas de execução.

\subsection{Influência da Espessura da Camada de Argamassa}

Este parâmetro foi avaliado nos modelos M1G15ILN-35, M2G22ILN-35

e M3G30ILN-35, com espessura de $15 \mathrm{~mm}, 22,5 \mathrm{~mm}$ e 30 $\mathrm{mm}$, respectivamente, e relação $f_{m} / f_{c}$ em torno de 0,75 .

Pode-se perceber durante o processo de execução, maior dificuldade em uniformizar a espessura na junta mais delgada. Já na junta mais espessa, observou-se que o preenchimento com graute fluido deve ser feito com cuidado, pois a presença de vazios tende a ser mais acentuada. 
No modelo com junta de $30 \mathrm{~mm}$ de espessura houve uma redução na tensão última de $21 \%$ em relação ao valor teoricamente absorvido pelo concreto pré-moldado. Nos outros dois modelos a redução foi em torno de $5 \%$.

Considerando-se uma das amostras de cada modelo, temos os gráficos mostrados nas Figuras 5.1 e 5.2. O modelo com junta de 22,5mm de espessura foi o mais resistente, principalmente por ter sido mais bem executado, porém menos dúctil. A junta mais espessa é a mais flexível, o que faz com que o modelo seja menos resistente. No modelo com junta de $15 \mathrm{~mm}$ de espessura percebe-se que ocorre uma grande acomodação inicial, provavelmente pela existência de vazios na junta. Observa-se também que em todos os modelos a tensão última atingida foi maior que a tensão última teoricamente absorvida pela argamassa, mesmo na junta com perda de resistência mais acentuada.

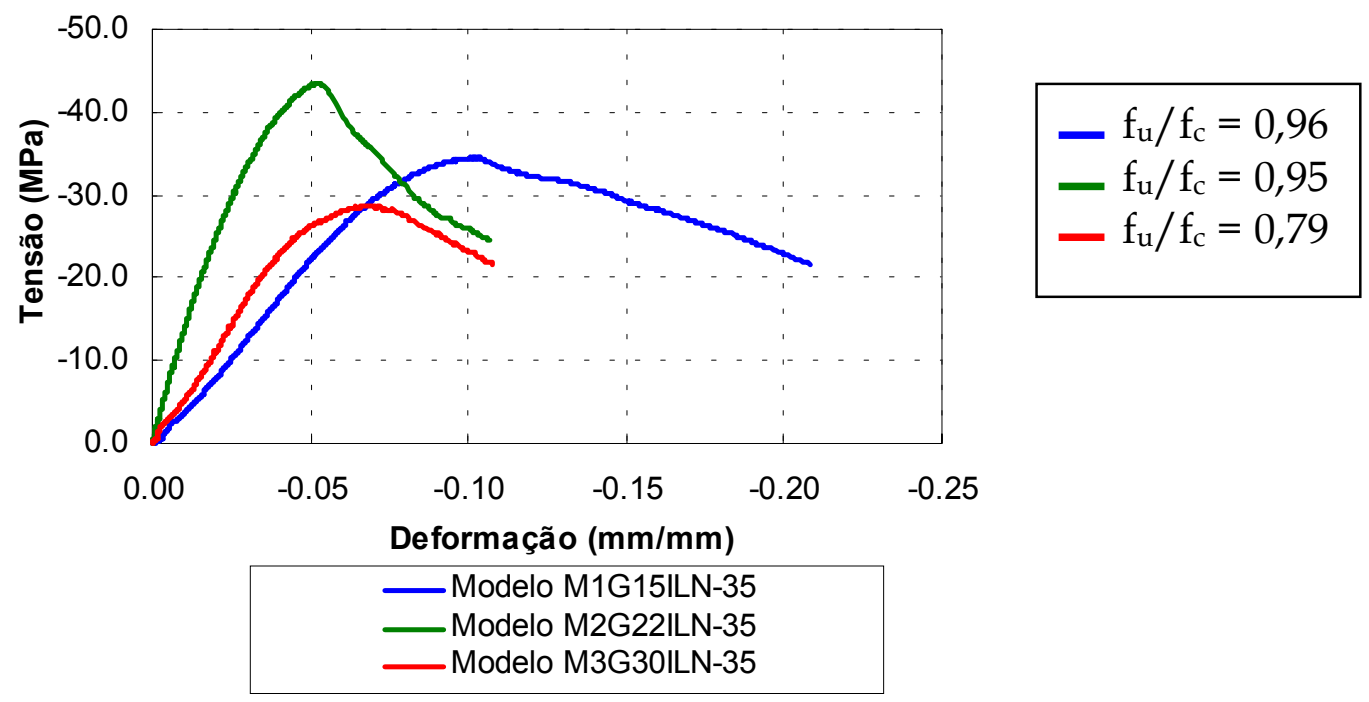

Figura 5. 1: Deformação aparente dos modelos relativa à espessura.

Calculando-se o módulo de elasticidade secante aparente do modelo, para $40 \%$ da tensão última atingida e comparando-se este valor com o valor definido pela NBR 6118 - Projeto de estruturas de concreto - Procedimento (2001), em função da resistência à compressão do concreto, tem-se a Tabela 5.1 
mostrada a seguir. Para as condições dos modelos ensaiados, a junta com 22,5mm apresentou melhor desempenho.

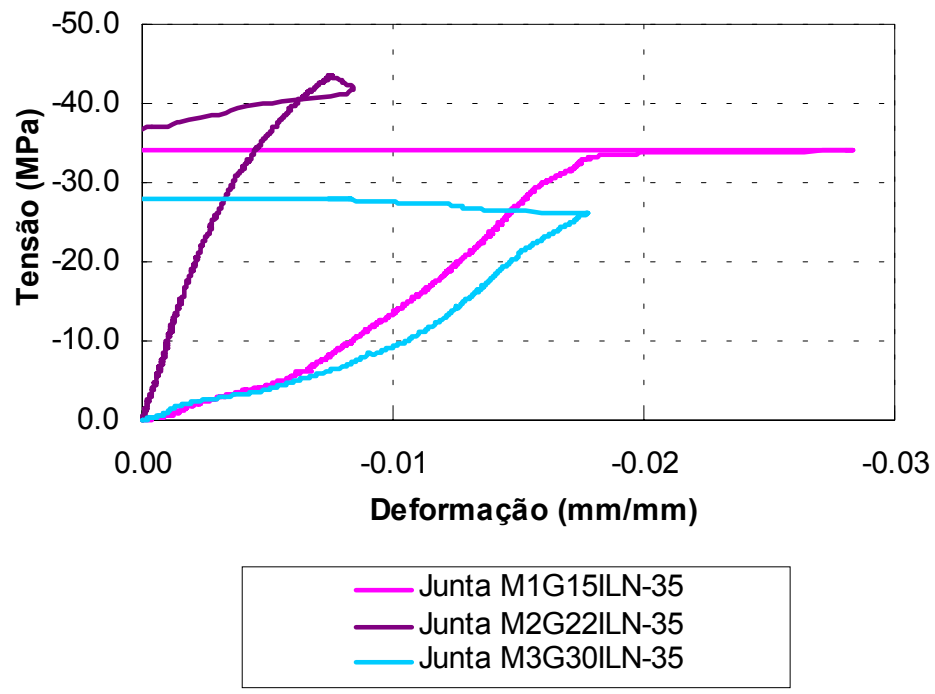

$$
\begin{array}{r}
-\mathrm{f}_{\mathrm{u}} / \mathrm{f}_{\mathrm{m}}=1,28 \\
-\mathrm{f}_{\mathrm{u}} / \mathrm{f}_{\mathrm{m}}=1,25 \\
-\mathrm{f}_{\mathrm{u}} / \mathrm{f}_{\mathrm{m}}=1,10
\end{array}
$$

Figura 5. 2: Deformação das juntas relativa à espessura.

Tabela 5. 1: Módulo de elasticidade aparente dos modelos

\begin{tabular}{|c|c|c|c|c|}
\hline Modelo & $\begin{array}{c}\text { Espessura da junta } \\
(\mathrm{mm})\end{array}$ & $\begin{array}{c}E_{\exp } \\
(\mathrm{MPa})\end{array}$ & $\begin{array}{c}\mathrm{E}_{\mathrm{c}} \\
(\mathrm{MPa})\end{array}$ & Diferença \\
\hline M1G15ILN-35 & 15 & 15403 & 31925 & $51,8 \%$ \\
\hline M2G22ILN-35 & 22,5 & 29383 & 37315 & $21,3 \%$ \\
\hline M3G30ILN-35 & 30 & 8758 & 33177 & $73,6 \%$ \\
\hline
\end{tabular}

Considerando-se os resultados experimentais e o modelo equivalente mostrado na Figura 5.3, pode-se determinar a deformabilidade da junta em função da tensão aplicada, através da deformação específica definida com a Equação 5.1. Essa equação é obtida aplicando-se a condição de compatibilidade de deslocamentos ao modelo equivalente da Figura 5.3. A Figura 5.4 mostra a variação da deformação em função do nível de tensão.

$$
\varepsilon_{\mathrm{J}}=\frac{\Delta \ell_{\mathrm{T}}}{\mathrm{h}_{\mathrm{J}}}\left(1-\frac{\mathrm{L}_{1}}{\mathrm{~L}_{1}-\mathrm{L}_{1}^{\prime}}\right)+\frac{\Delta \ell_{\mathrm{J}} \mathrm{L}_{1}}{\mathrm{~h}_{\mathrm{J}}\left(\mathrm{L}_{1}-\mathrm{L}_{1}^{\prime}\right)}
$$


onde: $\varepsilon_{\mathrm{J}}$ - deformação específica da junta;

$\Delta \ell_{\mathrm{T}}$ - deslocamento relativo do concreto pré-moldado, medido nos relógios comparadores;

$\Delta \ell_{\mathrm{J}}$ - deslocamento relativo da junta, medido nos relógios comparadores;

$\mathrm{L}_{1}$ - comprimento do trecho de concreto pré-moldado como mostrado na Figura 5.3;

$\mathrm{L}_{1} 1$ - comprimento do trecho de concreto pré-moldado adjacente à junta, como mostrado na Figura 5.3;

$h_{J}$ - espessura da junta.

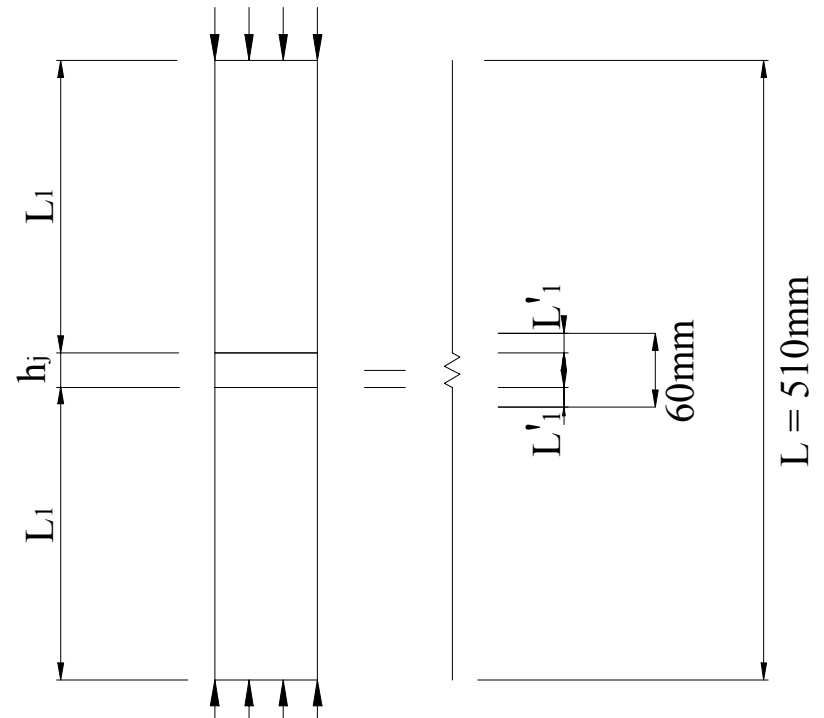

Figura 5. 3: Modelo equivalente para cálculo da deformabilidade da junta.

Para uma tensão de contato de $10 \mathrm{MPa}$, pode-se determinar a deformabilidade das juntas através da Equação 5.2 e comparar com o valor definido por BJLUGER (1988). Esses valores são mostrados na Tabela 5.2.

$$
\mathrm{D}_{\mathrm{J}}=\varepsilon_{\mathrm{J}} \cdot \mathrm{h}_{\mathrm{J}}
$$


onde: $\mathrm{D}_{\mathrm{J}}$ - deformabilidade da junta;

$\varepsilon_{\mathrm{J}}$ - deformação específica da junta;

$h_{\mathrm{J}}$ - espessura da junta.

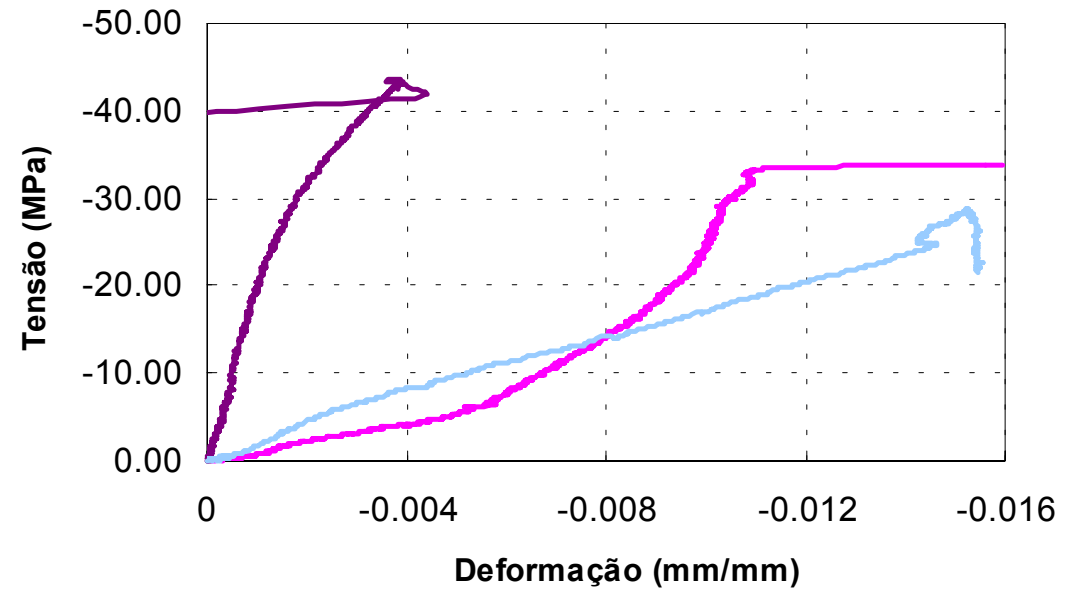

Modelo M1G15ILN-35

Modelo M2G22ILN-35

Modelo M3G30ILN-35

Figura 5. 4: Variação da deformação da junta em função do nível de tensão.

Tabela 5. 2: Deformabilidade das juntas.

\begin{tabular}{|c|c|c|c|c|}
\hline Modelo & $\begin{array}{c}\text { Espessura } \\
\text { da junta } \\
\text { (mm) }\end{array}$ & $\begin{array}{c}\text { Deformação } \\
\text { específica da junta } \\
(\mathrm{mm} / \mathrm{mm})\end{array}$ & $\begin{array}{c}\text { Deformabilidade } \\
\text { da junta } \\
\text { (m/MPa) } \\
\end{array}$ & $\begin{array}{c}\text { Deformabilidade } \\
\text { BJLUGER (1988) } \\
(\mathrm{m} / \mathrm{MPa})\end{array}$ \\
\hline 1G1 & 15 & $70,0 \times 10^{-4}$ & $1,05 \times 10^{-4}$ & \multirow{3}{*}{$0,2 \times 10^{-4}$} \\
\hline M2G22IL & 22,5 & 5,0 & 0,1 & \\
\hline M3G30ILN-35 & 30 & $50,0 \times 10^{-4}$ & $1,50 \times 10^{-4}$ & \\
\hline
\end{tabular}

Para a junta de 22,5 mm de espessura, obteve-se uma deformabilidade que corresponde a praticamente 50\% do valor definido por BJLUGER (1988). Já nas outras juntas, obteve-se valores 6 a 8 vezes maiores. Nesses casos podese dizer que não só houve influência da espessura, mas também das condições de execução que resultou na existência de vazios na junta. Entretanto, vale ressaltar que o valor definido por BJLUGGER (1988) se refere a uma interface concreto pré-moldado-junta e com isso seria multiplicado por dois para comparação com os modelos ensaiados. 
Comparando-se a configuração de ruína dos três modelos, mostrada na Figura 5.4, observa-se que a junta mais rígida acentua o efeito de descolamento do cobrimento de concreto no segmento pré-moldado superior. Em todos os modelos a ruína teve início com a expulsão da camada externa de argamassa, o que traz uma distribuição não uniforme de tensões. Na junta mais espessa, quase não houve propagação de fissuras para o segmento pré-moldado inferior.

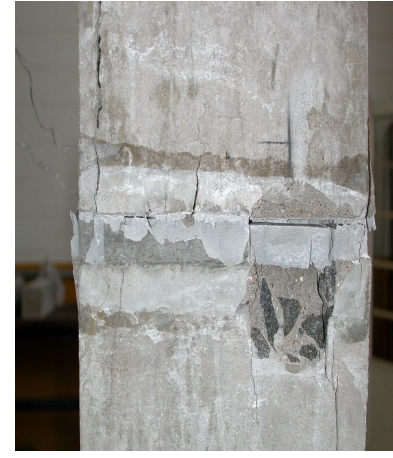

a) M1G15ILN-35

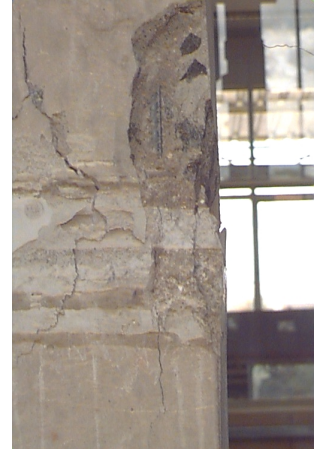

b) M2G22ILN-35

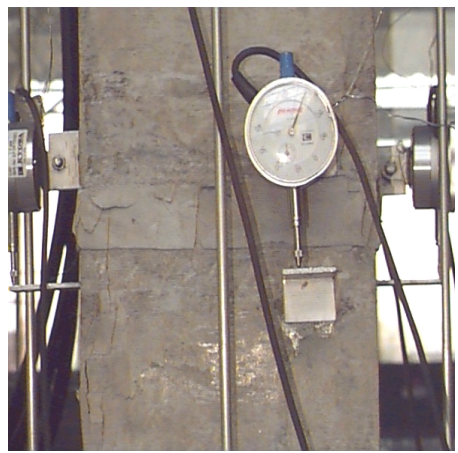

c) M3G30ILN-35

Figura 5. 5: Configuração de ruína das juntas nos modelos.

Ao final dos ensaios percebeu-se a quebra de aderência entre os segmentos, com separação na interface segmento superior/junta de argamassa como mostra a Figura 5.5. Pode-se perceber também a distribuição de fissuras na junta de argamassa e a definição de um núcleo resistente na junta.

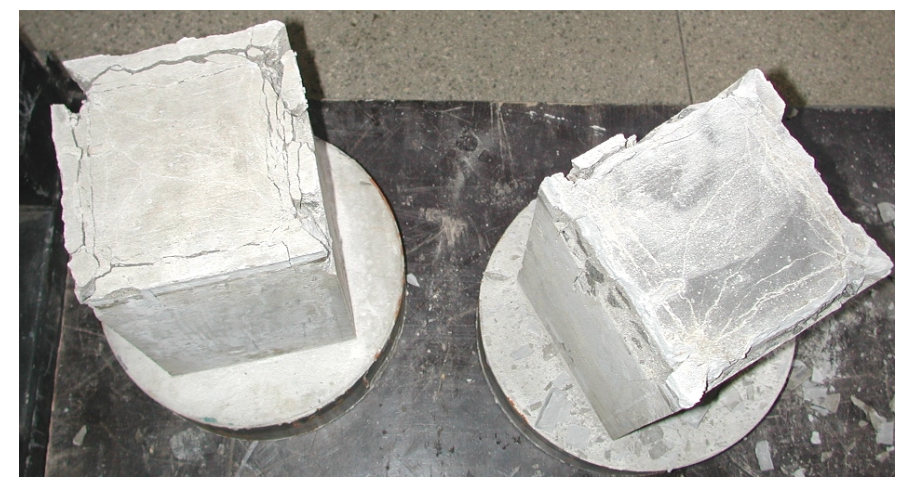

Figura 5. 6: Quebra de aderência na interface segmento superior/junta. 
Segundo BRUGGELING (1991), a área efetiva para a seção resistente da junta deve ser definida a partir de uma distância de $\mathbf{2} \mathbf{h}_{\mathbf{j}}$ da borda, devido à expulsão da camada externa de argamassa. Entretanto, nos ensaios realizados observou-se que essa região coincidia com a área confinada definida pelos estribos no segmento pré-moldado, ou seja, a redução nas dimensões da área da seção transversal era igual ao cobrimento de concreto no segmento prémoldado.

Como o modelo M1G15ILN-35 foi o modelo de referência adotado, fezse algumas simulações numéricas desse modelo no ANSYS 5.5.1, para avaliar a dispersão dos resultados experimentais. Nas simulações, adotou-se para o concreto e a argamassa, os critérios de resistência já descritos no Capítulo 2. Com o critério CONCRETE, foi possível visualizar o quadro de fissuração e com o critério de DRUCKER-PRAGER visualizou-se o comportamento global com o aumento de carregamento. Os gráficos obtidos com a simulação foram comparados com os valores experimentais nas Figuras 5.6 e 5.7.
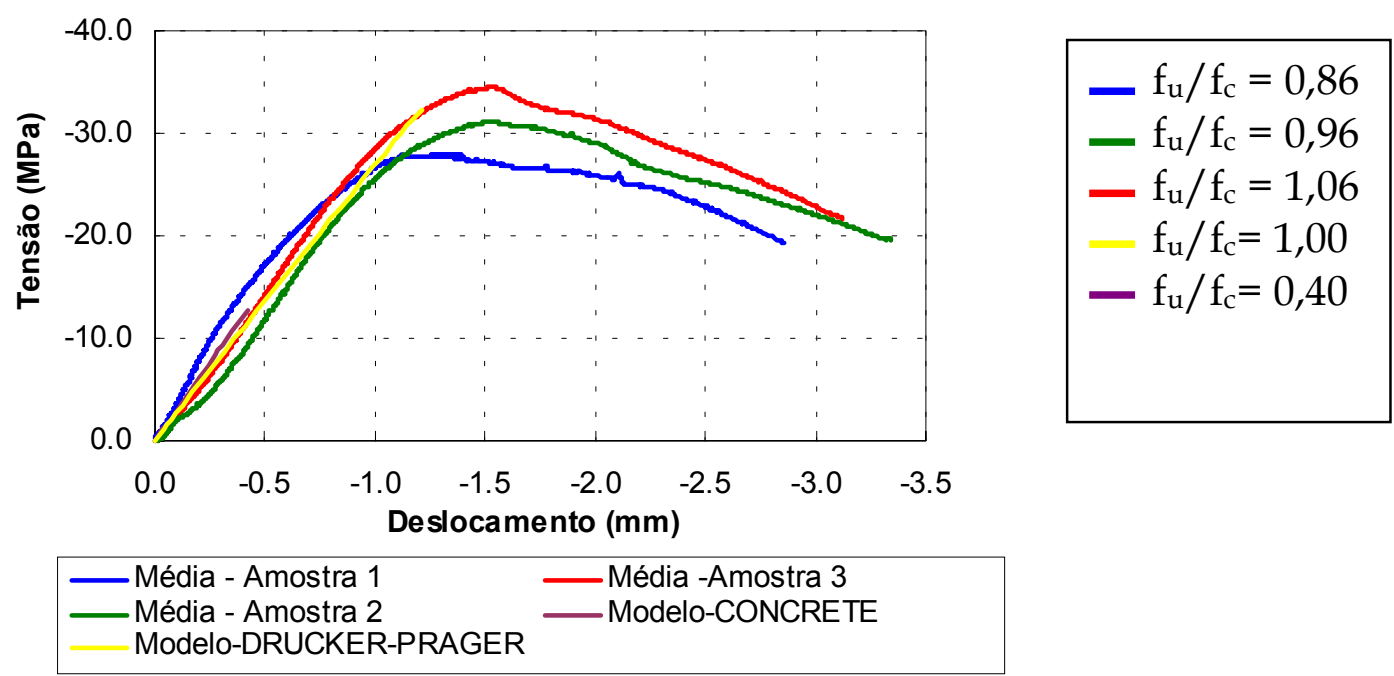

Figura 5. 7: Comportamento global do modelo.

Nos gráficos mostrados, os resultados com o critério CONCRETE acompanham os resultados com o critério DRUCKER-PRAGER até $40 \%$ da 
tensão aplicada. Depois disso o modelo perde a convergência.
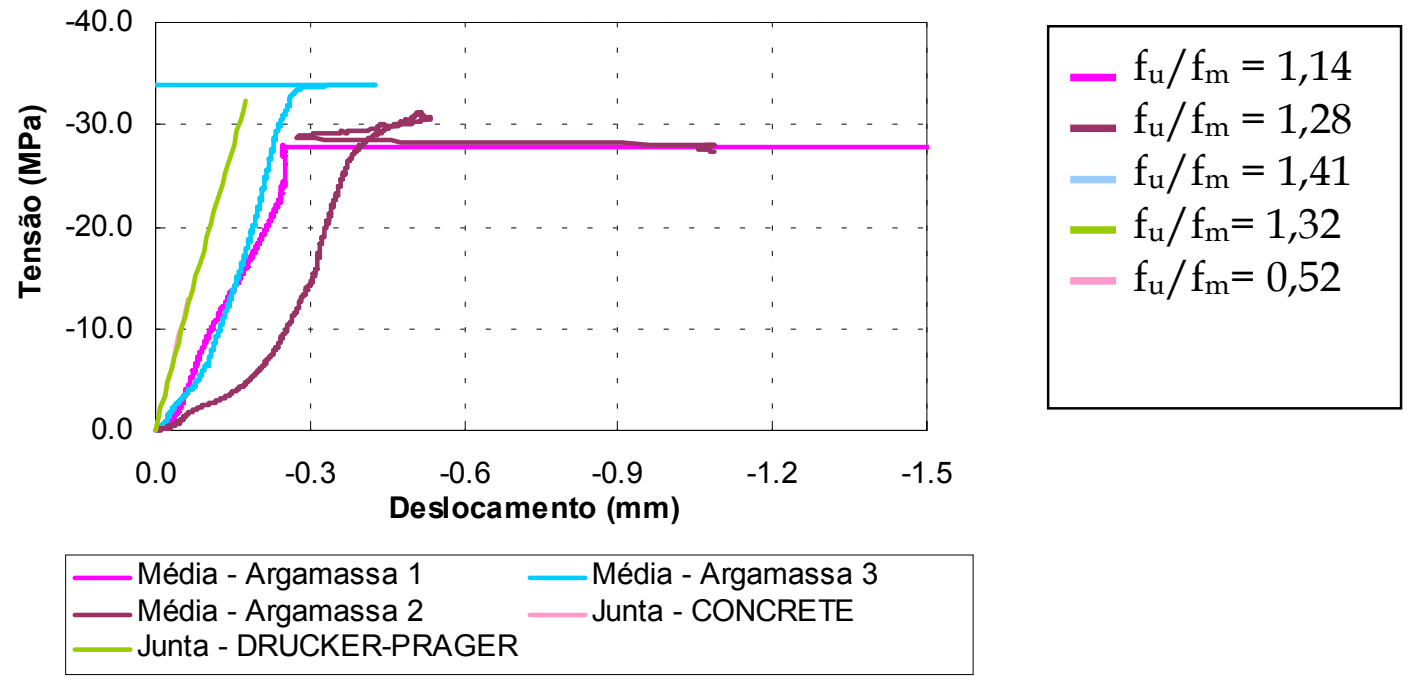

Figura 5. 8: Comportamento da junta de argamassa no modelo numérico.

Observou-se que no modelo numérico a junta fica bem mais rígida, apesar do comportamento global do modelo ter sido bem parecido com o experimental. Na Figura 5.8 tem-se a distribuição de fissuras no modelo antes da ruptura. Pode-se ver que, assim como no modelo experimental, o limite da região fissurada é definido pela posição dos estribos no segmento prémoldado.
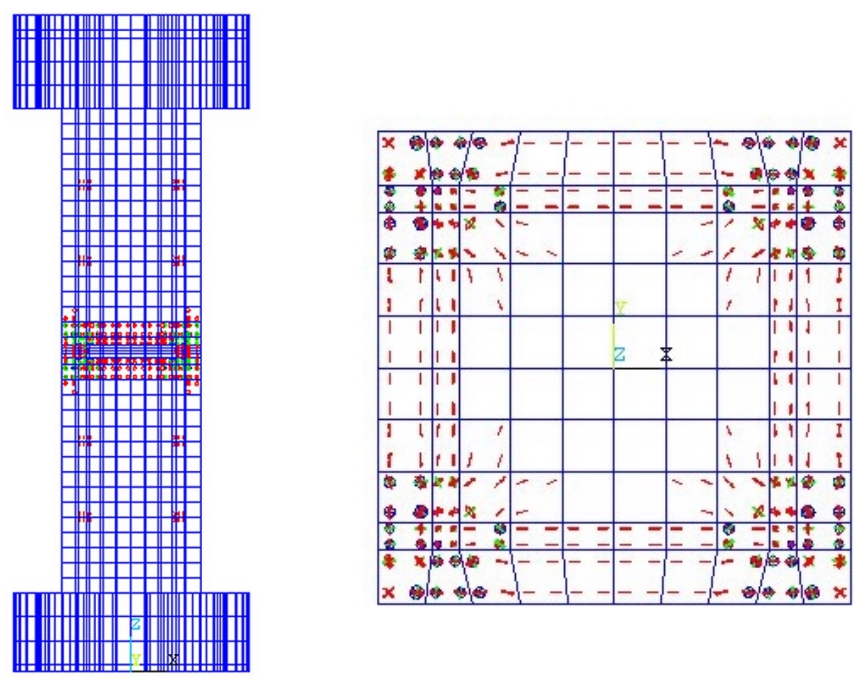

Figura 5. 9: Fissuração no modelo numérico e detalhe da seção da junta. 


\subsection{Influência da Relação entre as Resistências}

Este parâmetro foi avaliado com os modelos M1G15ILN-35, M4G15MLN-35 e M5G15SLN-35, cuja relação $f_{m} / f_{c}$ foi $0,75,0,9$ e 2,36, respectivamente. Essa variação na relação $f_{m} / f_{c}$ foi obtida usando-se três tipos de graute na junta. No primeiro modelo foi usado o graute mais fino Conbextra P, no segundo modelo foi usado um graute com uma granulometria maior denominado Fosgrout Plus e no terceiro modelo usou-se um graute à base de epóxi denominado Conbextra EPR. Em todos os modelos a espessura da junta foi de $15 \mathrm{~mm}$.

Apesar de não ser recomendado para uso em espessura menor que $20 \mathrm{~mm}$, usou-se o graute Fosgrout Plus para aumentar a resistência da camada de argamassa. Entretanto, percebeu-se que a presença de vazios na junta, como mostra a Figura 5.10, influenciou o comportamento do modelo.

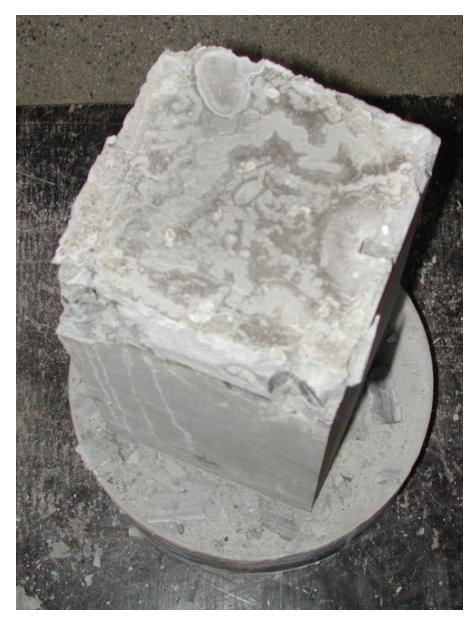

Figura 5. 10: Presença de bolhas de ar na junta.

Com os gráficos das Figuras 5.11 e 5.12, pode-se perceber que o aumento da relação $f_{m} / f_{c}$ pelo aumento da resistência da argamassa, mantendo-se o mesmo concreto pré-moldado, não trouxe ganhos significativos para a capacidade resistente da junta. No modelo com graute de alta resistência, 
alcançou-se apenas $45 \%$ da capacidade resistente da argamassa. Entretanto, a ruptura não ocorreu por esmagamento da camada de argamassa e sim por fendilhamento do segmento superior. No modelo cuja relação $f_{m} / f_{c}$ é próxima de 1,0, percebe-se que a diferença de deformabilidade entre os dois materiais não é tão acentuada quanto nos outros dois modelos, o que facilita a propagação de fissuras para o segmento pré-moldado inferior e diminui a capacidade resistente do modelo.
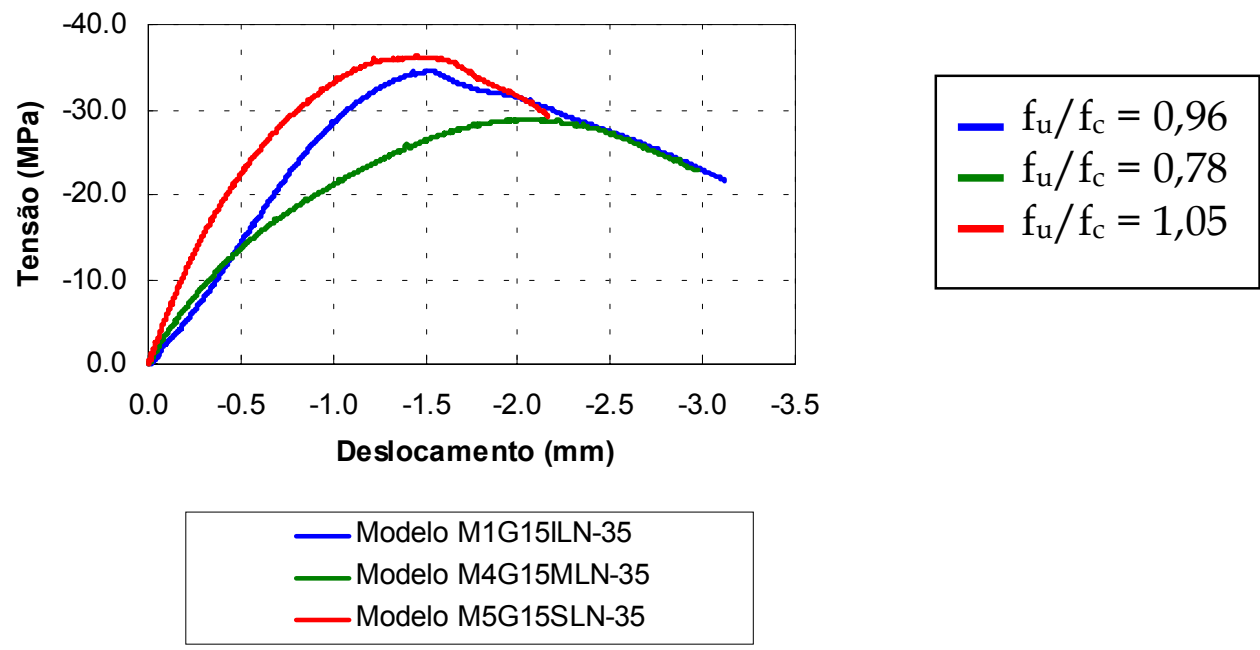

Figura 5. 11: Diagrama tensão $x$ deslocamento dos modelos variando-se a relação

$$
\mathrm{f}_{\mathrm{m}} / \mathrm{f}_{\mathrm{c}} \text {. }
$$
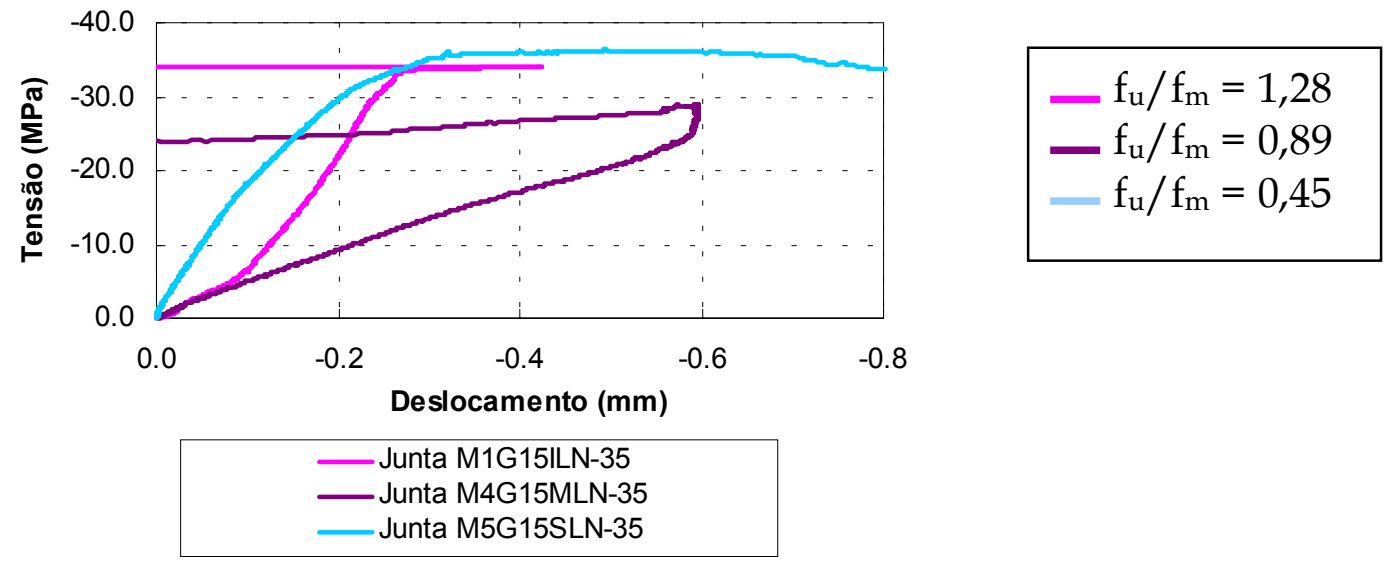

Figura 5. 12: Diagrama tensão $x$ deslocamnto das juntas com $h_{j}=15 \mathrm{~mm}$ variando-se a relação $\mathrm{f}_{\mathrm{m}} / \mathrm{f}_{\mathrm{c}}$. 
Observando-se a configuração de ruína das juntas nos três modelos, mostrada na Figura 5.13, vê-se que no caso b), devido à propagação das fissuras de um segmento para o outro, a região de ruína atinge altura igual a duas vezes a dimensão da seção transversal do modelo. Já no caso c), praticamente não se vê fissura na junta, conseqüentemente não houve fissura no segmento inferior. Observou-se também que não houve quebra de aderência no modelo com junta de epóxi.

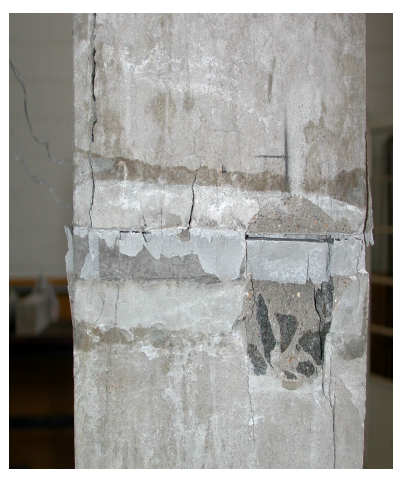

a) M1G15ILN-35

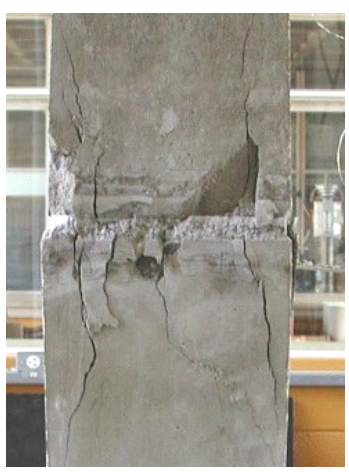

b) M4G15MLN-35

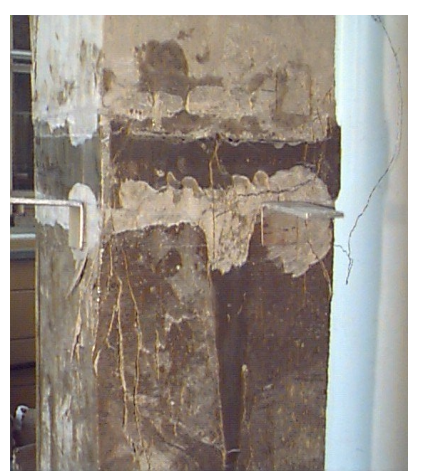

c) M5G15SLN-35

Figura 5. 13: Configuração de ruína das juntas.

Calculando-se a deformabilidade da junta nos três modelos para uma tensão de $15 \mathrm{MPa}$, após a acomodação inicial, através dos gráficos da Figura 5.12 e determinando-se com a Equação 4.2 o módulo de elasticidade equivalente, tem-se os valores mostrados na Tabela 5.3. Observa-se que a deformabilidade da junta no modelo M1G15ILN-35 é cerca de duas vezes e meia a do modelo M5G15SLN-35, cuja redução no módulo de elasticidade, comparado ao valor obtido através da NBR-6118 (2001), foi de 32\%. 
Tabela 5. 3: Diagrama tensão x deslocamento da junta e módulo de elasticidade equivalente dos modelos.

\begin{tabular}{|l|c|c|c|}
\hline \multicolumn{1}{|c|}{ Modelo } & $\begin{array}{c}\text { Deformabilidade } \\
\text { da junta } \\
(\mathrm{mm} / \mathrm{MPa})\end{array}$ & $\begin{array}{c}\text { Módulo de elasticidade } \\
\text { equivalente } \\
(\mathrm{MPa})\end{array}$ & $\begin{array}{c}\mathrm{E}_{\mathrm{c}} \text { teórico } \\
\text { (MPa) }\end{array}$ \\
\hline M1G15ILN-35 & $1,40 \times 10^{-2}$ & 12180 & 31925 \\
\hline M4G15MLN-35 & $1,60 \times 10^{-2}$ & 12948 & 33879 \\
\hline M5G15SLN-35 & $0,57 \times 10^{-2}$ & 22238 & 32605 \\
\hline
\end{tabular}

\subsection{Influência da Resistência do Concreto Pré-Moldado}

Para avaliar a influência da resistência do concreto pré-moldado, utilizou-se o modelo M6G15ILN-60 em comparação com o modelo M1G15ILN-35, como mostram as Figuras 5.14 e 5.15. Mesmo com uma relação $\mathrm{f}_{\mathrm{m}} / \mathrm{f}_{\mathrm{c}}$ menor, o modelo de alta resistência apresentou maior capacidade resistente. Entretanto, em relação ao valor teoricamente resistido pelo concreto, obteve-se um aproveitamento de apenas 58\%, ocasionando assim desperdício para o modelo.

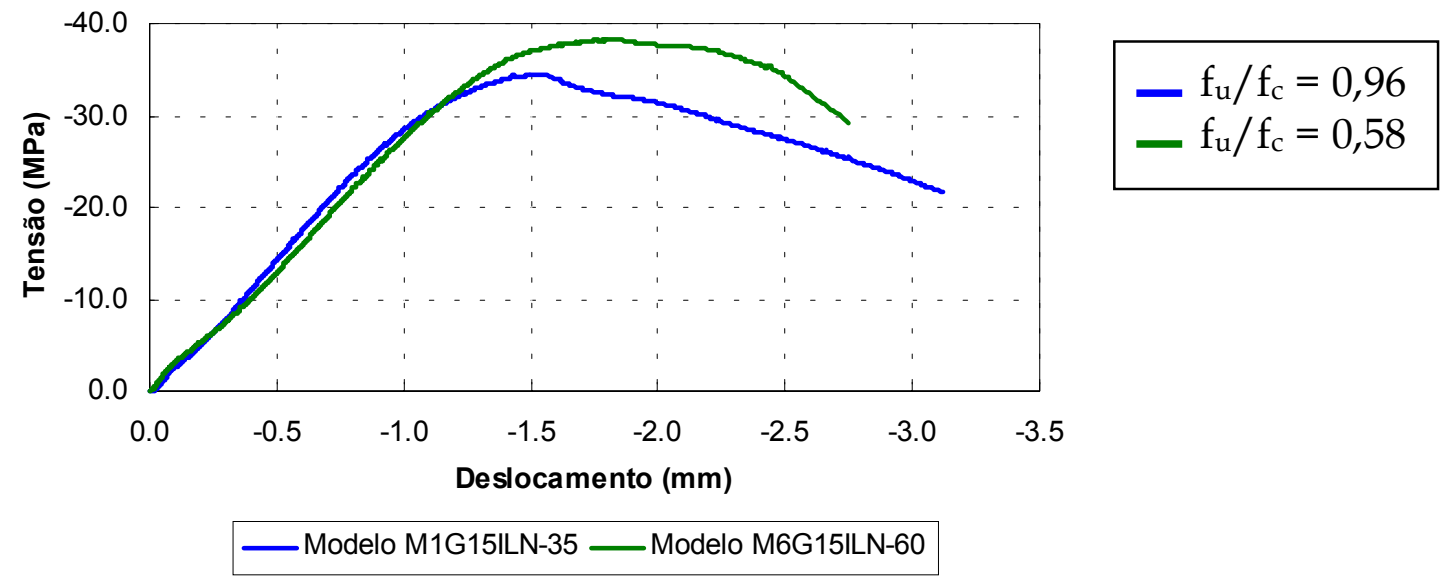

Figura 5. 14: Diagrama tensão $x$ deslocamento dos modelos variando-se a resistência do concreto pré-moldado. 
Apesar da junta de argamassa no modelo de alta resistência ser mais flexível, a capacidade resistente da junta foi 56\% maior que o valor teoricamente absorvido pela argamassa, devido ao confinamento exercido pelos segmentos pré-moldados.

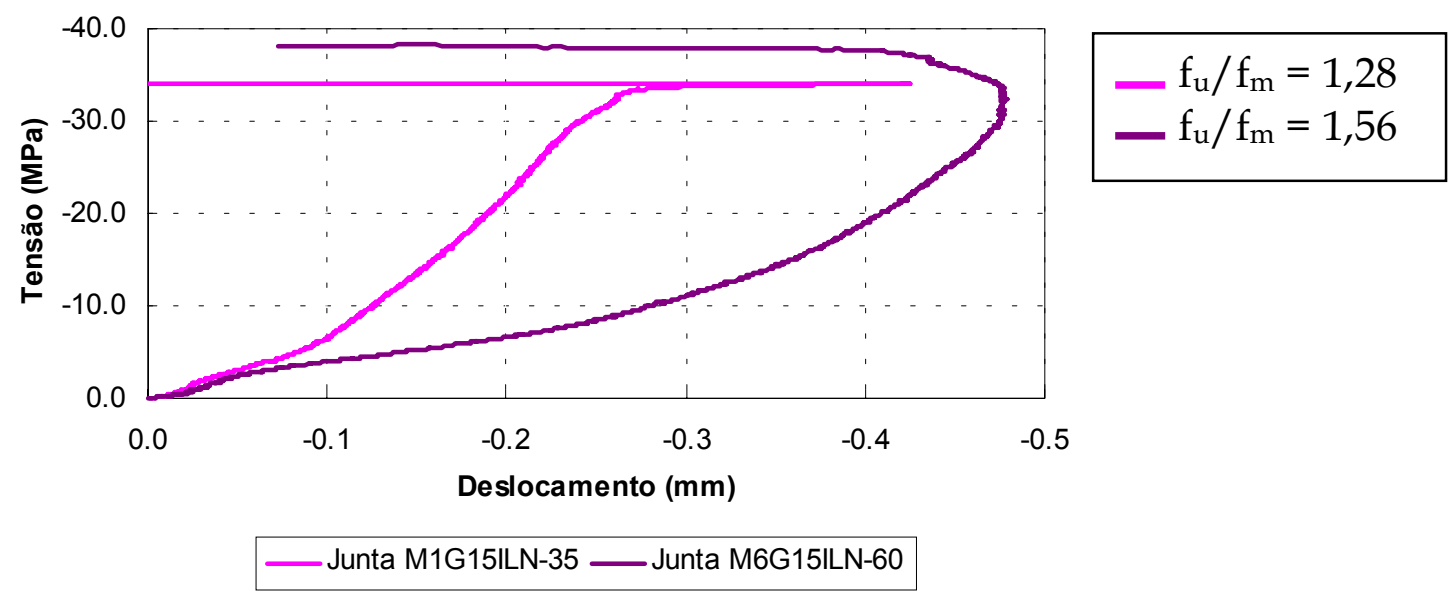

Figura 5. 15: Diagrama tensão $x$ deslocamento das juntas com espessura de $15 \mathrm{~mm}$.

Observando-se a configuração de ruína das juntas, mostrada na Figura 5.16, vê-se a influência significativa das tensões de fendilhamento no concreto de alta resistência. Assim como nos ensaios preliminares, o uso de um graute menos resistente na junta fez com que o modelo de alta resistência tivesse uma ruptura mais dúctil.

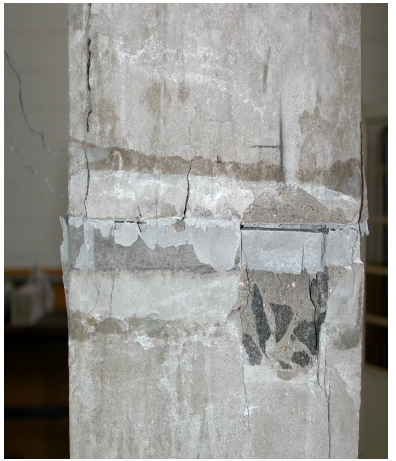

a) M1G15ILN-35

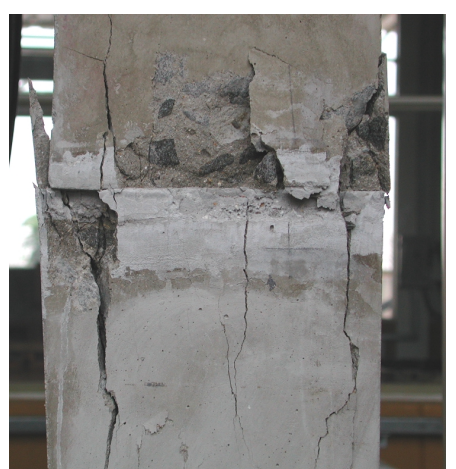

b) M6G15MLN-60

Figura 5. 16: Configuração de ruína das juntas. 


\subsection{Influência da Armadura de Reforço}

Seguindo as recomendações de BRUGGELING \& HUYGHE (1991), foi avaliada experimentalmente, a influência de uma armadura de reforço posicionada na região do elemento pré-moldado adjacente à ligação, através do modelo M7G15ILR-35, cuja relação $f_{m} / f_{c}$ foi igual a 1,0. Este modelo foi comparado com o modelo M4G15MLN-35, como mostram as Figuras 5.17 e 5.18 , por ter praticamente, a mesma relação $\mathrm{f}_{\mathrm{m}} / \mathrm{f}_{\mathrm{c}}$.
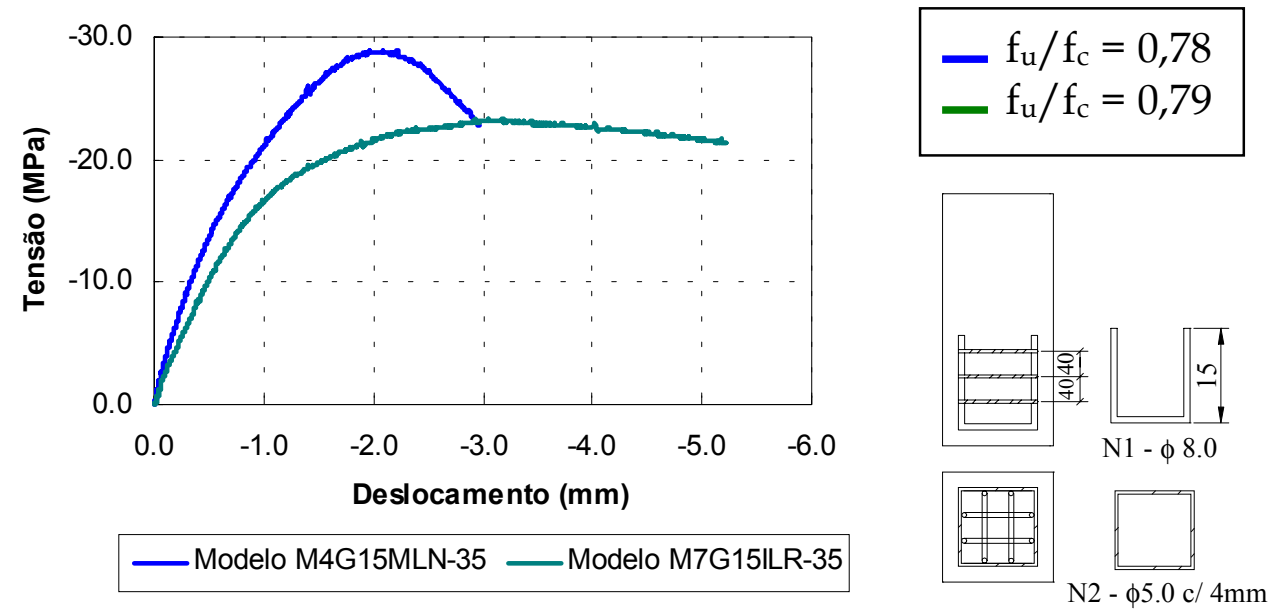

Figura 5. 17: Efeito da armadura de reforço no comportamento do modelo.

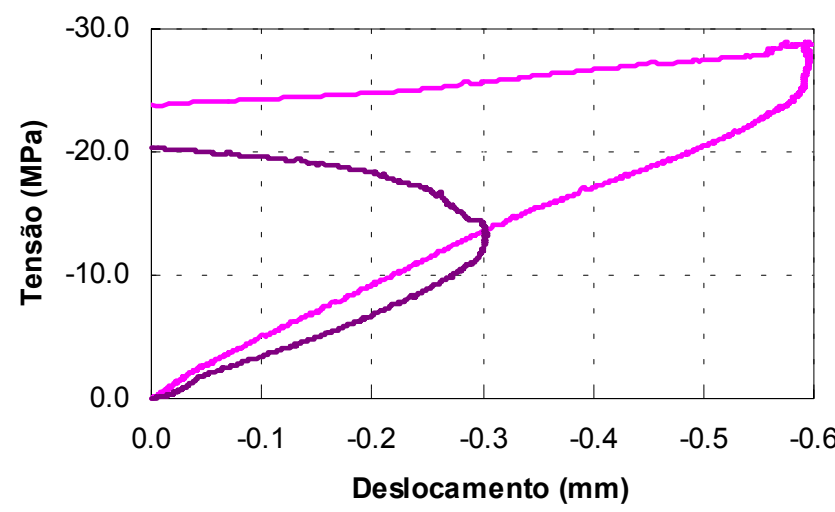

$$
\begin{array}{r}
\mathrm{f}_{\mathrm{u}} / \mathrm{f}_{\mathrm{m}}=0,89 \\
-\mathrm{f}_{\mathrm{u}} / \mathrm{f}_{\mathrm{m}}=0,80
\end{array}
$$

_Junta M4G15MLN-35 _ Junta M7G15ILR-35

Figura 5. 18: Efeito da armadura de reforço no comportamento da junta. 
Pode-se perceber que a presença da armadura não trouxe melhoria para a capacidade resistente do modelo, mas tornou-o mais dúctil e aumentou a capacidade resistente da junta. Com a configuração de ruína mostrada na Figura 5.19, percebe-se que as tensões de fendilhamento que causam o descolamento do cobrimento de concreto dos segmentos pré-moldados ficam mais restritas à região da junta, ou seja, definem uma área menor de ruptura.

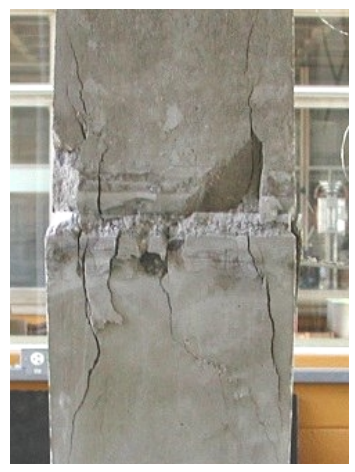

a) M4G15MLN-35

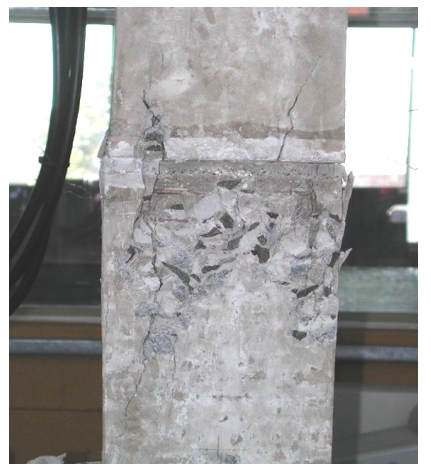

b) M7G15ILR-35

Figura 5. 19: Configuração de ruína do modelo sem armadura de reforço e com armadura de reforço.

Com os resultados obtidos através dos extensômetros elétricos colados nas armaduras, foram traçados gráficos tensão $\mathrm{x}$ deformação para todas as amostras ensaiadas. Um exemplo destes gráficos é mostrado na Figura 5.20. As barras 1, 2, 3 e 4 foram posicionadas no segmento pré-moldado inferior e as demais no segmento pré-moldado superior. Praticamente todas as armaduras entraram em escoamento com cerca de $60 \%$ da tensão última atingida no modelo, que foi 23,3 MPa. 

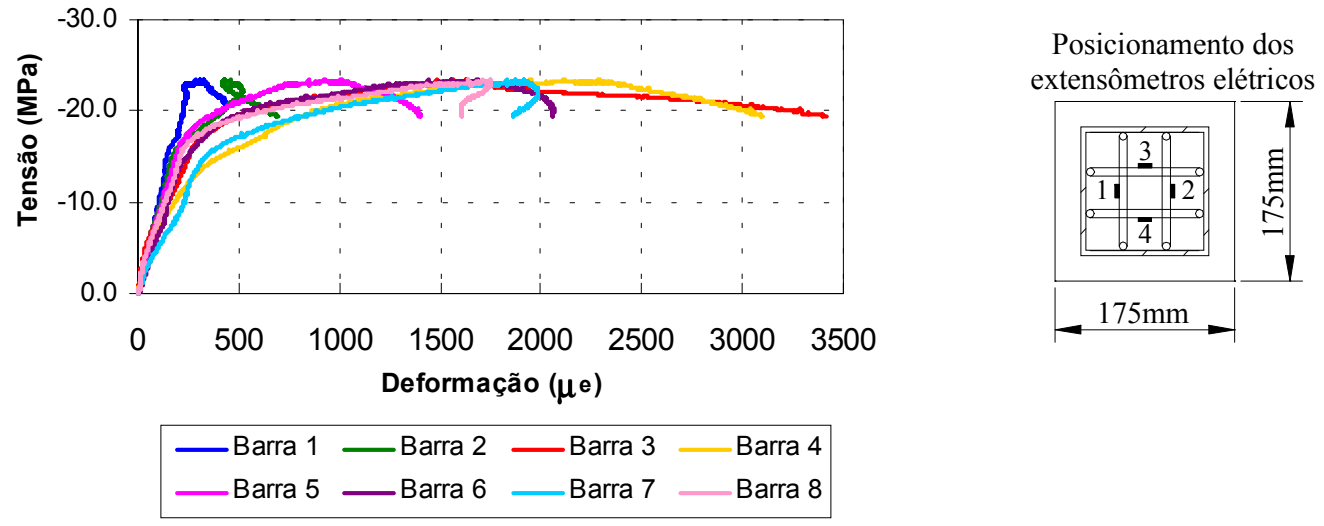

Figura 5. 20: Comportamento dos extensômetros colados nas armaduras.

\subsection{Influência do Tipo de Argamassa}

De acordo com VAMBESKY (1990), o graute fluido seria o mais indicado para preenchimento de juntas de argamassa. Pelos ensaios realizados verificou-se que isso ocorre se for usado um graute fino, pois a presença de agregados maiores na mistura pode facilitar o aparecimento de bolhas de ar na ligação. A partir daí, resolveu-se avaliar o comportamento da ligação usando para preenchimento uma argamassa seca do tipo "Dry Pack", mostrada na Figura 5.21a, comumente usada entre painéis pré-moldados na América do Norte, cuja resistência à compressão é geralmente alta. Este tipo de material foi avaliado no modelo M10DP15SLN-35, com relação $f_{m} / f_{c}$ igual a 1,26.

Durante a execução das amostras, verificou-se maior facilidade no preenchimento da junta, mesmo para uma espessura delgada. O preenchimento foi feito introduzindo o material por um dos lados da junta, como mostra a Figura 5.21b, e pressionando-o contra o fundo da forma para eliminar qualquer vazio. Na Figura 5.21c tem-se a junta já executada. 


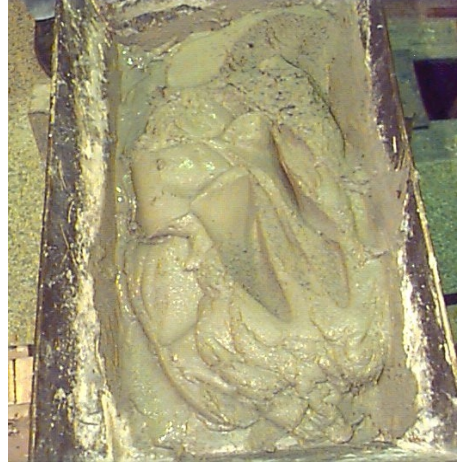

a) argamassa "Dry Pack"

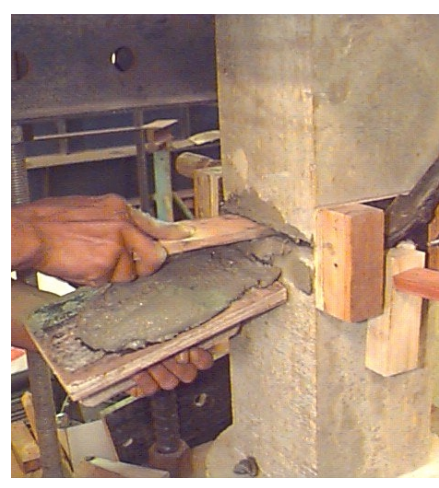

b) preenchimento da junta

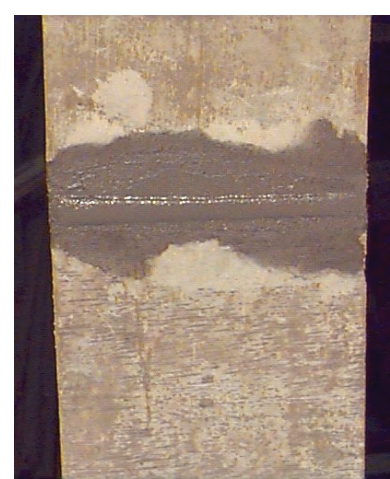

c) junta executada

Figura 5. 21: Junta preenchida com argamassa tipo “Dry Pack”.

Os resultados obtidos no modelo, comparados com os resultados do modelo M4G15MLN-35, podem ser vistos nas Figuras 5.22 e 5.23. Por ser uma argamassa mais resistente o modelo fica menos flexível, porém menos dúctil. Entretanto, após a acomodação inicial, tem-se um material de junta com comportamento mais uniforme até a ruptura. A tensão última atingida no modelo, 38,6 MPa, foi praticamente igual a resistência à compressão dos segmentos pré-moldados, $40 \mathrm{MPa}$, pode-se dizer que praticamente não houve redução.

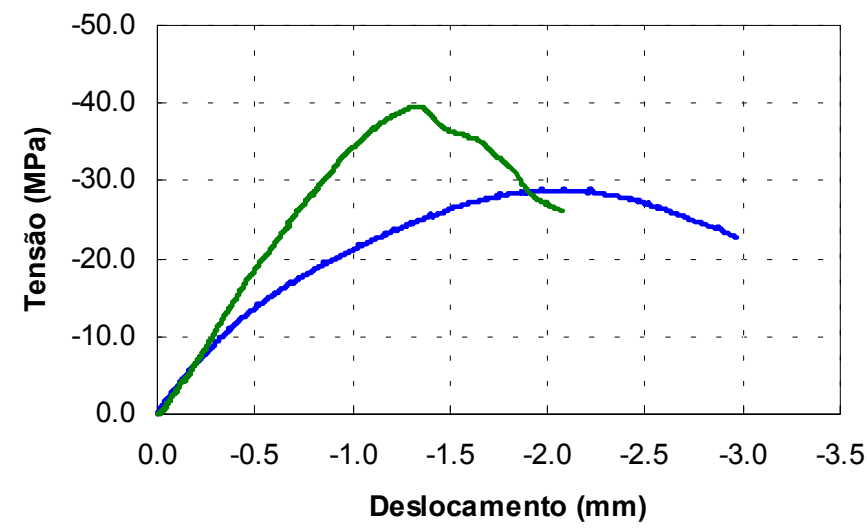

$$
\begin{array}{r}
-\mathrm{f}_{\mathrm{u}} / \mathrm{f}_{\mathrm{c}}=0,78 \\
-\mathrm{f}_{\mathrm{u}} / \mathrm{f}_{\mathrm{c}}=0,97
\end{array}
$$

Modelo M4G15MLN-35 Modelo M10DP15SLN-35

Figura 5. 22: Comportamento do modelo com junta de argamassa tipo "Dry Pack". 


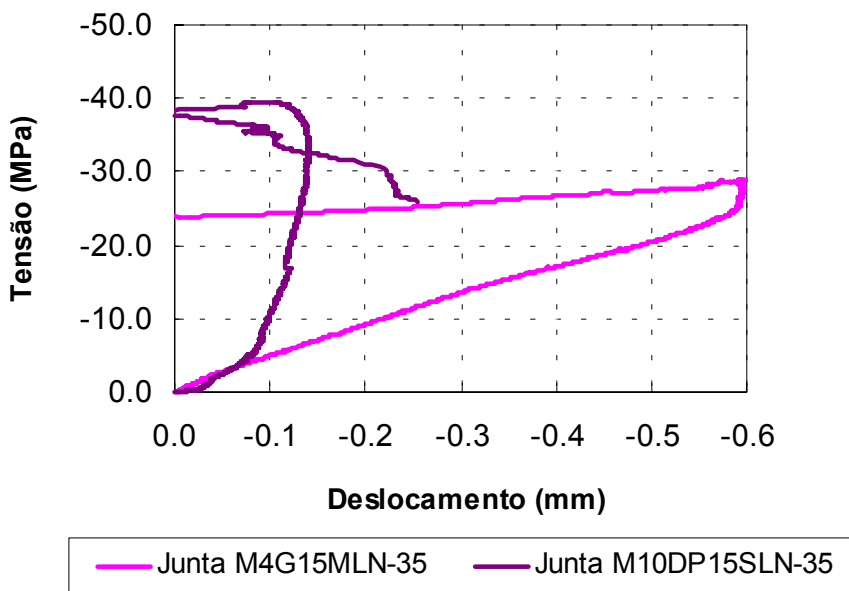

$\mathrm{f}_{\mathrm{u}} / \mathrm{f}_{\mathrm{m}}=0,89$

$-\mathrm{f}_{\mathrm{u}} / \mathrm{f}_{\mathrm{m}}=0,77$

Figura 5. 23: Diagrama tensão x deslocamento da junta de argamassa tipo "Dry Pack" em comparação com junta executada com graute.

A configuração de ruína do modelo, mostrada na figura 5.24, indica a presença de tensões de fendilhamento nos segmentos pré-moldados e menor deterioração da junta propriamente dita. Por ser um concreto de resistência baixa, o aumento de rigidez na junta trouxe maiores aberturas de fissuras no segmento inferior Ao final do ensaio verificou-se quebra de aderência na interface segmento superior/junta de argamassa.

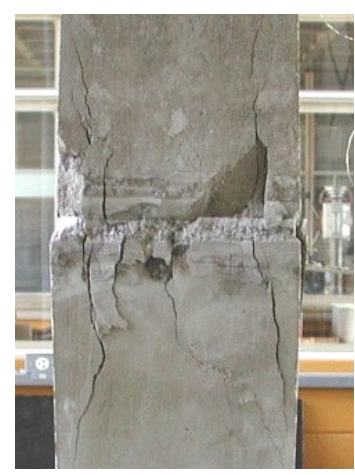

a) M4G15MLN-35

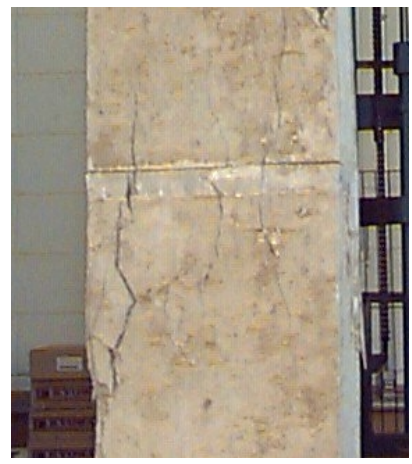

b) M10DP15SLN-35

Figura 5. 24: Configuração de ruína. 


\subsection{Influência de um Contato Descontínuo entre os Segmentos Pré-moldados}

Este parâmetro explorado anteriormente na simulação numérica, procurava caracterizar os efeitos causados pela transmissão de esforços de um elemento pré-moldado para o outro através de uma superfície de contato irregular. Pode-se observar que ocorre uma concentração de tensões nos pontos de aplicação do carregamento que faz com que os elementos sofram ruptura localizada.

Partindo dessa observação, procurou-se inicialmente, na investigação experimental, caracterizar o efeito da presença de uma camada de argamassa em relação ao contato direto entre as peças e a partir daí avaliar quais seriam as alterações de comportamento se a superfície dos segmentos pré-moldados fosse irregular. Foram avaliados modelos com resistência à compressão de $35 \mathrm{MPa}$ e $60 \mathrm{MPa}$.

Para o concreto de resistência mais baixa, o efeito da presença de uma camada de argamassa foi avaliado comparando-se o modelo M11SLN-35, sem junta de argamassa, com o modelo M1G15ILN-35 com junta de argamassa de $15 \mathrm{~mm}$ de espessura e relação $\mathrm{f}_{\mathrm{m}} / \mathrm{f}_{\mathrm{c}}$ igual a 0,75 , como mostra a Figura 5.25. Pode-se observar que a presença de uma argamassa entre os elementos diminuiu a flexibilidade e permitiu um aumento de $7 \%$ na capacidade resistente do modelo, em relação ao valor teórico absorvido pelo concreto prémoldado. Observou-se também que no modelo sem junta não houve ganho expressivo de resistência até a ruptura, o que significa que o processo de danificação dos segmentos pré-moldados começou muito cedo, caracterizando assim, uma região de ruptura maior, como mostra a Figura 5.26. 


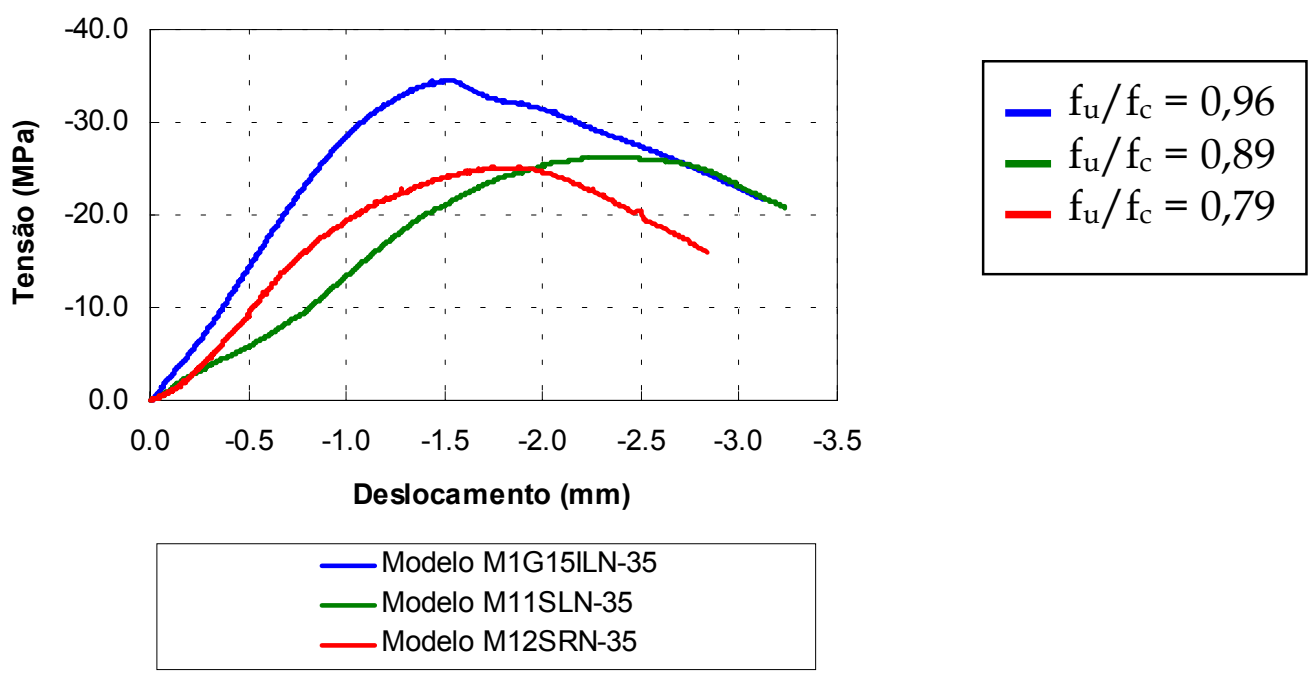

Figura 5. 25: Efeito da presença da junta de argamassa.

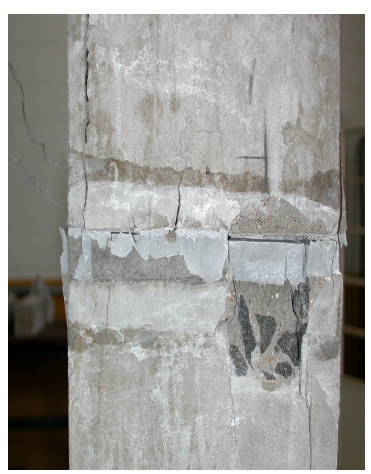

a) M1G15ILN-35

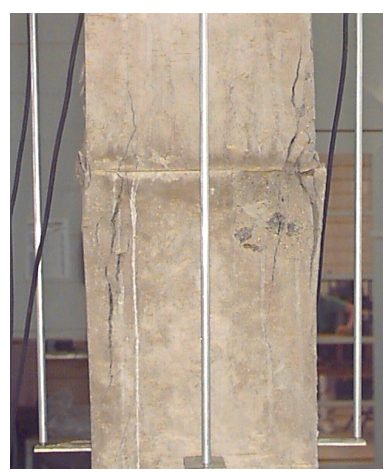

b) M11SLN-35

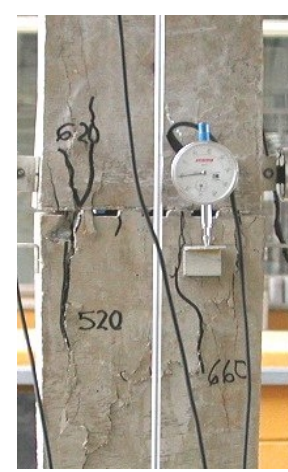

c) M12SRN-35

Figura 5. 26: Configuração de ruína dos modelos.

Com relação à descontinuidade na superfície de contato, avaliada com o modelo M12SRN-35, observou-se que em relação ao modelo M11SLN-35 houve um aumento de rigidez antes da ruptura, mas houve redução na capacidade resistente do modelo. Isso porque o processo de ruptura se inicia de forma mais localizada nos pontos de descontinuidade e se estende inicialmente para o elemento inferior, como mostra a Figura 5.24. Com a junta de argamassa esse efeito seria minimizado. 
Para o concreto de alta resistência, o efeito da presença de uma camada de argamassa foi avaliado comparando-se o modelo M13SLN-60, sem junta de argamassa, com o modelo M6G15ILN-60 com junta de argamassa de 15mm de espessura e relação $\mathrm{f}_{\mathrm{m}} / \mathrm{f}_{\mathrm{c}}$ igual a 0,40 , como mostra a Figura 5.27.

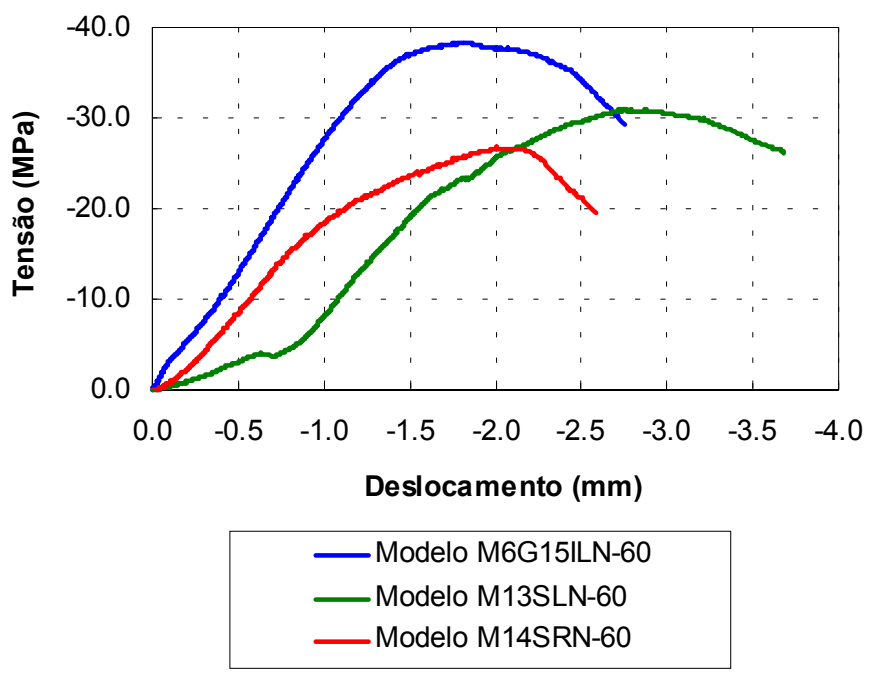

$$
\begin{array}{r}
-\mathrm{f}_{\mathrm{u}} / \mathrm{f}_{\mathrm{c}}=0,58 \\
-\mathrm{f}_{\mathrm{u}} / \mathrm{f}_{\mathrm{c}}=0,55 \\
-\mathrm{f}_{\mathrm{u}} / \mathrm{f}_{\mathrm{c}}=0,49
\end{array}
$$

Figura 5. 27: Efeito da junta de argamassa no modelo de alta resistência.

Assim como no caso anterior, a junta de argamassa proporcionou um ganho mais efetivo de resistência, pois uniformizou a distribuição de tensões entre os segmentos, além de aumentar a rigidez do modelo. Com relação à descontinuidade na superfície de contato, avaliada através do modelo M13SRN-60, observou-se que o modelo se mostrou mais rígido, porém menos dúctil devido à ruptura localizada, mostrada na Figura 5.28.

Nos modelos ensaiados sem junta, a perda da capacidade resistente em relação à resistência do concreto pré-moldado usado nos segmentos é mais significativa para os modelos de alta resistência. No modelo M14SRN-35, chegou-se a uma redução de $51 \%$. 


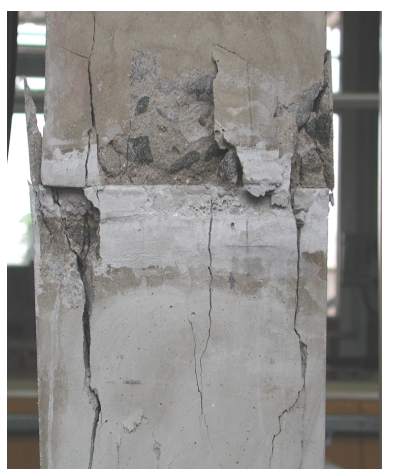

a) M6G15ILN-60

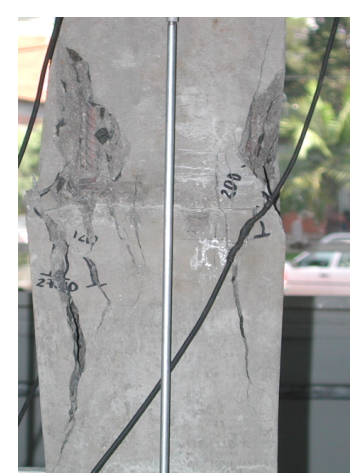

b) M13SLN-60

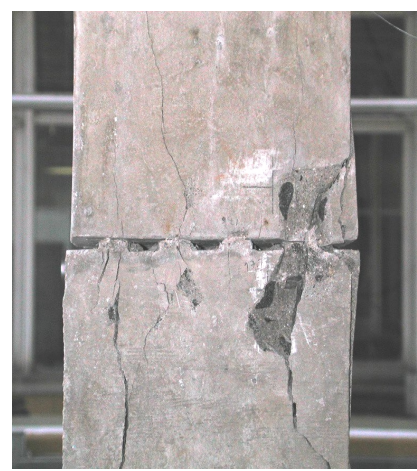

c) M14SRN-60

Figura 5. 28: Configuração de ruína dos modelos de alta resistência.

A rugosidade na superfície dos elementos pré-moldados foi executada colando-se faixas de madeira de $5 \mathrm{~mm}$ de espessura no fundo da forma, como descrito no Capítulo 4. Com esse procedimento as saliências ficaram muito altas, diferente do que ocorre na prática, entretanto obteve-se uma situação mais crítica para a concentração de esforços. A presença da junta de argamassa entre as peças, minimizaria essa concentração e a rugosidade poderia melhorar a condição de atrito na junta.

Segundo DILGER \& CHUI (1989), na ligação entre elementos prémoldados com concreto moldado no local, se a superfície dos elementos é muito rugosa, então toda a resistência à compressão do material de preenchimento pode ser considerada, o que significa dizer que não ocorre redução da capacidade resistente do material.

\subsection{Comportamento da Junta de Argamassa Comparada a Ligação com Almofada de Apoio de Argamassa Flexível}

Como dito anteriormente no Capítulo 4, além de analisar o comportamento de juntas de argamassa executada com materiais comercialmente disponíveis, foram ensaiados dois modelos colocando-se uma 
almofada de apoio de argamassa flexível entre os segmentos pré-moldados. Essa almofada de apoio vem sendo estudada por EL DEBS et al. (2001), como uma alternativa ao elastômero no caso de ligação viga-pilar.

No primeiro modelo, M8AF15SLN-35, os segmentos foram executados com superfície plana e foi usada uma almofada contendo fibras de polipropileno. No segundo modelo, M8AF15SLN-60, executado com segmentos pré-moldados de alta resistência, foi usada uma almofada com fibras de PVA. Já no modelo, M9AF15SRN-35, a almofada de apoio foi executada com fibras de polipropileno e o segmento pré-moldado inferior foi executado com uma superfície descontínua, como mostra a Figura 5.29. Em todos os modelos a espessura da almofada foi de $15 \mathrm{~mm}$.

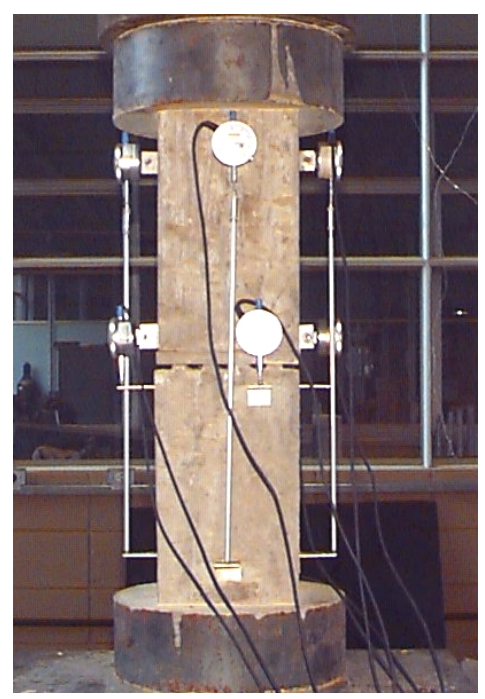

Figura 5. 29: Modelo M9AF15SRN-35.

A relação $f_{m} / f_{c}$ nas amostras do modelo M8AF15SLN-35, ensaiadas com almofada de fibra de polipropileno, foi igual a 1,2. Os resultados obtidos, mostrados nas Figura 5.30 e 5.31, foram comparados com os resultados do modelo M4G15MLN-35 de relação $\mathrm{f}_{\mathrm{m}} / \mathrm{f}_{\mathrm{c}}$ igual a 0,9 e com os resultados do modelo sem junta M11SLN-35.

Observou-se que a capacidade resistente dos três modelos foi 
praticamente a mesma, ou seja, o acréscimo na relação $f_{m} / f_{c}$ devido ao aumento da resistência à compressão da argamassa não teve efeito significativo. Porém a almofada de apoio é bem mais flexível e devido a essa flexibilidade, pode-se perceber uma maior distribuição das tensões na junta, conseqüentemente menor deterioração dos segmentos pré-moldados. A configuração de ruína dos modelos é mostrada na Figura 5.32.

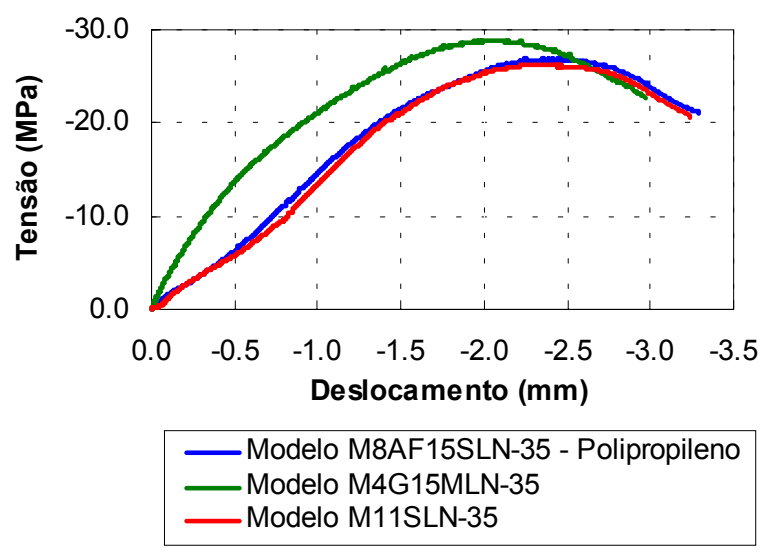

$$
\begin{aligned}
& -\mathrm{f}_{\mathrm{u}} / \mathrm{f}_{\mathrm{c}}=0,85 \\
& -\mathrm{f}_{\mathrm{u}} / \mathrm{f}_{\mathrm{c}}=0,78 \\
& -\mathrm{f}_{\mathrm{u}} / \mathrm{f}_{\mathrm{c}}=0,89
\end{aligned}
$$

Figura 5. 30: Comportamento do modelo com almofada de apoio de polipropileno.

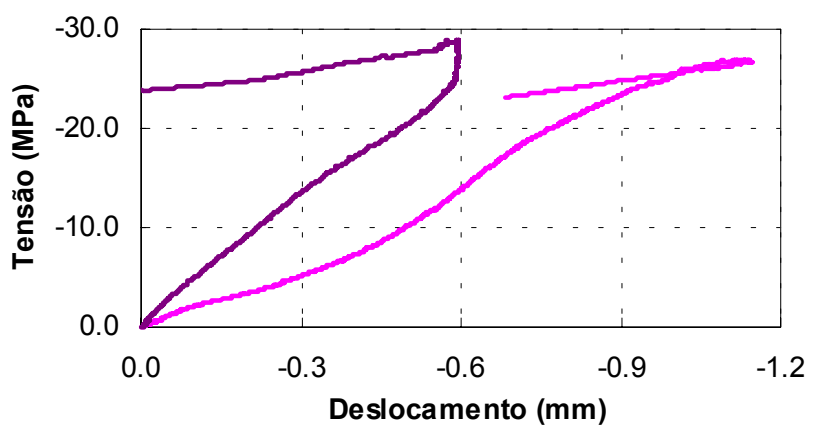

$$
\begin{array}{r}
-\mathrm{f}_{\mathrm{u}} / \mathrm{f}_{\mathrm{m}}=0,70 \\
-\mathrm{f}_{\mathrm{u}} / \mathrm{f}_{\mathrm{m}}=0,89
\end{array}
$$

_ Junta M8AF15SLN-35 _ Junta M4G15MLN-35

Figura 5. 31: Comportamento da junta com almofada de apoio de polipropileno. 


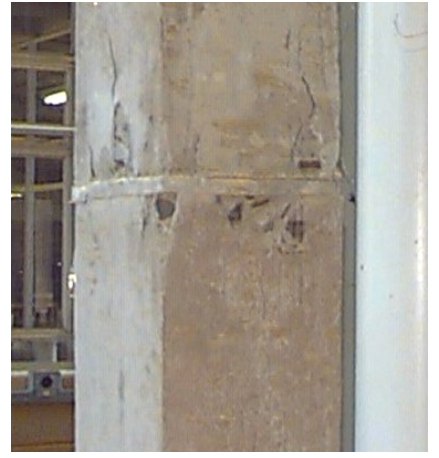

a) M8AF15SLN-35

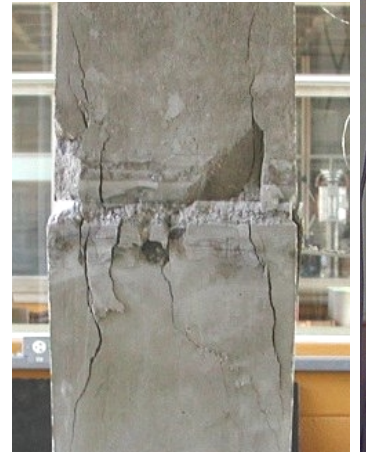

b) M4G15MLN-35

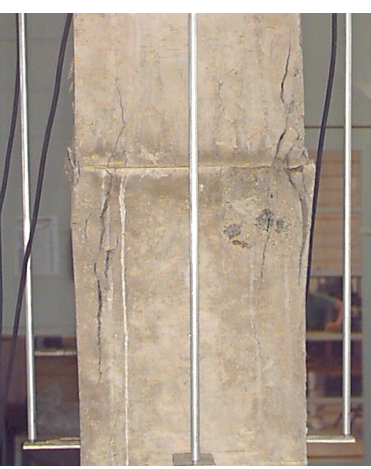

c) M11SLN-35

Figura 5. 32: Configuração de ruína dos modelos.

A ligação com almofada de apoio tende a ser uma situação intermediária entre a junta de argamassa e o contato direto entre as peças.

No modelo M8AF15SLN-60, ensaiado com almofada de fibra de PVA, usou-se um concreto de resistência 73,4MPa para os segmentos pré-moldados e a relação $f_{m} / f_{c}$ foi igual a 0,4 . Os resultados obtidos foram comparados com os resultados do modelo M6G15ILN-60 e do modelo M13SLN-60, como mostram as Figuras 5.33 e 5.34, por serem também de alta resistência.

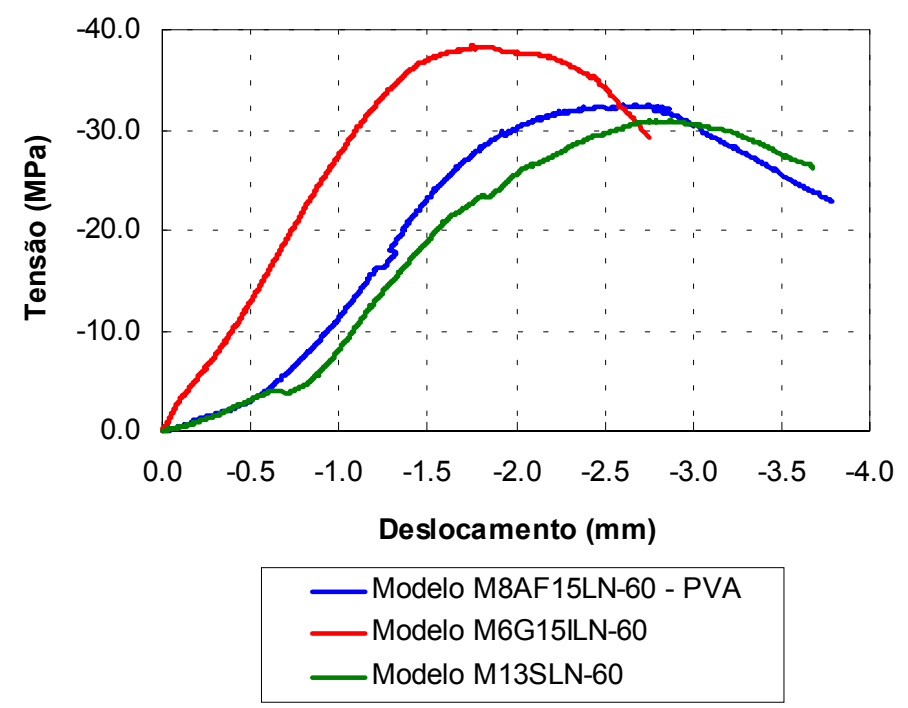

$$
\begin{array}{r}
-\mathrm{f}_{\mathrm{u}} / \mathrm{f}_{\mathrm{c}}=0,44 \\
-\mathrm{f}_{\mathrm{u}} / \mathrm{f}_{\mathrm{c}}=0,58 \\
-\mathrm{f}_{\mathrm{u}} / \mathrm{f}_{\mathrm{c}}=0,55
\end{array}
$$

Figura 5. 33: Comportamento do modelo com almofada de apoio de PVA. 
Observa-se que em relação ao valor teoricamente resistido pelo concreto pré-moldado, houve menor aproveitamento para o modelo com almofada de apoio de PVA, apesar do ganho de ductilidade em relação ao modelo com junta de argamassa. Talvez uma almofada com menos teor de fibra proporcionasse melhor comportamento.

Devido à flexibilidade da almofada de apoio o comportamento das tensões é mais uniforme, conseqüentemente ocorre menos deterioração dos segmentos pré-moldados, como mostra a Figura 5.35, e a ruptura se torna mais dúctil.

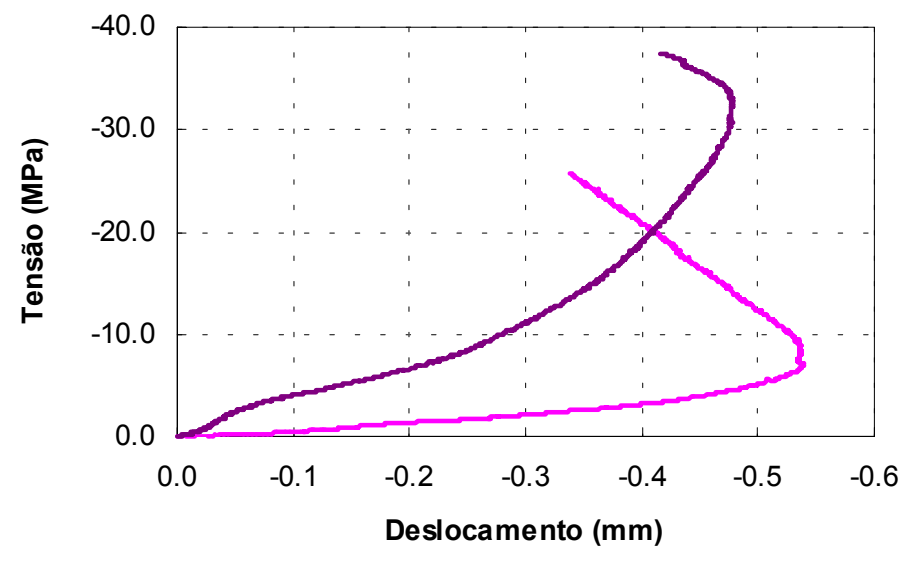

$\mathrm{f}_{\mathrm{u}} / \mathrm{f}_{\mathrm{m}}=1,20$

$\mathrm{f}_{\mathrm{u}} / \mathrm{f}_{\mathrm{m}}=1,56$

_ Junta M8AF15LN-60 - PVA _ Junta M6G15ILN-60

Figura 5. 34: Comportamento da junta com almofada de apoio de PVA.

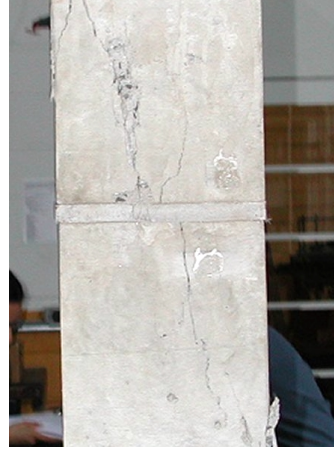

a) M8AF15SLN-60

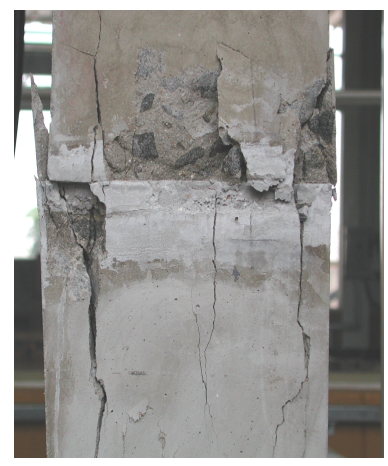

b) M6G15ILN-60

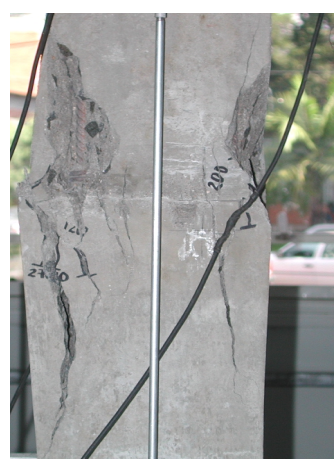

c) M13SLN-60

Figura 5. 35: Configuração de ruína do modelo com almofada de apoio de PVA comparada às dos outros modelos. 
Observando-se mais detalhadamente o comportamento das almofadas de apoio de polipropileno e PVA, como mostra a Figura 5.36, vê-se que a deformabilidade das duas almofadas é semelhante. Entretanto, a acomodação inicial da almofada de PVA é menor e seu comportamento é mais uniforme durante o carregamento. Isso porque, a fissuração na almofada de polipropileno ocorre muito cedo, conseqüentemente, deixa mais flexível a junta. Esta fissuração precoce prejudicou a instrumentação do modelo, pois causou o destacamento prematuro de parte do cobrimento no segmento prémoldado. Ao final dos ensaios pode-se ver que a almofada de Polipropileno ficou bem mais fissurada, como mostra a Figura 5.37. Observou-se também que, a tensão última no modelo com a almofada de PVA foi $20 \%$ maior que o valor teórico resistido pela argamassa.

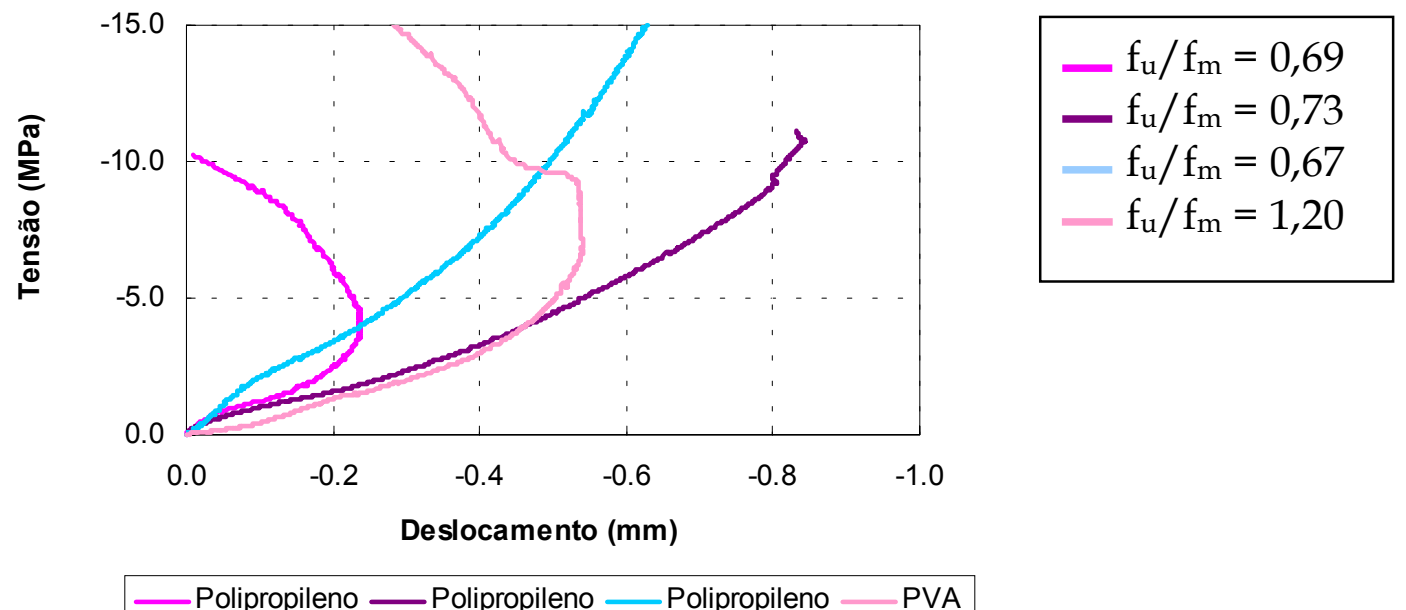

Figura 5. 36: Comportamento das almofadas de apoio. 


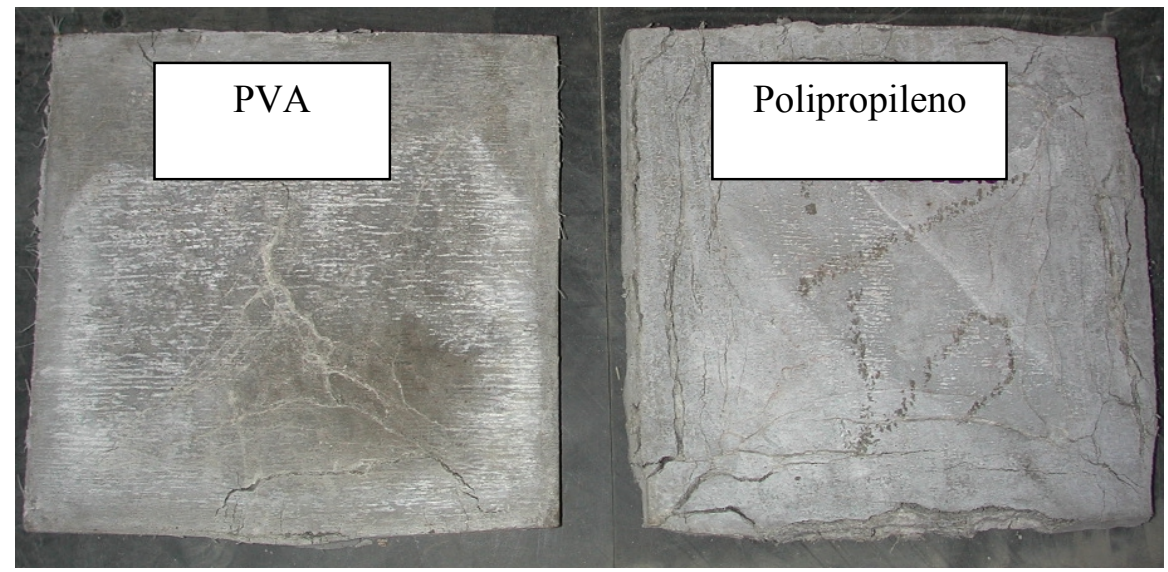

Figura 5. 37: Configuração de ruína das almofadas de apoio.

No modelo M9AF15SRN-35, foi avaliado o comportamento da almofada de apoio de polipropileno sobre uma superfície descontínua. Os resultados obtidos, mostrados nas Figuras 5.38 e 5.39, foram comparados com os resultados do modelo anterior com superfície plana e com o modelo M12SRN35 com superfície descontínua e sem almofada de apoio. Observa-se uma redução na capacidade resistente do modelo, maior deformabilidade na junta e um comportamento não uniforme devido à concentração de esforços nas saliências. Entretanto, tem-se um comportaemnto mais dúctil em relação ao modelo M12SRN-35.

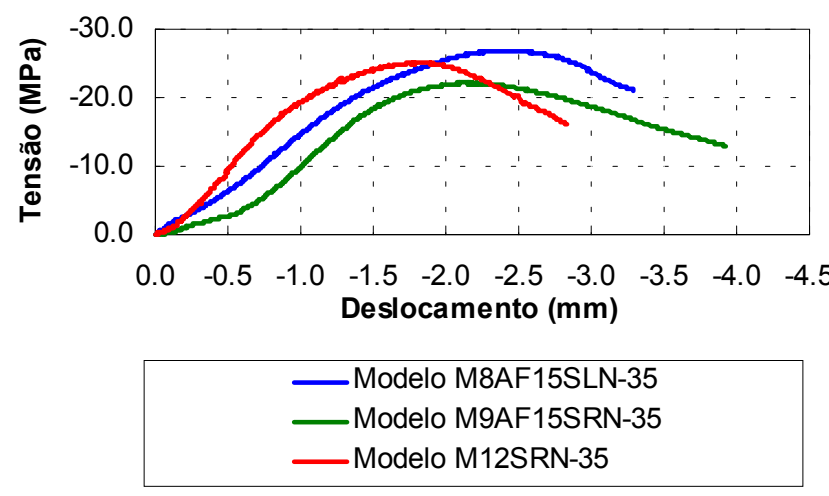

$$
\begin{array}{r}
-\mathrm{f}_{\mathrm{u}} / \mathrm{f}_{\mathrm{c}}=0,85 \\
-\mathrm{f}_{\mathrm{u}} / \mathrm{f}_{\mathrm{c}}=0,73 \\
-\mathrm{f}_{\mathrm{u}} / \mathrm{f}_{\mathrm{c}}=0,79
\end{array}
$$

Figura 5. 38: Comportamento do modelo com almofada de polipropileno sobre superfície descontínua. 


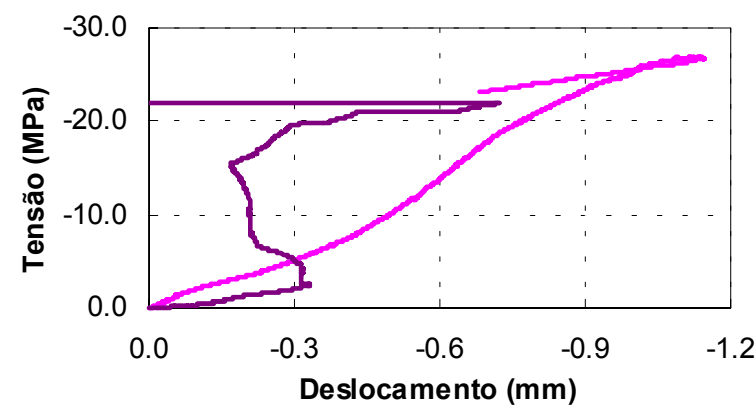

$$
\begin{aligned}
-\mathrm{f}_{\mathrm{u}} / \mathrm{f}_{\mathrm{m}} & =0,70 \\
-\mathrm{f}_{\mathrm{u}} / \mathrm{f}_{\mathrm{m}} & =0,55
\end{aligned}
$$

Figura 5. 39: Comportamento da junta com almofada de polipropileno sobre superfície descontínua.

Como visto anteriormente, a concentração de tensões embaixo dos pontos de contato faz com que ocorra ruptura localizada nos segmentos prémoldados. Devido à altura das saliências, os dois lados da almofada de apoio que ficavam em balanço sofreram flexão aumentando a deformabilidade no modelo e acelerando o processo de fissuração. A configuração de ruína do modelo e da almofada de apoio é mostrada na Figura 5.40. Pode-se perceber na almofada a definição de um núcleo praticamente intacto e o destacamento da camada externa.
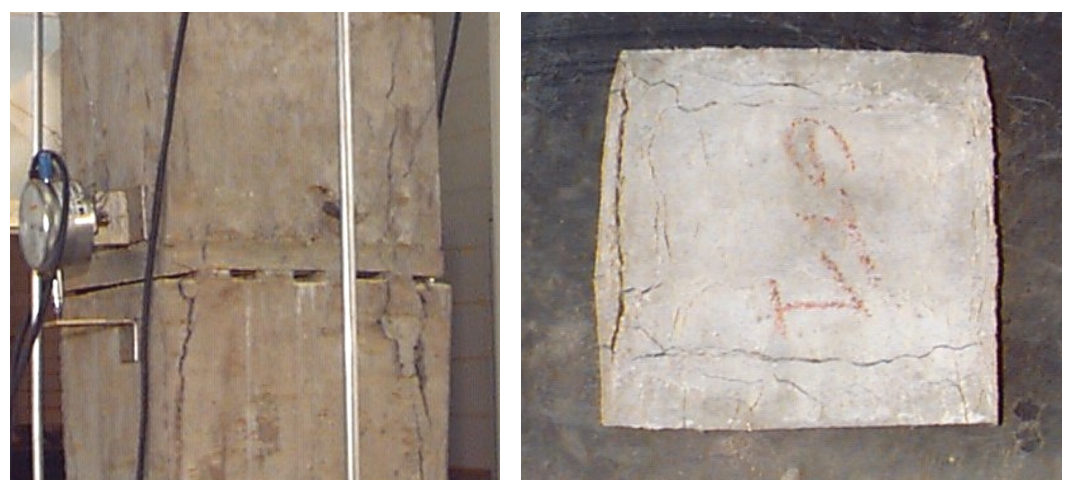

Figura 5. 40: Configuração de ruína do modelo e da almofada de apoio. 


\subsection{Comentários Adicionais}

Com a avaliação experimental da ligação, bem como com a simulação numérica dos parâmetros de influência, pode-se comprovar que a espessura da camada de argamassa e a relação entre as resistências do material da junta e do concreto pré-moldado são os fatores de maior importância. Aliado a isso, os procedimentos de execução, dependendo do material de preenchimento, pode agravar a perda da capacidade resistente do sistema.

Ao usar uma argamassa mais rígida na região da ligação, a junta de argamassa deixa de ser o ponto fraco do sistema e as tensões de fendilhamento no elemento pré-moldado passam a ter maior intensidade.

O uso de uma armadura de reforço na região da ligação não traz aumento para a capacidade resistente, entretanto aumenta a ductilidade do sistema e diminui a região de ruptura.

Com os resultados obtidos nos ensaios de diversas amostras, nas quais as variáveis eram as resistências do concreto pré-moldado e da argamassa, determinou-se o diagrama mostrado na Figura 5.41. Pode-se dizer que ao aumentar a resistência da camada de argamassa, sem o aumento da resistência do concreto pré-moldado, não se tem ganhos significativos para a capacidade resistente da ligação. Aumentando-se a resistência do concreto pré-moldado sem aumentar a resistência da camada de argamassa tem-se apenas uma pequena melhoria na capacidade resistente da junta. Aumentando-se a resistência do concreto pré-moldado e a resistência da camada de argamassa tem-se um aumento significativo na capacidade resistente do modelo, e as tensões de fendilhamento passam a ser o fator preocupante. 


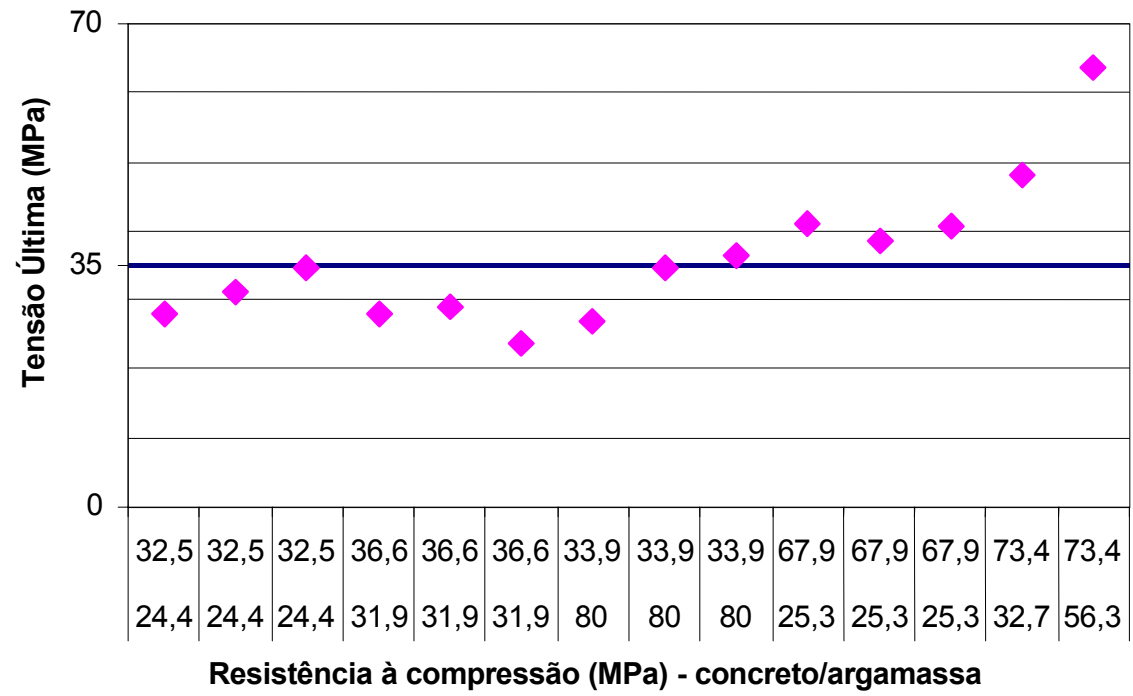

Figura 5. 41: Diagrama comparativo para as amostras ensaiadas.

Dessa forma, pensando-se numa situação otimizada para concreto usual de $35 \mathrm{MPa}$, a relação $\mathrm{f}_{\mathrm{m}} / \mathrm{f}_{\mathrm{c}}$ estaria em torno de 0,8 . Já para um concreto de alta resistência, seriam necessários mais ensaios para se ter um valor conclusivo, avaliando mais detalhadamente as tensões de fendilhamento.

A partir da análise feita nesse capítulo, serão tiradas as conclusões para o comportamento da ligação estudada. 


\section{Considerações Finais e Conclusões}

O levantamento bibliográfico realizado sobre o comportamento da ligação com juntas de argamassa mostrou que o número reduzido de pesquisas desenvolvidas faz com que não exista um consenso sobre as recomendações que devem ser adotadas na execução e projeto, principalmente considerando-se os novos materiais disponíveis no mercado. Nesse levantamento bibliográfico, bem como nas simulações numéricas desenvolvidas no trabalho, viu-se que os parâmetros que mais influenciam o comportamento da ligação são a espessura da camada de argamassa e a relação entre as resistências do concreto pré-moldado e da argamassa. Além disso, durante o processo de execução dos modelos ensaiados, pode-se perceber que as juntas de argamassa são bem sensíveis às condições de execução.

Numa junta mais delgada tem-se maior dificuldade em uniformizar a espessura. Já numa junta mais espessa, a presença de vazios tende a ser mais acentuada. Apesar de ELLIOT (1996) recomendar espessura da junta entre 10 e $15 \mathrm{~mm}$, com os resultados obtidos no trabalho chegou-se a conclusão que uma espessura de $20 \mathrm{~mm}$ seria a mais indicada, pois além de se ter minimizado o 
efeito de descontinuidade provocado pela presença da junta ter-se-ia melhor controle para uniformidade da espessura e aparecimento de vazios.

Observou-se também que, com essa espessura de junta, a capacidade resistente da ligação entre elementos pré-moldados de resistência usual de $35 \mathrm{MPa}$ teria uma redução em torno de $5 \%$ em relação ao valor teoricamente resistido pelo concreto, com relação $\mathrm{f}_{\mathrm{m}} / \mathrm{f}_{\mathrm{c}}$ em torno de 0,8 . Mesmo com esta redução, obteve-se um acréscimo de $28 \%$ em relação à resistência à compressão da argamassa, ratificando então o bom comportamento da junta.

$\mathrm{O}$ aumento da relação $\mathrm{f}_{\mathrm{m}} / \mathrm{f}_{\mathrm{c}}$ pelo aumento da resistência da argamassa, não trouxe ganhos significativos para a capacidade resistente da junta. Entretanto, a ruptura não ocorreu por esmagamento da camada de argamassa e sim por fendilhamento do segmento superior. Além disso, percebeu-se que quando as resistências dos dois materiais eram semelhantes, para um concreto pré-moldado usual de $35 \mathrm{MPa}$, não havia grande absorção de esforços até a ruptura e as fissuras se propagavam mais rapidamente de um elemento para o outro. Esse fato aumentava a região de danificação no elemento.

O uso de concreto de alta resistência no elemento pré-moldado faz com que as tensões de fendilhamento tenham maior importância e o efeito de descolamento do cobrimento é mais acentuado. Os ensaios mostraram que para um maior aproveitamento da capacidade resistente da junta, o material de preenchimento também deve ser de alta resistência.

A presença de uma armadura de reforço na região do elemento prémoldado adjacente à junta não trouxe aumento para a capacidade resistente do modelo, entretanto, aumentou a ductilidade no sistema e a capacidade resistente da junta, bem como restringiu a região de ruína às proximidades da mesma.

Os valores de deformabilidade da ligação, determinados nas simulações numéricas e no programa experimental, foram em sua maioria maiores que o indicado por BJLUGER (1988). Entretanto, viu-se que tanto as condições de 
execução quanto o material de preenchimento, interferem no comportamento da ligação. Isso faz com que não se tenha caracterizado um único valor de deformabilidade.

Dos diversos materiais usados para o preenchimento da junta, a argamassa do tipo "Dry Pack" foi a que ofereceu melhores condições de execução, mesmo para uma junta delgada. Por ser geralmente de alta resistência, colocada entre elementos pré-moldados de resistência usual de 35MPa praticamente não houve perda na capacidade resistente do modelo em relação à resistência do concreto pré-moldado. A ligação ficou menos deformável e conseqüentemente menos fissurada.

Adotando-se o preenchimento com graute fluido percebeu-se que quando os segmentos pré-moldados não possuíam superfícies perfeitamente planas, a falta de uniformidade na espessura da junta proporcionava o aparecimento de vazios e a aderência na interface concreto prémoldado/argamassa ficava prejudicada. Nesse caso, deve-se optar por graute com granulometria mais fina, embora seja menos resistente.

Tanto nos ensaios realizados, quanto nas simulações numéricas, observou-se que a área confinada pelos estribos no segmento pré-moldado definia a área efetiva para transmissão de esforços através da junta, ou seja, a redução nas dimensões da área da seção transversal era igual ao cobrimento de concreto no segmento pré-moldado.

De forma geral, chegou-se às seguintes considerações:

- junta de argamassa com 20mm de espessura;

- relação $\mathrm{f}_{\mathrm{m}} / \mathrm{f}_{\mathrm{c}}$ em torno de 0,8 para elementos pré-moldados com resistência usual de 35MPa;

- entre elementos pré-moldados de alta resistência, o material de preenchimento da junta deve ser de alta resistência ; 
- o uso de uma armadura de reforço em forma de grelha na região do elemento pré-moldado adjacente à junta, não altera a capacidade resistente do sistema, mas aumenta a ductilidade e reduz a região de danificação da ligação;

- o preenchimento da junta com argamassa seca diminui os defeitos de execução e conseqüentemente a deformabilidade da junta.

- considerar para cálculo da área efetiva da junta uma redução nas dimensões da seção transversal igual ao cobrimento de concreto no segmento pré-moldado;

Além dos materiais comercialmente disponíveis foram ensaiados alguns modelos colocando-se entre os segmentos pré-moldados uma almofada de apoio flexível à base de cimento com adição de fibras e modificada com látex, que vem sendo estudada como uma alternativa ao apoio com elastômero na ligação viga-pilar. Os primeiros resultados mostraram um bom comportamento na distribuição das tensões de contato, resultando numa melhor acomodação para os elementos pré-moldados, conseqüentemente menor danificação da região de ligação, mesmo nos elementos com superfície rugosa.

Ao final do trabalho percebeu-se que a abordagem dada ao assunto não é conclusiva. Como indicação para a continuidade da pesquisa, viu-se que no caso da armadura de reforço como só um modelo foi executado é necessário que se façam mais ensaios variando-se a taxa de armadura para tirar maiores conclusões.

Para a consideração da área resistente efetiva na junta, tornam-se necessários mais ensaios variando-se a espessura do cobrimento no elemento pré-moldado, para se chegar a uma definição conclusiva.

O estudo de uma almofada de apoio de argamassa mostrou-se uma boa alternativa para dissipação das tensões de contato, mesmo em superfície 
descontínua, pois a sua flexibilidade permite melhor acomodação dos elementos pré-moldados. Entretanto, ainda existe a necessidade de novos ensaios com outras composições para o material de tal forma que a redução da capacidade resistente do sistema seja mínima.

Sendo assim, vê-se que ainda há muito que percorrer para considerar que todos os parâmetros estão definidos e este trabalho representa apenas mais um passo no caminho do que ainda falta ser estudado. 


\section{Bibliografia}

AMERICAN CONCRETE INSTITUTE (1983). Building code requirements for reinforced concrete, ACI 318. Detroit.

AMERICAN CONCRETE INSTITUTE (1999). Building code requirements for reinforced concrete, ACI 318-R. Detroit.

ANSYS 5.5.1 (1998). MANUAIS

ASSOCIAÇÃO BRASILEIRA DE NORMAS TÉCNICAS (1987). NBR 7217 -

Agregados - Determinação da composição granulométrica. Rio de Janeiro, ABNT.

ASSOCIAÇÃO BRASILEIRA DE NORMAS TÉCNICAS (1987). NBR 9776 Agregados - Determinação da massa específica de agregados miúdos por meio do frasco de Chapman. Rio de Janeiro, ABNT.

ASSOCIAÇÃO BRASILEIRA DE NORMAS TÉCNICAS (1994). NBR 5738 - Concreto

- Ensaio de compressão de corpos-de-prova cilíndricos - Método de ensaio. Rio de Janeiro, ABNT.

ASSOCIAÇÃO BRASILEIRA DE NORMAS TÉCNICAS (1985). NBR 9062 - Projeto e execução de estruturas de concreto pré-moldado. Rio de Janeiro, ABNT.

ASSOCIAÇÃO BRASILEIRA DE NORMAS TÉCNICAS (2001). NBR 6118 - Projeto de estruturas de concreto - Procedimento (Projeto de revisão). Rio de Janeiro, ABNT.

BALLARIN, A. W. (1993). Desempenho das ligações de elementos estruturais prémoldados de concreto. São Carlos, Tese (Doutorado), EESC-USP, 255p.

BLJUGER, F. (1977) Non-linear concrete wall characteristics of significant importance in structural analysis. ACI Structural Journal, v.75, n.3, p.244-250, maijun. 
BJLUGER, F. (1978). Non-linear characteristics of joints in compression. In: RILEMCEB-CIB SYMPOSIUM MECHANICAL \& INSULATING PROPERTIES OF JOINTS OF PRECAST REINFORCED CONCRETE ELEMENTS, Athens, 1978. Proceedings. Athens, RILEM/CEB., p.159-169.

BLJUGER, F. (1988). Design of precast concret structures. Ellis Horwood Limited, Englan, 296p.

BRUGGELING A. S. G. \& HUYGHE, G. F. (1991). Prefabrication with concrete. A. A. Balkema, Netherlands, 377p.

CHEN, W. F. (1982). Plasticity in Reinforced Concrete. McGraw-Hill Book Company, EUA, 474p.

CHEOK, G. S.; LEW, H. S. (1991). Performance of precast concrete beam-to-column connections subject to cyclic loading. PCI Journal, v.36, n.3, p.56-67, mai-jun.

COMITÊ EURO-INTERNACIONAL DU BETON (1985) Draft guide for the design of precast wall connections, Bolletin D'Informattion 169, April, CEB.

COMITÊ EURO-INTERNACIONAL DU BETON (1991). Model Code, First draft, Bolletin D'Informattion 204, CEB-FIP.

COMITE EURO-INTERNACIONAL DU BETON (1995). High performance concrete -Recomended extensions to the model code 90 - Research needs, Bolletin D'Informattion 228, July, CEB.

DILGER, W. H. \& CHUI, J. (1989). Strength of skew joints in concrete compression members. PCI Journal, v.34, n.2, p.66-83, mar-abr.

DRAGOSAVIC, M. (1978). Load-bearing capacity of joints between precast elements. In: RILEM-CEB-CIB SYMPOSIUM MECHANICAL \& INSULATING PROPERTIES OF JOINTS OF PRECAST REINFORCED CONCRETE ELEMENTS, Athens, 1978. Proceedings. Athens, RILEM/CEB., p.29-40.

EL DEBS, M. K. (2000). Concreto pré-moldado: fundamentos e aplicações. EESCUSP, São Carlos, 2000. 465p. 
EL DEBS, M. K.; SOARES, A. M, M; BARBOZA, A. S. R (2001). A new material to be used as bearing pad in precast concrete connections. In: $1^{\text {ST }}$. INTERNATIONAL CONFERENCE ON INNOVATION IN ARCHITETURE, ENGINEERING AND CONSTRUCTION. Proceedings, 18-20th july. LOUGHBOROUGH, UK. Edited by C.J. ANUMBA, C. EGBU, A. THORPE. p.81-91.

ELLIOT, K. (1996). Multi-storey precast concrete framed structures, Blackwell Science Ltda, England, 601p.

FERREIRA, M. A. (1993). Estudo da deformabilidade de ligações para a análise linear em pórticos planos de elementos pré-moldados de concreto. São Carlos, Dissertação (Mestrado), EESC-USP, 166p.

FERREIRA, M. A. (1999). Deformabilidade de ligações viga-coluna em estruturas de concreto pré-moldado. São Carlos, Tese (Doutorado), EESC-USP, 231p.

GÖRGÜN, H. (1997). Semi-rigid behaviour of connections in precast concrete structures. Nottingham, PhD. Thesis, University of Nottingham, United Kingdom.

JOHAL, L. S.(PAUL); JENNY, D. P.; SHAIKH, A. F. (1991). Impact of past research and future research needs of the precast and prestressed concrete industry. $P C I$ Journal, v.36, n.6, p.52-59, nov-dez.

PROENÇA, S.P.B. (1988). Sobre modelos matemáticos do comportamento não-linear do concreto: análise crítica e contribuições. São Carlos. Tese (Doutorado) - Escola de Engenharia de São Carlos, Universidade de São Paulo, 271p..

SHU, C. C. \& HAWKINS, N. M. (1992). Behaviour of columns continous through concrete floors. ACI Structural Journal, v. 89, n.4, p. 405-414, jul-ago.

SOARES, A. M. M. (1998). Análise estrutural de pórticos planos de elementos préfabricados de concreto considerando a deformabilidade das ligações. São Carlos, Dissertação (Mestrado), EESC-USP, 217p. 
STROBAND, J.; POOT, S.; WALRAVEN, J. (1996). The effect of mortar joints between precast HSC columns loaded in compression. In: INTERNATIONAL SYMPOSIUM ON UTILIZATION OF HIGH-STRENGTH/HIGHPERFORMANCE CONCRETE, 4., Paris, 1996. Proceedings.Paris, France, AFPC/AFREM/ENPC., v.3, p.817-825.

VAMBERSKY, J. N. J. A. (1990). Mortar joints loaded in compression. In: INTERNATIONAL SEMINAR DELFT, The Netherlands, 1990. ProceedingsPrefabrication of concrete structures. Delft, Delft University Press. p.167-180. 


\section{Apêndice}

Neste apêndice estão mostradas as leituras obtidas nos ensaios preliminares e as dosagens das misturas usadas nos modelos ensaiados. 


\section{MODELO: Amostra 1 dos Ensaios Preliminares}

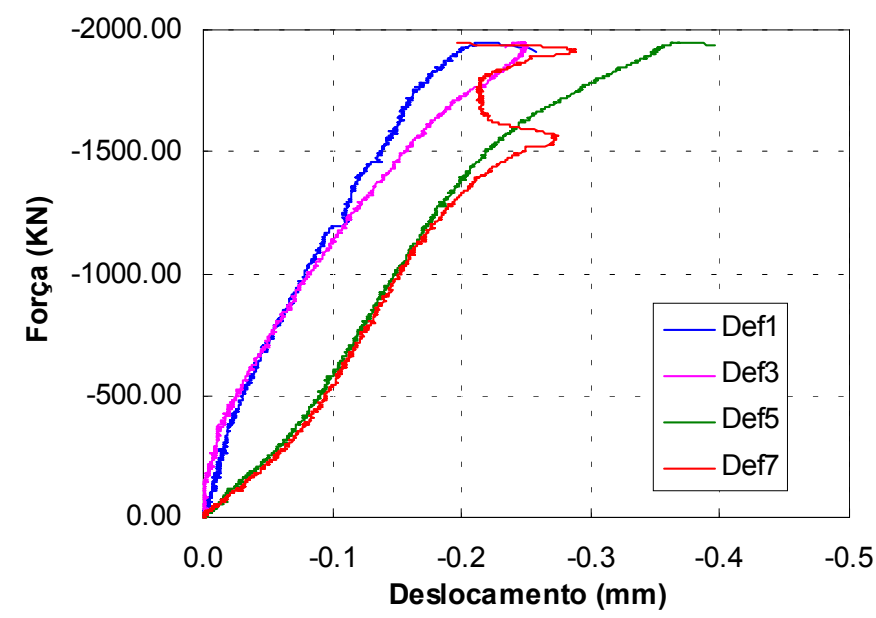

Figura A. 1: Leitura dos relógios comparadores de base $60 \mathrm{~mm}$.

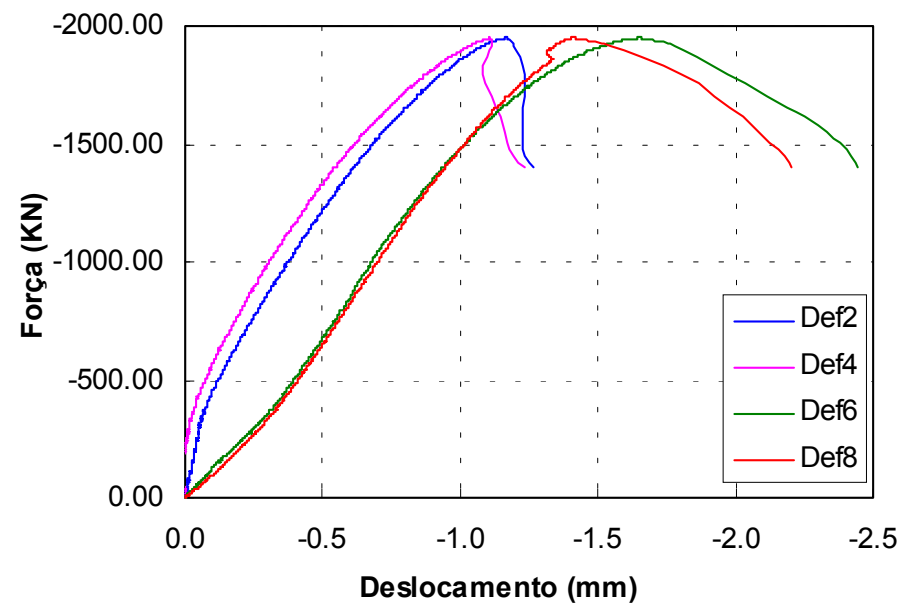

Figura A. 2: Leitura dos relógios comparadores de base 510mm. 


\section{MODELO: Amostra 2 dos Ensaios Preliminares}

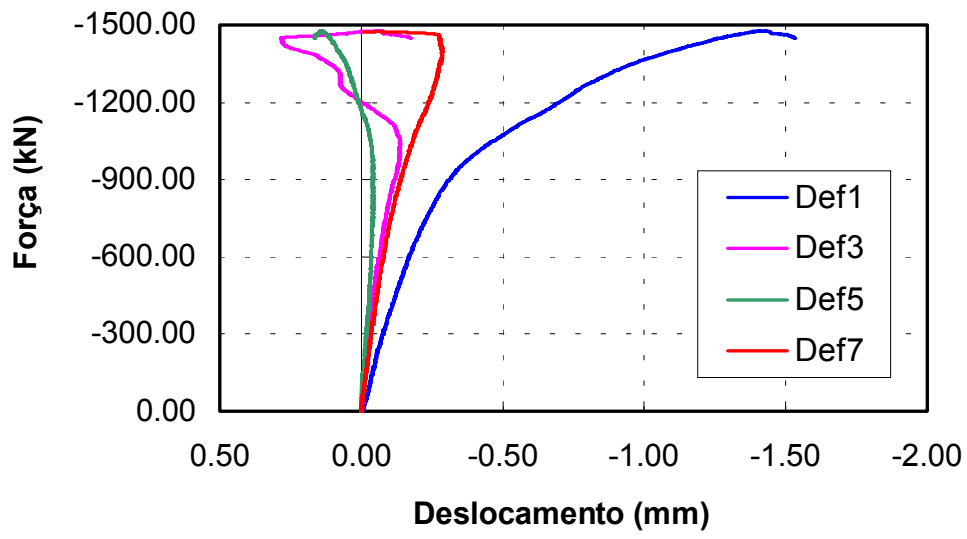

Figura A. 3: Leitura dos relógios comparadores de base $60 \mathrm{~mm}$.

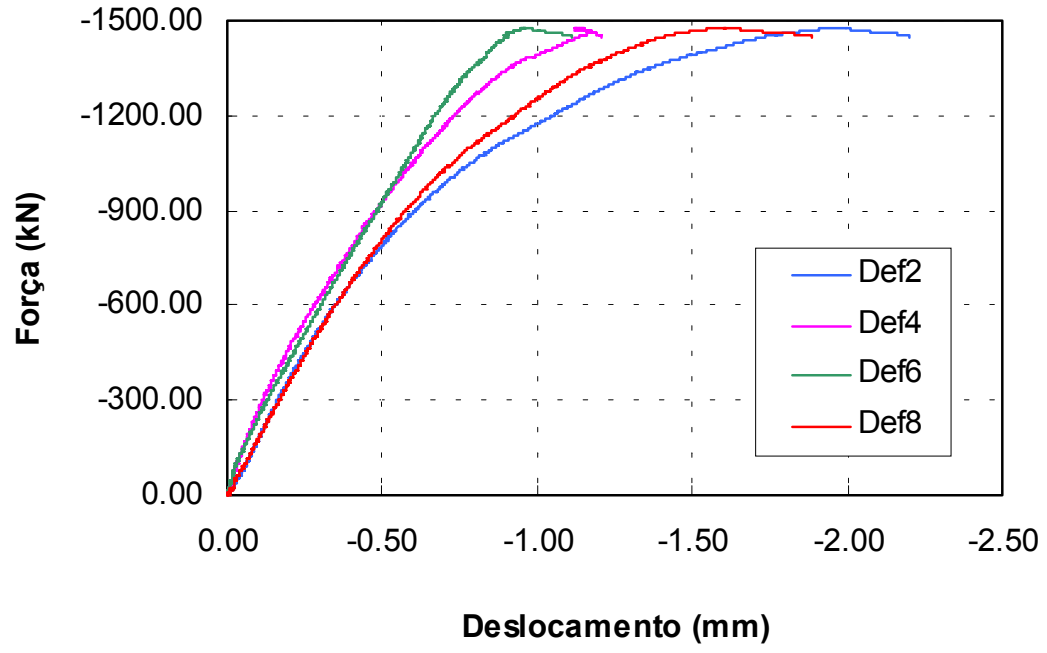

Figura A. 4: Leitura dos relógios comparadores de base 510mm. 


\section{MODELO: M1G15ILN-35}

Concreto dos Pilares - Traço: 1 : 1,66 : 2,98 : 0,56

\begin{tabular}{|c|c|c|c|}
\hline Cimento $(\mathrm{kg})$ & Areia $(\mathrm{kg})$ & Brita1 $(\mathrm{kg})$ & Água (litros) \\
\hline 38 & 63 & 114 & 21 \\
\hline
\end{tabular}

Concreto dos Anéis - Traço: $1: 2: 1: 0,4$

\begin{tabular}{|c|c|c|c|c|}
\hline Cimento $(\mathrm{kg})$ & Areia $(\mathrm{kg})$ & Pedrisco $(\mathrm{kg})$ & Água (litros) & Superplastificante (litros) \\
\hline 23 & 46 & 23 & 9,2 & 0,35 \\
\hline
\end{tabular}

Graute Fosgrout Plus - Traço: $1: 0,3$

\begin{tabular}{|c|c|}
\hline Grout & Água (litros) \\
\hline 7 & 2,1 \\
\hline
\end{tabular}

\section{MODELOS: M2G22ILN-35 e M3G30ILN-35}

Concreto dos Pilares - Traço: 1 : 1,66 : 2,98 : 0,56

\begin{tabular}{|c|c|c|c|}
\hline Cimento $(\mathrm{kg})$ & Areia $(\mathrm{kg})$ & Brita1 $(\mathrm{kg})$ & Água (litros) \\
\hline 38 & 63 & 114 & 21 \\
\hline
\end{tabular}

Concreto dos Anéis - Traço: $1: 2: 1: 0,4$

\begin{tabular}{|c|c|c|c|c|}
\hline $\begin{array}{c}\text { Cimento } \\
(\mathrm{kg})\end{array}$ & Areia $(\mathrm{kg})$ & Pedrisco $(\mathrm{kg})$ & $\begin{array}{c}\text { Água } \\
\text { (litros) }\end{array}$ & $\begin{array}{c}\text { Superplastificante } \\
\text { (litros) }\end{array}$ \\
\hline 23 & 46 & 23 & 9,3 & 0,32 \\
\hline
\end{tabular}

Graute Conbextra P - Traço: $1: 0,3$

\begin{tabular}{|c|c|}
\hline Grout & Água (litros) \\
\hline 9 & 3 \\
\hline
\end{tabular}

\section{MODELO: M4G15MLN-35}

Concreto dos Pilares - Traço: 1 : 1,66 : 2,98 : 0,56

\begin{tabular}{|c|c|c|c|}
\hline Cimento $(\mathrm{kg})$ & Areia $(\mathrm{kg})$ & Brita1 $(\mathrm{kg})$ & Água (litros) \\
\hline 38 & 63 & 114 & 21 \\
\hline
\end{tabular}

Concreto dos Anéis - Traço: $1: 2: 1: 0,4$

\begin{tabular}{|c|c|c|c|c|}
\hline $\begin{array}{c}\text { Cimento } \\
(\mathrm{kg})\end{array}$ & Areia $(\mathrm{kg})$ & Pedrisco $(\mathrm{kg})$ & $\begin{array}{c}\text { Água } \\
(\text { litros })\end{array}$ & $\begin{array}{c}\text { Superplastificante } \\
\text { (litros) }\end{array}$ \\
\hline 23 & 46 & 23 & 9,3 & 0,35 \\
\hline
\end{tabular}

Graute Conbextra P - Traço: $1: 0,18$

\begin{tabular}{|c|c|}
\hline Grout & Água (litros) \\
\hline 5 & 0,9 \\
\hline
\end{tabular}


MODELO: M5G15SLN-35

Concreto dos Pilares - Traço: 1 : 1,66 : 2,98 : 0,56

\begin{tabular}{|c|c|c|c|}
\hline Cimento $(\mathrm{kg})$ & Areia $(\mathrm{kg})$ & Brita1 $(\mathrm{kg})$ & Água (litros) \\
\hline 38 & 63 & 114 & 21 \\
\hline
\end{tabular}

Concreto dos Anéis - Traço: $1: 2: 1: 0,4$

\begin{tabular}{|c|c|c|c|c|}
\hline $\begin{array}{c}\text { Cimento } \\
(\mathrm{kg})\end{array}$ & Areia $(\mathrm{kg})$ & Pedrisco $(\mathrm{kg})$ & $\begin{array}{c}\text { Água } \\
(\text { litros })\end{array}$ & $\begin{array}{c}\text { Superplastificante } \\
\text { (litros) }\end{array}$ \\
\hline 23 & 46 & 23 & 9,3 & 0,35 \\
\hline
\end{tabular}

Graute Conbextra EPR

O graute usado para preenchimento foi obtido usando-se apenas $3,5 \mathrm{Kg}$ de agregado e adicionando-se toda a quantidade da base e do endurecedor, pois se pretendia diminuir a resistência da mistura.

\section{MODELO: M6G15ILN-60}

Concreto dos Pilares - Traço: 1 : 1,6 : 2,3: 0,45

\begin{tabular}{|c|c|c|c|}
\hline Cimento $(\mathrm{kg})$ & Areia $(\mathrm{kg})$ & Brita1 $(\mathrm{kg})$ & Água (litros) \\
\hline 44,4 & 71,1 & 102,2 & 20 \\
\hline
\end{tabular}

Concreto dos Anéis - Traço: $1: 2: 1: 0,4$

\begin{tabular}{|c|c|c|c|c|}
\hline Cimento $(\mathrm{kg})$ & Areia $(\mathrm{kg})$ & Pedrisco $(\mathrm{kg})$ & Água (litros) & Superplastificante (litros) \\
\hline 23 & 46 & 23 & 9,2 & 0,32 \\
\hline
\end{tabular}

Graute Conbextra P - Traço: $1: 0,21$

\begin{tabular}{|c|c|}
\hline Grout & Água (litros) \\
\hline 7 & 1,5 \\
\hline
\end{tabular}

\section{MODELO: M7G15ILR-35}

Concreto dos Pilares - Traço: 1 : 1,66 : 2,98: 0,56

\begin{tabular}{|c|c|c|c|}
\hline Cimento $(\mathrm{kg})$ & Areia $(\mathrm{kg})$ & Brita1 $(\mathrm{kg})$ & Água (litros) \\
\hline 38 & 63 & 114 & 21 \\
\hline
\end{tabular}

Concreto dos Anéis - Traço: $1: 2: 1: 0,4$

\begin{tabular}{|c|c|c|c|c|}
\hline Cimento $(\mathrm{kg})$ & Areia $(\mathrm{kg})$ & Pedrisco $(\mathrm{kg})$ & Água (litros) & Superplastificante (litros) \\
\hline 23 & 46 & 23 & 9,3 & 0,35 \\
\hline
\end{tabular}


Graute Fosgrout Plus - Traço: $1: 0,18$

\begin{tabular}{|c|c|}
\hline Grout & Água (litros) \\
\hline 5 & 0,9 \\
\hline
\end{tabular}

\section{MODELOS: M8AF15SLN-35 e M9AF15SRN-35}

Concreto dos Pilares - Traço: 1 : 1,66 : 2,98:0,56

\begin{tabular}{|c|c|c|c|}
\hline Cimento $(\mathrm{kg})$ & Areia $(\mathrm{kg})$ & Brita1 $(\mathrm{kg})$ & Água (litros) \\
\hline 38 & 63 & 114 & 21 \\
\hline
\end{tabular}

Concreto dos Anéis - Traço: $1: 2: 1: 0,4$

\begin{tabular}{|c|c|c|c|c|}
\hline Cimento $(\mathrm{kg})$ & Areia $(\mathrm{kg})$ & Pedrisco $(\mathrm{kg})$ & Água (litros) & Superplastificante (litros) \\
\hline 23 & 46 & 23 & 9,2 & 0,35 \\
\hline
\end{tabular}

Almofada de apoio com fibra de polipropileno CRACKSTOP da FOSROC

Traço: $1: 0,3: 0,3: 0,1-1 \%$ de fibras

\begin{tabular}{|c|c|c|c|c|}
\hline $\begin{array}{c}\text { Cimento } \\
(\mathrm{kg})\end{array}$ & Areia $(\mathrm{kg})$ & Látex $(\mathrm{kg})$ & Água (litros) & Fibras $(\mathrm{g})$ \\
\hline 9 & 2,7 & 2,7 & 0,9 & 68 \\
\hline
\end{tabular}

\section{MODELOS: M8AF15SLN-60}

Concreto dos Pilares - Traço: $1: 1,6: 2,3: 0,42$

\begin{tabular}{|c|c|c|c|}
\hline Cimento $(\mathrm{kg})$ & Areia $(\mathrm{kg})$ & Brita1 $(\mathrm{kg})$ & Água (litros) \\
\hline 50 & 80 & 115 & 21 \\
\hline
\end{tabular}

Concreto dos Anéis - Traço: $1: 2: 1: 0,4$

\begin{tabular}{|c|c|c|c|c|}
\hline Cimento $(\mathrm{kg})$ & Areia $(\mathrm{kg})$ & Pedrisco $(\mathrm{kg})$ & Água (litros) & Superplastificante (litros) \\
\hline 20 & 40 & 20 & 8,0 & 0,3 \\
\hline
\end{tabular}

Almofada de apoio com fibra de PVA

Traço: $1: 0,3: 0,3: 0,1-4 \%$ de fibras

\begin{tabular}{|c|c|c|c|c|}
\hline Cimento $(\mathrm{kg})$ & Areia $(\mathrm{kg})$ & Látex $(\mathrm{kg})$ & Água (litros) & Fibras $(\mathrm{g})$ \\
\hline 9 & 2,7 & 2,7 & 0,9 & 80 \\
\hline
\end{tabular}

\section{MODELO: M10DP15SLN-35}

Concreto dos Pilares - Traço: $1: 1,66: 2,98: 0,56$

\begin{tabular}{|c|c|c|c|}
\hline Cimento $(\mathrm{kg})$ & Areia $(\mathrm{kg})$ & Brita1 $(\mathrm{kg})$ & Água (litros) \\
\hline 38 & 63 & 114 & 21 \\
\hline
\end{tabular}


Concreto dos Anéis - Traço: $1: 2: 1: 0,4$

\begin{tabular}{|c|c|c|c|c|}
\hline Cimento $(\mathrm{kg})$ & Areia $(\mathrm{kg})$ & Pedrisco $(\mathrm{kg})$ & Água (litros) & Superplastificante (litros) \\
\hline 23 & 46 & 23 & 9,2 & 0,35 \\
\hline
\end{tabular}

Argamassa Shim Set - Traço: $1: 0,21$

\begin{tabular}{|c|c|}
\hline Argamassa & Água (litros) \\
\hline 7 & 1,5 \\
\hline
\end{tabular}

\section{MODELO: M11SLN-35}

Concreto dos Pilares - Traço: 1 : 1,66 : 2,98: 0,56

\begin{tabular}{|c|c|c|c|}
\hline Cimento $(\mathrm{kg})$ & Areia $(\mathrm{kg})$ & Brita1 $(\mathrm{kg})$ & Água (litros) \\
\hline 38 & 63 & 114 & 21 \\
\hline
\end{tabular}

Concreto dos Anéis - Traço: $1: 2: 1: 0,4$

\begin{tabular}{|c|c|c|c|c|}
\hline Cimento $(\mathrm{kg})$ & Areia $(\mathrm{kg})$ & Pedrisco (kg) & Água (litros) & Superplastificante (litros) \\
\hline 23 & 46 & 23 & 9,3 & 0,30 \\
\hline
\end{tabular}

\section{MODELO: M12SRN-35}

Concreto dos Pilares - Traço: 1 : 1,66 : 2,98: 0,56

\begin{tabular}{|c|c|c|c|}
\hline Cimento $(\mathrm{kg})$ & Areia $(\mathrm{kg})$ & Brita1 $(\mathrm{kg})$ & Água (litros) \\
\hline 25,3 & 42 & 75,4 & 14,2 \\
\hline
\end{tabular}

Concreto dos Anéis - Traço: $1: 2: 1: 0,4$

\begin{tabular}{|c|c|c|c|c|}
\hline Cimento $(\mathrm{kg})$ & Areia $(\mathrm{kg})$ & Pedrisco $(\mathrm{kg})$ & Água (litros) & Superplastificante (litros) \\
\hline 15,5 & 31 & 15,5 & 6,2 & 0,25 \\
\hline
\end{tabular}

\section{MODELOS: M13SLN-60 e M14SRN-60}

Concreto dos Pilares - Traço: 1 : 1,6 : 2,3 : 0,45

\begin{tabular}{|c|c|c|c|}
\hline Cimento $(\mathrm{kg})$ & Areia $(\mathrm{kg})$ & Brita1 $(\mathrm{kg})$ & Água (litros) \\
\hline 29,6 & 47,4 & 68,1 & 13,4 \\
\hline
\end{tabular}

Concreto dos Anéis - Traço: $1: 2: 1: 0,4$

\begin{tabular}{|c|c|c|c|c|}
\hline Cimento $(\mathrm{kg})$ & Areia $(\mathrm{kg})$ & Pedrisco $(\mathrm{kg})$ & Água (litros) & Superplastificante (litros) \\
\hline 15,5 & 31 & 15,5 & 6,2 & 0,25 \\
\hline
\end{tabular}

